\title{
THE DESIGN, DEVELOPMENT, AND EVALUATION OF A DIGITAL LITERACY GAME FOR PRETEENS
}

\author{
by \\ Sana Maqsood \\ A thesis submitted to \\ the Faculty of Graduate and Postdoctoral Affairs \\ in partial fulfillment of \\ the requirements for the degree of \\ DOCTOR OF PHILOSOPHY \\ School of Computer Science \\ at \\ CARLETON UNIVERSITY
}

Ottawa, Ontario

January, 2020

C Copyright by Sana Maqsood, 2020 


\begin{abstract}
The goal of our research is to develop an effective and empirically validated persuasive digital literacy game for tweens, meant for classroom use. Our secondary goal is to explore whether procedural rhetoric is an effective approach for designing digital literacy games. We developed the game in collaboration with MediaSmarts, a not-for-profit organization. The game, A Day in the Life of the JOs, is available in both English and French, and accessible on desktop computers and tablets. Thus far, the game has been launched in over 300 Canadian elementary schools. We conducted two user studies to evaluate the usability and effectiveness of the game with children and teachers. We found that the game was usable, effective at improving children's digital literacy, and was positively received. Our study with teachers show similar trends, and indicate that the game meets curriculum requirements, and can be used in classrooms. We also provide a model to conceptualize issues that teachers identify with children's use of digital media, and how they help them resolve these issues.
\end{abstract}




\section{Acknowledgements}

Many individuals were involved in supporting me throughout this journey.

First, I would like to thank my amazing supervisor Sonia Chiasson for her time, guidance, and compassion during my studies at Carleton. She took me on as an eager undergraduate student, and her dedication and expertise has shaped me into the researcher and person that I am today. I was very fortunate to learn from you, and I am grateful for your friendship. Thank you for being patient with my research and providing invaluable advice when I began teaching during the last year of my PhD.

Thank you to the members of my thesis committee Robert Biddle, Vicky McArthur, Hussein Al Osman, and Marshini Chetty for their feedback and guidance, which helped shape this thesis. I would especially like to thank Robert Biddle for introducing me to HCI, the many insightful discussions we have had, and being a mentor throughout my studies.

I would like to thank my collaborators MediaSmarts and Christine Mekhail, without whom this research would not have been possible. I would also like to acknowledge MITACS for funding this research. Thank you to the children and parents who participated in my user studies, evaluated prototypes, and provided feedback.

Finally, I would like to thank my parents and siblings for being supportive and understanding, while I completed this thesis. 


\section{Table of Contents}

Abstract ii

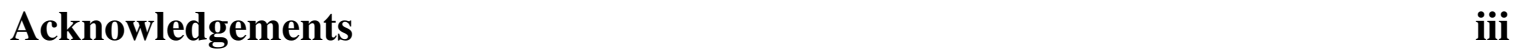

List of Tables $\quad x$

List of Figures $\quad$ xi

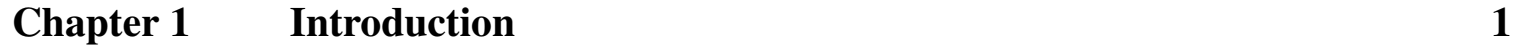

1.1 Motivation . . . . . . . . . . . . . . . . . . . . . 1

1.2 Research Statement . . . . . . . . . . . . . . . . . . 2

1.3 Contributions . . . . . . . . . . . . . . . . 2

1.4 Related Publications . . . . . . . . . . . . . . . . . . 4

1.5 Thesis Outline . . . . . . . . . . . . . . . . . . 5

\begin{tabular}{lll}
\hline Chapter 2 & Background & 6
\end{tabular}

2.1 Children's use of digital technologies . . . . . . . . . . . 6

2.2 Children's abilities $\ldots \ldots \ldots \ldots \ldots$

2.3 Digital literacy $\ldots \ldots \ldots \ldots \ldots$

$2.3 .1 \quad$ Efforts to improve digital literacy . . . . . . . . . . . . . . 10

2.3 .2 Roles of parents and teachers . . . . . . . . . . . . . . . 14

2.4 Properties of educational games . . . . . . . . . . . . . . 15

2.4 .1 Motivation . . . . . . . . . . . . . 15

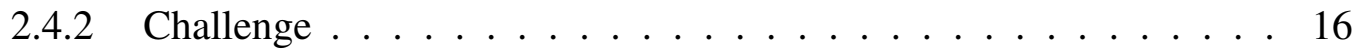

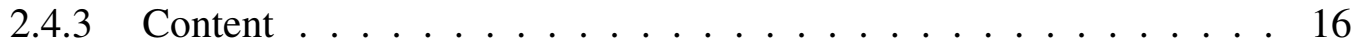

2.4 .4 Feedback . . . . . . . . . . . . . . . . . 17

2.4 .5 Narrative . . . . . . . . . . . . . . . . 18

2.5 Game design theories, principles and frameworks . . . . . . . . . . . 18

2.5 .1 Meaningful play ... . . . . . . . . . . . 18 
2.5 .2 Principles for learning games $\ldots \ldots \ldots \ldots \ldots$

2.5 .3 Design, Play, and Experience (DPE) . . . . . . . . . . . . 24

2.5 .4 Attention, Relevance, Confidence, and Satisfaction (ARCS) . . . 25

2.5 .5 Procedural rhetoric . . . . . . . . . . . . . . . 26

2.6 Digital literacy games . . . . . . . . . . . . . . . . . . . . . . . . . . . 29

2.6 .1 Audience . . . . . . . . . . . . . . . . . . . . . . . 29

2.6 .2 Topics . . . . . . . . . . . . . . . . . . 30

2.6 .3 Genre . . . . . . . . . . . . . . . . . 30

2.6 .4 Classroom use . . . . . . . . . . . . . . . 31

2.6 .5 Evaluation . . . . . . . . . . . . . . . 32

2.6 .6 Design process $\ldots \ldots \ldots \ldots \ldots$

2.7 Research roadmap . . . . . . . . . . . . . . . . . . 33

\begin{tabular}{|ll}
\hline Chapter 3 & Design of the JOs
\end{tabular}

$3.1 \quad$ Learning objectives $\ldots \ldots \ldots \ldots \ldots$

3.2 Game design $\ldots \ldots \ldots \ldots \ldots \ldots$

3.3 Detailed functionality of the game $\ldots \ldots \ldots \ldots \ldots \ldots \ldots$

3.3 .1 Scenarios . . . . . . . . . . . . . . . . . . 44

3.3 .2 Choices . . . . . . . . . . . . . . . . . . . . 44

3.3 .3 News feed . . . . . . . . . . . . . . . . . 46

3.3 .4 Scoring and Feedback $\ldots \ldots \ldots \ldots \ldots$. . . . . . . 47

3.3 .5 Characters . . . . . . . . . . . . . . . 48

3.3 .6 Navigation . . . . . . . . . . . . . . . . . . 49

$3.3 .7 \quad$ Audio . . . . . . . . . . . . . . . . . . . . . . . . . . . 49

3.3 .8 Content . . . . . . . . . . . . . . . . . . . . . 49

3.3 .9 Assessment . . . . . . . . . . . . . . . . 50

3.4 Digital literacy principles $\ldots \ldots \ldots \ldots \ldots \ldots$

3.5 Demonstration of game design principles $\ldots \ldots \ldots \ldots \ldots$

3.5 .1 Gee's learning principles and meaningful play . . . . . . . . 51

3.5 .2 Procedural rhetoric . . . . . . . . . . . . . . . . . 52 
3.6 Design process $\ldots \ldots \ldots \ldots \ldots \ldots$

3.6 .1 Team . . . . . . . . . . . . . . . . 55

3.6 .2 Timeline . . . . . . . . . . . . . . . 56

3.6 .3 Main stages of the design process $\ldots \ldots \ldots \ldots$

\begin{tabular}{lll}
\hline Chapter 4 & Technical Design and Implementation of the JOs
\end{tabular}

4.1 System requirements . . . . . . . . . . . . . . . . . . . . . 62

4.2 Technical Design and architecture $\ldots \ldots \ldots \ldots$. . . . . . . . 64

$4.2 .1 \quad$ API $\ldots \ldots \ldots \ldots \ldots \ldots$

4.2 .2 Game resources . . . . . . . . . . . . . . . . . . 65

4.2 .3 Session state $\ldots \ldots \ldots \ldots \ldots \ldots$

4.2 .4 Game flow . . . . . . . . . . . . . . . 72

4.3 Details of game features $\ldots \ldots \ldots \ldots \ldots \ldots$

4.3 .1 Scenarios $\ldots \ldots \ldots \ldots \ldots \ldots$

4.3 .2 Choices . . . . . . . . . . . . . . . . . . 75

4.3 .3 Newsfeed . . . . . . . . . . . . . . . . . . . 75

4.3 .4 Feedback . . . . . . . . . . . . . . . . . . . 77

4.4 Modularity of the design $\ldots \ldots \ldots \ldots \ldots$

4.4 .1 Adding or updating a scenario . . . . . . . . . . . . . . 79

4.5 Development process $\ldots \ldots \ldots \ldots$

\begin{tabular}{lll}
\hline Chapter 5 & Evaluating JOs with children & 81
\end{tabular}

5.1 Research questions . . . . . . . . . . . . . . . 81

5.2 Methodology . . . . . . . . . . . . . . . . 81

5.3 Recruitment and Consent . . . . . . . . . . . . . . . . . 83

5.4 Participants $\ldots \ldots \ldots \ldots \ldots \ldots \ldots \ldots \ldots \ldots$

5.5 Results . . . . . . . . . . . . . . . . . . . . 84

5.5 .1 Time and scores $\ldots \ldots \ldots \ldots$. . . . . . . . . . . . 84

5.5 .2 Usability . . . . . . . . . . . . . . . . 85

5.5 .3 Characters . . . . . . . . . . . . . . 86

5.5 .4 Digital literacy knowledge and behavioural intent . . . . . . . 86 
5.5 .5 Eyetracking . . . . . . . . . . . . . . . . . . . . . 89

5.6 Discussion . . . . . . . . . . . . . . . . . . . . . . 91

$5.6 .1 \quad$ Study outcomes $\ldots \ldots \ldots \ldots$. . . . . . . . . . . . 92

5.7 Limitations $\ldots \ldots \ldots \ldots \ldots \ldots \ldots$

5.8 Future work $\ldots \ldots \ldots \ldots \ldots$

5.9 Conclusion $\ldots \ldots \ldots \ldots \ldots \ldots \ldots \ldots \ldots \ldots \ldots \ldots \ldots \ldots$

\begin{tabular}{lll}
\hline Chapter 6 & Usability evaluation of the JOs with teachers & 97
\end{tabular}

6.1 Motivation and research questions $\ldots \ldots \ldots$. . . . . . . . 97

6.2 Methodology . . . . . . . . . . . . . . . . . . . . . . . 9 98

6.2 .1 Recruitment . . . . . . . . . . . . . . . . . . . . . . . 999

6.2 .2 Participants . . . . . . . . . . . . . . . . . . . . 99

6.2 .3 Pilot testing . . . . . . . . . . . . . . . . . . . . . 99

6.3 Research instruments . . . . . . . . . . . . . . . . . . . . 100

6.3 .1 Game . . . . . . . . . . . . . . . . . . . . . 100

6.3 .2 Questionnaires . . . . . . . . . . . . . . . . . 101

6.3 .3 Interview guide . . . . . . . . . . . . . . . . . . 102

6.4 Results . . . . . . . . . . . . . . . . . . . . . . . . . . 103

6.4 .1 Time and Scores . . . . . . . . . . . . . . . . . 103

6.4 .2 Usability . . . . . . . . . . . . . . . . . . . . . 104

6.4 .3 Learning . . . . . . . . . . . . . . . . . . . 110

6.4 .4 Usage in classrooms $\ldots \ldots \ldots \ldots$. . . . . . . . . . 111

6.5 Discussion . . . . . . . . . . . . . . . . . . . . . . . . . . 119

6.6 Limitations . . . . . . . . . . . . . . . . . . . . . . 121

6.7 Future work . . . . . . . . . . . . . . . . . . . . . . . 121

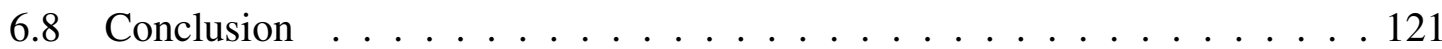

\begin{tabular}{lll}
\hline Chapter 7 & Exploring issues associated with children's media use & 123
\end{tabular}

7.1 Motivation and research questions . . . . . . . . . . . . . 123

7.2 Methodology . . . . . . . . . . . . . . . . . . . . . . . . 124

7.3 Analysis . . . . . . . . . . . . . . . . . . 125 
7.3 .1 Application of Grounded theory . . . . . . . . . . . . . . 125

7.3 .2 Researcher profile . . . . . . . . . . . . . 126

7.4 Behaviours, Technology, and Literacy (BTL) model . . . . . . . . . . . . . 128

7.5 Behaviours . . . . . . . . . . . . . . . . . . . . . 129

7.5.1 Social behaviours . . . . . . . . . . . . . . . . . . . 129

7.5 .2 Transgressive behaviours . . . . . . . . . . . . . . . 134

7.6 Technology . . . . . . . . . . . . . . . . . . . . . 138

$7.6 .1 \quad$ Properties of technology . . . . . . . . . . . . . . . 138

7.6 .2 Protection mechanisms . . . . . . . . . . . . . . . . . . 145

7.7 Literacy . . . . . . . . . . . . . . . . . . . . . 146

7.7 .1 Technology literacy . . . . . . . . . . . . . . . 146

7.7 .2 Teacher roles . . . . . . . . . . . . . . . 150

7.8 Discussion $\ldots \ldots \ldots \ldots \ldots \ldots$. . . . . . . . . . . . . . . . . . . . . . . . .

7.9 Limitations . . . . . . . . . . . . . . . . . 155

7.10 Conclusion . . . . . . . . . . . . . . . . 156

\begin{tabular}{lll}
\hline Chapter 8 & Discussion, future work, and conclusion & 157
\end{tabular}

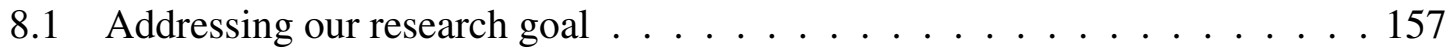

$8.1 .1 \quad$ Acceptance by children . . . . . . . . . . . . . . 157

$8.1 .2 \quad$ Acceptance by teachers . . . . . . . . . . . . . . 158

8.1 .3 Procedural rhetoric approach . . . . . . . . . . . . . . 159

8.2 Collaborating with MediaSmarts . . . . . . . . . . . . . . . 160

8.3 Application of game design principles . . . . . . . . . . . . . . 162

8.3 .1 Meaningful choices and scenarios . . . . . . . . . . . 162

8.3 .2 Characters ........................ 162

8.4 Designing digital literacy games . . . . . . . . . . . . . . . 163

8.4.1 Design recommendations . . . . . . . . . . . . . . 164

8.5 Contributions . . . . . . . . . . . . . . . . . 167

8.6 Future work . . . . . . . . . . . . . . . . . . . . . 168

8.7 Conclusion . . . . . . . . . . . . . . . . . . 168 
Bibliography

Appendix A Pre-test questionnaire for the children study

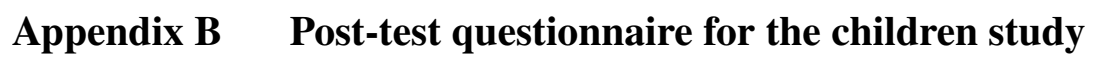

\begin{tabular}{|lll}
\hline Appendix C & One-week questionnaire for the children study & 203
\end{tabular}

\begin{tabular}{|lll}
\hline Appendix D & Pre-test interview for the children study & 205
\end{tabular}

\begin{tabular}{|lll}
\hline Appendix E & Post-test interview for the children study & 208
\end{tabular}

\begin{tabular}{|lll}
\hline Appendix F & One-week interview for the children study & 211
\end{tabular}

\begin{tabular}{|lll|}
\hline Appendix G & Pre-test questionnaire for the teacher study & 214
\end{tabular}

\begin{tabular}{|lll}
\hline Appendix H & Post-test questionnaire for the teacher study & 220
\end{tabular}

\begin{tabular}{|lll}
\hline Appendix I & Post-test interview for the teacher study & 223
\end{tabular} 


\section{List of Tables}

$2.1 \quad$ Core competencies from the MediaSmarts Digital literacy framework 11

$2.2 \quad$ Review of existing digital literacy games . . . . . . . . . . . 35

$3.1 \quad$ Digital literacy topics addressed by the game . . . . . . . . . 41

$3.2 \quad$ Distribution of work for the design and development of the JOs . . . 55

$5.1 \quad$ Children's mean game score and mean time per "day" (each day was played once per participant). . . . . . . . . . . . . . . . . . 84

$5.2 \quad$ Children's digital literacy knowledge and behaviour scores . . . . . . 86

6.1 Teachers' mean game score and mean time per game day (each day was played once per participant). . . . . . . . . . . . . 103

7.1 Example of how interview excerpts were coded. . . . . . . . . . . 127 


\section{List of Figures}

$2.1 \quad$ The Design, Play, and Experience (DPE) framework. $\ldots \ldots \ldots$

$3.1 \quad$ Main screen of the Jo's game $\ldots \ldots \ldots \ldots \ldots$

$3.2 \quad$ Scenes 1 and 2 of a scenario in the game. . . . . . . . . 42

$3.3 \quad$ Scenes 3 and 4 of a scenario in the game. . . . . . . . . . 43

$3.4 \quad$ Design process of the JOs game $\ldots \ldots \ldots \ldots \ldots$

$3.5 \quad$ Teams involved in the design and development of the JOs game. . . 55

$3.6 \quad$ Timeline of the design and development of the JOs game $\ldots \ldots$. . 57

$3.7 \quad$ Three visual designs for the JOs game. . . . . . . . . . . . . . 59

$4.1 \quad$ Technical architecture of the JOs game. . . . . . . . . . . . 64

$4.2 \quad$ Main resources of the game. $\ldots \ldots \ldots \ldots \ldots$

$4.3 \quad$ HTML code for the first day in the game. . . . . . . . . . 67

$4.4 \quad$ Tab-separated data for the contents of the newsfeed. . . . . . . . . 69

$4.5 \quad$ Communication among game resources. . . . . . . . . . 71

$4.6 \quad$ Sequence of actions when a game scenario is played. . . . . . 73

$4.7 \quad$ Generation of a scene. . . . . . . . . . . . . . . . 75

$4.8 \quad$ Feedback provided after completing a day in the game. . . . . . 77

$5.1 \quad$ Methodology of the user study with children $\ldots \ldots \ldots$. . . 82

$5.2 \quad$ Children's usability evaluation of the game $\ldots \ldots \ldots \ldots$

$5.3 \quad$ Digital literacy knowledge and behavioural intent scores. . . . . . 87

$5.4 \quad$ Scanpath of a child's gaze when reading choices in a scenario. . . . 90

$5.5 \quad$ Scanpath of a child's gaze when processing graphics and text $\ldots 90$

$6.1 \quad$ Methodology of the user study with teachers $\ldots \ldots \ldots$. . . . 98

$6.2 \quad$ Teachers' usability evaluation of the game . . . . . . . . . . 104

6.3 Teacher's digital literacy knowledge scores. . . . . . . . . . 110

$6.4 \quad$ Methods of using the game in a classroom . . . . . . . . . 114 
$7.1 \quad$ Snapshot of our codes organized on post-it notes $\ldots \ldots \ldots$. . . 125

$7.2 \quad$ Behaviours, Technology, and Literacy (BTL) model . . . . . . . 128 


\section{Chapter 1}

\section{Introduction}

\subsection{Motivation}

Digital literacy represents skills and competencies required to create and consume media in the 21st century [157]. These include knowing how to stay safe online, protecting your personal information, and verifying the authenticity of information found online [18, 110, 157, 196]. However, many users are lacking these critical skills; recently publicized incidents include people falling for misinformation, unknowingly providing their personal information to suspicious social media apps, or behaving improperly on social media 68, 115,206, 207].

Children are especially vulnerable because their cognitive and social skills are still developing [62,285]. Despite this, 99\% of Canadian children over 8 years old are online on a daily basis and $75 \%$ of 8-16 year olds use social media platforms and other online tools to interact with peers [284]. They are increasingly expected to navigate and make sense of the online world as part of their school work (e.g., doing research for a school report) and as part of their everyday lives (e.g., for entertainment or communicating with others). We thus note a distinct need to educate children about relevant digital literacy issues [22, 283].

Digital literacy education for children must take into account their development stage, abilities, and sociocultural contexts [62]. From an instructional perspective, children best acquire knowledge by experiences, discoveries, and hands-on exploration [32, 44, 239]. Games are particularly well-suited to facilitate this type of learning and have been shown to motivate learners, provide them opportunities to practice learned skills, and change attitudes [7, 51, 59, 64, 73, 256].

In this way, games are an appropriate mechanism for digital literacy education because they allow children to practice different behaviours and learn their consequences before encountering them in real-life [142]. They also allow children to try dangerous behaviours without putting themselves in actual danger. Ultimately, the goal of these games is to 
persuade children to act in a safer, more privacy-conscious, and ethical manner online in their real lives. However, based on our review (Section 2.6.4) few of the existing digital literacy games for children have been evaluated to see whether they are actually effective at improving digital literacy skills and competencies.

\subsection{Research Statement}

The goal of our research is to develop an effective and empirically validated persuasive digital literacy game for tweens, meant for classroom use. Our secondary goal is to explore whether procedural rhetoric is an effective approach for designing digital literacy games.

The objectives of this research are:

Objective 1: Contribute to the design of a digital literacy game for 11-13 year old children (tweens), that is educational and incorporates various aspects of fun, such as engagement, motivation, and challenge.

Objective 2: Implement the fully functional game using web-based technologies.

Objective 3: Evaluate the game with children to determine whether it is effective at improving their digital literacy knowledge and behavioural intent.

Objective 4: Evaluate the game with teachers, and develop an understanding of the issues they identify with children's use of digital media.

\subsection{Contributions}

The main contributions of the completed research are:

1. We developed a web-based production-quality digital literacy game for tweens, in collaboration with MediaSmarts 1 , a national, not-for-profit charitable organization which promotes digital and media literacy in Canada [197]. The game, A Day in the Life of the JOs [25, 192], is available in both English and French, and accessible on

\footnotetext{
${ }^{1}$ The relationship with MediaSmarts is explained in Chapter 3 The game design was completed in collaboration with Christine Mekhail, a Masters of HCI student and graphic designer, details of this collaboration are also available in Chapter 3 .
} 
Desktop and tablets. It has been deployed in 30 school districts covering over 300 Canadian elementary schools, and an additional 35 school districts are currently previewing the game for use within their respective schools. MediaSmarts has received positive feedback from these schools, including the following comments:

- "The game is very timely with its focus on pre-high school students"

- "With the topics covered, it is hitting all the right markers"

- "The scenarios are great and certainly reflect our students' realities online"

- "The messaging in the JOs is bang on'

- "Great messages and I can see how you could take those lessons and extend them to more projects/conversations."

2. We show the effectiveness of the game at improving digital literacy and overall usability with users from the target demographic. We conducted a two-part user study with 25 tweens. We found that the game was usable for children, and they liked the scenarios and main characters. Both their digital literacy knowledge and behavioural intent improved immediately after playing the game, and one week later. We also found that it encouraged further conversations about digital literacy between participants and their parents.

3. We provide evidence of the effectiveness of procedural rhetoric for teaching about digital literacy. Two key aspects of an effective procedural rhetoric game are engaging narrative and meaningful choices. Through our preliminary qualitative analysis, we find that participants specifically identified the storyline as engaging and relatable. They also noted that the choices were realistic and enabled them to reflect on their real-life behaviours. Rather than providing a prescriptive set of "dos and don'ts", the game fosters a more reflective and engaged type of learning that encourages children to reflect more deeply about what they would do if they encounter these situations in real-life.

4. We provide evidence that teachers find the game usable for teaching digital literacy in their classrooms. We conducted a two-part user study with 21 Grade 4-8 Canadian 
teachers. We found that they liked the game scenarios and thought they were authentic and represented children's real-life experiences on digital media. They also liked that the game aligned with their curriculum requirements, making it an appropriate resource for classroom use. The game was also effective at improving teachers' own digital literacy knowledge.

5. We provide the Behaviours, Technology, and Literacy model to conceptualize issues that teachers face around children's use of digital media. This model was developed by analyzing the interview data from Grade 4-8 teachers.

6. We provide lessons learned based on our research and experience of designing and evaluating a production-quality digital literacy game with a non-academic partner.

\subsection{Related Publications}

Part of the research in this thesis has appeared in peer-reviewed academic venues.

The following is the full peer-reviewed conference paper:

- Sana Maqsood, Christine Mekhail, and Sonia Chiasson. A Day in the Life of JOs: A Web based Game to Increase Children's Digital Literacy. In Interaction Design and Children (IDC). ACM, 2018.

The posters and workshop papers are:

- Sana Maqsood. [Extended Abstract] Evaluation of a Persuasive Digital Literacy Game for Children. In SIGCHI Conference on Human factors in Computing Systems (CHI) Student Research Competition. ACM, 2018.

- Sana Maqsood, Christine Mekhail, and Sonia Chiasson. [Poster] A Day in the Life of JOs: A Web based Game to Increase Children's Digital Literacy. SERENE-RISC Cybersecurity Workshop, 2018.

- Sana Maqsood, Christine Mekhail, Sonia Chiasson. [Poster] A Day in the Life of the JOs - A Web-based Game to Increase Children's Digital Literacy. NSERC Collaborative Learning of Usability Experiences (CLUE) Symposium, 2018. 
- Sana Maqsood, Sonia Chiasson. [Poster] A Day in the Life of the JOs - A Webbased Game to Increase Children's Digital Literacy. Canadian Celebration of Women in Computing (CAN-CWIC), 2017.

The game has also started appearing in media articles. We are aware of the following two articles:

- MITACS Impact Stories. New video game helps kids fight online dangers, November 2017 [202].

- Yukon Digital Literacy \& Citizenship Blog for Teachers and Students. A Day in the Life of the JOs, July 2019 [25]

\subsection{Thesis Outline}

The following is the road map of our research:

- Chapter 3: We present the design of our game, and discuss how it follows procedural rhetoric principles. We also discuss our overall design process, which involved an interdisciplinary team consisting of a visual designer, developer, project manager, and educators from MediaSmarts.

- Chapter 4: We present the implementation details of our game, including the development frameworks and technologies used.

- Chapter 5: We discuss the details of our methodology and the results from a user study evaluating the game with 25 tweens.

- Chapter 6: We discuss the methodology and the results of a study evaluating the game with 21 Grade 4-8 teachers.

- Chapter 7: We analyze interview data from teachers and develop the Behaviours, Technology, and Literacy model, which conceptualizes issues that teachers identify around children's use of digital media.

- Chapter 8: We provide our discussion and reflections from the research. 


\section{Chapter 2}

\section{Background}

\subsection{Children's use of digital technologies}

Children are increasingly using digital technologies, both at home and school, for entertainment and school work [33, 35, 112, 172]. Their usage patterns are evolving; tweens' (9-12 year olds) usage resembles the online behaviours of teenagers from 3-4 years ago [41]. Children are starting to use digital technologies as young as 2 years of age, and many have an online presence due to the activities of their parents [41]. Children not only consume digital media, but are also using it to create and disseminate information online [22, 41]. While digital technologies present children with new opportunities, they also introduce them to various risks, which compromises their digital well-being. These risks include cyberbullying, online hate, collection of personal data, advertising, and exposure to false information [22]. The anonymity of the internet may result in children being cyberbullied online or inadvertently participating or contributing to the cyberbullying of others. This can be exacerbated when children are allowed to bring their own devices to school (i.e., BYOD schools), and thus are more connected during the day. Most children involved in these situations do not fully understand the consequences of their actions, such as how an innocent joke can have negative effects on another individual [41]. Children generally have trouble with self-regulation, and assessing risks, which leaves them more vulnerable to online threats [41, 314, 322]. They are using the internet daily to search for information and learn new things [33, 283]. Interestingly, they are also searching for information on sensitive topics such as health, sexuality, physical health issues, and relationship problems [33,285]. However, given the vast amount of information available on the internet, children may feel overwhelmed, and have difficulty differentiating credible information from misinformation [77, 95]. They are also unable to identify advertising in content, especially when it is inconspicuous, such as in a YouTube toy review video [95].

Given these risks, there is a need to educate children to improve their digital literacy 
skills, and develop their critical thinking and reasoning skills on the use of technology [22, 283]. In general, older children are more confident and capable in their digital literacy skills than younger children, who require more parental support [33, 283].

However parents are not always equipped to help children, especially when their own digital literacy skills are poor [31,33]. For example, a recent survey with South African parents revealed that their digital literacy skills were the same as 12-14 year olds [33]. Thus, while they may be able to help younger children, these parents will not be able to support them as they get older and their technology use evolves [33].

In an attempt to manage the challenges and risks associated with technology, parents typically use one of two different parenting styles, restrictive or enabling, to monitor or control children's use of technology [169]). This choice has an effect on children's digital literacy skills [31, 169, 283, 315]. A restrictive parenting style prevents children from being exposed to online risks, but also limits their opportunities for learning the relevant skills and for being exposed to the benefits of the technology. An enabling style exposes children to more risks but allows them to take advantages of opportunities provided by digital technology [169]. From an educational perspective, an enabling style is preferred, because it allows children to build resilience and develop coping strategies to online risks [169]. It is also important to note that exposure to risks does not always translate to harm [169]. The type of parenting style adopted varies across the world, and depends on the parent's cultural practices, beliefs, education level, fear of risks, and digital literacy skills [41,169]. Typical mediation styles are also different between mothers and fathers; in many families fathers may take on a more active role in development of children's digital literacy skills, since they report being more comfortable with technology [41].

\subsection{Children's abilities}

Compared to adults, children have different cognitive, physical, and emotional abilities which need to be considered when designing educational technology for them [62]. Piaget proposed that children's development can be categorized into four stages, and at each stage they acquire new cognitive, physical, and emotional abilities [239]. All children pass through each stage, and a stage cannot be skipped. However, they may go through them at different speeds and reach them at different ages [239]. The following are the four stages 
in Piaget's development model:

Sensorimotor (0-2 year olds) Focused on the development of children's basic senses, such as touch, smell, and hearing. In this stage, children use their senses to interact with the environment, gather information, and become familiar with their surroundings [173].

Preoperational (2-7 year olds) Children at this age are egocentric, see the world from only their own perspective, and have trouble seeing things from another person's point of view [239]. As a result, they have trouble sharing technology with others [62]. The main development of this stage is that children learn to use symbols, can manipulate them, and develop language skills [239]. They can only focus on one object at a time, and do not understand hierarchies. Interfaces designed for this age group should avoid complex navigational structures, and should present the actions available clearly [126].

Concrete operational (7-11 year olds) At this stage, children begin to develop logical reasoning, and can also understand hierarchies and reverse actions, which are used in many technologies [239]. They can also perform operations on objects mentally without needing the physical object [126]. With regards to others, they begin to see things from other people's perspective, so can collaboratively use technology with their peers [126].

Formal operational (12- 16 year olds) Children develop deductive reasoning skills, are able to think more abstractly, and can logically consider different options, before making a choice [239]. The higher-order cognitive skills acquired in this stage allow them to reflect on their decisions, and apply learned knowledge to new situations [71].

Our target audience for this thesis is children who are in the late concrete operational and early formal operational stages of development. These children are capable of reflecting on scenarios, considering the consequences of different online actions, and seeing situations from different perspectives. 


\subsection{Digital literacy}

As the internet became mainstream in the late 1990's, Gilster defined the term digital literacy as "the ability to understand and use information in multiple formats from a wide range of sources when it is presented via computers" [104]. It included technical skills from computer literacy, and critical thinking skills from information literacy that users should possess, such as searching for information online. Over the next two decades, this definition has evolved to accommodate new types of technology such as social media and the Internet of Things (IoT). In general, the definition of digital literacy has shifted from including technology specific skills (e.g., know what is a URL) to more general competencies and cognitive skills that can be applied to various technologies and contexts [18, 155, 157]. However, at the present, there is no common definition of digital literacy, and many stakeholders have created their own [117, 166, 198, 210,287]. For example, Stordy defines digital literacy as "The abilities a person or social group draws upon when interacting with digital technologies to derive or produce meaning, and the social, learning and work-related practices that these abilities are applied to" [287]. Hadziristic proposed a digital literacy framework with three core components: technical skills, cognitive abilities, and critical thinking skills [117]. Technical skills include capabilities required to created digital content, cognitive abilities include being able to evaluate and process information and adapt to new technologies, and critical thinking includes the ability to critically assess information and understand its socio-cultural contexts [117]. MediaSmarts defines digital literacy as "the wide variety of ethical, social and reflective practices associated with technology, that are embedded in work, learning, leisure and daily life. Thus, digital literacy is more than just the technological "know-how" [198].

The lack of consensus in the definition is partly due to the interdisciplinary nature of the domain, which includes various stakeholders such as educators, theorists, policy makers, linguists, and media studies' researchers, and each has their own perspective on what it means to be digitally literate. There is also disagreement over the types of skills that should be included in digital literacy. When Gilster initially defined the term, it included skills that are also covered by other domains that pre-date digital literacy, such as information

literacy, computer literacy, and network literacy [104]. Over time, this overlap has grown as traditional and digital media have become more blended [117, 155]. 
- Computer literacy was first introduced in the late 1970s, and represented the ability to use tools to manipulate data and write programming code [42]. As computers became popular, this term evolved from programming skills to the ability to use computer applications to solve everyday problems [16].

- The term network literacy was introduced in the mid 1990s to represent the skills and competencies required to navigate the web [18].

- Information literacy originated in the late 1970s from the field of library and information studies, and represented the literacy and competencies individuals need to participate in the information society [241]. It included competencies such as the ability fact check information, which is still important today in the era of fake news.

Not having a common definition of digital literacy presents some challenges. First, it makes it difficult to standardize the type of skills and competencies that someone needs to be considered digitally literate. The lack of common language makes it difficult for educators to share training material and resources with others. For example, digital literacy resources designed for US teachers might not be directly applicable or usable by Canadian schools. Some students may also be inadequately trained, as one educational environment may provide a more thorough digital literacy training compared to others. In this thesis, we use the definition of digital literacy created by MediaSmarts, which provides an emphasis on the skills and competencies required by children [198]. Their definition incorporates skills and competencies from different domains that are required to use digital technology in an ethical and socially responsible manner. The core topics covered by MediaSmarts's definition are described in Table 2.1.

\subsubsection{Efforts to improve digital literacy}

\section{Government}

To improve users' digital literacy, governments need to introduce policies to standardize digital literacy education, especially for K-12, and provide investments for educational programs [117, 128, 155]. Having standardized digital literacy education ensures that everyone is learning the appropriate competencies, which can then be evaluated using standardized 


\begin{tabular}{l|l}
\hline Component & Topics covered \\
\hline Ethics and Empathy & $\begin{array}{l}\text { Addresses social-emotional skills and empathy towards others as well as their ability to make ethical } \\
\text { decisions in digital environments when dealing with issues such as cyberbullying, sharing others' } \\
\text { content and accessing music and video content. }\end{array}$ \\
\hline Privacy and Security & $\begin{array}{l}\text { Essential skills for managing privacy, reputation and security online. This includes making good } \\
\text { decisions about sharing content, understanding data collection techniques, protecting oneself from } \\
\text { malware and other software threats, and being aware of their digital footprint. }\end{array}$ \\
\hline Community & $\begin{array}{l}\text { Informs on the rights as citizens and empowers users to influence positive social norms in online spaces } \\
\text { and to speak out as active, engaged citizens. }\end{array}$ \\
\hline Digital Health & $\begin{array}{l}\text { Includes skills such as managing screen time and balancing online and offline lives; managing online } \\
\text { identity issues. }\end{array}$ \\
\hline Consumer Awareness & $\begin{array}{l}\text { Skills for navigating commercialized online environments, such as recognizing and interpreting adver- } \\
\text { tising. }\end{array}$ \\
\hline Finding and Verifying & $\begin{array}{l}\text { Skills to effectively search the Internet for information, and evaluate the information from these } \\
\text { sources. }\end{array}$ \\
\hline Making and Remixing & $\begin{array}{l}\text { Skills to create digital content and use existing content while respecting legal and ethical considera- } \\
\text { tions. }\end{array}$ \\
\hline
\end{tabular}

Table 2.1: Seven core competencies from the MediaSmarts Digital literacy framework. Adapted from [198]

assessment methods [117, 128, 155, 249]. After recognizing digital literacy as an essential skill in 2006, Europe, through work done by the European Union (EU) has become a leader in understanding children's digital literacy practices, and developing awareness tools and resources for children, teachers, and parents [46, 86, 118, 164, 214, 215, 224, 228, 233, 234,272]. EU Kids Online, a multinational research network produced outcomes between 2006-2014, which enhanced European children's online opportunities, and educated them about possible risks and appropriate safety measures [233]. It also led to other initiatives, such as DigiLitEY and Global Kids Online, to further understand young children's media use and associated risks across Europe and other countries [45,234].

The US and Canada have both made commitments to improve citizens' digital literacy, as outlined in their Blueprint for Reform and Digital Literacy Exchange action plans [47, 111, 218, 219, 221]. While Canada has made some efforts to improve users' digital literacy, such as the Get Cyber Safe initiative [217], there are still some challenges that need to be overcome, in order to compete in the 21st century [128]. First, due to the large geographical landscape, not everyone has equal access to the internet, which greatly limits their ability to access opportunities and resources to improve their digital literacy [128]. This is also an issue in other countries, where certain groups, such as lowincome individuals, minorities, and newcomers are being excluded from opportunities due to a lack of access to the Internet, computers, and digital technology [5, 117]. However, efforts are being made to remedy this situation through various programs, such as Canada's 
Digital Literacy Exchange program, which focuses on improving the digital literacy of the most vulnerable [90, 219, 296]. Canada also does not have a national digital literacy strategy, which leaves each province responsible for incorporating digital literacy in their K-12 curriculum [117, 128]. While most provinces have made efforts to incorporate it in their curriculum [2, 54, 123, 213, 216, 220, 223, 225, 227, 229], the topics covered and how they are taught is inconsistent, which means that students from different areas are not learning the same skills and competencies [128].

\section{Non-profit organizations}

Non-profit organizations, such as Common Sense Media, MediaSmarts, and the National Center for Missing and Exploited Children all have developed resources to raise children's awareness of various digital literacy issues [79, 81, 82, 87, 113, 188, 197]. Some of the resources are directly targeted for children [82, 186, 195], while others are designed for teachers and parents to use with children [80, 183, 193]. Out of these, Common Sense Media and MediaSmarts provide the most comprehensive set of resources for children, teachers, and parents [182]. In 2010, Common Sense Media developed a rigorous digital literacy curriculum for K-12 teachers, in collaboration with educators and researchers at the Harvard Graduate School of Education [188]. This curriculum is regularly updated to incorporate teacher feedback and reflect changes in digital technology [189]. Their curriculum and other resources, such as lesson plans and online games for children, have been used by 700,000 teachers across 50 US states [181].

MediaSmarts has developed a comprehensive digital literacy framework for schools, and provide classroom resources for K-12 that align with the seven core components of their framework and the curriculum of different schools across Canada [198]. The core components of the framework are ethics and empathy, privacy and security, digital health, consumer awareness, finding and verifying, and making and remixing. Table 2.1 shows the topics covered within each of these components, and we used this framework to design the content for our digital literacy game. The framework fosters a gradual release of responsibility towards digital independence for students, and sees teachers as facilitators who work with them to find solutions and promote positive engagement with technology [117]. 


\section{For-profit organizations}

Educational technology and high-tech companies, such as Google, Facebook, and Microsoft have all recently designed tools to improve children's awareness of digital literacy issues [65, 70, 109]. Of these, Google's free digital literacy curriculum and Interland game, part of their Be Internet Awesome program, are most popular with educators [110]. This program was designed in partnership with digital safety experts at the Internet Keep Safe Coalition and the non-profit ConnectSafely [110]. While it is great that high-tech companies are finally creating resources to improve users' awareness of security and privacy issues with digital technologies, their use raises some concerns with regards to transparency and effectiveness. For example, they may exclude topics, such as teaching about corporate data collection and targeted marketing to end users, from their educational program because these may negatively affect their business model. Seale et. al, critically analyzed the Be Internet Awesome game and found exactly that. Specifically, they found that while well designed, the game only presents information to children at a surface level, ignores elements outside of the user's control, and portrays Google in a very positive light as a benevolent and authoritative Internet expert [270]. As they noted, the Google logo is predominantly displayed everywhere in the game and associated materials, which subconsciously could lead users to view Google as a trusted source, when they and other technology companies are responsible for many privacy violations and data leaks [6, 68, 135, 177, 208, 232, 271, 292, 294, 300,-302, 318]. Other resources, such as Facebook's Youth Privacy Portal are integrated within the technology platforms, so could be used to attract more consumers [70] who must create accounts to access the educational material. Thus, before using digital literacy resources designed by for-profit corporations, educators should critically analyze them to ensure that students are getting an unbiased, objective content.

\section{Academic research}

Recently, researchers have explored using comics and interactive e-books to educate children about cybersecurity [319-321]. For example, Zhang-Kennedy et. al developed the interactive e-book Cyberheroes for 7-9 year-olds and empirically evaluated it with children [319]. While effective and engaging, we note that these tools are prescriptive and 
do not allow children to explore various aspects of their online behaviours. Games on the other hand, are experiential learning tools, and can be used to model nuanced cybersecurity situations where the correct behaviour is not always clear. Children can explore these situations by trying out different behaviours in a simulated environment, and learn from their experiences. This type of experiential learning can build agency in players, and help them transfer learning from the game to situations in the real-world.

\subsubsection{Roles of parents and teachers}

As children primarily use technology at home or school, both parents and teachers have a responsibility to teach them responsible media use, online safety, and other relevant digital literacy skills [33,41, 128, 161, 169,315]. Young children, especially those 0-8 years, learn digital skills by observing and imitating their parents and siblings, so parents need to model positive digital behaviours in the home [31,41,161]. In this sense, improving parents' digital literacy will also directly improve children's competencies and digital well being [31]. Besides modeling appropriate behaviour, parents also need to provide clear guidelines for appropriate use within the home. For example, if siblings do not receive consequences for negative online behaviours, then children may think those behaviours are permissible. Despite this responsibility, parents and teachers report being unprepared to teach children digital literacy skills and competencies due to lack of knowledge and training [161,169].

When it comes to digital technology, many parents resort to a restrictive parenting style to regulate children's access to technology, rather than teaching them critical thinking skills and empowering them to make their own decisions [31, 60, 169, 299]. Parents report using this approach because they are overwhelmed, do not possess the appropriate skills, and are afraid of the unknown dangers children may encounter online [31, 41, 60, 161, 169]. For instance, some parents avoid talking about online safety with children, because they are afraid it may trigger them to engage in the dangerous behaviours they are being taught to avoid [41]. However, an authoritative and restrictive parenting approach is not effective, because it limits children's opportunities and they may not turn to their parents for help when they encounter dangerous situations [31, 33, 169]. Byrne et al. [33], reviewed interviews with children across four countries, and found that children first turn to their peers for help, rather than parents or teachers, which may further undermine their ability to protect 
children. This could be because the children do not trust the adults or find that they are not prepared to help them adequately, as adults may handle the situation more formally than the children would want [33, 161].

Despite the influence of parents, both parents and schools believe that teachers are responsible for teaching children appropriate digital literacy competencies [22, 31, 33, 41, 128]. However, many teachers are also unprepared to take on this task, because they lack training, funding, have a fear of failure, and need to constantly update lessons due to changes in technology [114, 128]. Thus, governmental efforts at incorporating digital literacy into the curriculum will struggle with implementation, if teachers are not provided with proper training and resources. In summary, efforts to improve children's digital literacy need to be holistic, and in addition to designing resources (e.g., games) for children, we also need to design resources for parents and teachers, so they are prepared to help children deal with various situations involving digital media [31, 41, 124]. Some organizations have started to provide resources for parents and teachers, but more work needs to be done to change attitudes and encourage them to utilize these resources $[65,69,85,182$, 193, 194, 198]. In addition to this, mechanisms are needed to allow parents and teachers to collaborate and share information on best practices [161].

\subsection{Properties of educational games}

In this section, we discuss properties and mechanics that make good educational games. Specifically, we discuss the aspects of motivation, challenge, content, feedback, and narrative.

\subsubsection{Motivation}

Motivation is the desire to engage in an activity or satisfy a need, and it has an effect on learning [175, 176]. Motivated learners spend more time and effort on the learning activity, which leads to better outcomes. Many educational games fail to achieve their learning goals because students do not find the game enjoyable, which reduces their motivation to play the game [127, 253]. Effective learning activities utilize intrinsic motivation, where the learner engages in the activity because of free will, and not because of external rewards or constraints (i.e., extrinsic motivation) [58, 127,240]. 
Another aspect that contributes to motivation in learning is flow, a state where users become highly focused, are less aware of themselves and their surroundings, experience an altered sense of time, and feel fully in control of their actions [53]. This state of flow induces feelings of fun, pleasure, enjoyment, and creates lasting memories [53]. Being in the state of flow also leads to deeper learning of the educational material in the game [97]. Thus, for educational games to be effective, they need to motivate learners and lead them to a state of flow [253]. Properties of games that can increase player motivation include maintaining balance between challenge and skill, having clear goals, having meaningful content, providing feedback, and having engaging narrative [75, 171, 176, 200, 244, 253, 262, 265].

\subsubsection{Challenge}

Games that present players with an adequate amount of challenge are fun, which is essential for educational games [145, 304]. Challenging games can motivate players and keep them engaged [145]. However, the challenge in the game must match the player's skillset, otherwise it can lead to frustration. Easy challenges cause boredom, whereas very difficult challenges cause frustration, so a balance must be created to keep players in the flow [9]. Annetta et. al defined pleasurable frustration as the state where the challenge is exciting but still difficult, and argue that players reach this state when they reach the pinnacle of flow [9]. The state of pleasurable frustration can be facilitated by creating challenges that are slightly above the players' skillsets, and increasing their complexity as the player progresses through the game and gains more skills [9, 127, 139, 171, 176, 253].

\subsubsection{Content}

When designing a new educational game, it is tempting to take an existing game that is successful and enjoyable, and turn it into a learning game. For example, the game Cyberbully Zombies [88] is modeled after the popular game Plants and Zombies [93], and is designed to teach children about cyberbullying in schools. Much like the original game, Cyberbully Zombies players place shooters in front of their school to defend it from cyberbullies (i.e., zombies) [88]. The problem is that since the learning content is not embedded in the game 
mechanics, players do not actually learn anything useful about how to deal with cyberbullying in real-life. Instead, they are immersed in the game play of defeating zombies. Thus, for a learning game to be both educational and enjoyable, the educational content must be integrated into the game mechanics, so players learn the content while engaging with the mechanics of the game [75, 127,200].

According to Hussain et al, how well the learning objectives of a game integrate with the mechanics can depend on the genre of the game [127]. Specifically, they suggest that certain genres of games are better suited for certain types of learning objectives [127]. Since fighting games rely on patterns and repetitions, they are most appropriate for skill and drill learning outcomes [127]. Arcade and puzzle games are great for teaching declarative knowledge, because they utilize pattern matching and recall abilities [127]. Similarly, action-adventure games are most appropriate for teaching scientific concepts, because they foster problem solving skills [127].

\subsubsection{Feedback}

Effective educational games provide frequent feedback to players on their actions, so players can analyze the outcomes of their actions and evaluate their progress in the game [53, 204]. Receiving this feedback helps them learn and also keeps them in flow, which contributes to the overall enjoyment of the game [53]. In addition to immediacy, feedback should be timed appropriately, be meaningful to learners, be stated in a positive way, and help learners correct their behaviour [120]. While frequent feedback is desirable, providing too much can be disruptive and may break the players' flow in the game.

Feedback in educational games includes two core components: responses to user actions and explanations of the actions [145]. The responses to user actions need to be immediate, brief, and confirm the success or failure of the user's action [145]. The explanation debriefs users' on their choices and provides them with advice on how to improve in the future [145]. In addition to the frequent feedback, more detailed debriefing should be provided at the end of the game to allow players to reflect on their choices, outcomes, feelings, and attitudes in the learning activity [145]. Generally, feedback messages should use encouraging language and tone, but should not make players feel as if they are being talked down to, especially in games designed for children [76, 78, 145]. 


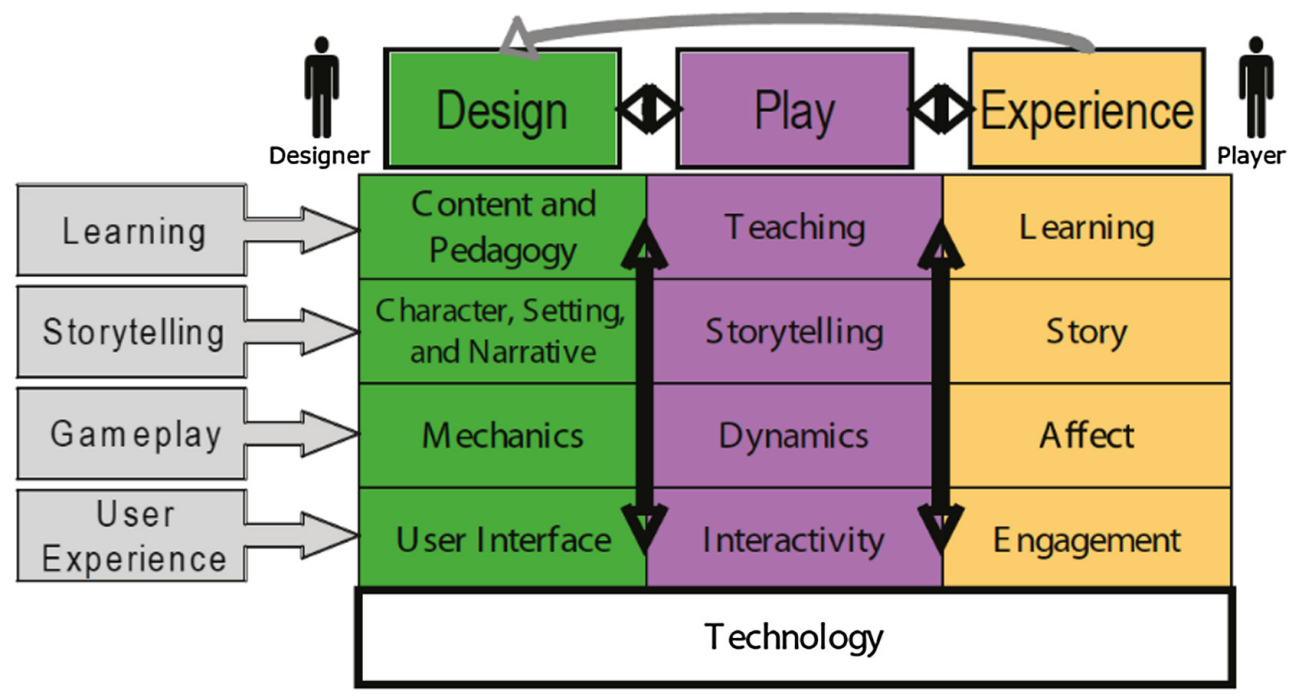

Figure 2.1: The Design, Play, and Experience (DPE) framework.

\subsubsection{Narrative}

A well designed storyline or fiction immerses players and makes them feel as if they are part of the game world, which leads to increased engagement. The immersive experience can be improved by allowing players to customize elements in the game (e.g., player avatar), which makes them feel in control and part of the simulated game world [9, 145]. For the narrative to be believable, it needs to be appropriate for the educational topic of the game [145]. For example, a game teaching players about history should not be set in the present world, and instead should be set in a historical context.

\subsection{Game design theories, principles and frameworks}

We begin by describing several design theories, principles, and frameworks for educational games, and then provide a detailed discussion on procedural rhetoric, the theory we used to design our digital literacy game.

\subsubsection{Meaningful play}

Salen and Zimmerman [262] state that the goal of designing a successful game is to create meaningful play. Meaningful play emerges from the players' interaction with the game, and includes more than the game itself. Specifically, it considers the player's context of play, 
which determines their experience of playing the game. For example, a player randomly moving chess pieces on the board by themselves has a different play experience compared to when they are engaged in a match with another player. In both cases, the player is taking the same actions in the game (i.e., moving a chess piece), but in the case of a match, their actions have a meaning and purpose and lead to a meaningful play experience [262].

Games are dynamic systems, where the player takes an action and the system responds in some manner. The rules of a game define the types of actions that the player is allowed to take, and the player uses the feedback provided by the game to evaluate the consequences of their action, and plan their next move. Thus, playing a game means making choices. In games that result in meaningful play, each choice has a purpose, otherwise the player has no motivation for making that choice [262]. Thus, to create meaningful play the game must offer players meaningful choices, where the players are aware of the possible options, are able to choose one option out of several possibilities, and understand how their choice affects the game state [262]. The meaning of an action in the game is determined by the relationship between the action and the outcome [262]. By taking actions in the game, the player is able to create new meanings within the game system [262]. Salen and Zimmerman define two types of meaningful play, descriptive and evaluative [262].

\section{Descriptive}

The descriptive definition of meaningful play states that a game provides players with a set of actions, and when an action is taken the game responds with an outcome [262]. Essentially, this is what happens in all games. However, we know that some games are more meaningful than others. Salen and Zimmerman provide the Evaluative definition to describe such games. Specifically, the evaluative definition can be used to assess whether a game offers meaningful play beyond what the structure of a game naturally provides.

\section{Evaluative}

The evaluative definition states that meaningful play occurs when the relationships between actions and outcomes are both discernable and integrated into the larger context of the game [262]. Discernable means that the game clearly communicates the possible actions and their outcomes to the player [262]. If the player does not know the outcome of an 
action they have taken, then that action loses its meaning and the play experience is not meaningful. The outcome of each action in the game also needs to be somehow integrated into the larger game context for meaningful play [262]. This means that when the user takes an action, it has an immediate significance in the game, but also affects the play experience at a later point in the game [262]. If an action does not have an impact on the larger game context, then it is less meaningful to the player than the other actions. Salen and Zimmerman acknowledge that the application of meaningful play is different for every type of game, and there is no standard strategy for creating meaningful play in games [262].

\subsubsection{Principles for learning games}

Children spend countless hours playing challenging and complex video games that require significant cognitive effort. When they fail in the game, they do not give up but rather try again with a different strategy [96]. In fact, many players dislike games that are too short and easy [96]. Gee observed this phenomenon and wanted to explore why children spend so much time and effort playing games, but not on traditional learning activities in schools, which many find boring [96]. Some critics of games state that children find video games fun because they are not actually learning anything [96]. As Gee points out, this is not true and many video games subconsciously teach players about important issues such as ethics, identity, and responsibility [96].

Gee analyzed several popular entertainment games to understand their properties that make learning fun compared to traditional learning mechanisms in schools. He found that good video games incorporate learning principles that are supported by cognitive science and human learning research [96]. Specifically, games focus on active or experiential learning (i.e., learning by doing) while traditional educational methods focus on passive learning (i.e., learning facts). Research has shown the passive learning is less effective than active learning, because in the real-world children need to know how to apply the facts they have learned [94]. In the context of cybersecurity, passive learning involves providing children tips on how to stay safe online. While knowing these facts is important, they are insufficient when children are actually faced with dangerous situations online. In these cases, active learning, where students are allowed to practice being in these situations, is a more effective learning technique. 
Given the advantages of educational games, some educators have tried to incorporate them in their classrooms [96]. However, some of these efforts have failed because the games are using passive learning mechanisms often masked by a cool gaming element (i.e., the chocolate covered broccoli phenomenon) [96]. Gee proposed 36 learning principles for creating engaging learning environments in classrooms that utilize some of the effective learning techniques that are present in games [96]. He also proposed 16 learning principles exhibited by good games [98]. Since we utilize several of these principles in our work, we provide an overview of them in this section.

\section{Gee's principles for effective learning games}

Identity: Learning requires an extended amount of commitment from the learner. Good video games provide players with an identity, which helps them commit to playing the game [98]. Players can either inherit a strongly formed identity provided by the game, or they can build their own character (i.e., identity). After inhabiting the identity, players invest time and effort into building and nurturing the identity, and thus make a long-term commitment to playing the game.

Interaction: Games are interactive systems, where constant communication takes place between the player and the system. Players interact with the system by taking actions, and the system responds by providing feedback on the actions, and presents new challenges to the player [98]. Good games contextualize all possible actions within this relationship between the player and the world modelled by the game [98].

Production: In good games, players are not only consumers but also help create the game by their actions in the game [98]. In this manner, each player has a unique experience of playing the game. By creating the game world, players feel a sense of ownership and control over their learning in the game [98].

Risk taking: Good games encourage players to explore, take risks, and try new things in the game world [98]. This is done by lowering the consequences of failure in the game, such as allowing players to start from the last saved point upon failure. Failure in games is natural, and players use the feedback from their failures to improve their 
strategies in the game [98]. This is in contrast to traditional learning in schools, which provide less opportunities for failures, risk, and exploration [98].

Customization: Good games allow players to customize the play experience according to their unique learning style [98]. Some games accomplish this by providing different difficulty levels or allowing players to solve a problem using different strategies. This type of customization is not possible in traditional learning in schools which follow a specific curriculum [98].

Agency: Adherence to the first five principles makes players feel a sense of agency and control over their actions and learning, which is uncommon in traditional learning mechanisms in schools.

Well-order problems: The problems that players face in good games are ordered, and players learn to solve easy problems before moving on to more difficult challenges [98]. Learning to solve earlier problems provide players with the skills and knowledge they need to solve harder problems. Some games accomplish this by providing different levels, where the problems at each level match the players' skill set [98].

Challenge and consolidation: Games present players with a set of challenging problems and allow them to solve these problems, until they have mastered or routinized the solutions [98]. The mastery is achieved through repetition. Once mastery is achieved for a set of problems, the game presents the player with a new set of challenges that require them to master new skills and consolidate them with their previously mastered skills. This is referred to as the "Cycle of Expertise" [21], which is how individuals become an expert in anything.

"Just in time" and "On demand": To reduce the cognitive load on players, good games present information (e.g., verbal or text) to players only when they need it or when they explicitly request it from the game [98]. In addition to this, the information presented is context sensitive, which means players are only provided the information that they need for a particular situation or task in the game [98].

Situated meanings: When learning new words, we associate them with the image of an object from our experiences in the real world [98]. Gee refers to this as situated 
learning, which is in contrast to learning new words by looking up their definition in a dictionary (i.e., learning new words by learning more words) [98]. Good games provide an ideal environment for situated learning, where words are presented in the context of images, actions, and experiences in the game, which makes learning them easier [98].

Pleasantly frustrating: Good games provide players with new challenges that are within their realm of competence [98]. Players find the task challenging, but feel like it is doable. This flow state and is a highly motivating state for learners [53].

System thinking: Games represent complex systems and encourage players to think about the relationships between different aspects of the system, and how their actions affect these relationships [98]. Some games accomplish this by creating an environment where one action affects the player's future actions or the actions of other players in the game [98]. This type of system thinking is required in learners today to help them understand the complexities of the global world [98].

Explore, think laterally, rethink goals: Instead of emphasizing the completion of tasks as fast as possible, good games encourage players to explore different possibilities before making a choice [98]. They encourage them to think of problems laterally rather than just linearly, and use this thinking and exploration to reconsider their goals occasionally [98].

Smart tools and distributed knowledge: In games, the player manipulates various aspects of the game world, such as the characters. These are known as smart tools, because the objects being manipulated, such as the characters, have their own knowledge and skill set which they lend to the player [98]. Thus, the player can utilize these smart tools to complete tasks or solve problems, without having to learn the knowledge and skills provided by these tools [98]. In multi-player games, the knowledge is further distributed among players and their smart tools. Gee states that learning in this type of distributed world is more realistic, because in modern workplaces individuals need to know how to use the tools around them to complete tasks [98].

Cross-functional teams: In the modern workplace, individuals work in cross-functional 
teams where each individual has different expertise and the group works together towards a common goal. Gee states that to prepare children for the modern workplace, schools should teach them how to work in cross-functional teams [98]. This type of skill can be learned from massively multi-player games such as World of WarCraft [311], where players work in cross-functional teams to accomplish a common goal in the game [98].

\subsubsection{Design, Play, and Experience (DPE)}

DPE (Figure 2.1) is an educational game design framework that considers the design from both the design team and the player's perspective [309]. This framework includes the player's needs, which are typically ignored by traditional game development processes which only consider the design team's perspective. At each stage of the design process, the designers must consider the player's needs, create the game, and then test it with players. This iterative process continues until the design meets the player's needs, and is dependent on the available technology.

The framework has three main components: design, play, and experience. The design team designs the game, and the player plays the game, which results in the player experience. To ensure the game results in the expected outcomes, the design team must create goals for the resulting player experience. The goals can then be used to guide the design and evaluate the effectiveness of the implementation. The design team is interdisciplinary, and consists of designers, developers, educators, and project managers. Play is the mediator between design and experience, and represents the process of playing the game, which can be different for each player, given their unique cognitive, social, cultural, and experiential background.

\section{Aspects of game design}

The framework incorporates four aspects of serious games in the design process: learning goals, storytelling, game mechanics, and overall user experience. The designer specifies the learning goals for the game; these guide the intended teaching that occurs when the player plays the game and experiences the intended learning. The learning goals should be testable, so they can be evaluated by testing the prototype with players. 
Storytelling is at the heart of an engaging game. In the DPE model, designers create the story by defining the characters, setting, and narrative. The act of storytelling happens during play, and combines the designer's story with the choices and interactions of the player.

The game mechanics appear in the play layer, which defines what the player does in the game (i.e., choices possible). The designer creates the rules for the game, and these manifest as behaviours during play, resulting in certain emotions for the player.

Since the user interface provides players access to the game, it is the key to an engaging game play experience. In the user experience layer, the designer creates the user interface to have a specific interactivity during play. The goal at this stage is to promote engagement for the player.

\subsubsection{Attention, Relevance, Confidence, and Satisfaction (ARCS)}

ARCS is a motivation based theory for designing digital instructional activities and games for students [149]. The theoretical model has four main components. Each component has sub-categories intended to increase motivation in learning environments. The following are the main components and sub-categories of the model:

- Attention: The learning activity must maintain the learner's attention and keep them engaged throughout the activity [149]. This can be achieved by having them actively participate (e.g., by taking explicit actions), stimulating their curiosity (e.g., including a challenge), and maintaining their attention using elements such as humor and storyline.

- Relevance: It must be clear to the learners why they need to participate in the learning activity, and how it transfers to the real world [149]. This can be achieved by matching activities with learners' needs, and providing them with meaningful choices.

- Confidence: The activity must make learners feel confident in their ability to successfully complete tasks [149]. This can be achieved by making the learning objectives clear so learners can evaluate their likelihood of success, providing help on 
failures, and providing varying levels of difficulty, which can be matched with the learners' skills.

- Satisfaction: Learners must feel content after completing a learning activity, which can motivate them to continue the activity or replay it if they are finished [149]. This can be achieved by offering them rewards for the correct behaviour, or providing them opportunities to practice the learned behaviour.

ARCS has been used successfully to design engaging educational games and online learning tools for cybersecurity, math, language, software engineering, and the environment [14, 102, 141, 148, 154, 165, 168, 290, 313]. CyberAware, a quiz-based cybersecurity game, used ARCS to increase users' understanding of firewalls, antivirus software, phishing, security patches, and software updates [102]. It motivated players and kept them engaged in the game by providing mini-games with challenging questions and an interesting storyline (Attention), explaining the objectives of the game (Relevance), scaling the difficulty of the mini-games upon progress (Confidence), and rewarding players by unlocking subsequent mini-games and challenges (Satisfaction).

\subsubsection{Procedural rhetoric}

Bogost [26] defined procedural rhetoric as the practice of using processes or mechanics to construct an argument in a game. This principle is useful in educational games that are trying to make a statement to the player [26]. Games employing procedural rhetoric make their argument by embedding it within the rules of the game. As players interact with the simulated game world, they progressively discover the argument presented by the game. For example, Debt Ski [91] utilizes procedural rhetoric to educate young people about the dangers of excessive debt and teaches them financially responsible behaviour. In the game, players control a piggy bank with the objective of increasing income and happiness [91]. Income is earned throughout the game and happiness is increased by buying merchandise. Towards the end of the game, players arrive at the conclusion that debt can be accrued easily and balance is needed between happiness (spending) and income. The power of procedural rhetoric is that players are more likely to believe an argument if they experience it for themselves in a simulation, compared to being told about it. There has been some 
criticism of procedural rhetoric within the literature [57, 263, 312]. For example, Sicart argues that Bogost's definition of procedural rhetoric disregards the role of the player and implies that designers are able to curate the player's experience in the game [276]. While we recognize these criticisms, we believe that procedural rhetoric is still an appropriate framework for our game because of its mechanisms for communicating the message of the game to the player. In our interpretation and application of procedural rhetoric, we consider the player an important part of the play experience, and believe that each player will have a unique experience in the game, based on their own personal beliefs, attitudes, and prior experiences.

Although procedural rhetoric was formally defined in 2007, researchers have used such strategies prior to that to create persuasive games for various application areas. These games used theories of persuasion from psychology or social sciences as their underlying theoretical framework [78]. Since its definition, procedural rhetoric has been mostly used by independent game studios to create behaviour change games [92]. However, the success of these games is typically measured by their popularity or usage [91], and not their effectiveness at changing the intended behaviour. With only a few exceptions [61, 72, 106, 259] noted below, not much work in $\mathrm{HCI}$ has used procedural rhetoric explicitly to design or evaluate educational games.

\section{Use of Procedural Rhetoric in HCI}

Researchers have explicitly used procedural rhetoric to design behaviour change games for homelessness [259], understanding Attention Deficit Hyperactivity Disorder (ADHD) [106], energy conservation [61], and healthy eating [72].

- Spent is a game to increase positive attitudes towards the homeless [259]. Players are provided with $\$ 1000$, with the goal of surviving for a month, where each day requires them to make difficult choices. By playing the game, players realize that homelessness is a matter of circumstances and not character [259]. An evaluation showed that affective learning improved after playing the game [259].

- Drawn to Distraction facilitates understanding of ADHD among caregivers and adults [106]. 
It shows players that ADHD individuals have an increased drive to engage in immediately rewarding activities, despite knowledge of their long term harm [106]. A study showed an improvement in players' understanding of ADHD.

- Doucet et al. designed a real-time strategy game to educate users about energy conservation [61]. Set in a post apocalyptic world, the player survives by defeating zombies. Positive energy behaviour helps players survive and negative behaviour jeopardizes survival. A study showed that players enjoyed the game and it improved their knowledge of sustainable energy use [61].

- In Fitter Critters, a game to teach children healthy eating habits, players care for a virtual pet. They make choices affecting the health of the pet, and consequently learn about health and nutrition. Each choice has both positive and negative effects on the pet's well being, so players learn which choices are most beneficial [72]. A study showed that it was positively received by children and resulted in increased nutrition knowledge, positive attitudes toward healthy eating, and healthy eating selfefficacy [267]. Although Fitter Critter was evaluated in a classroom, it did not track student progress to help teachers incorporate the game into their curriculum.

The four games reviewed here show that procedural rhetoric can be used effectively to design different types of games for various application areas. However, they are different from our work because most of them were designed for adults and none were initially designed to be used in a classroom setting.

Based on the experience of designing Fitter Critters, Ferrara proposed the following five guidelines for designing games using procedural rhetoric [72]. We will use these guidelines as the basis for designing our digital literacy game.

1. Defining a core message for the game (P-G1): The game must be designed around a clear and concise statement of what the players should do or believe [72].

2. Offering meaningful choices (P-G2): Meaningful choices should be offered, and there should be benefits to making the wrong choice, which will foster exploration and discovery [72]. 
3. Enabling self-directed discovery (P-G3): The game should allow self-directed discovery of the message, which will give players a feeling of ownership and insight [72].

4. Tying the message to strategy (P-G4): Games with the goal of winning should embed the message into the winning strategy, which will drive players efficiently towards the message [72].

5. Keeping the simulation realistic (P-G5): The simulation should be realistic, giving it credibility and allowing players to apply the learned behaviour in the real-world.

A related research area, Persuasive Technology, uses methods of persuasion to influence behaviour change. Although many children's educational games have employed persuasive technology, for example to encourage physical activity [1,11], learn math and computational thinking [10, 138], and promote energy conservation [116], these do not make explicit use of procedural rhetoric as a method of persuasion.

\subsection{Digital literacy games}

Many organizations have developed games to educate users about various digital literacy issues [87, 109, 182, 197]. We reviewed 25 digital literacy games released between 2000 and 2019, designed by universities, and not-for-profit organizations such as Common Sense Media, Childnet, Canadian Centre for Child Protection, and the National Centre for Missing and Exploited Children (NCMEC). We reviewed digital, board, and card games. Out of these, 15 were designed for children and the others were for adults or everyone. Table 2.7 (at the end of this chapter) summarizes the results from our review. We reviewed each game according to four factors: target audience, educational topics addressed, design process, and the evaluation process.

\subsubsection{Audience}

Most of the games were designed to improve end users' awareness of common cybersecurity threats, and a few were designed to train cybersecurity professionals on how to protect 
systems from these threats. Digital literacy covers a broad range of complex topics. However, regardless of the topic, the main learning objective of any digital literacy game is to build critical thinking skills in the player. Most of the games designed for children were targeted towards 8-13 year olds, which is typically when children start to go online and use social networking websites.

\subsubsection{Topics}

The games addressed similar topics that are important for 8-13 year olds, such as phishing, malicious software, passwords, cyberbullying, social networking, online communication, data privacy, fake news, and copyright. Most games addressed multiple digital literacy topics, either as different levels in the game or as mini-games within the main game. An advantage of this approach is that the knowledge acquired from one topic may help improve children's understanding of another topic. However, from a design perspective, it can be challenging to integrate content for different topics into one educational game, which can negatively affect the usability and learning outcomes of the game [127].

\subsubsection{Genre}

As explained by Hussain et al., the genre of an educational game should be chosen based on the learning objectives of the game, to ensure that the learning content can be integrated into the game [127]. The most effective games to teach critical thinking are real-time strategy (RTS) and role-playing (RPG) games, which puts players in a simulation and require them to make decisions that affect the resources or branching narratives in the game [127]. The most common genre was simulations, where players took on the role of a main character and proceeded through the storyline to accomplish a goal, which typically involved protecting themselves or others from threats. As they proceeded through the game, players made choices, which had consequences on their or others' security/privacy. The outcomes of their choices were reflected in the narrative of the game. For example, in DataK, designed by the Radio Télévision Suisse, players act as an assistant data protection manager to the mayor of Dataville [291]. As they proceed through the game, they face various dilemmas and have to make decisions that impact the privacy of the town's citizens.

Other games were arcade or puzzle based, such as the games included in Google's Be 
Internet Awesome digital literacy program [109]. In such games, the player controls a character and completes puzzles or challenges (e.g., jumping on a platform), and the learning content is part of the puzzle or challenge. Puzzle or arcade style games are the least effective for teaching digital literacy, because they focus on teaching declarative knowledge, facts, or statement and do not build critical thinking skills required to be digitally literate [127]. For example, in the case of phishing, these games can be used to teach users how to spot and report phishing emails, but when phishing attacks evolve, users will not have the critical thinking skills required to prevent these new attacks.

Both single player and multi-player games were used to teach digital literacy. In cooperative multi-player games, players work together to complete a task whereas in competitive games, they compete against each other to complete the task. These games have several advantages over single player games, as they teach players how to work in a team, communicate effectively, and learn from more experienced members in the group [171]. In digital literacy games, players typically act as the attacker to compromise a system or as a defender to protect it from attackers. Multi-player games can also be a hybrid of cooperative and competitive. For example, in the Sims style game Immersive Security Education Environment, two teams compete with each other, one acting as the adversary and the other as the target of a cyber attack. The goal of the target team is to actively defend themselves from attacks while the adversary team needs to find the target's weaknesses [260]. An advantage of these games is that they allow players to explore attacks from both the attacker and victim perspectives, and thus build more complete mental models of how these attacks actually work.

\subsubsection{Classroom use}

Games designed for classroom use typically have an accompanying teacher's guide that can be used to plan lessons for students [127]. For the games that we reviewed, four had teacher guides [109, 185, 187, 298]. These guides provide a list of topics covered in the game, describe how their learning objectives align with the curriculum, give advice on how to incorporate the game in a lesson, and suggest how to assess students. Assessment is done using pre-test and post-test questionnaires or a group discussion of what was learned in the game. For example, the teacher guide for Zoe \& Molly, an online safety game developed 
by the Canadian Centre for Child Protection, provides a lesson plan [82]. It recommends teachers start the lesson by reading the comics associated with the game, playing a module (level) in the game, and getting the students to complete a provided post-test quiz [83]. Teachers' guides are essential for games designed for classrooms, because they help reduce the workload for teachers, and ensure that lessons are taught in a consistent manner.

\subsubsection{Evaluation}

The usability of a game, including fun, is typically assessed by conducting a user study with the target audience of the game, and collecting their feedback using questionnaires, game logs, or interviews. Assessment of players' learning in the game is more challenging and can take place as a summative or formative assessment [253]. In a summative assessment, players' knowledge is assessed at the end of the game, whereas in formative assessment, learning is assessed repeatedly throughout the game [30]. Formative assessment is the preferred approach, and is done by reviewing the players' progress and activities in the game [275]. A problem with this approach is that the quizzes disrupt game flow, so they may annoy players and cause them to complete the assessment without really paying attention to the questions [171,253]).

Despite the advantages of assessment, many educational games are not evaluated with users to determine whether they are actually effective at educating users [125|127|179|280]. Those that are evaluated often follow an informal evaluation process that lacks scientific rigor in terms of study design, measurement, data collection, and analysis [12, 19, 37, 48, 49, 103]. The most common approach to evaluate learning in educational games is using pretest and post-test questionnaires administered before and after playing the game [179,238].

We found similar results for persuasive games. For example, after reviewing sixty persuasive games, Soekarjo et al., found that only $25 \%$ were actually tested with users [280]. We found slightly improved results in our review of digital literacy games. Of the 25 games reviewed, 13 were evaluated with users. Twelve evaluated only the usability of the game, and six assessed solely whether the game was effective at teaching digital literacy. Only five games evaluated both the usability and effectiveness of teaching digital literacy [17, 102, 203, 307, 310]. The most common assessment approach for effectiveness was using pre-test and post-test questionnaires as part of a summative assessment. 


\subsubsection{Design process}

We looked at the design process of the reviewed games to better understand how they were created. Specifically, we looked at how the content was created, the composition of the design team, and the design principles or frameworks used. Very few games provided complete details of their design process, but most provided some details. Six games reported being created using interdisciplinary design teams consisting of designers, educators, and developers, which is the preferred approach for designing educational games. A few provided details on the creation of the educational content. Common approaches included aligning content with the digital literacy curriculum, using real-world examples, and consulting teachers. With regards to design principles, five reported that they defined their own learning objectives and used these to guide the design process. Five used reported using common game design guidelines and frameworks, such as the theory of procedural rhetoric.

\subsection{Research roadmap}

Our literature review shows that children face various risks online, and there is an urgent need to develop tools to help them improve their digital literacy. Governments, non-profit, and for-profit organisations are all working towards this goal. However, we found several gaps in the literature around digital literacy games and education efforts, which we address in this thesis.

Most digital literacy games designed for children lack evidence on whether they are actually effective at teaching the intended behaviour. Furthermore, they do not follow any established design methodologies or guidelines, which risks that they are either fun or educational (rather than both), and thus not effective. We fill these gaps, by applying the theory of procedural rhetoric to develop a digital literacy game for tweens. We then tested the game with children and teachers to evaluate its usability and effectiveness.

Our literature review revealed that children model the online behaviours of adults around them, and that both parents and teachers play key roles in educating children about proper online behaviours. However, both feel unprepared and need tools to help them. Parents also expressed a desire to exchange best practices with teachers and be involved in their child's 
learning. Our aim is to develop a game that parents and teachers can play to improve their own digital literacy and become familiar with issues facing today's children, and thus feel confident in discussing these complex topics with children. The game can also be used to start a dialogue between parents, teachers, and children about digital literacy practices at home and school.

While teachers play an important role in children's learning, they also have unique requirements that designers must take into account when designing games for classrooms. However, many educational games fail to do this, which results in games that teachers cannot use or are unsatisfactory. The last part of our research fills this gap. While we involved teachers in the design process from the start, we also conducted a user study to evaluate the usability and effectiveness of the functional prototype with them.

In our review of the literature, we further found little research exploring digital literacy practices in the classroom. We aim to get a deeper understanding these practices. Specifically, we explore the types of problems they are seeing with children's media use and how they help students resolve difficult situations. The literature is currently missing this perspective, and developing a deeper understanding of teachers needs and practices can help the design of future digital literacy tools for them. 
Table 2.2: Review of existing digital literacy games

\begin{tabular}{|c|c|c|c|c|c|c|c|c|}
\hline Name & Description & Year & Target & Topic & Creator & Eval? & Evaluation process & Design process \\
\hline $\begin{array}{l}\text { Internet } \\
\text { Hero [146] }\end{array}$ & $\begin{array}{l}\text { Players complete four quests (mini-games) in } \\
\text { a virtual world to save it from evil forces. The } \\
\text { virtual world represents the Internet and evil } \\
\text { forces represent common internet threats. }\end{array}$ & 2014 & $\begin{array}{l}9-12 \\
\text { years }\end{array}$ & $\begin{array}{l}\text { Email spam, } \\
\text { malicious soft- } \\
\text { ware, social } \\
\text { media }\end{array}$ & Academic & Yes & $\begin{array}{l}\text { Used questionnaires and game logs } \\
\text { to evaluate overall usability. }\end{array}$ & $\begin{array}{l}\text { Explorative design approach. Used } \\
36 \text { learning principles to create the } \\
\text { game [96] }\end{array}$ \\
\hline $\begin{array}{l}\text { Sim } \\
\text { Safety } \\
{[143]}\end{array}$ & $\begin{array}{l}\text { 3D world with multi-player mini-games mod- } \\
\text { elling common internet safety scenarios. } \\
\text { Players complete the scenario according to } \\
\text { their assigned role and are scored on their } \\
\text { performance. Teachers and parents can join, } \\
\text { allowing everyone to experience scenarios } \\
\text { from different perspectives. }\end{array}$ & 2010 & $\begin{array}{l}10-12 \\
\text { years }\end{array}$ & $\begin{array}{l}\text { Cyberbullying, } \\
\text { social network- } \\
\text { ing, online } \\
\text { communica- } \\
\text { tion. }\end{array}$ & $\begin{array}{l}\text { Academic } \\
\text { in part- } \\
\text { nership } \\
\text { with the } \\
\text { EU }\end{array}$ & Yes & $\begin{array}{l}\text { Pilot-tested with schools during de- } \\
\text { velopment. Usability was evaluated } \\
\text { using game logs and interviews with } \\
\text { children in a user study [40]. In- } \\
\text { game quizzes assess players' under- } \\
\text { standing of the material during play. }\end{array}$ & $\begin{array}{l}\text { An interdisciplinary design team of } \\
\text { educators, pedagogists, and scien- } \\
\text { tists created the game. A game de- } \\
\text { sign framework was used to assess } \\
\text { that the final game was educational } \\
\text { and entertaining. }\end{array}$ \\
\hline $\begin{array}{l}\text { Security } \\
\text { Empire } \\
{[231]}\end{array}$ & $\begin{array}{l}\text { A competitive multi-player game, with the } \\
\text { goal of building the most profitable green en- } \\
\text { ergy company. Practicing secure behaviours } \\
\text { is a secondary task for players representative } \\
\text { of users' in real life. }\end{array}$ & 2014 & $\begin{array}{l}\text { High } \\
\text { school }\end{array}$ & $\begin{array}{l}\text { Phishing, pass- } \\
\text { words, encryp- } \\
\text { tion, malware, } \\
\text { antivirus }\end{array}$ & Academic & Yes & $\begin{array}{l}\text { Designs were iteratively tested with } \\
\text { high school students. Usability was } \\
\text { evaluated using game logs and a } \\
\text { user study. }\end{array}$ & $\begin{array}{l}\text { Designed in collaboration with } \\
\text { teachers, principals, and school } \\
\text { administrators. Content aligned } \\
\text { with internet security learning } \\
\text { objectives [84]. }\end{array}$ \\
\hline $\begin{array}{l}\text { Cyber } \\
\text { Aware [102] }\end{array}$ & $\begin{array}{l}\text { Quiz-like mini games, each addressing differ- } \\
\text { ent cybersecurity topics. Different design ap- } \\
\text { proaches were used for each game, such as } \\
\text { matching or picking answers from a list. }\end{array}$ & 2015 & $\begin{array}{l}9-11 \\
\text { years }\end{array}$ & $\begin{array}{l}\text { Firewalls, an- } \\
\text { tivirus, security } \\
\text { patches, and } \\
\text { phishing }\end{array}$ & Academic & Yes & $\begin{array}{l}\text { Usability and effectiveness was } \\
\text { evaluated using pre-test and post- } \\
\text { test questionnaires. }\end{array}$ & $\begin{array}{l}\text { Designed using the Attention, Rele- } \\
\text { vance, Confidence, and Satisfaction } \\
\text { (ARCS) motivation model. }\end{array}$ \\
\hline $\begin{array}{l}\text { Social4 } \\
\text { School [23] }\end{array}$ & $\begin{array}{l}\text { Multi-player simulation, where players learn } \\
\text { appropriate social media behaviours. They } \\
\text { receive points for positive social media be- } \\
\text { haviours. }\end{array}$ & 2017 & $\begin{array}{l}9-11 \\
\text { years }\end{array}$ & $\begin{array}{l}\text { Social network- } \\
\text { ing }\end{array}$ & Academic & Yes & $\begin{array}{l}\text { Usability was evaluated using user } \\
\text { studies with children and teachers. }\end{array}$ & $\begin{array}{l}\text { An interdisciplinary design team of } \\
\text { Computer Science UX, and teachers } \\
\text { collaboratively designed the game. }\end{array}$ \\
\hline
\end{tabular}


Table 2.2: Review of existing digital literacy games (Continued)

\begin{tabular}{|c|c|c|c|c|c|c|c|c|}
\hline Name & Description & Year & Target & Topic & Creator & Eval? & Evaluation process & Design process \\
\hline $\begin{array}{l}\text { The } \\
\text { Watchers } \\
247\end{array}$ & $\begin{array}{l}\text { A collaborative table-top game, where play- } \\
\text { ers complete missions as secret agents to pro- } \\
\text { tect their city from cyberthreats. Each mis- } \\
\text { sion teaches a different privacy topic. }\end{array}$ & 2014 & $\begin{array}{l}8-10 \\
\text { years }\end{array}$ & 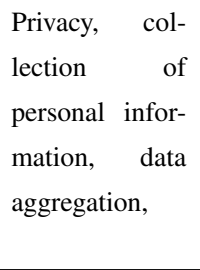 & $\begin{array}{l}\text { Academic } \\
\text { and } \\
\text { Atmo- } \\
\text { sphere } \\
\text { Indus- } \\
\text { tries }\end{array}$ & No & $\begin{array}{l}\text { N/A. Informal assessments were } \\
\text { completed with children as co- } \\
\text { designers. }\end{array}$ & $\begin{array}{l}\text { Participatory design was used to } \\
\text { co-design the game with children. } \\
\text { Heuristics created by the team were } \\
\text { used to guide the design process. }\end{array}$ \\
\hline $\begin{array}{l}\text { Net- } \\
\text { Detectives } \\
310\end{array}$ & $\begin{array}{l}\text { Role-playing game for schools, where play- } \\
\text { ers acts as a detective investigating security } \\
\text { incidents happening in their school. }\end{array}$ & 2003 & $\begin{array}{l}9-12 \\
\text { years }\end{array}$ & $\begin{array}{l}\text { Internet safety, } \\
\text { privacy, chat- } \\
\text { rooms }\end{array}$ & $\begin{array}{l}\text { Childnet } \\
\text { Interna- } \\
\text { tional }\end{array}$ & Yes & $\begin{array}{l}\text { Usability and effectiveness of the } \\
\text { game was evaluated with class- } \\
\text { rooms, as well as teachers to under- } \\
\text { stand their perspectives of using the } \\
\text { game. }\end{array}$ & N/A \\
\hline $\begin{array}{l}\text { The } \\
\text { Privacy } \\
\text { game } 15\end{array}$ & $\begin{array}{l}\text { Multi-player competitive card game model- } \\
\text { ing the internet. By playing the game, users } \\
\text { learn secure information sharing behaviours, } \\
\text { build mental models of how data is collected } \\
\text { online. }\end{array}$ & 2013 & All & $\begin{array}{l}\text { Privacy, sharing } \\
\text { information on- } \\
\text { line, data ag- } \\
\text { gregation }\end{array}$ & Academic & Yes & $\begin{array}{l}\text { Usability of the game was evaluated } \\
\text { with student students, game design- } \\
\text { ers, experienced gamers, youth, and } \\
\text { security professionals. }\end{array}$ & $\begin{array}{l}\text { The theory of procedural rhetoric } \\
\text { was used to design the game. }\end{array}$ \\
\hline $\begin{array}{l}\text { ATC game } \\
{[156]}\end{array}$ & $\begin{array}{l}\text { Collaborative multi-player game where play- } \\
\text { ers work as a team of air traffic controllers } \\
\text { guiding planes in an airport, while mitigating } \\
\text { various security events. }\end{array}$ & 2012 & $\begin{array}{l}\text { Univ. } \\
\text { students }\end{array}$ & $\begin{array}{l}\text { Network secu- } \\
\text { rity }\end{array}$ & Academic & No & N/A & N/A \\
\hline $\begin{array}{l}\mathrm{d} 0 \times 3 \mathrm{~d} ! \\
{[107]}\end{array}$ & $\begin{array}{l}\text { Collaborative table-top card game where } \\
\text { players act as white-hat hackers and break } \\
\text { into a computer network to steal security as- } \\
\text { sets without detection. }\end{array}$ & 2012 & K-12 & $\begin{array}{l}\text { Network secu- } \\
\text { rity }\end{array}$ & Academic & Yes & $\begin{array}{l}\text { Informally tested with middle } \\
\text { school, high school, and university } \\
\text { students. }\end{array}$ & $\begin{array}{l}\text { Designed using seven design goals } \\
\text { (e.g., needs to be fun) defined by the } \\
\text { design team. }\end{array}$ \\
\hline $\begin{array}{l}\text { What.Hack } \\
307 \text {. }\end{array}$ & $\begin{array}{l}\text { Role-playing game where players must in- } \\
\text { spect emails to protect their network from } \\
\text { phishing attacks. }\end{array}$ & 2019 & All & Phishing & Academic & Yes & $\begin{array}{l}\text { Usability and effectiveness of the } \\
\text { game was evaluated using a user } \\
\text { study. Results were compared with } \\
\text { other phishing awareness options. }\end{array}$ & $\begin{array}{l}\text { Designed using three goals defined } \\
\text { by the team. Was based on the de- } \\
\text { sign of Paper Please, a document in- } \\
\text { spection game [236]. Content was } \\
\text { created using real phishing emails. } \\
\text { [236]. }\end{array}$ \\
\hline
\end{tabular}


Table 2.2: Review of existing digital literacy games (Continued)

\begin{tabular}{|c|c|c|c|c|c|c|c|c|}
\hline Name & Description & Year & Target & Topic & Creator & Eval? & Evaluation process & Design process \\
\hline $\begin{array}{l}\text { Smells } \\
\text { Phishy } \\
{[17]}\end{array}$ & $\begin{array}{l}\text { Competitive table-top board game, where } \\
\text { players buy items on a shopping list, without } \\
\text { being phished by online shopping websites. }\end{array}$ & 2016 & $\begin{array}{l}12+ \\
\text { years }\end{array}$ & Phishing & Academic & Yes & $\begin{array}{l}\text { Usability and effectiveness was } \\
\text { evaluated using a user study. }\end{array}$ & $\begin{array}{l}\text { Designed to meet three learning } \\
\text { goals specified by the designer. }\end{array}$ \\
\hline $\begin{array}{l}\text { Friend } \\
\text { Inspector } \\
{[39]}\end{array}$ & $\begin{array}{l}\text { Social media game to improve users aware- } \\
\text { ness of privacy settings on Facebook. }\end{array}$ & 2014 & All & Privacy & Academic & No & N/A & $\begin{array}{l}\text { Designed to meet goals defined by } \\
\text { the desingers, and some established } \\
\text { game design guidelines. [153]. }\end{array}$ \\
\hline $\begin{array}{l}\text { Immersive } \\
\text { Security } \\
\text { Envi- } \\
\text { ronment } \\
{[260]}\end{array}$ & $\begin{array}{l}\text { Competitive SIMS style game, where two } \\
\text { teams compete, one as the adversary and the } \\
\text { other as the target of a cyber attack. This re- } \\
\text { flects what happens in real life to users. }\end{array}$ & 2012 & $\begin{array}{l}\text { Univ. } \\
\text { students }\end{array}$ & $\begin{array}{l}\text { Network secu- } \\
\text { rity, TCP/IP }\end{array}$ & Academic & No & $\begin{array}{l}\text { Players' knowledge is evaluated us- } \\
\text { ing in-game quizzes, embedded in } \\
\text { the game. }\end{array}$ & N/A \\
\hline $\begin{array}{l}\text { Cash City } \\
\text { [203] }\end{array}$ & $\begin{array}{l}\text { Multi-player board game similar to } \\
\text { Monopoly, where players make security } \\
\text { decisions as part of their main tasks in the } \\
\text { game. Postive security descions are re- } \\
\text { warded, and neative decisions are penalized. }\end{array}$ & 2010 & Employees & $\begin{array}{l}\text { Phishing, } \\
\text { malware, } \\
\text { passwords }\end{array}$ & Academic & Yes & $\begin{array}{l}\text { Usability and effectiveness was } \\
\text { evaluated using multiple studies } \\
\text { throughout the design process. Re- } \\
\text { sults were also compared with a } \\
\text { control group. }\end{array}$ & $\begin{array}{l}\text { Designed using several established } \\
\text { game design principles }[20,282] \text {. }\end{array}$ \\
\hline $\begin{array}{l}\text { Cyber } \\
\text { CIEGE } \\
{[136]}\end{array}$ & $\begin{array}{l}\text { Scenario based simulation, where players act } \\
\text { as employees of an IT company, assisting } \\
\text { clients and protecting assets from cybercrim- } \\
\text { inals. }\end{array}$ & 2006 & Employees & $\begin{array}{l}\text { malware, on- } \\
\text { line safety, } \\
\text { passwords, se- } \\
\text { curity policies } \\
\end{array}$ & $\begin{array}{l}\text { US } \\
\text { Naval } \\
\text { School }\end{array}$ & Yes & $\begin{array}{l}\text { Effectiveness was evaluated using a } \\
\text { user study, and results were com- } \\
\text { pared with a control group. }\end{array}$ & N/A \\
\hline $\begin{array}{l}\text { Zoe \& } \\
\text { Molly } \\
\text { online } \\
{[82}\end{array}$ & $\begin{array}{l}\text { Narrative based game where players com- } \\
\text { plete a series of online safety scenarios in- } \\
\text { volving the main characters of Zoe and } \\
\text { Molly. }\end{array}$ & 2013 & $\begin{array}{l}8-10 \\
\text { years }\end{array}$ & $\begin{array}{l}\text { Sharing photos } \\
\text { online, viewing } \\
\text { inappropriate } \\
\text { content, phish- } \\
\text { ing, stranger } \\
\text { danger, }\end{array}$ & $\begin{array}{l}\text { Canadian } \\
\text { Centre } \\
\text { for Child } \\
\text { Protec- } \\
\text { tion }\end{array}$ & No & $\begin{array}{l}\text { Assessment questionnaires are pro- } \\
\text { vided in the teacher guide. Also } \\
\text { available through the online quiz. }\end{array}$ & N/A \\
\hline $\begin{array}{l}\text { Jo Cool } \\
\text { or Jo Fool } \\
{[195]}\end{array}$ & Quiz teaching safe web browsing behaviours. & Yes & $\begin{array}{l}10-13 \\
\text { years }\end{array}$ & $\begin{array}{l}\text { Online safety } \\
\text { and personal } \\
\text { information }\end{array}$ & $\begin{array}{l}\text { Media } \\
\text { Smarts }\end{array}$ & N/A & N/A & \\
\hline
\end{tabular}


Table 2.2: Review of existing digital literacy games (Continued)

\begin{tabular}{|c|c|c|c|c|c|c|c|c|}
\hline Name & Description & Year & Target & Topic & Creator & Eval? & Evaluation process & Design process \\
\hline $\begin{array}{l}\text { Be Internet } \\
\text { Awesome } \\
{[109]}\end{array}$ & $\begin{array}{l}\text { A suite of platform games (e.g., puzzles), } \\
\text { each addressing a different digital literacy } \\
\text { topic. }\end{array}$ & 2017 & $\begin{array}{l}9-12 \\
\text { year olds }\end{array}$ & $\begin{array}{l}\text { Sharing on- } \\
\text { line, phishing, } \\
\text { fake news, } \\
\text { passwords, } \\
\text { cyberbullying }\end{array}$ & Google & Yes & $\begin{array}{l}\text { Usability was evaluated with chil- } \\
\text { dren at various stages of the design } \\
\text { process. [52]. }\end{array}$ & $\begin{array}{l}\text { Created in partnership with iKeep- } \\
\text { Safe using an interdisciplinary de- } \\
\text { sign team. }\end{array}$ \\
\hline $\begin{array}{l}\text { Digital } \\
\text { Passport } \\
{[186]}\end{array}$ & $\begin{array}{l}\text { Suite of platform and quiz games designed } \\
\text { for parents and teachers. Each game ad- } \\
\text { dresses a different digital literacy topic. }\end{array}$ & 2012 & $\begin{array}{l}8-11 \\
\text { years }\end{array}$ & $\begin{array}{l}\text { Passwords, } \\
\text { sharing online, } \\
\text { cyberbullying, } \\
\text { copyright }\end{array}$ & $\begin{array}{l}\text { Common } \\
\text { Sense } \\
\text { Media }\end{array}$ & No & $\begin{array}{l}\text { A teacher evaluation system can } \\
\text { be used to assess students' perfor- } \\
\text { mance, and award certificates. }\end{array}$ & $\begin{array}{l}\text { Designed using content from exist- } \\
\text { ing digital literacy modules are pop- } \\
\text { ular with teachers. }\end{array}$ \\
\hline $\begin{array}{l}\text { Carnegie } \\
\text { Cadets } \\
297\end{array}$ & $\begin{array}{l}\text { Role-playing game for classrooms, where } \\
\text { players act as a new recruit at a cyber training } \\
\text { academy, and complete missions addressing } \\
\text { different cybersecurity topics. }\end{array}$ & 2007 & $\begin{array}{l}9-11 \\
\text { years }\end{array}$ & $\begin{array}{l}\text { Phishing, pass- } \\
\text { words, sharing } \\
\text { online, cyber- } \\
\text { bullying, online } \\
\text { threats }\end{array}$ & Academic & No & N/A & N/A \\
\hline $\begin{array}{l}\text { Cyberbully } \\
\text { Zombies } \\
\text { 88] }\end{array}$ & $\begin{array}{l}\text { Plants and zombies style game, where players } \\
\text { defend their school from cyberbullies (zom- } \\
\text { bies). They learn how to deal with cyberbul- } \\
\text { lies and earn rewards for correct behaviours. }\end{array}$ & 2011 & $\begin{array}{l}8-12 \\
\text { years }\end{array}$ & Cyberbullying & NCMEC & No & N/A & N/A \\
\hline $\begin{array}{l}\text { Digital } \\
\text { Compass } \\
{[184]}\end{array}$ & $\begin{array}{l}\text { Choose-your-adventure style game, where } \\
\text { players help characters in a story with differ- } \\
\text { ent digital literacy issues. }\end{array}$ & 2015 & $\begin{array}{l}11-14 \\
\text { years }\end{array}$ & $\begin{array}{l}\text { Phishing, on- } \\
\text { line safely, } \\
\text { cyberbullying, } \\
\text { fake news }\end{array}$ & $\begin{array}{l}\text { Common } \\
\text { Sense } \\
\text { Media }\end{array}$ & No & $\begin{array}{l}\text { In-game mini-quizzes are used to as- } \\
\text { sess players' performance. }\end{array}$ & $\begin{array}{l}\text { Game content aligns with eight core } \\
\text { topics of Common Sense Media's } \\
\text { Digital Citizenship Curriculum. }\end{array}$ \\
\hline $\begin{array}{l}\text { DataK } \\
{[291]}\end{array}$ & $\begin{array}{l}\text { Players act as an assistant data protection } \\
\text { manager to the mayor of Dataville, and make } \\
\text { decisions affecting the privacy of citizens. }\end{array}$ & 2016 & $\begin{array}{l}15 \text { years } \\
\text { and } \\
\text { older }\end{array}$ & $\begin{array}{ll}\text { Data } & \text { privacy } \\
\text { and aggrega- } \\
\text { tion }\end{array}$ & $\begin{array}{l}\text { Radio } \\
\text { Télévi- } \\
\text { sion } \\
\text { Suisse }\end{array}$ & No & $\begin{array}{l}\text { Assessment exercises are available } \\
\text { in the teacher guide. }\end{array}$ & $\begin{array}{l}\text { Design based on an 18-month jour- } \\
\text { nalistic investigation by On en Parle } \\
\text { radio program, and supervised by } 15 \\
\text { experts from different field. }\end{array}$ \\
\hline $\begin{array}{l}\text { Data } \\
\text { Dealer } \\
{[230]}\end{array}$ & $\begin{array}{l}\text { Single-player game where players act as a } \\
\text { data dealer and collect, sell, and steal others } \\
\text { personal information to become a data mogul. }\end{array}$ & 2013 & All & Data privacy & $\begin{array}{l}\text { Cuteacute } \\
\text { Media } \\
\text { OG }\end{array}$ & No & N/A & $\begin{array}{l}\text { Designed by an interdisciplinary } \\
\text { team of developers, designers, and } \\
\text { researchers. }\end{array}$ \\
\hline
\end{tabular}




\section{Chapter 3}

\section{Design of the JOs}

In this section, we describe the functionality of our new game followed by an overview of the design process used to create the game.

\subsection{Learning objectives}

Our educational game for 11-13 year old children has the following learning objectives:

1. Improve children's understanding and knowledge of digital literacy issues, including privacy and security.

2. Develop children's critical thinking skills about novel situations that they may face online, especially on social media. Most will likely have social media accounts soon, given that the minimum age requirement of most social media platforms is 13 (e.g., [34, 129-134, 162, 190]).

To meet our learning objectives, we used several game design principles to create a game that provides an empowered learning environment for children. Our goal was to create a game that allows children to explore, practice different strategies, and learn from their experiences, which is more effective than a passive learning environment [96]. Specifically, we used Gee's guidelines for learning games [96], Salen and Zimmerman's recommendations for meaningful play [262], and Ferrara et al's. [72] guidelines for utilizing procedural rhetoric. Ferrara et al's. design guidelines include defining a core message (P-G1), offering meaningful choices (P-G2), enabling self-directed discovery (P-G3), tying the message to strategy (P-G4), and keeping the simulation realistic (P-G5) (see Section 2.5.5).

\subsection{Game design}




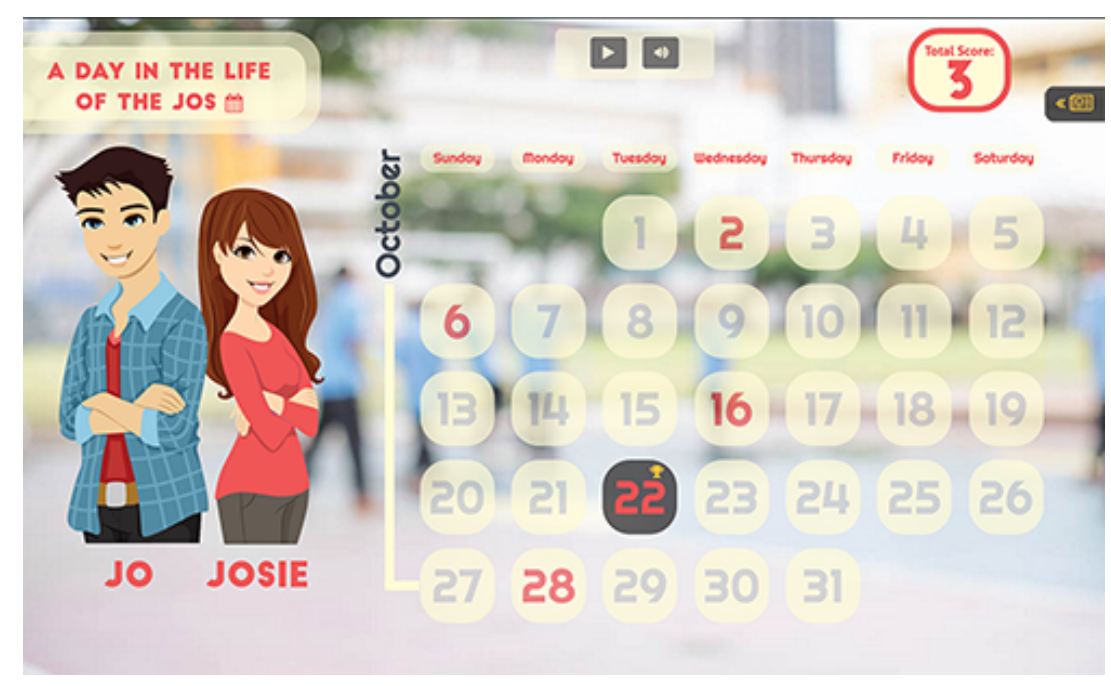

Figure 3.1: Main screen of the Jo's game

The main message of our game is that life with digital media is complex, and the correct behaviour is not always clear. However, we have choices and the choices we make have consequences (good or bad) on our personal and digital lives (P-G1). Given this, we used a-day-in-the-life approach to design our game, where players follow the main characters of Jo and Josie through a series of events in their daily life and help them make smart decisions online. The main characters are avid social media users, and reflect our target audience who are digital natives and use multiple electronic devices in their daily lives. By playing the game, children are able to see possible consequences of their choices in a simulation before they make them in the real world.

Since the game is meant to be used in a classroom setting, an additional constraint was to keep the game short so that it can be completed as part of a lesson (typically lasting under 60-minutes) and foster discussion among students. It also needed to have measurable educational goals which can be used by teachers to evaluate students' performance. In collaboration with us, MediaSmarts specified the target audience, identified educational topics, and created scripts for the game.

Figure 3.1 shows the opening screen of our new game, where the calendar represents a typical school month for the player. The game has five days which are active in the calendar and are highlighted in red. Days with a dark grey background have been completed by the player. As detailed in Table 3.1, each day addresses a different digital literacy topic, and includes five scenarios covering different aspects of the topic (for a total of 25 implemented 
scenarios). A short introduction and instructions on how to play the game are provided. To begin, players select a day from the calendar which directs them to the main screen for that day. The visual design is different for each day, reflecting the topic addressed by the day, and the page links to five related scenarios. Each scenario shows Jo or Josie in a situation where they require the player's help in deciding how to behave safely.

Figure 3.2 and Figure 3.3 show a scenario in the game. The first two screens present the scenario to the player. After viewing the scenario, players are presented with three choices and have to decide what Jo/Josie should do. For example, in this scenario Josie takes a picture of a friend without her permission and wants to post it on social media. The player must help her decide what she should do in this situation. After making a choice, players immediately see the consequences of their choice in the news feed component, which acts as an aggregator of the characters' digital media platforms. A score also helps players keep track of how well they are doing in the game in terms of making privacy-conscious choices.

\subsection{Detailed functionality of the game}

In this section, we provide details of the different components in our game such as the scenarios, choices, newsfeed, scoring, feedback, and the characters. We discuss these in light of Gee's design principles and discuss how they fit with procedural rhetoric theory.

\begin{tabular}{l|l}
\hline Day & Scenarios \\
\hline Cyberbullying & $\begin{array}{l}\text { Sharing gossip, sharing funny video or photos of others, defending people be- } \\
\text { ing bullied, and dealing with online bullies. }\end{array}$ \\
\hline Online tracking & $\begin{array}{l}\text { Providing data to apps, deleting data online, phishing, browser and search en- } \\
\text { gine histories. }\end{array}$ \\
\hline Privacy & $\begin{array}{l}\text { Using apps like Snapchat, sharing pictures without consent, using public com- } \\
\text { puters, asking others to remove pictures, and managing your online reputation. }\end{array}$ \\
\hline Sharing photos & $\begin{array}{l}\text { Sharing pictures or videos of others without consent, understanding copyright, } \\
\text { dealing with a depressed friend, sharing private photos of yourself }\end{array}$ \\
\hline Fact checking & Verifying the authenticity of information on social media, wikis, and websites \\
\hline
\end{tabular}

Table 3.1: Digital literacy topics addressed by the game 


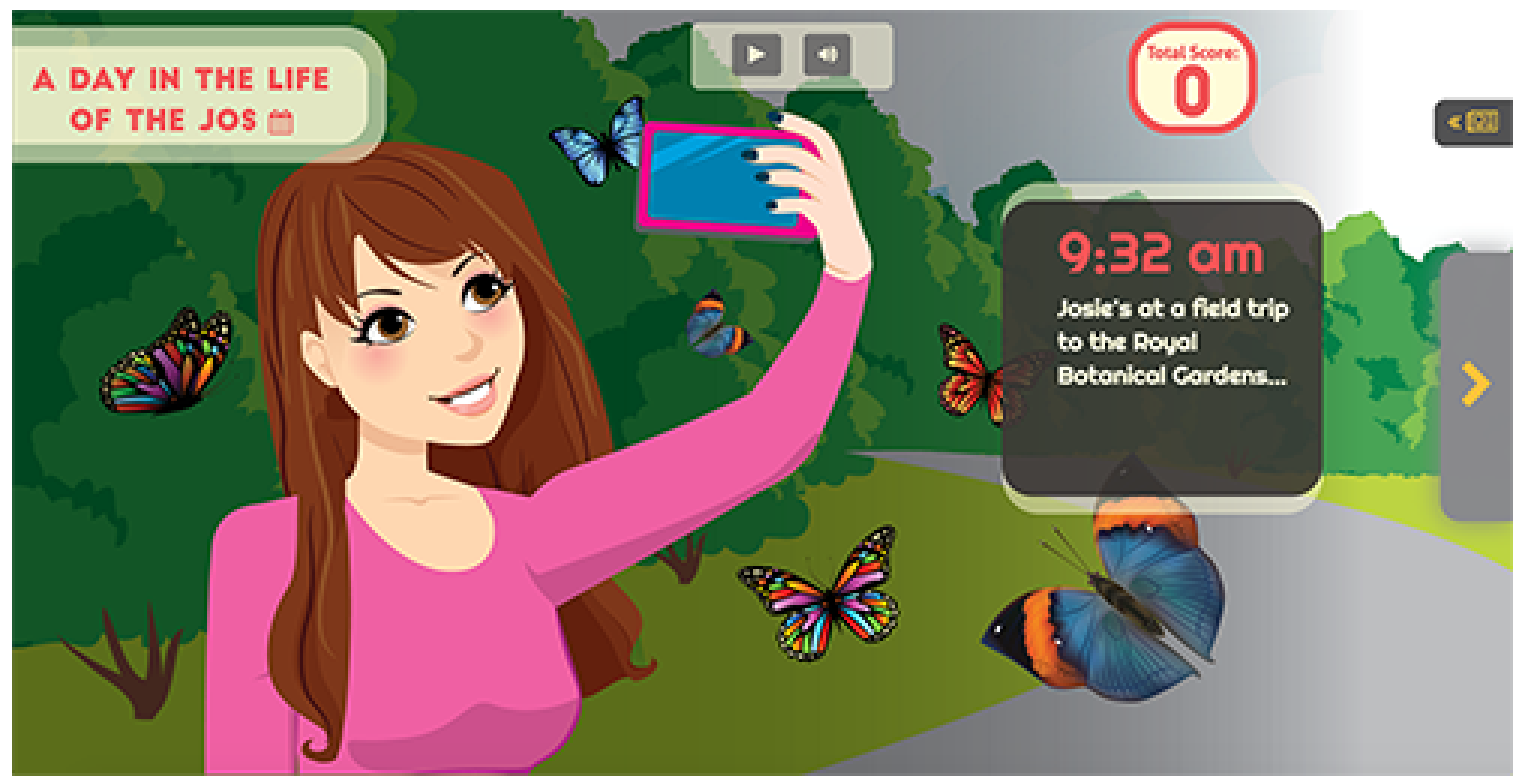

(a) Introduction screen

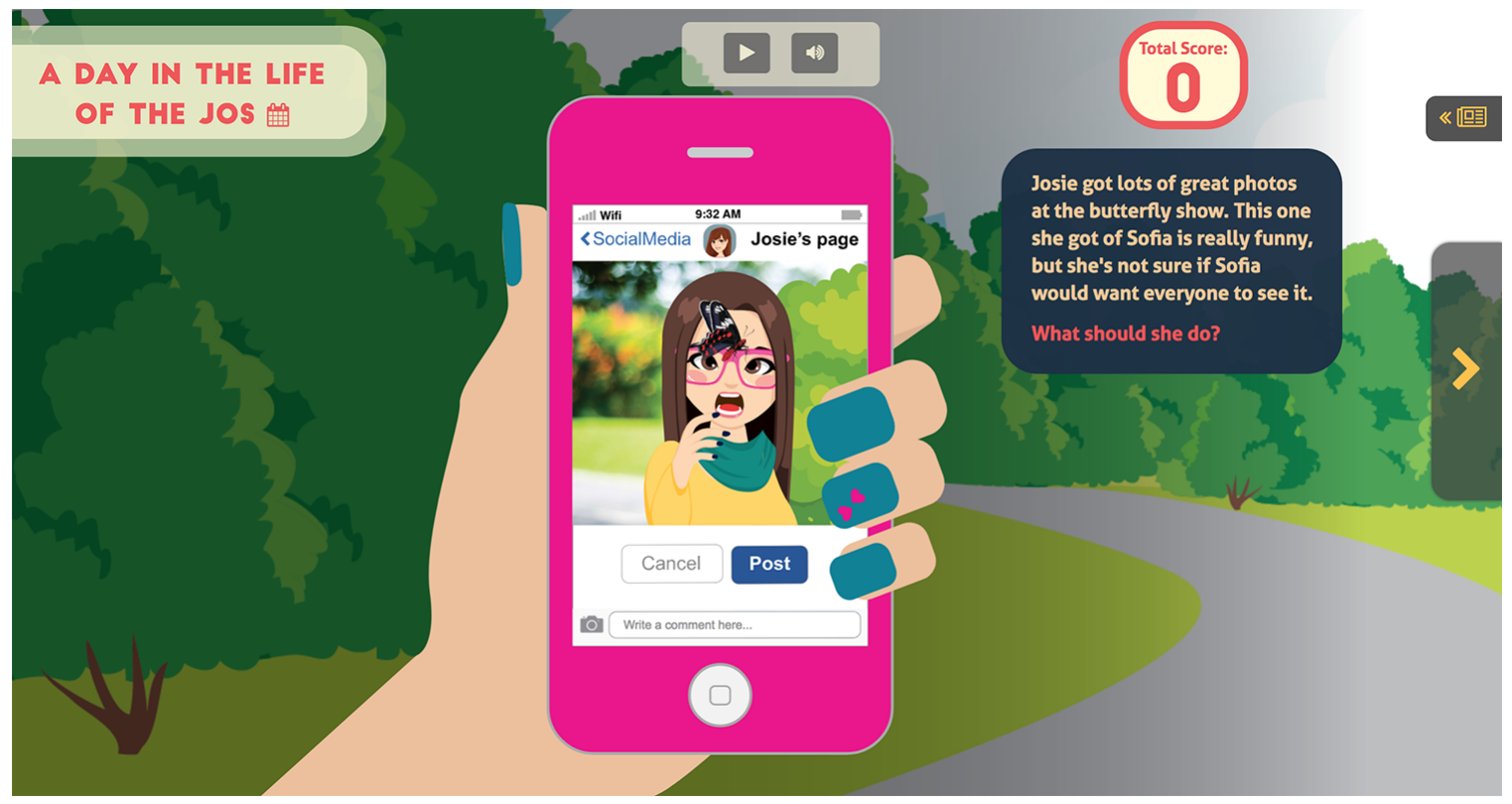

(b) Middle screen

Figure 3.2: Scenes 1 and 2 of a scenario in the game. 


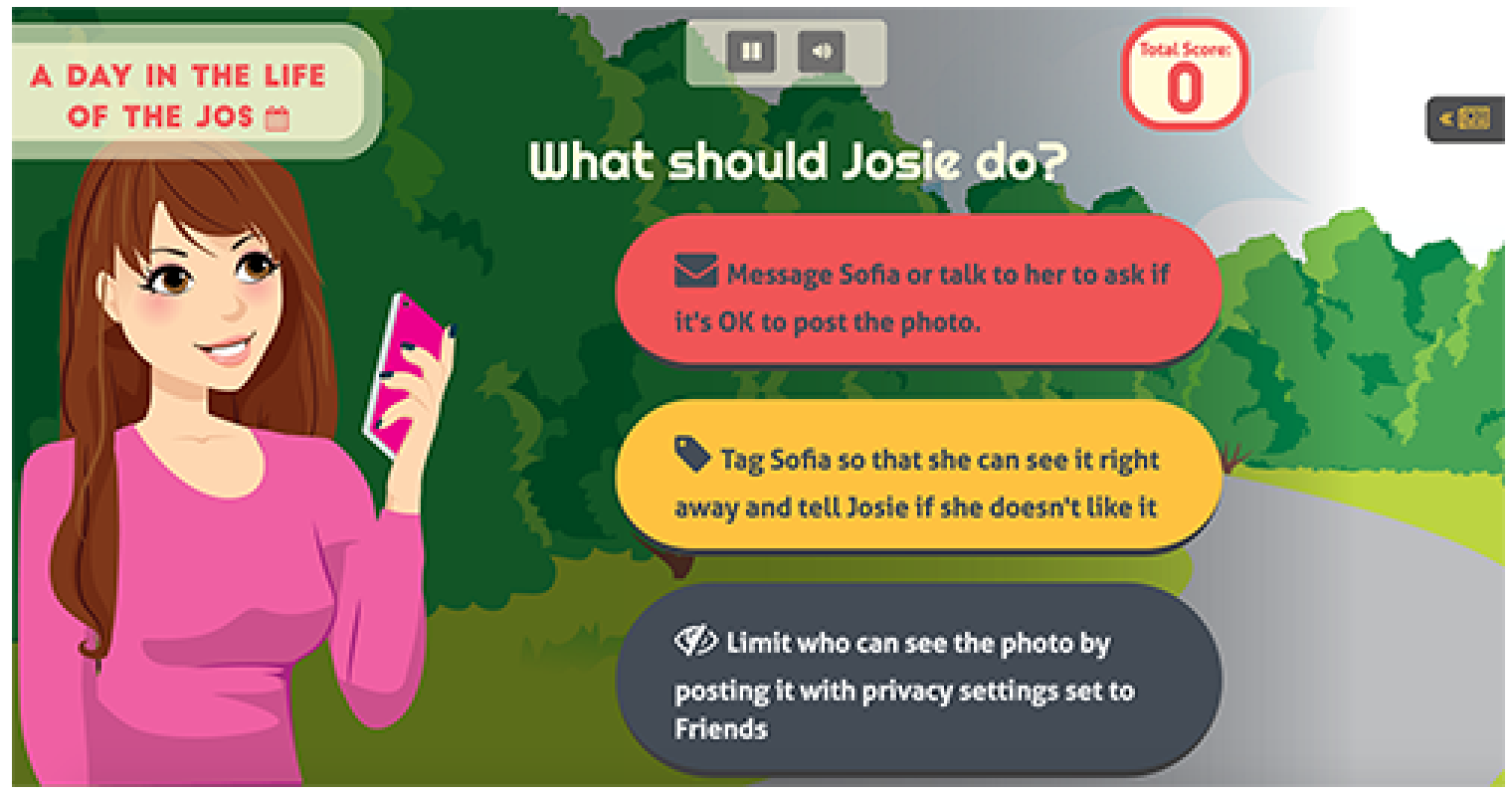

(a) Choices screen

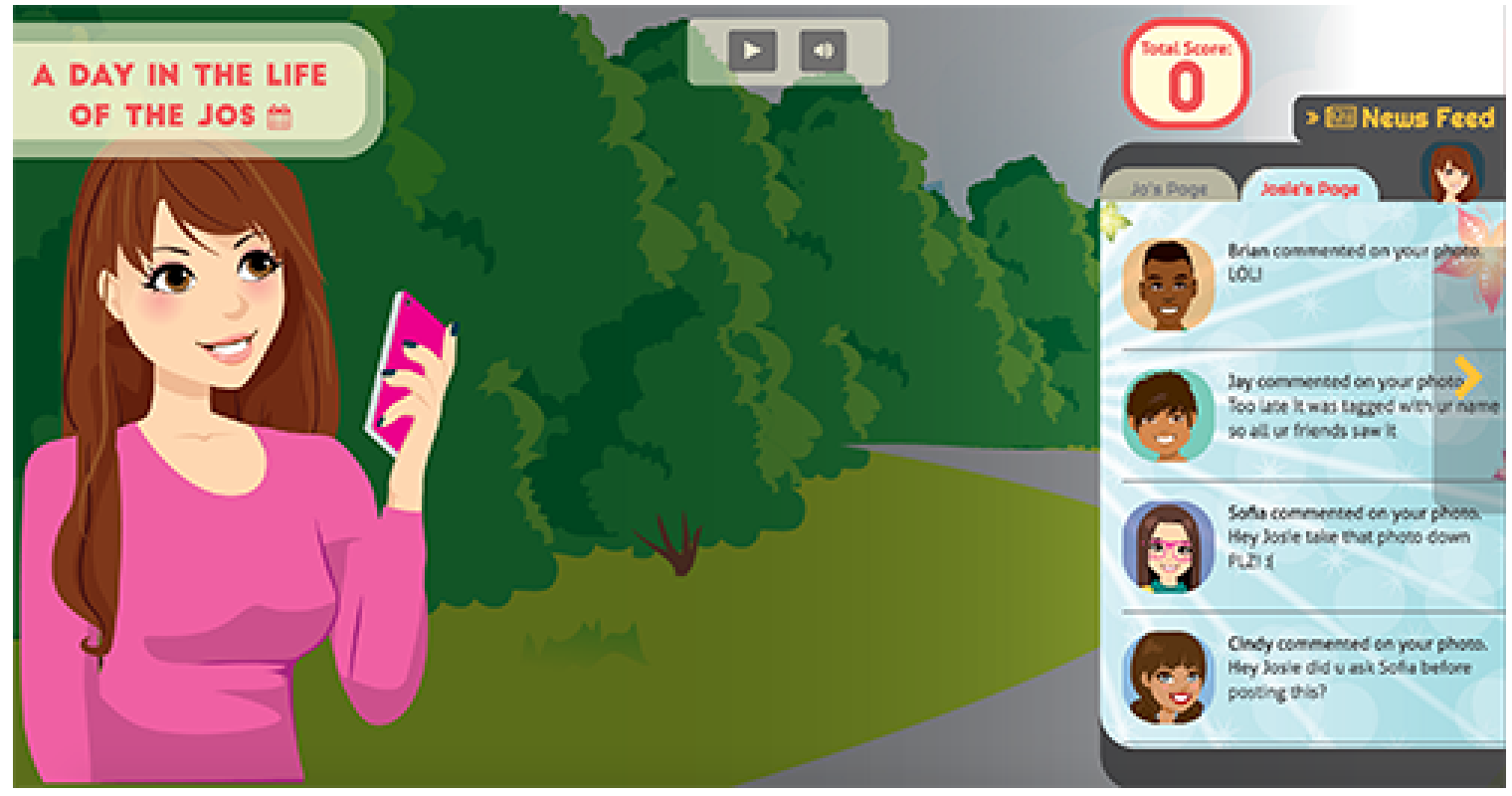

(b) News feed showing the consequences

Figure 3.3: Scenes 3 and 4 of a scenario in the game. 


\subsubsection{Scenarios}

Scenarios are composed of text and graphics, and are presented via a series of animations. The scenarios are quite diverse, for example Josie working with a friend in science class, or the siblings playing an online game with friends. Scenarios in a day must be completed in temporal order. Progress is automatically saved when a scenario is completed, so players can return to the game to continue at any time. Players can replay completed days, which is useful if they want to see the outcomes of different choices. When replayed, the game score and the content of the news feed are adjusted accordingly.

We spent significant effort into devising realistic, relatable scenarios so that children are engaged and invested in the game outcomes [178]. When children are able to see themselves in situations presented in the game, they are more likely to learn from them and apply the learned material to situations outside of the game [24, 178, 200]. Some scenarios required the main characters to engage in negative behaviours (e.g., sharing someone's photo without permission). To make these scenarios relatable, we framed them to represent situations where the characters accidentally engaged in the behaviour without malicious intent. Our intent was for children to develop empathy for the characters, and understand how children their age might engage in these behaviours. Thus, by playing the game, children not only saw how to avoid these behaviours but could also develop an understanding and empathy for individuals (e.g., friends) who might engage in them.

\subsubsection{Choices}

Choices in a scenario (Figure 3.3a) are the main mechanism of procedural rhetoric [27] in the game (P-G2). By playing a day in the game, players experience the consequences of their choices on Jo/Josie's digital lives and come to realize the main message of the game (P-G3). There are positive and negative consequences of engaging in each choice, so players have incentives to engage in each option in the game. For example in the scenario shown in Figure 3.3a, if Josie chose to post the picture, then the news feed would show her friends' reactions. Her friend Sofia is mad at her for posting the photo, while others think the photo is funny, so she's getting both positive and negative reactions to her choice, which reflects something that may actually happen in real life. From a privacy perspective, Josie would get 0 points for posting the photo, but this is contrasted with the social capital 
that she gets from her friends' reactions in the newsfeed.

We designed the choices to reflect the real world, so the correct choice was not always clear, requiring players to think critically of the choices and the situation. This allows players to explore and discover the consequences of different choices. Players can take a risky approach and pick all the "bad" choices, just to see their effects on Jo/Josie's digital lives, or they can try to pick the safest choices in each case. This design respects Gee's Risk taking principle, and allows children to explore risky behaviours in a safe simulated environment, where the consequences are less severe than the real-world [98]. This design might lead children to choose riskier choices compared to the real-world, because they are interested in exploring the consequences of these choices in a safe environment.

The consequences of players' choices are immediately apparent on Jo/Josie's lives. Thus, the rhetoric of our game is reinforced through the user's choices. We provided three choices for every scenario in the game, to adequately capture the nuances of the choices available to children in real life, without creating a choice paradox ${ }^{1}$. The type of choices provided follow Gee's Pleasantly frustrating principle, where the correct choice is not obvious, requiring players to critically think about the different options. However, the correct choice is also not impossible to find, so the player is not left frustrated.

The choices in conjunction with the newsfeed create an environment of meaningful play as described by Salen and Zimmerman [262]. When players make a choice in a scenario the feedback of their choice is immediately shown in the newsfeed. This respects the discernibly principle of meaningful play, where the result of an action is clearly communicated to the player, so they know what happened and whether their action was meaningful [262]. The second component of meaningful play is that the relationship between the action and outcome should be integrated into the larger context of the game [262]. When an action does not impact future aspects of the game or experience, it loses meaning as the player has no incentive for engaging in that action [262]. In our game, each action (choice) of the player is meaningful because it impacts the overall story that they are creating in the game.

\footnotetext{
${ }^{1}$ The choice paradox is a psychological principle, where having too many choices makes users anxious and leaves them unable to make a choice. That is because the more choices users have, the more effort they need to exert comparing all the different options before making a choice. This process is stressful, so when presented with too many options users are less likely to make a choice [269].
} 


\subsubsection{News feed}

The news feed is the second component of procedural rhetoric in our game. After making a choice, players see the results and consequences of their choice in the newsfeed, which nudges players towards the main message of the scenario. For example, in the scenario shown in Figures 3.2 and 3.3, if the player chooses the option of Josie should limit who can see the photo, the newsfeed will show that Josie's friend Sophia is mad at her for posting the photo without her permission. The consequences shown will help the player reconsider their use of privacy settings on social media. Seeing the consequences in the newsfeed will also promote reflection, where the player can think of their choice and how it relates to their behaviour in the real world. After playing several scenarios, players should come to the conclusion that life with digital media is nuanced, and they need to think critically about the various choices available before taking action.

The newsfeed respects Gee's Production principle, where players are influencing their own ending to a scenario (i.e., story). This helps players feel empowered and in control of their learning, which should lead to better engagement and improved learning of the content [98]. The game also applies Gee's System thinking principle, and encourages players to think about the relationships between different systems (i.e., digital media platforms), and how their actions affect others in the system [98]. For example, in scenarios involving social media, children learn how their actions affect others, and also how the actions of other people affect their privacy. In the scenario shown in Figures 3.2 and 3.3, after choosing to post a photo without Sophia's permission, children learn that Josie has accidentally compromised her friend's privacy. Thus, the game helps children understand the security, privacy, and ethical implications in complex sociotechnical systems that represent the digital world.

The newsfeed is a consistent element in the game, accessible from any screen, and allows players to review the consequences of their choices on demand, helping them reflect on the learned material. Players can display/hide the feed and can switch between Jo and Josie's feeds (Figure 3.3b). When a scenario is played, the news feed is automatically hidden by the game and it is automatically displayed again at the end of the scenario to show

the consequences of the player's choice. The visibility of the news feed is controlled by game during a scenario, to guide players' attention to relevant components as they progress 
through the scenario. The news feed can also help players review their choices, which may encourage them to replay the scenarios and make different choices to explore different outcomes (P-G3). According to Gee's Challenge and consolidation principle, games allow players to master a challenge before presenting them with a new set of challenges that require the use of the mastered skills [98]. While this aspect is not built into our game, the replayability feature allows teachers to implement this part of learning outside of the game. For example, teachers can assign children a day, and only allow them to move on to the second day, once they have demonstrated sufficient mastery..

The newsfeed is an aggregate social media feed. We stayed away from mirroring any specific social media platform. Instead, the newsfeed shows a reverse chronological series of posts and actions from other people in Jo and Josie's lives with no mention of platform. Some are public and others are private messages. Actions might include "unfriending" or comments on Jo or Josie's photos. Each posted item has a headshot image of the person and a textual description. For each choice in the game, 3-5 new items appear in the newsfeed one at a time, using a fade-in animation.

\subsubsection{Scoring and Feedback}

Players choose one of three choices at the end of a scenario, and each choice is worth 0 , 1 , or 2 points. The total score for the game is always visible (Figure 3.1) and reflects children's overall privacy preserving or social conscious mindset. After completing a scenario, players are told whether they made the most appropriate choice. Detailed feedback is provided after a day is completed, and explains the player's performance for the whole day. It shows their choices per scenario and associated score, then offers commentary and advice of better alternatives if appropriate (PG-4). This review screen allows players to reflect on their choices and the learned material, which is intended to aid retention and application of the material to real world settings. Low scores in the game might nudge players to redo completed scenarios to achieve a better score, leading them to the correct behaviour (PG4). However, even the low-scoring choices are educational because they teach players the consequences of negative behaviours.

The feedback provided at different points in the game (immediately after viewing the consequences of a choice and after completing a whole day) provide children with several 
opportunities to reflect on the consequences of their choices. Reflection allows children to realize what they did wrong and how they can improve in the subsequent parts of the game. To minimize disruptions, the short message at the end of a scenario only tells the player how their choice affected Jo or Josie. The complete summary provided at the end of a day shows them their choice, consequences, the correct choice, and how they can improve in the future. This kind of reflection leads to a better understanding of the educational material than simply being told that a choice was incorrect [50]. It also helps with the retention and knowledge transfer of the material learned from the game [127].

Feedback was also made available directly to teachers. In parallel development, MediaSmarts hired developers to build a teacher evaluation framework to host the JOs and the other MediaSmarts games. The framework was developed based on feedback from teachers about their needs and with extensive consultation with us. All outcomes of our game are available for tracking in the teacher evaluation framework. With the framework, teachers can monitor student performance through game scores and detailed reports about each student's choices and actions.

\subsubsection{Characters}

According to Gee's Identity principle, children learn from games when they can inhabit a character and manipulate the character by making choices for them [98]. Our game respects this principle, as children can take on the role of Jo or Josie and make choices that have consequences on their digital lives. Manipulating the characters can increase children's engagement and commitment to playing the game, which results in deeper learning [98].

It is important that children have positive associations with the game characters, otherwise they would be less inclined to learn from them [9, 171]. To facilitate positive associations, we chose two main characters in our game so both boys and girls could relate, and designed them to be representative of 11-13 year old children. When using them in game scenarios, we made sure that both Jo and Josie were represented equally in situations where they were the victims of negative behaviour and situations where they had an opportunity to practice negative behaviour. We similarly tried to include diversity in ethnicity, abilities, and appearance among the secondary characters. Jo and Josie are siblings who attend middle school and take part in extracurricular activities such as basketball. They play video 
games, have cellphones, and use computers at school and at home for homework. They engage with their friends in person and through various digital channels.

\subsubsection{Navigation}

We used an explicit control (Figure 3.2a, yellow arrow on right edge) to transition between scenes within a scenario. This accommodates children's different reading levels and speed by allowing them to control the pace of transition. The game's logo, located at the topleft of the screen can be used to return to the Calendar page at anytime during gameplay. Players can only move forward through scenes, to reinforce the relationship with real life. However, players can replay an entire day once completed in its entirety.

\subsubsection{Audio}

To reduce children's cognitive load, we minimized the amount of text used in the game and provided audio narration for all the text. Players can control the audio using the persistent audio player located at the top of the screen. Narration was done by a hired voice actor in both English and French. Audio could be set to autoplay with each scene transition, allowing children to follow along with text as it appeared on the screen.

\subsubsection{Content}

Game content was designed at an appropriate reading level for our target audience in collaboration with teachers experienced in designing educational material for children. We minimized text where possible by including meaningful and visually appealing graphics. The scenarios were designed to be realistic and representative of the lives of 11-13 year old children to encourage transfer of lessons in the game to real world settings (PG-5). Scenarios were designed to be light-hearted and humorous to keep children engaged. We implemented twenty-five scenarios, and structured the design such that more (up to 150) can be added in the future. 


\subsubsection{Assessment}

Assessment was a key game requirement for our educational partner. Each scenario addresses a specific topic and teachers can use the child's score and choice in the scenario to evaluate performance and determine where students are facing difficulties or have misconceptions. Additional assessment indicators on player behaviour, such as time on task, can be included in the future. A comprehensive evaluation framework has been developed to allow teachers to regularly evaluate children's performance when the game is deployed in schools.

\subsection{Digital literacy principles}

The principles of digital literacy are nuanced, and in many cases the correct behaviour depends on the context of the situation and the user's personal beliefs and attitudes. For example, personal privacy does not necessarily mean that an individual should never share any information about themselves, but rather that it is an individualized choice and some people may choose to disclose more than others. In this case, our aim would be to help players consider the consequences (good and bad) and make an informed decision for themselves.

This makes it challenging to design learning tools to improve children's digital literacy. In The JOs game, the design team determined which choice was considered the best option in each scenario (in most cases, this was the most privacy-preserving). Given the nuances of the situations represented in our game, it is possible that some players may disagree with our choices. However, when this happens, we believe that it will generate meaningful discussion among the players and the teacher about the different choices in the game. This type of discussion fosters critical thinking skills in children and creates a sense of agency, which is required when they encounter these situations in real-life. Thus, the objective of our game is to create an environment that allows children to explore different aspects of nuanced digital literacy topics and generate discussion, which ultimately fosters their critical thinking skills. 


\subsection{Demonstration of game design principles}

\subsubsection{Gee's learning principles and meaningful play}

Our game exhibits characteristics of procedural rhetoric and various educational design principles to create an environment that allows children to explore different online safety behaviours and practice them in a safe environment. The replayability feature makes failure a natural part of the learning process, as children can replay a scenario to explore different outcomes. Gee specified sixteen principles for designing effective educational games and states that the number of principles applied to a game determines how effective it is as an educational tool. Thus, the more principles a game respects, it becomes a better learning tool. Our game applies ten out of the sixteen principles. According to Gee's Agency principle, an environment demonstrating these ten principles is an environment where players can feel a sense of ownership over what they are learning, because they are helping to create the learning environment by making choices in the game [98].

Our game is self-contained and can be played by children with varying levels of digital literacy skills. This aspect of our game respects Gee's Performance before competence principle, where players can perform in the game before becoming competent in it, which is the reverse of traditional educational methods [98]. For children with low digital literacy skills, we believe that the additional support and classroom conversations surrounding the game can be especially beneficial. Information in our game is broken down into chunks, and players are only provided the relevant chunk when they need it in the game. For example, the content associated with each scenario is split into various scenes and the newsfeed, to avoid overwhelming players with the content. This respects Gee's Just in time and On demand principle [98].

Salen and Zimmerman's principles of meaningful play [262] are apparent in our game. Our intention is that players will find the experience of playing the game meaningful, which will contribute to their engagement and improved learning of the digital literacy content. Players make choices in the game to create a story about the digital lives of Jo and Josie. Scenarios can be considered different scenes in the story. In each scenario, players make a choice on how they want that scene to end. Each choice is meaningful for the player because it creates a different ending for the scene. The choices affect the larger game 
context, by manipulating the player's total game score. A player's experience in the game depends on the choices that they have made, which means that players will have different experiences. This contributes to the fun and replayability of the game. Players may want to play the game again to make different choices and experience different outcomes. At any point, players can review the story they have created so far by reviewing Josie and Jo's newsfeeds to see the consequences of their choices on the characters' digital lives.

\subsubsection{Procedural rhetoric}

The theory of procedural rhetoric is evident in the design the JOs game. Specifically, our design fits with Ferrara et al's. design guidelines [72] for procedural rhetoric. We review parts of our design in light of these principles.

(P-G1) Define a core message and (P-G5) Keep the simulation realistic: Our game has a main message, which the players can piece together after playing multiple days in the game. To re-iterate, the main message of our game is that life with digital media is complex, and the correct behaviour is not always clear. However, we have choices and the choices we make have consequences (good or bad) on our personal and digital lives.

However, each scenario in the game also has its own message, which the player can discover by making choices in the scenario and viewing the consequences of their choice in the newsfeed. For example, the scenario shown in Figure 3.2 and Figure 3.3, represents a situation that children actually encounter in the real-world.

(P-G2) Offer meaningful choices: After presenting the scenario, the player is provided with three possible choices, and must pick an action that Josie should do (Figure 3.3). We designed the choices to reflect the real world so that the correct choice was not always clear, requiring players to think critically of the choices and the situation. This type of design allows players to explore and discover the consequences of different choices. It also makes each choice meaningful for the player.

(P-G3) Enable self-directed discovery and (P-G4) Tie the message to strategy: After making a choice, players immediately see the consequences of their choice on Jo and 
Josie's digital lives in the newsfeed. At this point, players may have an "ah ha!" moment as they realize the unexpected effects of their choice on Jo and Josie. We used an animation to present the events in the newsfeed sequentially to the player. This was partly done for usability, but also to create suspense around the final outcome. For example, in the scenario shown in Figure 3.3. if Josie chose to post Sophia's photo without her permission, then the newsfeed will sequentially show her friends' reactions. Her friend Sophia will be mad at her for posting the photo, while others think the photo is funny. Josie receives both positive and negative reactions to her choice, which is representative of what may actually happen in real life. The final event associated with this choice is that Sophia unfriends Josie on social media. After viewing the consequences and reflecting on their choice, the player may rethink their use of privacy settings, they may understand the importance of respecting other people's privacy, and they may realize that their expectations of privacy may not be the same as someone else. Thus, the final message of a scenario depends on the choices of the player and their own personal experiences. This exemplifies the rhetorical aspect of procedural rhetoric, where players experience the consequences of their choice, and then have to figure out on their own what that means for them.

To summarize, the choices and the newsfeed form the core of the procedural rhetoric in the JOs game. The choices made by the player determine the consequences shown in the newsfeed. The newsfeed helps player reflect, realize the consequences of their actions, and come to the conclusion of what the scenario's main message is for them.

\subsection{Design process}

We used an iterative user-centered design process to create the game in collaboration with MediaSmarts and Christine Mekhail, a Masters of HCI student and graphic designer. Figure 3.4 represents the phases completed so far. Different team members worked on different phases of the project, as described in Section 3.6.1. Table 3.2 shows the distribution of work between Christine and myself for the various design activities. Christine created the visual designs and I assisted with some aspects of the visual design. Creation of the visual design included creating the artwork and look and feel of the game. We worked together to create the game design, which included creating the game concept, mechanics, and the storyline. I was solely responsible for the technical design, which included creating the game 


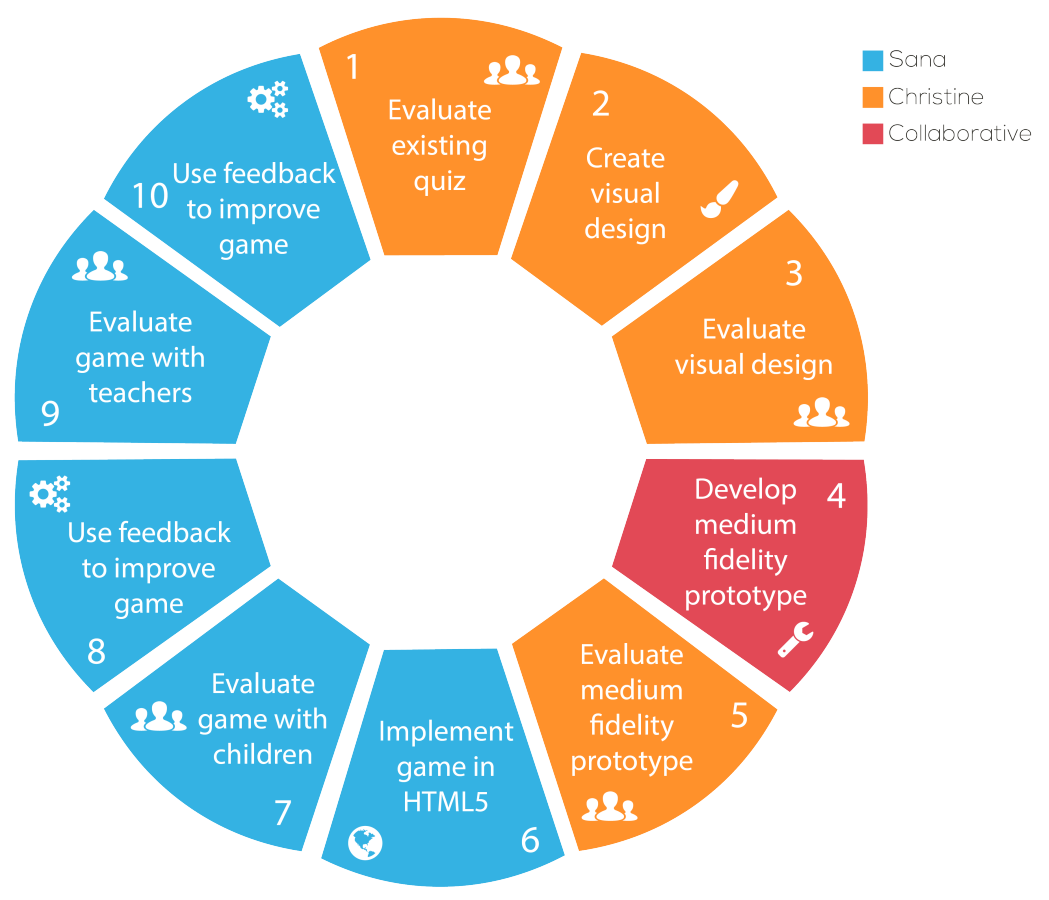

Figure 3.4: Design process of the JOs game. The colours represent the primary student involved.

architecture, implementing the game, and integrating it into the MediaSmarts framework.

We provide an overview of the whole process here for context. We used the "Jo Cool or Jo Fool" quiz [195] designed by MediaSmarts as a starting point for the conceptual design of our new game. Designed in 2000, the "Jo Cool or Jo Fool" quiz teaches 10-13 year olds safe web browsing behaviours [195], and is still being used in schools despite being significantly outdated.The quiz also presents scenarios but is text-heavy and does not include feedback like our newsfeed.

We began by conducting a user study of the quiz to discover areas of weaknesses and strengths (step 1). Christine conducted the user study and the findings from it were discussed with MediaSmarts to identify requirements for the game, educational topics, and the target audience. Next, we created three candidate visual designs for the game and Christine evaluated them with children (step 2 and 3). Feedback from the study was used to improve and create our final visual design, which was then prototyped in Adobe Illustrator and partially implemented in HTML5 (step 4).

Christine then conducted a user study to evaluate our medium fidelity prototype with children (step 5). Using feedback from the study, we refined our visual and game design 


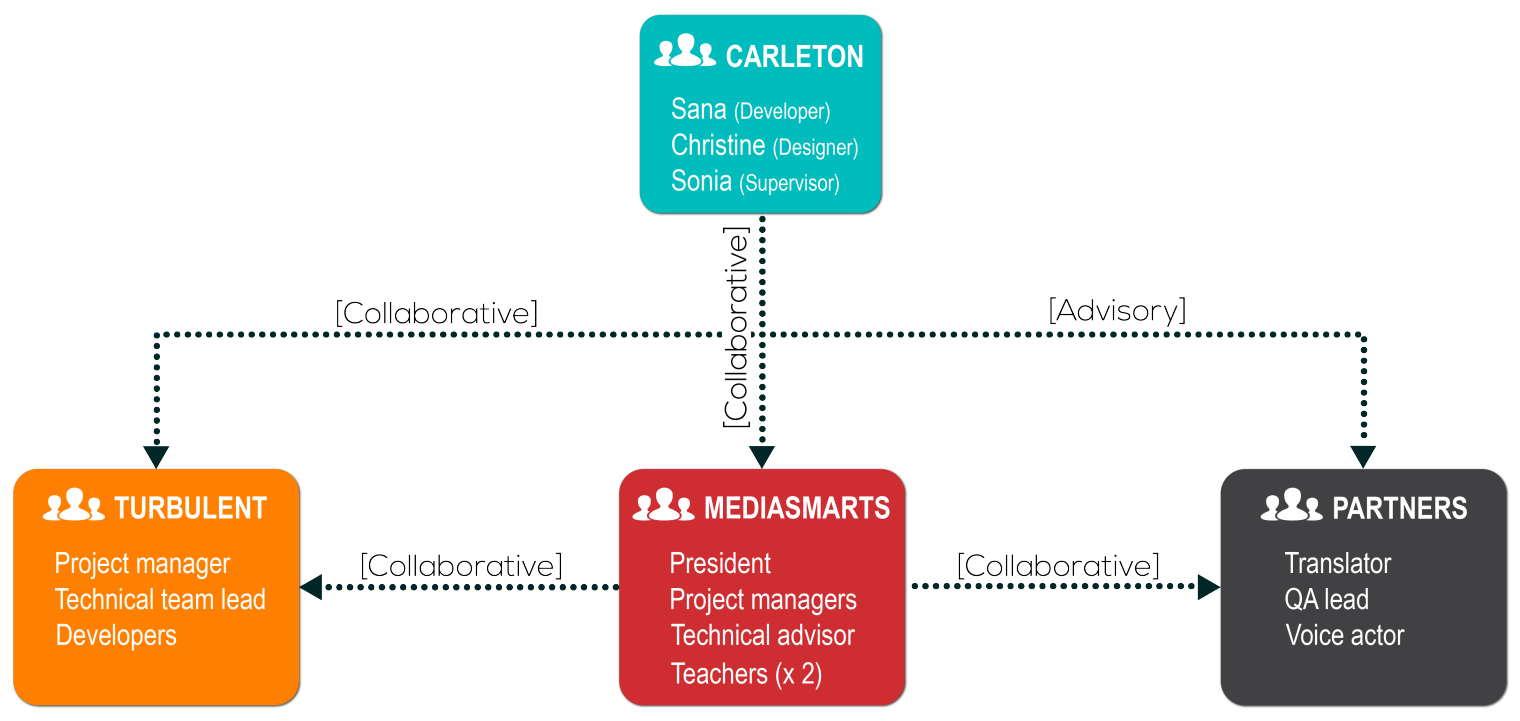

Figure 3.5: Teams involved in the design and development of the JOs game.

and completely implemented them in HTML5 to create a production quality game (step 6). I then conducted a two-part summative study with children on the high-fidelity prototype to evaluate its usability and effectiveness at meeting the learning goals (step 7). We improved the prototype based on feedback from the children (step 8), and then I tested the prototype with teachers (step 9) to explore how it can be used in classrooms. Details of the steps in the design process are provided in section 3.6 .3 .

\subsubsection{Team}

An interdisciplinary team of designers, developers, and teachers worked on the game over the past fours years (Figure 3.5). With a background in HCI and graphic design, Christine Mekhail created most of the visual designs, and we worked together to create the game

\begin{tabular}{l|l|l|l}
\hline Design type & Description & Sana & Christine \\
\hline Visual design & $\begin{array}{l}\text { This involved creating the artwork and look } \\
\text { and feel of the game. }\end{array}$ & $10 \%$ & $90 \%$ \\
\hline Game design & $\begin{array}{l}\text { This involved creating the game concept, me- } \\
\text { chanics, and storyline. }\end{array}$ & $50 \%$ & $50 \%$ \\
\hline Technical design & $\begin{array}{l}\text { This involved creating the game architecture, } \\
\text { implementing the game, and integrating it } \\
\text { into the MediaSmarts framework. }\end{array}$ & $0 \%$ \\
\hline
\end{tabular}

Table 3.2: Distribution of work for the design and development of the JOs 
concept and design. Christine user tested the visuals and medium fidelity prototype with children. I have a background in HCI, Computer Science, and web development, with expertise in security/privacy. I helped with the game design, developed the technical design and implemented the game, evaluated it with children and teachers, and managed the project over the past four years. Our educational partner, MediaSmarts, was closely involved at each stage of the design process, to ensure that their requirements and goals were being satisfied.

Different members of the MediaSmarts team were involved at different stages of the project. In the beginning, we worked closely with the MediaSmarts president and two teachers to capture game requirements and create the initial visual designs and conceptual design of the game. During the technical design and development phase, I worked closely with their technical advisor to capture technical requirements for the game and ensure that it would be compatible with MediaSmarts' back-end systems. Two project managers were involved throughout the life-cycle of the project to help keep it on track. After the functional prototype was developed, MediaSmarts hired the company Turbulent ${ }^{2}$ to develop back-end systems to support all their educational resources, including the JOs game. Since our game was the first to onboard to these systems, I worked closely with Turbulent during development to ensure that the systems would meet the requirements for the JOs game. This involved providing feedback on system requirements and testing the system at different stages of development. After the back-end systems were developed, I worked with Turbulent to onboard the game to their platform. The Turbulent team included a project manager, technical team lead, and several developers. Other partners involved in the development of the JOs game included a Francophone translator, a QA lead, and a voice actor who recorded audio for the game text. These individuals were hired by MediaSmarts at different stages of the project and I worked with them as needed.

\subsubsection{Timeline}

Figure 3.6 shows the major milestones in the design and development process over the past four years. The project started in the summer of 2015, with Christine evaluating the existing quiz with children and then developing the game concept and initial visual designs

\footnotetext{
${ }^{2}$ https://www.turbulent.ca/
} 


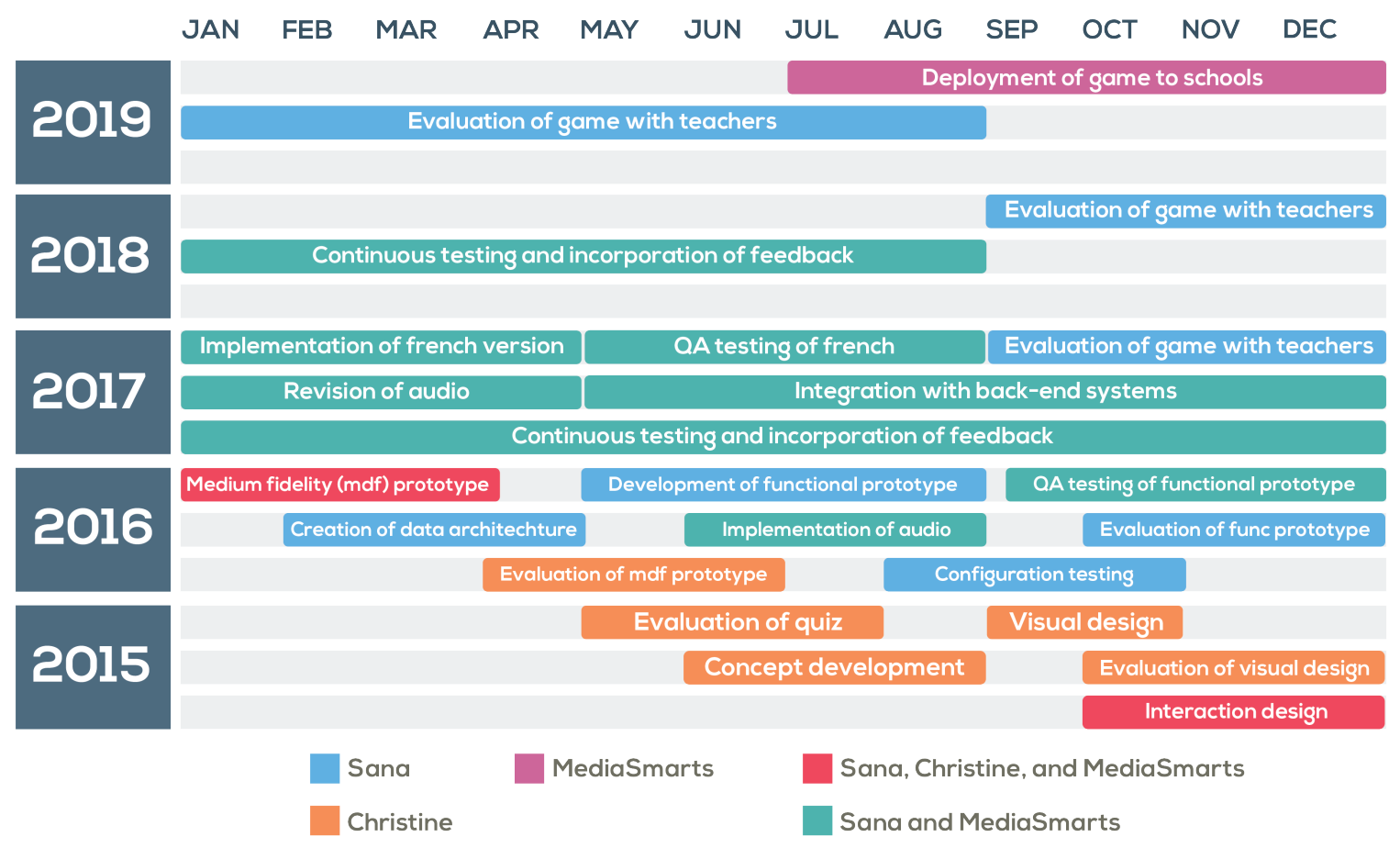

Figure 3.6: Timeline of the design and development of the JOs game

in collaboration with MediaSmarts. I joined the team a few months later, and worked with Christine to complete the game and interaction design, while she tested the visual design with children. At the beginning of 2016, Christine and I worked together to develop the medium fidelity prototype, which she tested with children. During this time, I created the data architecture in collaboration with MediaSmarts, to ensure compatibility of the game with their back-end systems to be developed in the future. Christine left the project in the beginning of summer of 2016 to finish her Masters thesis. Over the summer, I developed the functional prototype of the game, incorporating user feedback from testing of the mediumfidelity prototype and feedback from teachers at MediaSmarts. In this stage, I also did a gap analysis and worked with MediaSmarts to update or create new content and graphics when required. Depending on the complexity of the graphics, I either created them or worked with another graphic designer to complete the work. During development, I also implemented audio for the in-game text. This was completed in two stages. First, a teacher at MediaSmarts recorded the audio, and these recordings were used to implement and test audio in the game. Once the English and French game content was finalized, a professional voice actor re-recorded the audio which was then updated in the game. 
After development of the functional prototype, it was extensively tested by MediaSmarts. After testing, the game content was finalized. Next, I tested the compatibility of the functional prototype on different browsers, platforms, and devices to meet MediaSmarts' business needs. The game was tested on a total of nine different configurations. During this time, I also tested the functional prototype with children to evaluate its effectiveness at improving their digital literacy. At the beginning of 2017, I implemented the French version of the game and revised the game audio with the recordings created by the professional voice actor. A Francophone QA tester, hired by MediaSmarts reviewed the French version of the game and compared it with the English version. I worked with MediaSmarts and the Francophone QA tester to make the required changes to the game in both languages. For the remainder of the year, I worked with Turbulent to integrate the game with MediaSmarts' back-end systems. Continuous testing of the game took place throughout the year, and I made frequent changes to the game incorporating feedback by MediaSmarts. This testing also continued into 2018. In 2019, I user tested the game with teachers to gather their feedback and understand the use of such games in classrooms. In July 2019, MediaSmarts began deploying the game to schools.

\subsubsection{Main stages of the design process}

Steps 1, 2, 3 and 5 in the design process (Figure 3.6.3) were primarily completed by Christine Mekhail as part of her Master's thesis [199]. This included evaluating the old "Jo Fool or Jo Cool" quiz, creating the visual designs, working on the initial game concept, evaluating the visual designs, and evaluating the medium fidelity prototype.

Steps 4, 6, 7, 8, 9 and 10 are contributions to this thesis. This included working on the game design, developing the medium fidelity prototype in collaboration with Christine, incorporating changes from the evaluation with children, implementing the fully functional web-based game (using HTML5, JavaScript, CSS, SVG), evaluating the functional game with children, evaluating the functional game with teachers, and improving the game based on feedback received from the children, teachers, and the MediaSmart team.

I was also involved in the earlier stages, providing advice on the overall design and functionality. A summary of the earlier stages is presented in this chapter for context and their details can be found in Christine's thesis [199]. Details of steps 6, 7, 8, 9, and 10 are 


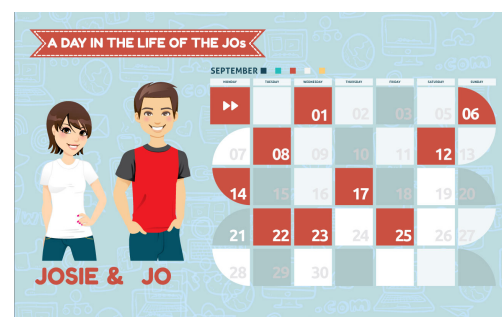

(a) Design 1

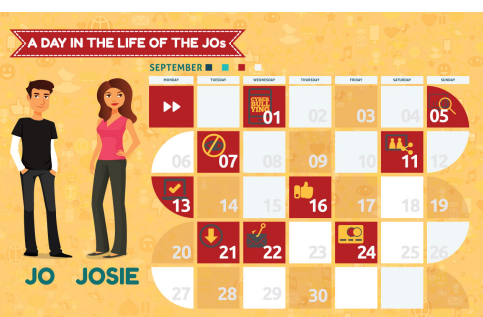

(b) Design 2

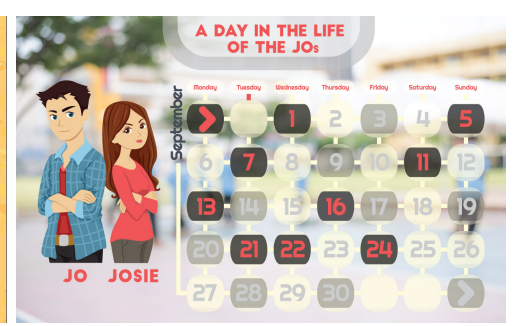

(c) Design 3

Figure 3.7: Three visual designs for the JOs game.

presented in Chapters 4, 5, 6, and 7 of this thesis respectively.

\section{Evaluation of the old quiz (Step 1)}

Christine conducted a formative user study with 16 children ( 7 girls, 9 boys) between the ages of 11 and 14 to evaluate the existing "Jo Cool or Jo Fool" quiz [195]. Participants completed a pre-test questionnaire, completed parts of the quiz, and then completed a posttest questionnaire. The quiz consists of twelve mock websites which users assessed to determine whether the characters Jo and Josie made the correct decision. For example, a website might collect personal information, and the user is asked whether Jo was right to provide his information. Each participant attempted two or three websites in the quiz. The websites were assigned to ensure coverage of all scenarios.

Eyetracking data revealed that children read the text line-by-line or in a zig-zag pattern. In the zig-zag pattern, they read some text, drifted their gaze to another object on the screen, and then returned to the text. This pattern was commonly observed in slow readers who frequently asked whether they really needed to read the text. Participants skipped reading chunks of text on websites which were text-heavy. However, the eyetracking revealed that participants were drawn to Jo and Josie's faces, especially when they made eye-contact with the user.

Participants felt they learned only a moderate amount from the game and this was confirmed through the pre-test and post-test knowledge questions. For 7 out of 12 scenarios, knowledge did not improve, because children already had the correct knowledge or because they retained their misconception. Overall, children liked the characters of Jo and Josie and the scenario-based approach. However, they did not like the visuals, found the content outdated, and ignored large blocks of text. For our new game, we kept the main 
characters of Jo and Josie, a brother sister duo, and the scenario-based approach since they were positively received by users.

\section{Evaluation of visual design (Step 3)}

Christine created three alternative visual designs for the game (Figure 3.7) and tested them with eight 10-12 year old children to evaluate the age appropriateness of the main characters, overall colour scheme, and design. For continuity, four returned from the previous study. Participants were shown the three designs in random order. She asked about character preference, layout, background, and colour scheme. She also tested the text of some of the game scenarios. Since the scenarios did not have a visual representation, she read a script and asked about the content and choices that Jo and Josie should make.

Based on the feedback, Christine combined the facial expressions of the characters in Design 1 with the bodies of Design 3, and chose the colour scheme and layout of Design 3. Figure 3.1 shows our final design. Participants had a strong sense of wrong and right in the scenarios. For example, in the bullying scenario they wanted to confront the bully or ask them to stop. However, this is not always the best choice as confronting bullies can worsen the aggression. These comments suggest including scenarios where the line between right and wrong is unclear, so children can learn about more nuanced situations. They also wanted more visuals to describe scenarios instead of text.

\section{Evaluation of medium fidelity prototype (Step 5)}

This study assessed the usability of the medium fidelity prototype, the interaction flow, and the storyline before full implementation. I fully implemented the cyberbullying day in HTML5, JavaScript, CSS, and SVG, and the remaining four days were tested in PowerPoint using a wizard-of-oz approach. At this stage, I also implemented initial versions of the scoring, news feed, and review screen in the web-based prototype. Christine conducted a user study of the medium-fidelity prototype with fourteen 11-13 year old children. For continuity, four returned from previous testing sessions. Participants completed a pre-test questionnaire and interview, played the game, and then completed a post-test questionnaire and interview (see [199] for details).

Each participant played the functional day in the web-based prototype and a second 
pseudo-randomly assigned day in Microsoft PowerPoint. Participants were audio recorded and an eyetracker recorded their gazes during gameplay. Participants found the length of the content to be acceptable, found the scenarios interesting, enjoyed playing the game, found the game fun, and liked the visual design. Returning participants liked the visual design better than the old quiz. Eyetracking data revealed that participants were attracted to characters' faces and other game elements, such as the score and news feed. Qualitative feedback confirmed that participants liked the scoring and news feed features. They expressed excitement after receiving a high score or wanted to know how they could improve. Overall, participants liked the game; they particularly liked how the game showed current events using electronic devices and social media. They also liked the age appropriateness of the content, use of animations, and feedback. 


\section{Chapter 4}

\section{Technical Design and Implementation of the JOs}

In this chapter, we provide details on Step 6 of our design process (Figure 3.4), which was to develop the technical design and implement the game in HTML5, CSS, and JavaScript. We also provide details on how the game was integrated into the MediaSmarts' back-end systems.

\subsection{System requirements}

We used an iterative approach to develop the technical design of the game. This involved starting with a set of system requirements, which evolved over 4 years as the project progressed. MediaSmarts specified the requirements based on their project needs, which were agreed to by all parties involved in the development process. A major requirement was that the game should work properly on different devices, platforms, web browsers, and screen sizes. These extensive compatibility requirements were created to maximize adoption of the game in Canadian schools, which have access to different types of technologies and browsers, and many do not have access to the latest technology. Maximizing adoption of the game was especially important because the game will become a licenced resource offered to schools by MediaSmarts.

The following is the complete and final set of requirements for the game:

1. The game must be accessible online using a web browser (i.e., a web-based game).

2. The game must work on the following platforms:

- Windows 10.

- Mac OSX (v10.10 and above. As of December 25th, 2019 the latest stable version is v10.15). 
- iPad Pro (9.7inch and 12.9inch), with iOS v10 and above. As of December 25th, 2019 the latest stable version is v13.3.

3. The game must be accessible on the following major web browsers:

- Internet explorer (v11).

- Microsoft edge (v39 and above. As of December 25th, 2019 the latest stable version is $\mathrm{v} 44)$.

- Firefox (v43 and above. As of December 25th, 2019 the latest stable version is v71).

- Chrome (v47 and above. As of December 25th, 2019 the latest stable version is v79).

- Chrome mobile (v47 and above. As of December 25th, 2019 the latest stable version is v79).

- Safari (v9 and above. As of December 25th, 2019 the latest stable version is v13).

4. The game must function properly on and accommodate different screen sizes. The minimum screen size supported should be $1024 \times 768$ on mobile and desktop devices.

5. The game must have audio narration of the game text to accommodate children's varying reading skills.

6. The game must be bilingual, so it can be used in both English and French schools.

7. The game must have efficient load times, especially on slower internet connections which exist in many schools.

Only the requirements for the game itself are specified here and we do not include requirements for other systems required to host or support the game. These are considered out of scope for this thesis. A challenge throughout the project was maintaining compatibility as new versions of browser and operating systems were released during the multi-year development cycle. This required continuous testing, re-factoring, and updating of the various game components. 


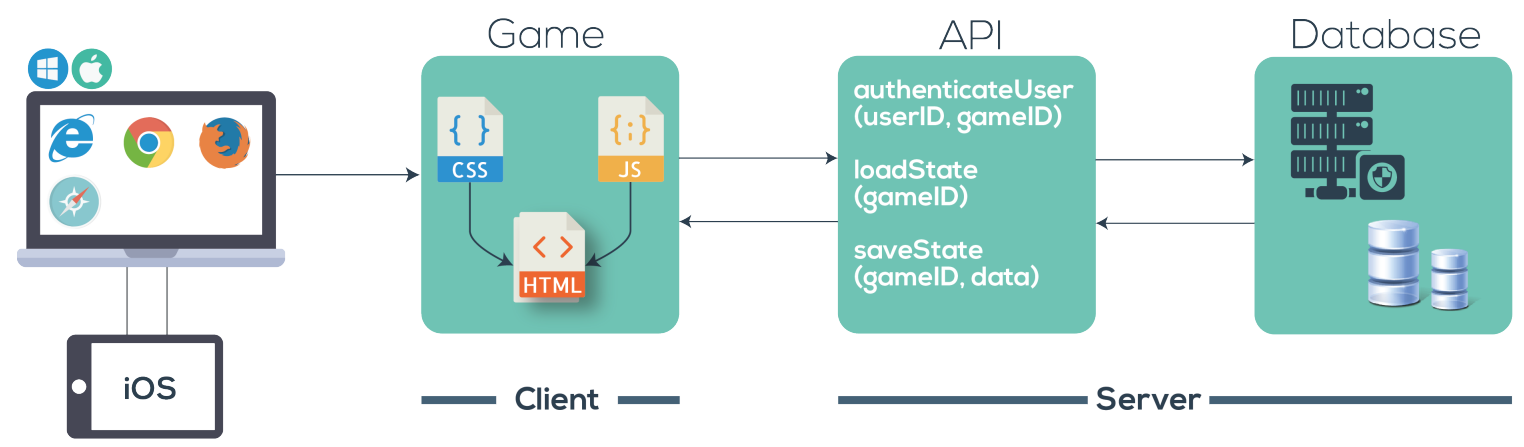

Figure 4.1: Technical architecture of the JOs game.

\subsection{Technical Design and architecture}

Figure 4.1 provides an overview of the technical architecture and main resources of the game. The game was implemented in HTML5 and used an API to connect to a back-end database platform developed by MediaSmarts.The API was developed in JavaScript and uses JSON objects to connect the game to the MediaSmarts' back-end database platform to save and retrieve game data. The platform manages user authentication, data storage, and report generation for all of MediaSmarts' licenced resources. We worked closely with MediaSmarts throughout the entire process of creating this API and back-end platform.

\subsubsection{API}

Since the JOs was the first game available on the platform, it was used to generate the requirements for the API and platform, and to test the implementation. During the initial development of the JOs, we also created a temporary database and PHP script to save and retrieve data from the game. We developed this before the design of the MediaSmarts' platform, to allow us to develop and test key functionalities of the game.

When MediaSmarts was interviewing potential contractors to develop the API, we participated in these meetings, demonstrated the game, explained the technical design, and provided the contractor with our database architecture and table schemas. Once the contracting company, Turbulent, was hired, we worked closely with their team while they designed the API. They used our database architecture to create the initial requirements for the API, and we regularly provided feedback on the API specification and documentation. This involved providing them feedback on the API functions, such as whether they had 


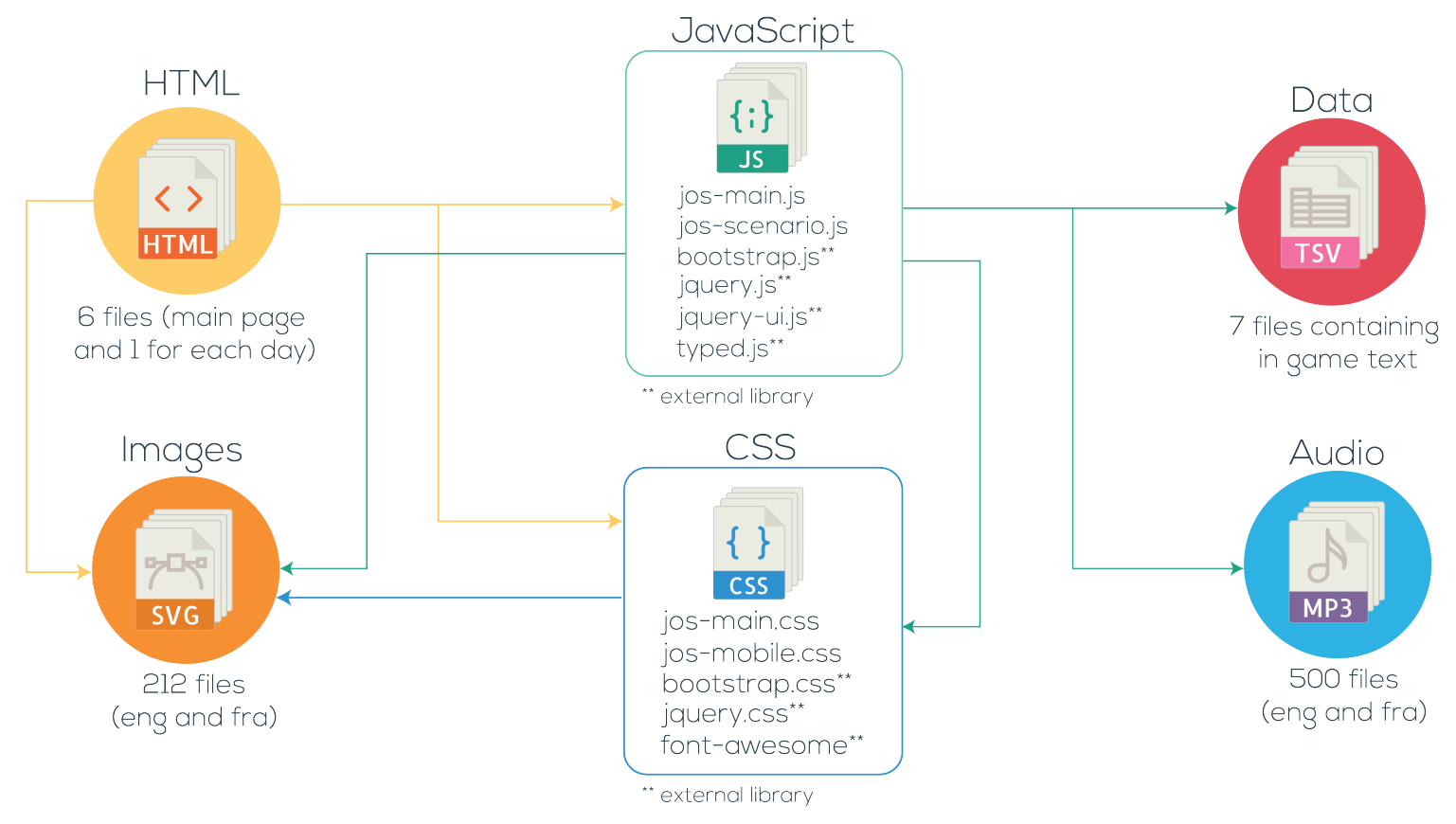

Figure 4.2: Main resources of the game.

the appropriate level of abstraction. We tested each version of the API with our game to discover bugs and improve the API and MediaSmarts' platform for the next iteration. In parallel, we provided feedback and testing for the teacher evaluation portal associated with the game, which was also developed by Turbulent.

\subsubsection{Game resources}

Figure 4.2 shows the main resources of the game. The game was designed using HTML5, CSS, and JavaScript. We used the JQuery library and the Bootstrap framework to create a responsive design so that the game automatically adjusts for display on multiple devices, screen sizes, browsers, and platforms [235,250]. The game consists of 25 scenarios. Each scenario is composed of three or four scenes, and each scene has graphics, text, and audio associated with the text.

\section{HTML files}

We created six HTML5 files to contain the structure of the game which is manipulated using JavaScript and CSS. The first file contains the structural code for the main page of 
the game, which has a calendar layout linking to the main page of each day. The HTML5 page of each day contains the structural code for five scenarios and their associated scenes. Animations were added to the scenes using the JQuery-UI [266] and typed [28] libraries.

Figure 4.3 shows a snippet of the HTML code for a day in the game. Partial code for the main page is shown at the top, followed by code for each of the five scenarios. As most

of the code for displaying a scene is dynamically generated at run-time, minimal markup for each of the three scenes is provided in the scenario code. In most cases, only a reference to the scene image is provided. Each scenario and its associated scenes have a unique ID (e.g., d1-sc1, stp1), which are used to dynamically generate code at run-time. During code generation, these IDs are used to retrieve key game resources, such as images, text, and audio for the scenarios. Images with an associated French version are tagged with the "fra" keyword, which allows the correct language-specific image to be displayed at run-time.

The code for a whole day, which includes five scenarios, each with three scenes is organized into one HTML file for easy maintainability. Because of this, we used a show/hide functionality to switch between different views of the day. The presence of the "hidden" keyword hides an element from view, and its absence makes the element visible. When the HTML page for a day is first loaded, all of the scenarios are hidden from view and only the main view of the day (with links to the scenarios) is visible.

\section{Text files}

The text for the game is stored in seven tab-separated files (.tsv), each containing English and French text for a different part of the game (e.g., scenes, newsfeed, main pages). These files were created from game scripts in Microsoft Word, which MediaSmarts developed in collaboration with us. We extracted text from the scripts and organized it into multiple tab-separated files so that it can be accessed by the game. Figure 4.4 shows how the contents of the newsfeed component were organized in a tab-separated file. This file contains data for the consequences of all possible choices in the game. When the player makes a choice in a scenario, the newsfeed is dynamically created through queries of the contents stored in this file. We stored the text for the game in external tab-separated files because of modularity and maintainability. During development, members of the MediaSmarts team had full access to the text files and were able to edit the game text directly, facilitating 


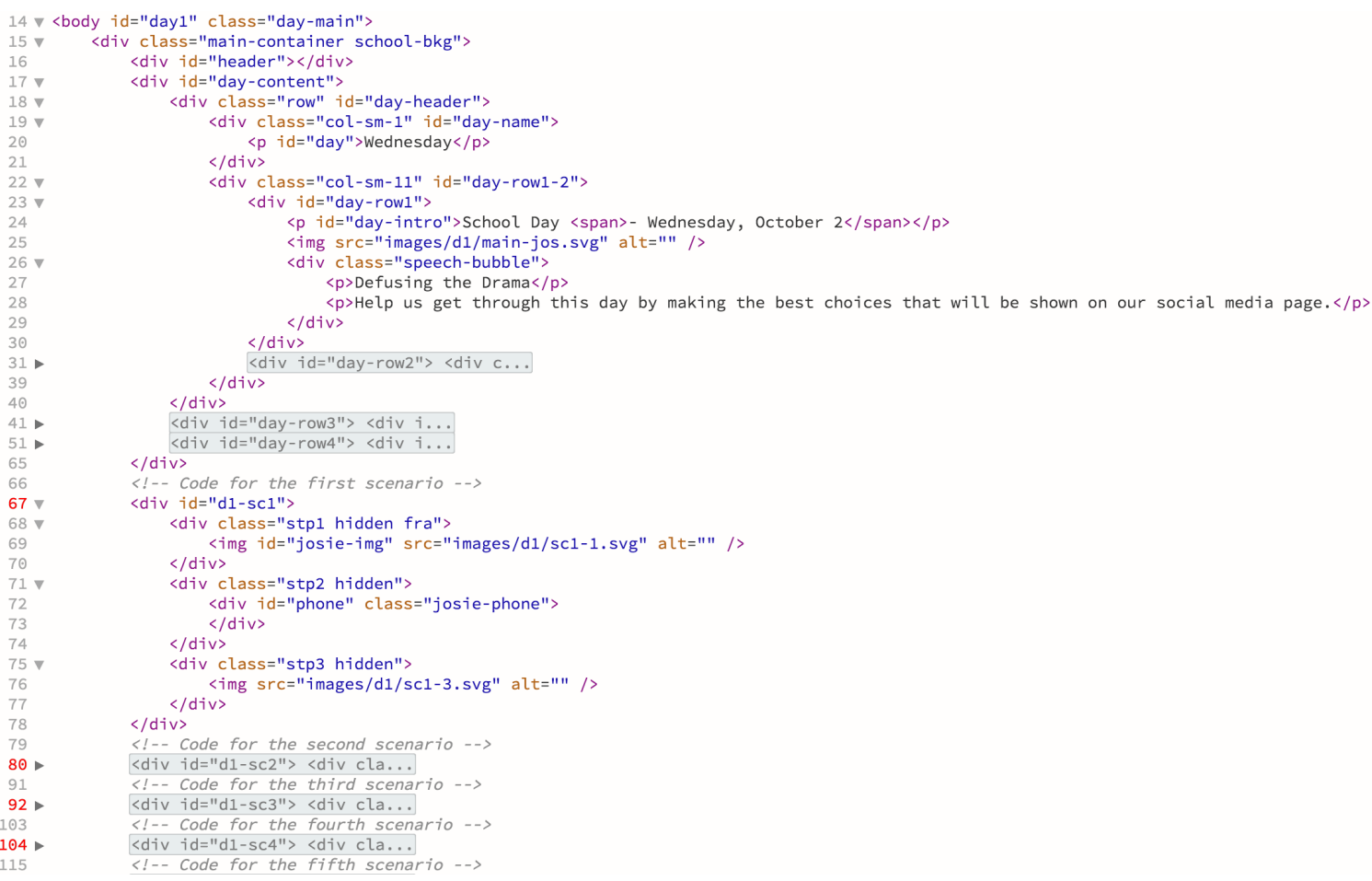

Figure 4.3: HTML code for the first day in the game.

multidisciplinary collaboration. This was especially useful during the quality assurance and translation processes of the game text. In the future, changes to the game text will be inexpensive as they can be done by MediaSmarts without the need of a developer.

When the game is first loaded, text from each of the tab-separated files is converted to a JSON object using the D3 JavaScript library [29]. These objects are then stored as session data in the user's browser, using the built-in browser session storage feature. This provides the game persistent local access to the data, which is used to dynamically generate game content, such as scenarios and their scenes. Thus, by storing data in the browser session, we reduce the load time of resources during game play. The data is destroyed when the browser session is terminated (i.e., by closing the browser tab or window). The following JSON objects are stored in the browser's session storage to capture English and French data for various parts of the game:

1. Day content: This object stores text that appears on the main page of a day.

2. Scene content: This object stores text that appears within the scenes of a scenario. Some of the text appears in multiple places in the game, so we only store it once in 
the JSON object to avoid repetition. For example, the scene titles appear in both the main page of a day and in the scenes, but they are only stored in the scene content's JSON object. The following attributes are stored for the first two scenes of each game scenario: day, scenario, English title of scene 1, French title of scene 1, scene 1 time in English, scene 1 time in French, English description of scene 1, French description of scene 1, English description of scene 2, and French description of scene 2.

3. Choices: This object stores information about the different choices available in the game scenarios. For each choice, the following attributes are stored: day, scenario, choice number, English choice text, French choice text, points for the choice, icon, short feedback in English, and short feedback in French.

4. Choices feedback: This object stores feedback data for the game choices. For each choice, the following attributes are captured: day, scenario, choice number, English title, French title, English feedback, and French feedback.

5. News feed data: This object stores data for the elements/posts that appear within the news feed of the game. For each element, the following attributes are stored: day, scenario, choice number, order in the feed, post author, English post title, French post title, type, English post description, French post description, English image, and French image.

6. Messages data This object stores data for a specific scene that appears in some scenarios. This scene includes a phone and uses animation to show text messages exchanged between two parties. The text associated with these messages is stored within this JSON object.

7. Template content: This object stores text that appears within the template of the game, such as labels for the score feature and title of the game. Storing template content in a JSON object makes it easy to switch between English and French versions of the game.

Some attributes of the JSON objects are used as a key to retrieve the stored data; these are identified with underline in the descriptions above. For example, the combined key $d 2$-scl is used to retrieve the data associated with the scenes in the first scenario of day 2 . 


\begin{tabular}{|c|c|c|c|c|c|c|c|c|c|c|c|}
\hline day & scenario & feedNum & choiceNum & author & titleEng & titleFra & type & descriptionEng & descriptionfra & videoDescEng & videoDescFra \\
\hline 1 & 1 & 1 & 0 & sofia & Sofia messaged you. & \multicolumn{2}{|c|}{ Sofia vous a envoyé un text } & \multicolumn{4}{|c|}{ OMG!!! Did you see how Cit As-tu vu comment Laurie regardait Félix ce matin en musi } \\
\hline 1 & 1 & 2 & 1 & josie & You messaged Sofia. & \multicolumn{2}{|c|}{ Vous avez envoyé un $\mathrm{r}$ text } & $\mathrm{R} \cup$ sure Cindy wants peop & \multicolumn{3}{|c|}{ Es-tu certaine que Laurie veut que tIm le sache? Elle ne se } \\
\hline 1 & 1 & 3 & 1 & sofia & Sofia messaged you. & \multicolumn{2}{|c|}{ Sofia vous a envoyé un text } & OMG I didn't think of that! I & \multicolumn{3}{|c|}{ J'avais vrm pas pensé à ça! J'en ai parlé à Laurie et elle ét } \\
\hline 1 & 1 & 4 & 2 & josie & You messaged Jo. & \multicolumn{2}{|c|}{ Vous avez envoyé un $\mathrm{r}$ text } & Did U hear about Cindy anc & \\
\hline 1 & 1 & 5 & 2 & jo & You posted on Brian's & \multicolumn{2}{|c|}{ 's Vous avez publié sur la text } & Hey Brian way 2 go! & \multicolumn{3}{|c|}{ c Savais-tu pour Laurie et Félix? Parles-en pas à personne. } \\
\hline 1 & 1 & 6 & 2 & brian & Brian commented on: & \multicolumn{2}{|c|}{ Félix a fait un comment text } & ??? & ??? & & \\
\hline 1 & 1 & 7 & 2 & jo & You replied to Brian's & Vous avez répondu au & text & If $\mathrm{U}$ feel eyes on UR back... & \multicolumn{3}{|c|}{ I Si tu sens des yeux dans ton dos - $c$ pcq qqun te regarde } \\
\hline 1 & 1 & 8 & 2 & brian & Brian replied to your c & Félix a répondu à votre & text & Who sits behind me...Cindy & \multicolumn{2}{|c|}{ y Qui est assis derrière moi... Laurie? } & \\
\hline 1 & 1 & 9 & 2 & jo & You replied to Brian's & Vous avez répondu au & text & Aw man...don't tell Cindy or & \multicolumn{3}{|c|}{ r Eille mais.... dis pas à Laurie ou à Josée que je te l'ai dit... } \\
\hline 1 & 1 & 10 & 3 & josie & You posted on Cindy': & Vous avez publié sur la & text & Brian's perfect for you! Gre: & \multicolumn{3}{|c|}{ Félix est parfait pour toil Contente d'apprendre que $L<3 \mathrm{~F}$} \\
\hline 1 & 1 & 11 & 3 & cindy & Cindy commented on & Laurie a fait un comme & text & Mind UR own business JOS & \multicolumn{3}{|c|}{ \& Mêle-toi de tes affaires JOSÉE! Félix a lu ton msg et tous s } \\
\hline 1 & 1 & 12 & 3 & cindy & Cindy has unfriended & \multicolumn{2}{|c|}{ Laurie vous a désamič́ text } & & & & \\
\hline 1 & 2 & 1 & 0 & jay & Jay posted a video. & Léo a publié une vidéo. & video-photo & \multicolumn{4}{|c|}{ Check out this video of Ben Regardez cette vidéo de d1-sc2-sm 1} \\
\hline 1 & 2 & 2 & 0 & kooldude & kooldude commented & kooldude a fait un com & text & LOL! & LOL & & \\
\hline 1 & 2 & 3 & 0 & grey51 & Grey51 commented o & Grey51 a fait un comm. & text & What a luzr. & Pas fort & & \\
\hline 1 & 2 & 4 & 0 & rob & Rob commented on $\mathrm{J}$ : & Rob a fait un comment & text & \multicolumn{3}{|c|}{ I'm sharing this with all my 1 Je partage avec tous mes amis! } & \\
\hline 1 & 2 & 5 & 1 & jo & You commented on Je & Vous avez fait un comn & text & \multicolumn{3}{|c|}{ Sorry Ben but this is hilario J'm'excuse Ben, mais c'est hilarant! } & \\
\hline 1 & 2 & 6 & 1 & ben & Ben replied to your co & Ben a répondu à votre & video-photo & \multicolumn{3}{|c|}{ Hey JO since U like funny v Eille JO! T'aimes ça rega d1-sc2-sm2 } & \\
\hline 1 & 2 & 7 & 1 & jay & Jay commented on his: & : Léo a fait un commente & : text & LOL. & LOL & & \\
\hline 1 & 2 & 8 & 1 & ben & Ben replied to Jay's c & Ben a répondu au com & video-photo & Don't laugh JAY, UR next. & \multicolumn{2}{|c|}{ Ris pas LÉO, C à ton tol d1-sc2-sm3 } & \\
\hline 1 & 2 & 9 & 2 & jo & You reported Jay's vic & Vous avez signalé la vic & c text & & & & \\
\hline 1 & 2 & 10 & 2 & siteOwner & The site owner messa & Le propriétaire du site I & I text & \multicolumn{4}{|c|}{ Thank you for your report. $v$ Merci pour ce signalement. Nous avons examiné la vidéo } \\
\hline 1 & 2 & 11 & 2 & jo & You sent Ben a privat€ & $€$ Vous avez envoyé un $\mathrm{n}$ & text & Hey man JAY shouldn't hav & Hé, Léo n'aurait pas dû te & e faire ça. & \\
\hline
\end{tabular}

Figure 4.4: Tab-separated data for the contents of the newsfeed.

\section{Audio files}

The narration of the game text is compiled from 500 professionally narrated .mp3 audio files (250 in English and French), and each file is between 5-40 seconds in duration. Playing of the appropriate audio narration is synced with the animated presentation of the text. An audio player was implemented in HTML5 to allow players to control the audio. They can play, pause, repeat, or mute the audio. The default setting of the audio is autoplay unless the user chooses to mute the audio using the player. The audio files use a naming convention that enables easy referencing during the dynamic creation of scenarios at run-time. For example, the audio files associated with a scene are named using the format: day-scenarioscene-language.mp3 (e.g., d1-sc2-1-eng.mp3).

\section{Graphic files}

A total of 212 custom graphics were used within the scenarios. We used the Scalable Vector Graphics (SVG) format for all the images so they could resize to different screen sizes and resolutions without losing quality. To reduce the load time on slower internet connections, the image file sizes were optimized smaller than $1 \mathrm{MB}$, and $70 \%$ were smaller than $300 \mathrm{~KB}$. This optimization process was challenging because we had to balance the efficiency of 
the game with the aesthetic quality of the graphics, which is quite important in children's educational games [89,308]. The image files are also named using a format similar to the audio files, so they can be referenced during the creation of scenarios at run-time (e.g., d1-sc2-2-fra.svg).

\subsubsection{Session state}

The game state is maintained using six JSON session objects, which are continuously updated as the game is played. These objects are saved to the server using an API at key points in the game, such as when a scenario is completed. When the game is first loaded, the game state is retrieved from the server and the game UI is updated accordingly. The following list provides a description of each JSON game state object:

1. State of days: This object stores information about whether a day or scenario has been completed. This data is used to update the game user interface to mark the completed scenarios and provide users access to the uncompleted scenarios.

2. Day attempts: Records the number of times the user has completed each day in the game. This data is used by the teacher evaluation module to evaluate children's performance.

3. Review of feedback: Records information about whether the user has fully reviewed the feedback provided at the end of a day.

4. State of visits: Records information about whether the user has visited the main page of each day in the game.

5. Josie's feed: Records the state of Josie's news feed, so it can be restored when the user returns to the game. For each feed element, a unique ID representing the element is stored, and is used to recreate the element.

6. JO's feed: Records the state of JO's feed, and its format is the same as Josie's feed. 


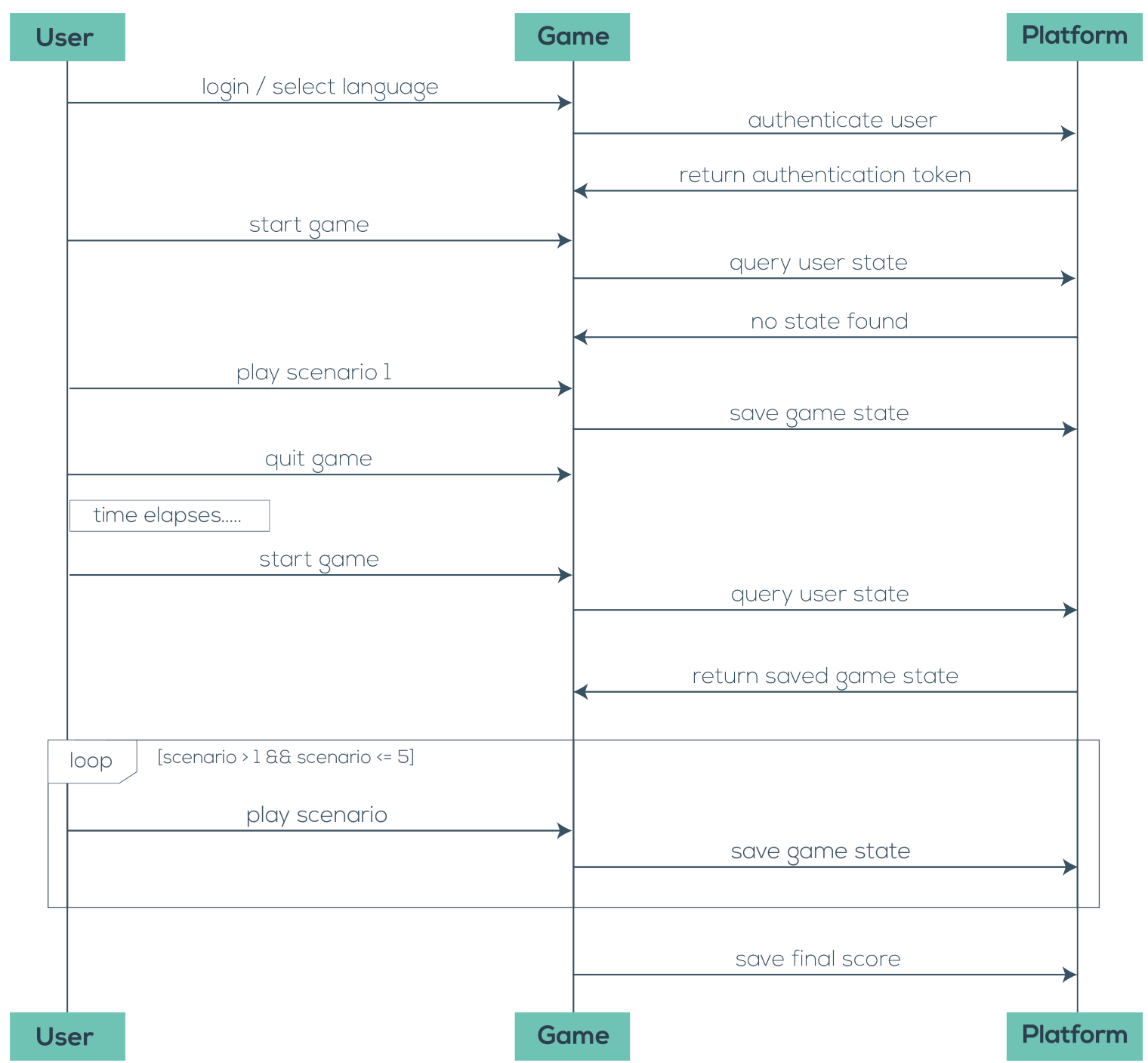

Figure 4.5: Communication among game resources.

\section{API for game state}

The game state data is saved to the server using an API developed by MediaSmarts. Figure 4.5 shows a sequence diagram illustrating how the game uses the API to communicate with the platform. Users access the game by logging into the MediaSmarts secure website and selecting the JOs game. They can resume a previous session or start a new game if a previous session does not exist. Users begin by playing a scenario in a day of the game (e.g., scenario 1 of the data mining day/topic), and, upon completion, the game uses the API to save the user's progress and game state to the platform. This allows users to play part of the game (e.g., one scenario) and continue later. The game passes JSON data 
to the API which is then processed by the platform. The code in Listing 4.1 shows a sample of the data passed to the API. Some of the data elements are standardized, which means they are collected from all games that use the API, while others are specific to our game. For example, the required data elements game_id, chapter_index, progress, and comment are standardized, while the optional additional_data field allows games to store custom JSON data specific to their needs. Our game stores 13 data elements representing user progress and session state. The standardized fields are used by a comprehensive teacher evaluation module that allows teachers to evaluate student performance on various MediaSmarts' resources.

Listing 4.1: JSON code for saving game data using the API

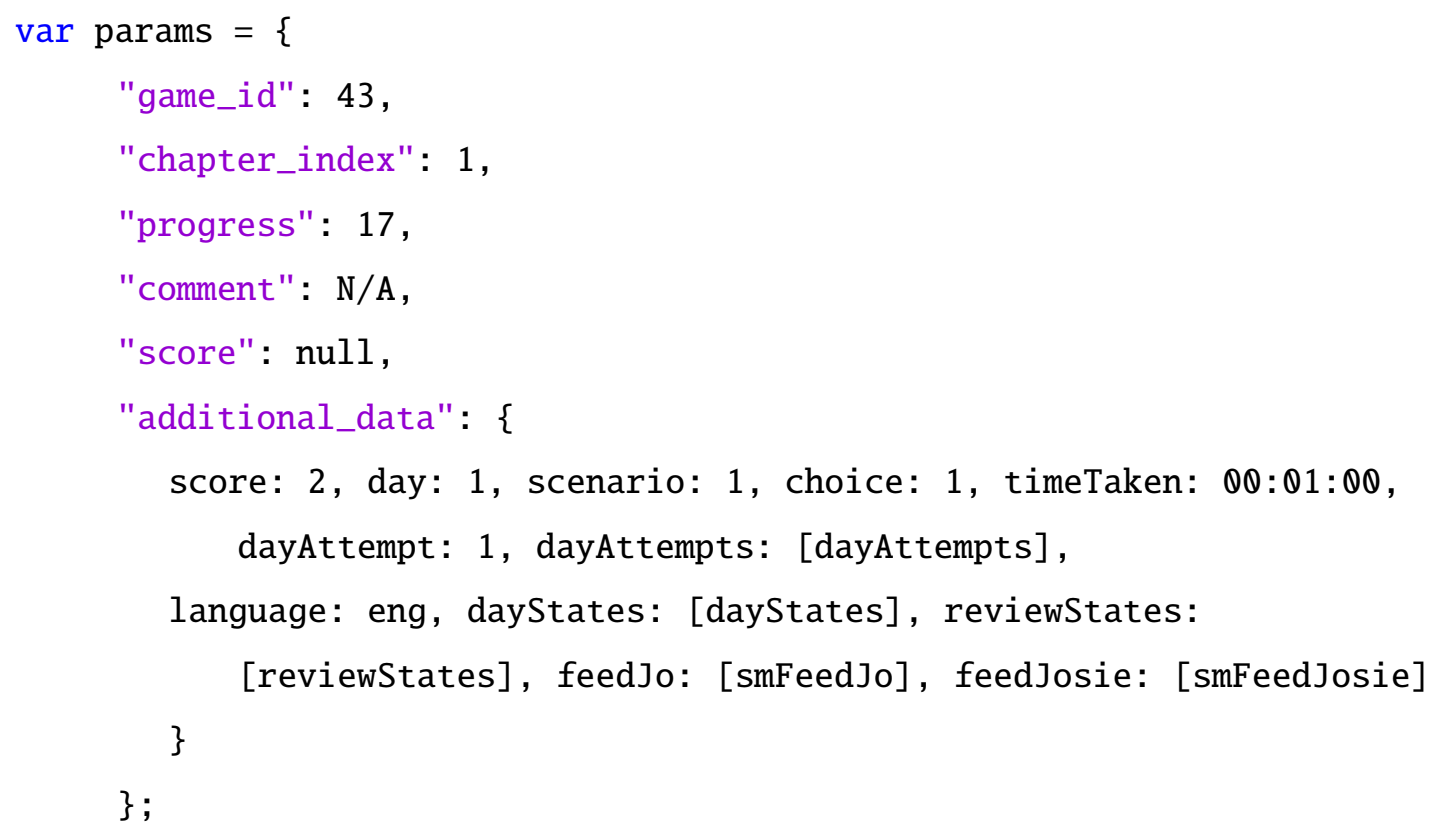

\subsubsection{Game flow}

Figure 4.6 shows the flow of the game when the user plays a scenario. Assuming the user is logged in, they load the game which brings them to the calendar page with links to the five days in the game. After selecting a day, the user is shown the main page for that day with links to the five scenarios. The user starts by playing a scenario which loads the first scene in the scenario. A scene is compiled dynamically with an image, text, and audio narration. After viewing the scene, the user proceeds to the next scene using a button. This process is 


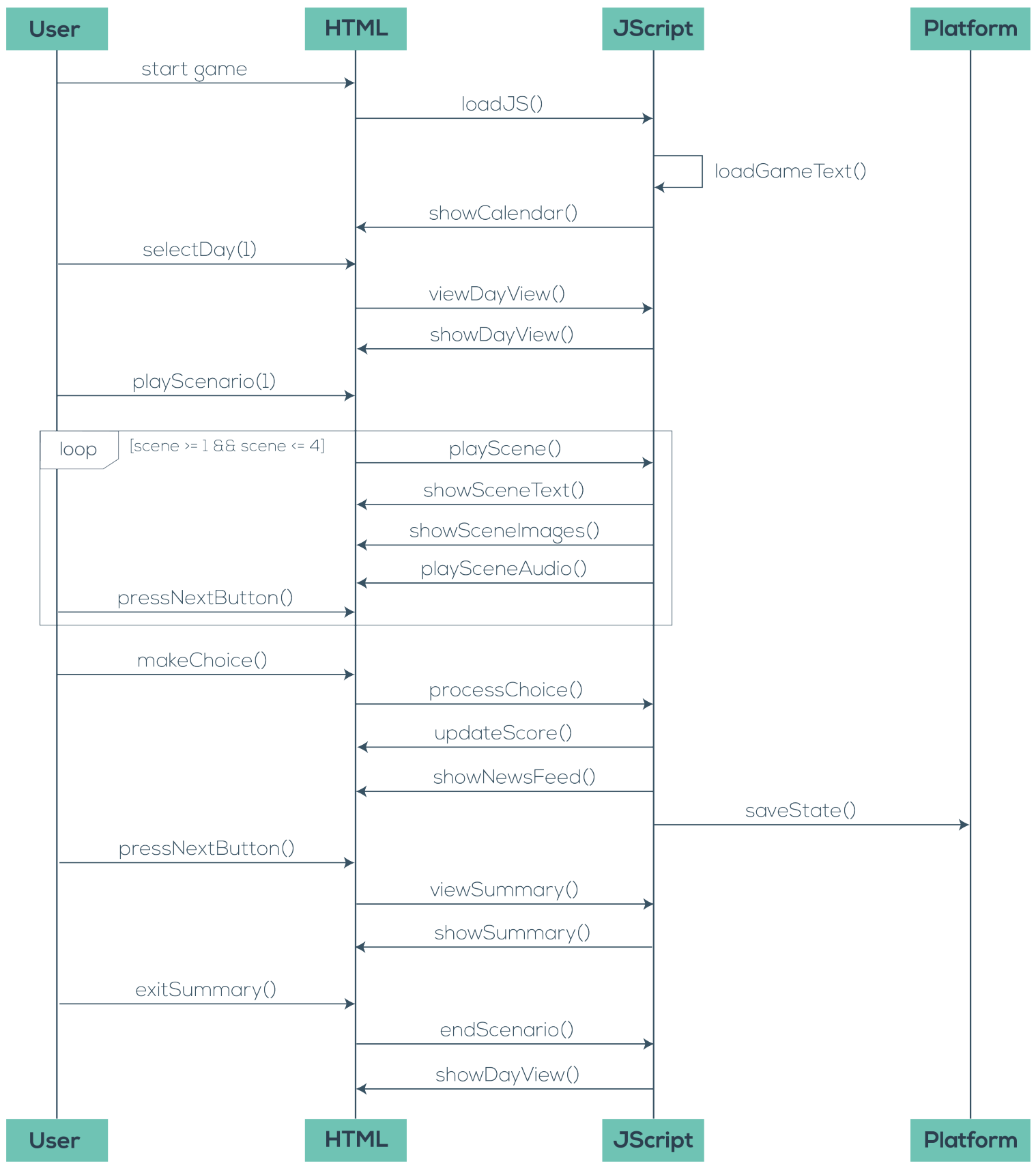

Figure 4.6: Sequence of actions when a game scenario is played. 
repeated for the remainder of the scenes. Scenarios have 3-4 scenes each. In the last scene, users make a choice for the scenario, which updates their score and dynamically shows the consequences of their choice in the news feed. At this point, the state of the game is saved on the platform, and the user presses a button to see brief feedback about their choice. After reviewing the feedback, users are brought back to the main page of the day, from where they can play the next scenario.

\subsection{Details of game features}

The main components of the game, such as scenarios, choices, and newsfeed are dynamically generated using game resources such as audio, graphics, text, HTML, and JavaScript. This section outlines how these key game components are dynamically generated.

\subsubsection{Scenarios}

Figure 4.7 shows how a scene in a scenario is generated. The HTML code for the first scene is loaded, followed by loading of the image associated with the scene. If the game is being played in French, and the image has a corresponding French version, then the French image is loaded instead. Most images in the game are unilingual, and only images with embedded text have French equivalents. These images are tagged with the "fra" keyword in the HTML code, which is used by the script to load the French equivalent of the image. To load the French image, the script appends "-fra" at the end of the image's filename (e.g., sc1-1.svg is transformed to sc1-1-fra.svg). After loading the image, it is displayed to the user using a fade-in animation. Next, the text associated with the scene is loaded and displayed to the user. The unique id of the scenario (e.g., d1-sc1) is used to retrieve the scene text from the JSON data stored in the browser's session storage. Depending on the language of the game, either the English or the French text is retrieved. This text is then dynamically inserted into the HTML code and shown to the user using the typing animation (i.e., text is displayed one character at a time). The language-specific audio for the scene text is retrieved and played as the text is displayed to the user. The speed of the text animation is synced with the audio, to create a cohesive user experience. After the user presses the "next" button, the second scene is displayed. This involves hiding the first scene from view, and then repeating the steps shown in Figure 4.7 for the second scene. 


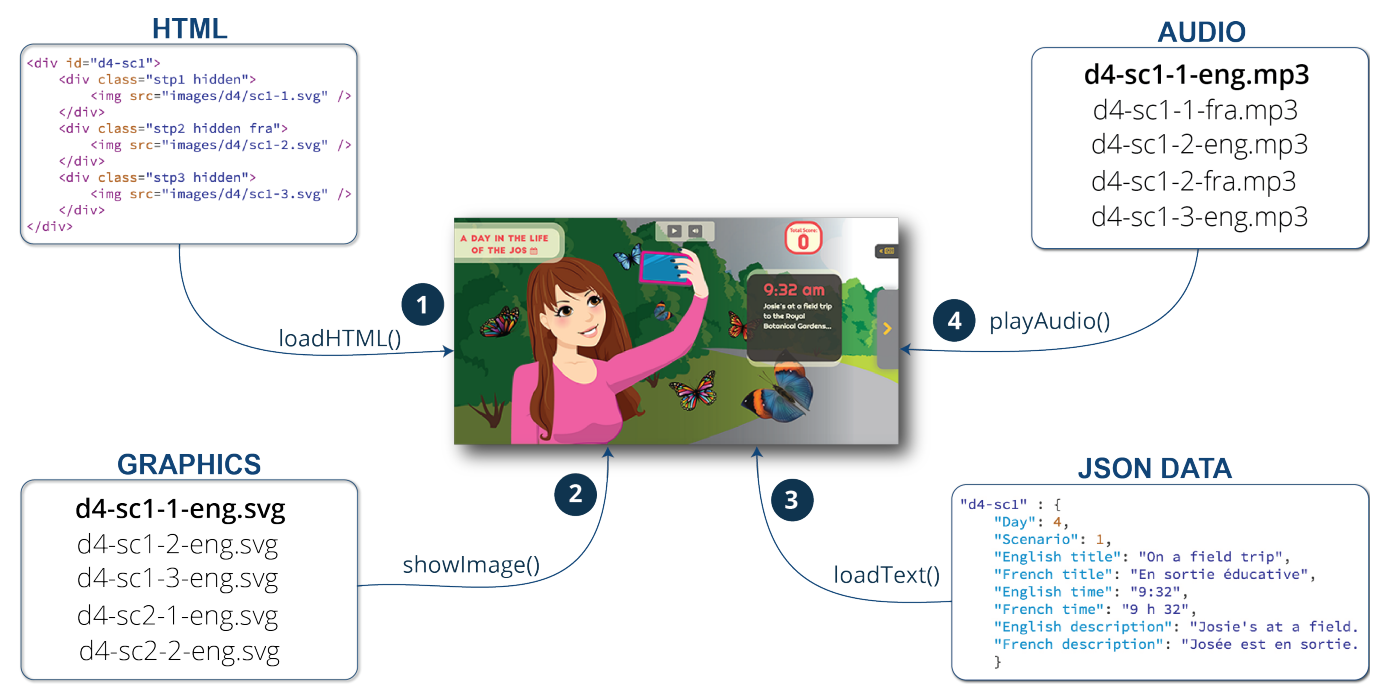

Figure 4.7: Generation of a scene.

\subsubsection{Choices}

The third scene in a scenario always shows the choices available to the player and allows them to pick a choice for the scenario. This screen is generated using a similar process as the other scenes. After loading the HTML code, the image associated with the scene is displayed using a fade-in animation. Next, the choices for the scenario are retrieved from the JSON data stored in the browser's session storage. The data is retrieved by referencing the unique id associated with the scenario. The icons associated with the choices were created using the font FontAwesome to increase interoperability of the game on different devices and reduce the number of images used in the game. After loading the data, the language-specific list of choices for the scenario are created and inserted into the HTML. Each choice is tagged with a unique ID. The choices are displayed to the user one at a time using a slide-in animation. A language-specific audio narration of the choices is retrieved and played as they are being displayed to the user.

\subsubsection{Newsfeed}

After the user makes a choice, the list of choices are hidden from view and the total game score is updated. The score is updated by retrieving the points associated with the choice, adding them to the total score, and updating the game state. At this point, the game state is only updated on the client's side and changes are not sent to the server. This means 
that if the game is aborted at this stage (e.g., closing the browser window), the user would need to replay the scenario after resuming their session. After updating the score, a slidein animation is used to make the newsfeed visible to the user. The newsfeed displays consequences of the choices made by the player. Depending on the choice, 2-7 items are displayed in the newsfeed reflecting the consequences of the choice. Each item in the feed has an icon, title, description, and sometimes an image. A separate feed is available for Jo and Josie, the two main characters in the game, and players can switch between their feeds using tabs located at the top of the newsfeed.

Elements associated with the current choice are dynamically generated and displayed in the newsfeed. First, the HTML code for the newsfeed is loaded. Next, the elements associated with the choice are retrieved from the JSON data stored in the browser. This data stores information for 294 potential newsfeed elements, and the elements displayed to the user are dependent on the choices made in the game. After retrieving the necessary elements, HTML is generated for each element and it is then displayed to the user using a fade-in animation. The most recent element is displayed at the top of the list, similar to a real social media feed. A 2-second delay is added between the presentation of elements to provide users with sufficient time to read each element. After displaying all the elements, the game state is changed to reflect the updated score, newsfeed, and state of the scenario. A scenario is only considered complete when all elements associated with it have been displayed in the newsfeed. The game state is then saved to the server, allowing the user to resume the game at any time.

\section{Re-population of the newsfeed}

When a session is resumed, the newsfeed is restored from the game state data stored on the server. The state data stores a unique ID for each element of the newsfeed and the order in which each is displayed in the feed. Each ID in the state data is mapped to the persistent newsfeed JSON data storage to retrieve the content associated with that feed element. Next, this content is used to generate the HTML code for the element, which is then displayed in the newsfeed. 


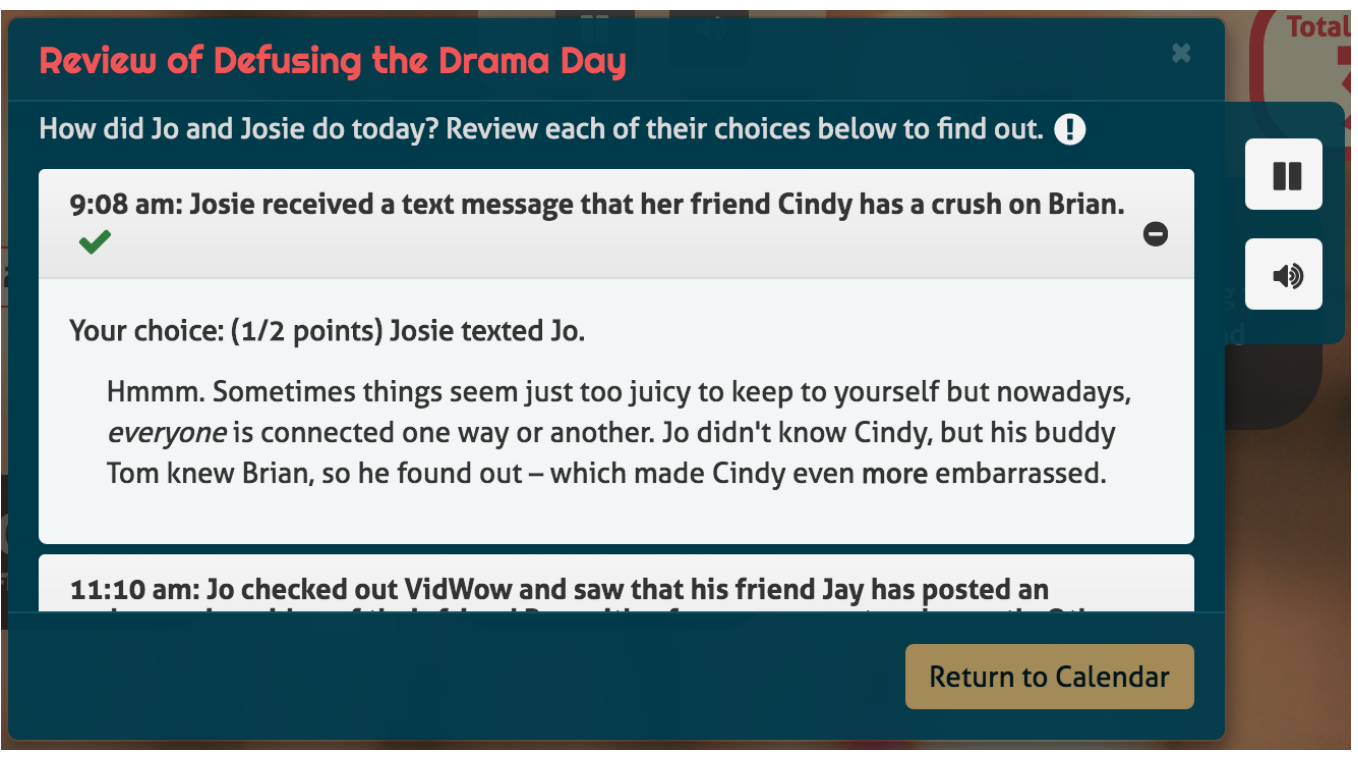

Figure 4.8: Feedback provided after completing a day in the game.

\subsubsection{Feedback}

Feedback on player choices is provided at two points in the game, immediately after completing a scenario and after completion of a day (i.e., completing all five scenarios for that day). Both types of feedback are provided using a UI modal that is overlayed on the game. Feedback is dynamically generated depending on the player's choices. The end-of-scenario feedback is short, and is compiled by retrieving the JSON data associated with the choice and then displaying it in the modal. An audio narration of the feedback is automatically played as it is displayed to the user.

The end-of-day feedback is more comprehensive (Figure 4.8). It reviews the consequences of each choice and provides advice on how to make better choices in the future. It also tracks whether the user has reviewed all of the feedback, which was an educational requirement specified by MediaSmarts. The feedback includes the choice made, associated score, and commentary on the choice per scenario. A vertical scroll-bar can be used to navigate through the feedback. The title of each scenario can be used to expand or collapse the feedback details. Audio narration is provided for each component.

The feedback screen is dynamically created in five main steps. First, the feedback data associated with each scenario is retrieved from the JSON data stored in the browser's session storage. The game maintains a record of the user's choices, and this information 
is used to retrieve the relevant feedback. Next, HTML is generated from the languagespecific JSON feedback data. The appropriate audio files are retrieved and loaded into the HTML. Finally, feedback for each scenario is presented to the user, and its audio narration is automatically played.

\subsection{Modularity of the design}

Educational digital literacy games can become outdated, due to the evolution of technology, cyberattacks, and the introduction of new threats. The "Jo Cool or Jo Fool" quiz was designed by MediaSmarts in 2000, and is significantly outdated in terms of its content, design, graphics, and technology. For example, its content refers to ICQ messaging an ordering music CDs, and it uses Flash, which has poor support by modern web browsers and mobile devices. However, despite these shortcomings, the quiz remains a popular resource and is still being used by many schools across Canada. Updating digital literacy games, such as "Jo Cool or Jo Fool" require a significant amount of development effort, which is not always feasible. Thus, due to how quickly these resources can become outdated, there is a need to future-proof the design of new digital literacy resources.

At the beginning of the project, we recognized this as a key technical design requirement for the JOs game, and this governed most of our technical design decisions. To this effect, we created a plug-in architecture for the game so that individual components can be updated with little-to-no development effort. The following were the key design requirements for our modular plug-in game architecture:

1. The user-interface and the game logic should be separated.

2. All game assets including the audio, graphics, and text should be separated from the game logic.

3. The game should use common web development frameworks to future-proof the underlying technology of the game.

We created the architecture of our game so the game content, such as scenarios, could easily be updated with no development effort. Similarly, new scenarios can be added to address emerging threats and areas of concern for children (e.g., spotting misinformation 
in the era of "fake news"). This modularization would also allow for translating the game into different langagues besides the current English and French. With regards to the development technology, we used popular web-based frameworks such as Bootstrap [235] and JQuery [250], which are frequently updated by their authors to accommodate changes in web-browser technologies.

\subsubsection{Adding or updating a scenario}

When a scenario becomes outdated, it can be updated by creating new graphics, modifying the text in the game's external .tsv files, and recording new audio narration for the updated text. After modifying these resources, the updated scenario is available in the game without requiring any programming effort. Similarly, new scenarios or days can be added in the game with little development effort. To add a new day, the following steps would need to be completed:

1. Design graphics for the new scenarios.

2. Create text for the scenarios, and update the .tsv files with the new text.

3. Record audio narration for the new text.

4. Create an HTML5 file to store markup for the new day.

5. Update the calendar HTML5 file to add a link to the new day.

\subsection{Development process}

We used an incremental approach to develop the game, which allowed us to frequently test the game with MediaSmarts and adapt our implementation throughout the project. We worked together on the game design. After the graphic designer completed the visual designs, I worked with her to complete the interaction design. This involved deciding how users should navigate between different parts of the game and the types of controls they will use. As part of this process, we also considered the development technology and made changes to the visual design if a feature could not be implemented due to technology, time, or costs. Next, I created a technical architecture for the game and implemented one scenario 
in HTML5. The project team user tested the prototype for interaction flow and compliance with the requirements, and changes were made to the design as required. After making the changes, all scenarios in the game were fully implemented. This process involved optimizing images for web and transforming all of the text from scripts into the seven tabseparated files. Gaps identified during this process were resolved by making changes to the design, text, or graphics. In some cases, new graphics were created by a graphic designer or myself.

The MediaSmarts platform system was developed towards the end of the project and was not available during the development of the game. To develop and test the complete functionality of the game, such as being able to save game state, I used PHP and MySQL to create a temporary database for the game. The design of this database and the game was used to develop requirements for the MediaSmarts platform, which was created to host all of their licenced games. During development of this system, I provided advice on the requirements of the system and assisted in testing the API with the game. This involved connecting the API to the game, testing functionality of the API, and working with developers to resolve any bugs or issues.

The requirements of the game evolved as development progressed, so the design had to be updated to accommodate the new requirements. For example, when the requirement for providing audio for the game text was added, we updated the design to include an audio player which was accessible to the player at all times. Since this was a long-term project, the game was regularly tested on different web browsers to ensure compliance, and updates were made to the game when browser upgrades affected the functionality. 


\section{Chapter 5}

\section{Evaluating JOs with children}

I conducted a user study with twenty-five 11-13 year old children to evaluate the functional prototype of our game. Children played three days in the game and completed questionnaires and interviews to provide us with feedback on the usability of the game. We also looked at whether their digital literacy knowledge and behavioural intent improved after playing the game.

\subsection{Research questions}

We had the following four research questions for our user study:

1. RQ1: Do children find the A Day in the Life of the JOs game usable?

2. RQ2: What do children think about the A Day in the Life of the JOs game?

3. RQ3: Does the game improve children's digital literacy knowledge?

4. RQ4: Does the game improve children's digital literacy behavioural intent?

\subsection{Methodology}

We conducted a two-part study to evaluate the usability and effectiveness of our fully functional game with children. The effectiveness of the game was determined by improvements in children's digital literacy knowledge and behavioural intent. For our purposes, we use Ajzen's definition of Behavioural Intent from the Theory of Planned Behaviour: Behavioural intent represents users' perceived likelihood of engaging in a particular behaviour in the future [4]. It is an antecedent of future behaviour and is determined by several factors, including users' attitude toward the behaviour, subjective norms, and their perceived behavioural control [4]. To evaluate the effects of online safety awareness training, it is 
Session 1 (60-minutes)

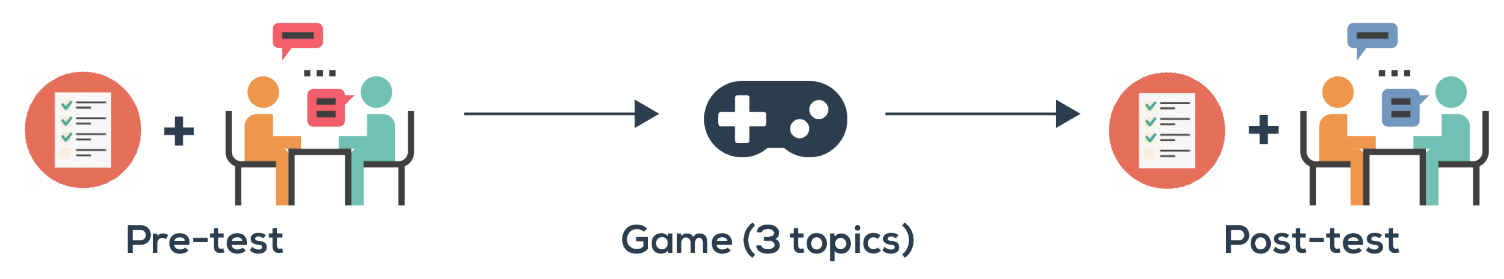

Session 2 (15-minutes)

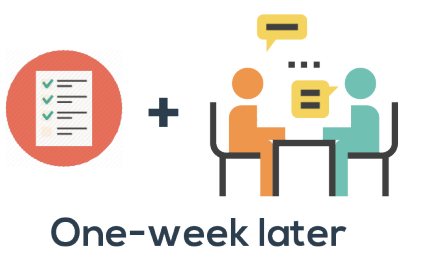

湜 Questionnaire

Interview

Figure 5.1: Methodology of the user study with children

common practice to measure users' behavioural intent, because we cannot put them in dangerous situations to evaluate their actual behaviour [211, 277, 286]. For these situations, behavioural intent is an appropriate measure, because it is a predictor of whether users will take part in certain behaviours in the future [4,66].

Figure 5.1 shows the methodology of our study, which was approved by Carleton University's Research Ethics Board (REB).

The first session took an hour, and the second session about 15 minutes. In session 1, participants completed a pre-test questionnaire (Appendix A) and a short interview (Appendix D. Next, they played the English version of the game on a laptop and completed a post-test questionnaire (Appendix B and interview (Appendix E). To keep the session length manageable, children played three of the five days, which were selected using a Latin square. The game was instrumented and recorded user choices, time to complete tasks, and the number of points earned. We also used an eyetracker to track gaze during gameplay. Participants were encouraged to think aloud while playing.

The second session took place one week after the first, and assessed whether children retained the knowledge learned in the game. In the second session, children completed a questionnaire (Appendix C) and an interview (Appendix F).

The pre-test questionnaire included demographic questions and 15 5-point Likert scale 
knowledge questions (three questions per day of the game). An example knowledge question was: When using your mobile device, how often would you fact-check information before sharing it on social media?. Participants responded by choosing an option from always, often, sometimes, rarely, and never. The post-test questionnaire collected opinions of the game and repeated the 15 knowledge questions. These questions were also repeated in the one-week questionnaire to see if children improved and retained knowledge.

The interviews evaluated whether children could apply their knowledge to new situations. They were provided with five situation-based questions (one per day of the game), regardless of which days they played, with reasoning that playing part of the game may raise their awareness and critical thinking skills in related topics not explicitly covered. We asked what they would do, how it would affect their privacy and that of others. For example: All your friends are playing a popular online game so you decide to sign-up for the game as well. When you sign-up, the game asks you to provide your full name (first and last name) and your home address, so that other players can contact you. What would you do in this situation? How might this affect your privacy? How might this affect others' privacy? We created three sets of the questions and used a Latin square to decide which to use in the pre-test, post-test, and one-week interviews. The sets were similar in structure and evaluated the same topics, but had a different context to avoid children simply repeating their previous answers. Each interview took about 10 minutes and was audio recorded.

\subsection{Recruitment and Consent}

Participants were recruited through social media parenting groups, snowballing, and by distributing flyers in the Ottawa area. At the start of the session, a parent provided written consent for their child's participation and the child provided verbal consent. Each participant received a \$20 gift certificate or cash. Parents were reimbursed for parking costs when applicable. Sessions took place in our research lab or other quiet, mutually convenient locations (e.g., public library). When sessions took place outside the lab, we chose locations with minimal distractions. We also ensured that other children or adults were not nearby, to avoid accidentally audio recording them. 


\begin{tabular}{cccc}
\hline \multicolumn{1}{c}{ Day } & N & Score $(/ \mathbf{1 0})$ & Time $(\mathbf{m i n}: \mathbf{s e c})$ \\
\hline Cyberbullying & & $\boldsymbol{M}(\boldsymbol{S D})$ & $\boldsymbol{M}(\boldsymbol{S D})$ \\
\hline Online tracking & 16 & $7.38(1.15)$ & $4: 31(0: 54)$ \\
\hline Privacy & 15 & $6.40(2.20)$ & $4: 47(0: 52)$ \\
\hline Sharing photos & 15 & $7.67(1.95)$ & $5: 10(1: 10)$ \\
\hline Fact checking & 13 & $9.54(1.56)$ & $4: 48(0: 57)$ \\
\hline
\end{tabular}

Table 5.1: Children's mean game score and mean time per "day" (each day was played once per participant).

\subsection{Participants}

Twenty five children (10 girls and 15 boys) participated in the study. Fifteen were 11, nine were 12, and one was thirteen years old. They spent an average of 1 hour and 27 minutes online per day. Participants had access to computers (96\%), tablets (80\%), smartphones (44\%), and music players (28\%). Most used social media several times a day (40\%), while some used it daily (16\%) or monthly (8\%). Most children (92\%) reported some knowledge of how to protect their privacy online and how to behave on social media, saying they learned it from school (88\%), parents (76\%), and friends (16\%).

\subsection{Results}

I analyzed data from the game logs, questionnaires, and interviews to evaluate the usability and effectiveness of the game.

\subsubsection{Time and scores}

Using the gamelogs, we tabulated some performance statistics. Table 6.1 shows players' mean scores and the time they took to complete each day in the game. The number of participants $(N)$ varies because participants only played 3 game days each. On average, they took approximately 5 minutes to complete each day. The scores show that participants found the photo sharing day easiest. They found the days covering online tracking and fact checking information most difficult, which suggests that participants were least familiar with these topics. 


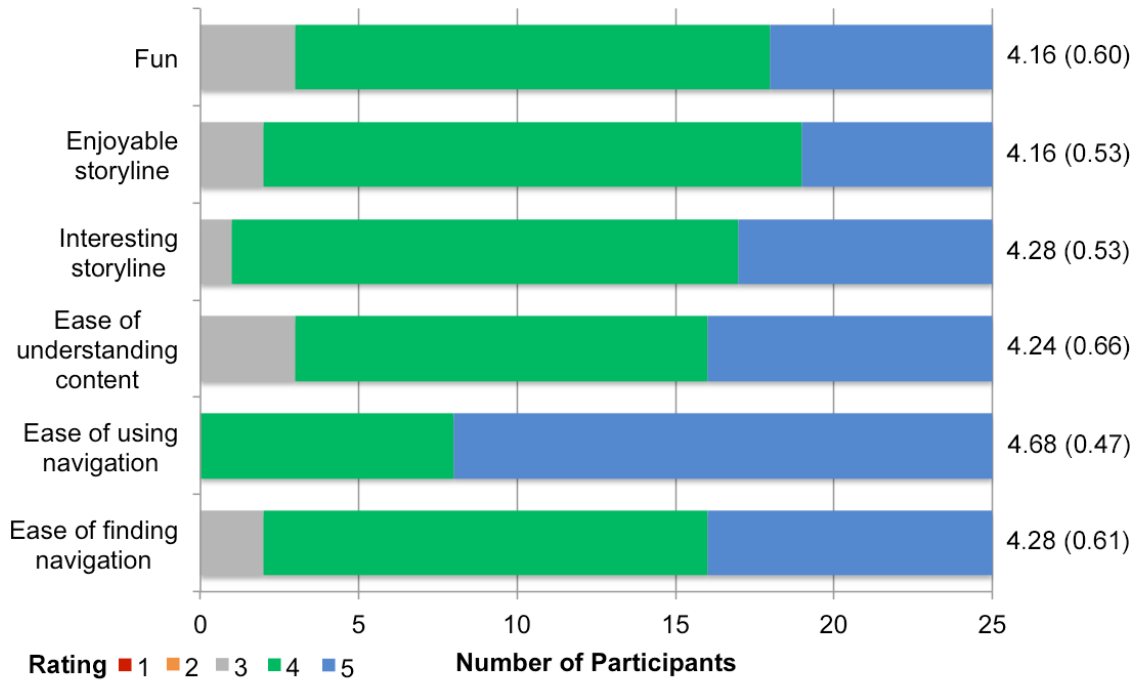

Figure 5.2: Children's usability evaluation of the game $(1=$ most negative, $5=$ most positive $)$

\subsubsection{Usability}

We start our analysis by addressing the following research questions:

- RQ1: Do children find the A Day in the Life of the JOs game usable?

- RQ2: What do children think about the A Day in the Life of the JOs game?

The post-test questionnaire (Appendix B), included seven questions to evaluate the usability of the navigation, content, storyline, and fun of the game. One question measured the challenge aspect of the game, but we observed that children had different interpretations of "challenge", making the results unreliable, so we excluded it from our analysis. All questions used a 5-point Smileyometer [248]. Figure 5.2 shows that participants were very positive in their responses. Most were able to find and use the navigation controls easily, and found the game content easy to understand.

We gathered further usability feedback in the interviews. Some did not understand certain words or could not read the text because it was too small on a 13-inch laptop screen (1280 x 800 resolution). Most found the storyline interesting and enjoyable, because they learned new concepts (e.g., using the rumor busting website Snopes), liked the overall design and artwork, liked the characters, and found it realistic and relatable. One participant stated I liked that the scenarios were realistic. They could mentally prepare you if you encounter them in the future, so you would know how to deal with them. Most participants 


\begin{tabular}{ccccc}
\hline Measure & Total & Pre-test & Post-test & One-week-test \\
\hline & & $\boldsymbol{M}(\boldsymbol{S D}) \boldsymbol{\%}$ & $\boldsymbol{M}(\boldsymbol{S D}) \boldsymbol{\%}$ & $\boldsymbol{M ( S D )} \boldsymbol{\%}$ \\
\hline Knowledge (3 days played) & 45 & $33(3) 73 \%$ & $36(4) 80 \%$ & $36(4) 80 \%$ \\
Behavioural Intent (3 days played) & 27 & $17(3) 63 \%$ & $20(3) 74 \%$ & $21(3) 77 \%$ \\
\hline Knowledge (all days) & 75 & $55(4) 73 \%$ & $60(5) 80 \%$ & $60(5) 80 \%$ \\
Behavioural Intent (all days) & 45 & $30(4) 67 \%$ & $35(4) 78 \%$ & $36(5) 80 \%$ \\
\hline
\end{tabular}

Table 5.2: Children's digital literacy knowledge and behaviour scores at three time points, for the three days played, and all five days in the game. The Total column indicates the total possible score for each measure.

found the game fun, because it offered lots of interactions, engaged their critical thinking skills, included appealing graphics, and was relatable for their age group.

\subsubsection{Characters}

We asked children's opinion of the main characters, Jo and Josie, using open-ended questions. Most had positive perceptions of the characters. $52 \%$ thought that the characters were nice, interesting, and likeable. $24 \%$ thought that the characters were realistic and relatable. One user stated They were kind of relatable because they're around my age and if I used social media more often, I could also be having these problems, so it would be valuable to play this game and learn. We asked children to rate the characters' likeability on a 5-point Smileyometer, with 1 being very dislikeable and 5 being very likeable. Most found the characters likeable $(M=4, S D=0.64)$. Participants were clearly engaged with the characters and had formed opinions of them. Most said they would like to be friends with Jo (40\%) and Josie (52\%) if they were real people. Participants wanted to be friends with the characters because they had similar interests (e.g, skateboarding, video games), thought they were nice, and smart. One user stated Josie also seems like a nice person, and she has a lot of good friends that would be able to back her up in situations, and by extension back me up in a lot of sticky situations. Those participants who were unsure about being friends with Jo (44\%) and Josie (36\%) explained that it was because they did not know enough about them or did not have shared interests.

\subsubsection{Digital literacy knowledge and behavioural intent}

Addressing the following research questions: 

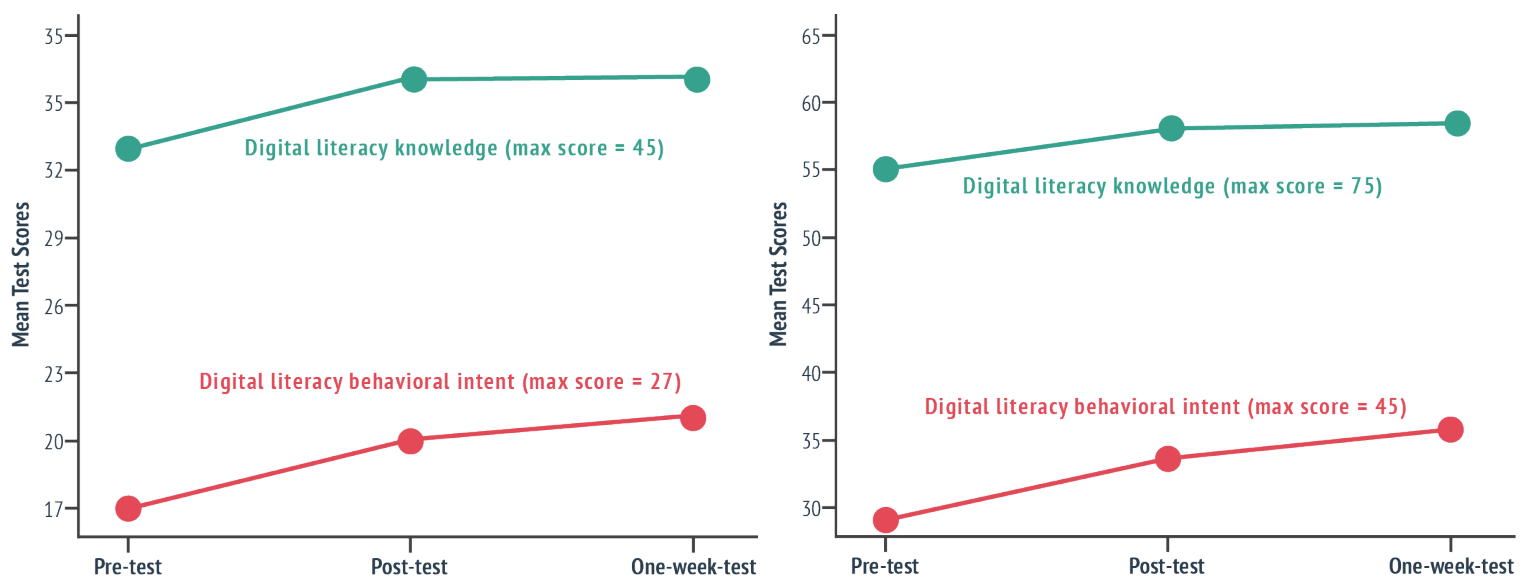

(a) Digital literacy knowledge and behavioural in- (b) Digital literacy knowledge and behavioural intent scores for the three days played. tent scores for all days.

Figure 5.3: Digital literacy knowledge and behavioural intent scores.

- RQ3: Does the game improve children's digital literacy knowledge?

- RQ4: Does the game improve children's digital literacy behavioural intent?

Children's digital literacy was measured using the fifteen 5-point Likert scale knowledge questions and five behaviour scenarios that they completed at three time points: pretest, post-test, and after one week (Figure 5.3). While children only played three days in the game, they answered digital literacy knowledge and behavioural intent questions corresponding to all five days in the game. When analyzing the data, I looked at the responses corresponding to the days completed, and also for all the days, to see if learning from one topic improved their understanding of the others.

\section{Knowledge}

Days played: I tabulated participants scores for the nine 5-point Likert scale questions corresponding to the days completed, and gave them a total digital literacy knowledge score out of 45 (5 per question). Table 5.2 shows a summary of participants' pre-test, posttest, and one-week test knowledge scores. We conducted a one-way repeated measures ANOVA to determine whether children's digital literacy knowledge scores changed over time. Using a Greenhouse-Geisser correction, we found statistically significant differences in children's digital literacy knowledge scores over the three time points $(F(1.61,38.69)=$ 
41.61, $\left.p<.001, \eta_{p}^{2}=.63\right)$. Post-hoc analysis using the Bonferroni correction revealed that children's knowledge scores improved significantly from pre-test to post-test $(p<.001)$ and from pre-test to one-week test $(p<.001)$ (Figure 5.3a). No significant differences were found between post-test and one-week scores $(p<.116)$, suggesting that children had retained the knowledge they learned in the game.

All days: The scores for all fifteen 5-point Likert scale questions were added to give participants' a total digital literacy knowledge score out of 75 (5 per question) (Table 5.2). I conducted a one-way repeated measures ANOVA to determine whether children's digital literacy knowledge scores changed over time. Using a Greenhouse-Geisser correction, we found statistically significant differences in children's digital literacy knowledge scores over the three time points $\left(F(1.56,37.35)=11.05, p<.001, \eta_{p}^{2}=.32\right)$. Post-hoc analysis using the Bonferroni correction revealed that children's knowledge scores improved significantly from pre-test to post-test $(p<.004)$ and from pre-test to one-week test $(p<$ .004) (Figure 5.3b). No significant differences were found between post-test and one-week scores $(p=1.00)$. We thus see the same pattern as in the 3-day scores.

\section{Behavioural Intent}

Children's behavioural intent scores were derived from the interview data. The interviews were transcribed from audio recordings and I organized the responses in Excel according to the 15 interview questions ( 3 questions $\times 5$ scenarios). I coded each response on a 3-point scale $(3=$ very good, $2=$ marginal, $1=$ poor $)$ for a total out of 45 points. 1

A second researcher independently coded the responses for the first 13 participants. A Cohen's Kappa (k) test showed moderate agreement between myself and the other researcher's analysis of the pre-test $(\mathrm{k}=0.65,95 \% \mathrm{CI}$ : 6 to $.7, p<.001)$, post-test $(\mathrm{k}=0.62$, 95\% CI: 0.5 to $0.7, p<.001)$, and one-week-test scores ( $\mathrm{k}=0.57,95 \%$ CI: 0.5 to $0.7, p<$ $.001)$. In cases of disagreement, myself and the second researcher discussed and consolidated the scores to be used in the final analysis. Since we had moderate agreement, and had calibrated scores for the first half of the responses, only I coded the responses for the remaining 12 participants.

\footnotetext{
${ }^{1}$ One question was poorly worded and could be interpreted in different ways. This resulted in too much variability in responses. We assigned it the middle score of 2 for each participant.
} 
Days played: The behavioural intent scores were computed from responses to three scenarios, giving participants a total score out of 27 (3 questions $\times 3$ scenarios $\times 3$-points per question). Table 5.2 shows a summary of children's digital literacy behavioural intent scores. I conducted a one-way repeated measures ANOVA on these scores to see if they improved over time. Using a Greenhouse-Geisser correction, we found that the scores significantly improved over the three time points $\left(F(1.61,38.69)=41.61, p<.001, \eta_{p}^{2}\right.$ $=.63)$. Post-hoc analysis conducted using Bonferroni correction revealed that children's behavioural intent scores improved significantly from pre-test to post-test $(p<.001)$, and pre-test to one-week test $(p<.001)$. No significant differences were found between posttest and one-week scores $(p<.116)$.

All days: I also looked at the behavioural intent scores for all five days in the game, which were out of 45 ( 3 questions $\times 5$ scenarios $\times 3$-points per question) (Table 5.2). A Mauchly's Test of Sphericity found that the scores significantly improved over the three time points $\left(F(2,48)=50.13, p<0.001, \eta_{p}^{2}=.68\right)$. Post-hoc analysis conducted using Bonferroni correction revealed that children's behavioural intent scores improved significantly from pre-test to post-test $(p<.001)$, pre-test to one-week test $(p<.001)$, and post-test to one-week test $(p<.019)$; again showing that playing the game led to sustained improvements.

\subsubsection{Eyetracking}

I examined fixation patterns in the videos generated by the eyetracker to see which elements of the game received attention from users and how users interacted with the elements. In general, elements in the game did not compete for children's attention because we used animation to sequentially present elements and guide their attention.

\section{Elements}

Common elements include the audio player, score area, and "next button". Most users noticed the audio player, but none used it to control the voice narration in the game, which was on by default. In fact, this area received the least attention, suggesting that the audio was at a good reading pace for children, and synced well with the game text. Children looked at their total score periodically, especially after making a choice in a scenario. They 


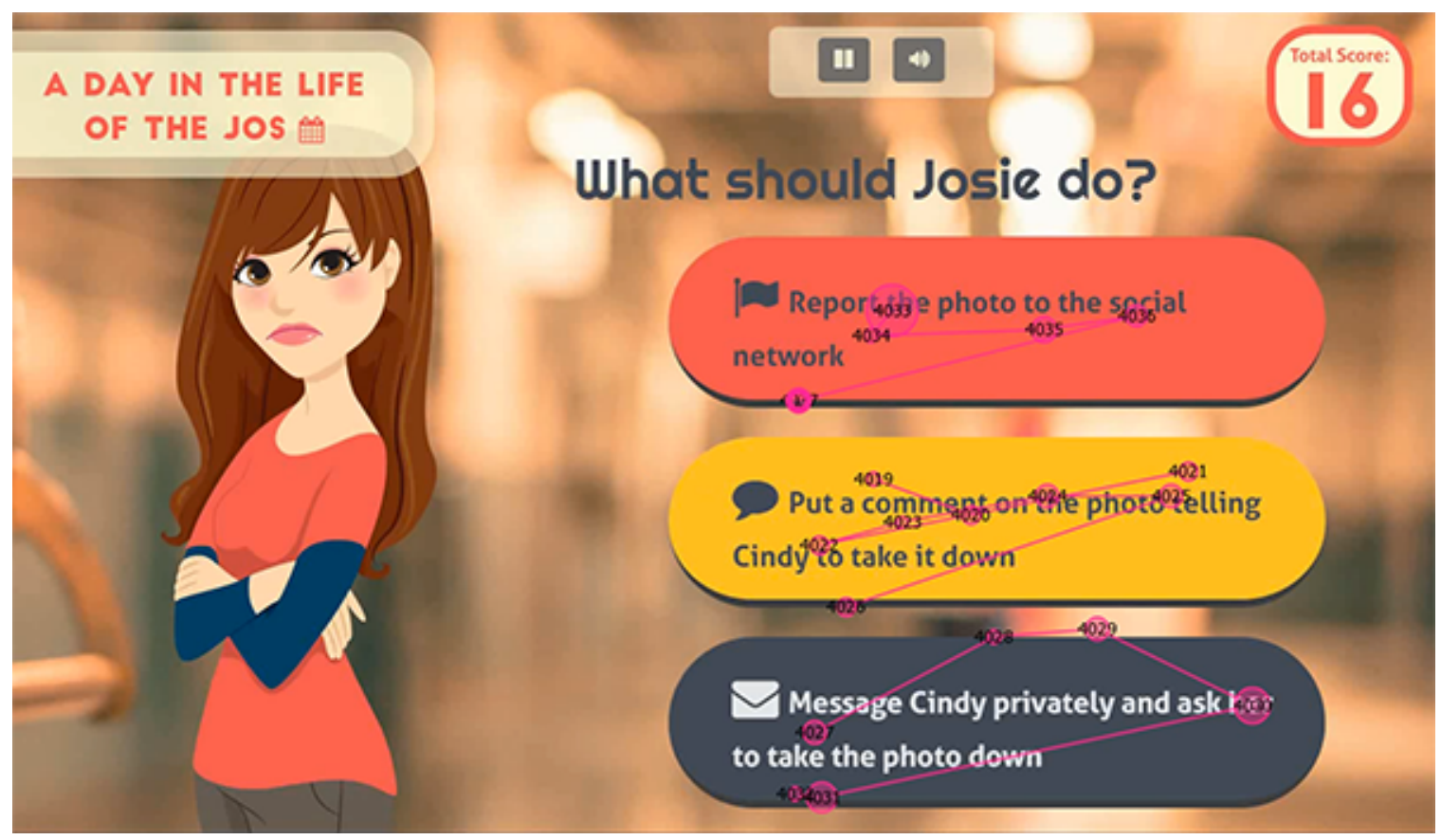

Figure 5.4: Scanpath of a child's gaze when reading choices in a scenario.

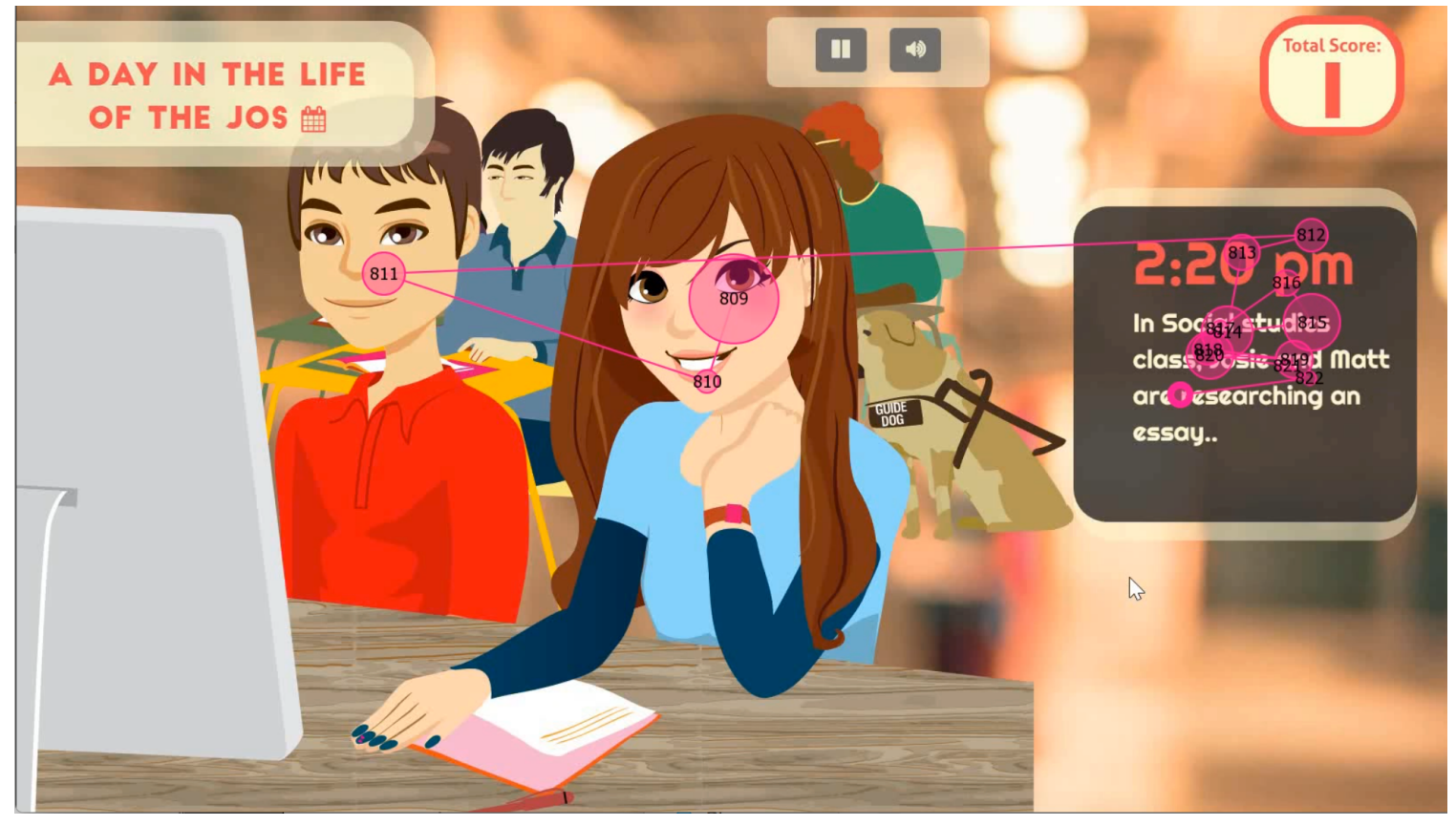

Figure 5.5: Scanpath of a child's gaze when processing graphics and text in the game. Larger bubbles indicate longer fixations. 
used the score to evaluate their performance, which suggests that it acted as a motivator. Users were able to easily locate and use the "next" button to navigate between scenes in a scenario.

\section{Text and Graphics}

The game contains a considerable amount of text, however, we tried to facilitate reading by using humor, chunking text, and combining text with visuals. We used eyetracking to determine children's reading behaviour, and found that they read most of the game text and news feed. In the feed, a new entry sometimes appeared before children were finished reading the previous entry. When this happened, children continued to read the previous entry and moved to the new one when they were finished. Some children read the text multiple times, especially when it was long, but most read it only once, suggesting that it was at an appropriate reading level. Many children did not read text embedded in an image. This could be because they thought it was not important, the font was too small, or the text was too long. They sometimes did not read text in the day review screen, possibly because it was too long or they were listening to the audio narrator instead. We observed that after playing two consecutive days in the game, children started to experience reading fatigue, which is when they would skip reading text in the day review screen. Children paid close attention to the list of choices presented in each scenario. They read each option multiple times, suggesting that they were considering the consequences of each option before making their choice. This was evident from their gaze patterns (Figure 5.4) and the time spent on the choices page. When game characters were present, children focused on their faces, particularly the eyes (Figure 5.5).

\subsection{Discussion}

We discuss results specific to the user study in this chapter, and keep broader reflections related to the game as a whole for Chapter 8 . 


\subsubsection{Study outcomes}

\section{User experience:}

Children found the game usable, the characters of Jo and Josie relatable, and the scenarios representative of situations that they may encounter in real life. While playing the game, children talked about the main characters of Jo and Josie as if they were real, making statements such as "The Jos get into a lot of trouble...", or "Come on Josie, don't do that!". After playing a scenario, children wanted to play more to see what would happen to Jo and Josie. They were also surprised to see the consequences of some of their choices. These results show that our narrative was engaging, and motivating, which contributed to children's improved learning in the game. We observed that some children used an exploratory strategy to play some scenarios. Instead of choosing the correct option, they chose the option that was most interesting for them, to see the consequences of that choice. Teachers can also use this approach when using the game in classrooms. They can instruct students to play the game and always make the correct choice, or pick the worst option and discuss the consequences of their choices with their peers as a learning opportunity.

Most children found the number of choices provided sufficient and were able to find a choice that represented their decision in the game. However, some wanted to see more choices, did not find their choice on the list, or wanted to choose multiple options. After reviewing these scenarios, we found that some children had incorrect security and privacy mental models, which may be the reason why they could not find an appropriate choice. When designing the game, we decided to provide three choices for each scenario, because we believed that would adequately represent various possibilities, while keeping the complexity of the game manageable. Our testing with children shows that the number of choices provided were adequate for most participants.

\section{Difficulties:}

We made some minor improvements to the game based on user feedback. Some children found the speed of the text animations too fast, so we slowed them down in the final version of the game. Children found the scenarios in the verifying information day more challenging than others, because they were not familiar with the topics addressed. This day 
discussed topics such as copyright and fact checking the information that they read online. Some children were new to these topics, while others had heard about them in school, but could not recall what they learned. When the game is used in schools, teachers can assign days based on the children's pre-existing knowledge, so the challenge is better matched with their skill set.

\section{Effectiveness:}

Children's digital literacy knowledge and behavioural intent improved after playing the game. When analysing behavioural intent, we only looked at the scored responses to the five situation based scenarios given to children at pre-test, post-test, and one-week.

\section{Debriefing and reflection:}

Our game provides an experiential learning environment, where players are debriefed on their choices and are provided opportunities to reflect on what they have learned. In the JOs, we found that the primary source of reflection was the consequences for a choice displayed in the newsfeed. Immediately after making a choice, children were debriefed on their action via the elements that were sequentially displayed in the newsfeed. After viewing the consequences, children had an "ah ha!" moment, and then many reflected on their choice and determined how they were going to improve in the next scenarios. Another reflection opportunity is provided by the review screen at the end of completing a day (i.e., five scenarios) in the game. This screen provides feedback on the choices made, and also provides children with advice on how to make better choice in the future. Compared to the debriefing in the newsfeed, this screen provides more detailed feedback to children on their choices, which results in a longer period of reflection. In our study, we observed that children took the time to go over this feedback and made connections between the outcomes of different scenarios. They were also particularly interested in the best choice in each scenario and learning how they can make better choices in the future. The newsfeed provides feedback within the game world, directly from the in-game characters. The review screen steps back and takes a more instructive tone from an observer perspective and offers commentary on the game. 
Parents: An advantage of experiential learning is that the learning continues outside the learning environment as students apply the learned material to different situations. In our user study, several families reported that the game led to family conversations about online security and privacy issues, which we see as a positive outcome. We also observed this during the study when some parents were seated next to the child. However, to prevent parents from influencing children's performance in the game, we tried to minimize these discussions by seating the parent/child in different locations of the study space. These observations show that the game has the potential to be used as a catalyst for privacy and security conversations between parents and children. When used in schools, it can also foster conversations between children or with the teacher. We explore this further in Chapter 6 .

\subsection{Limitations}

We note several limitations related to our work.

Testing time: We only tested children after one week when evaluating improvements in children's digital literacy; we cannot be certain whether these improvements will remain long-term. A longitudinal study would be needed to understand whether these improvements are sustained and whether these result in lasting real-life behaviour changes.

Use of self-reports: We measured improvements in digital literacy using self-reports and hypothetical scenarios, so children's actual behaviour in real life may be different than what they reported.

Selection bias: We note that some of our results may have been influenced by a sampling bias in terms of the participants that we recruited for our study. Specifically, we found that test scores were quite high and improvements in children's digital literacy were fairly small between test points (pre-test/post-test and post-test/one-week). This could be because we recruited participants who were already relatively digitally literate. As shown by the demographics information, most of our participants used multiple digital devices daily, had regular access to the internet, and already had learned about some security and privacy issues from their parents or at school. Furthermore, since we primarily recruited participants from social media parenting groups, it is possible that the parents who responded to our advertisement were already conscious about their children's digital literacy, and had 
taken steps to educate them about these topics.

Future studies should recruit participants with diverse backgrounds and different socioeconomic status to collect a more representative sample of the user population. This can be achieved by advertising the study in community centres and partnering up with after school programs which include children from different backgrounds and socioeconomic status. With a more representative sample, we hope to see more improvements in digital literacy than was observed in our user study.

Lack of a control group: When testing the usability and effectiveness of our game, we did not compare the results against existing educational mechanisms that teachers are currently using in schools. Since this study was a first step in our evaluation process, we were interested in understanding children's perception of the game. Our next step is to evaluate the game with teachers and understand their digital literacy practices in schools, which is addressed in Chapter 7. Once we have a better understanding of the mechanisms that are used by teachers, in future work we will compare the game against a suitable control group.

\subsection{Future work}

In future work, we will evaluate the game with parents to understand their perceptions, and explore how it can be used collaboratively in families to promote security and privacy conscious conversations. We will also evaluate the usability and effectiveness of the game with children from different socioeconomic (SES) backgrounds to explore any effects of SES on children's digital literacy. In classrooms, we will evaluate the usability and effectiveness of the game against experiential learning mechanisms that are commonly used by teachers.

\subsection{Conclusion}

We conducted a user study with 11-13 year old children to evaluate the usability and effectiveness of our new digital literacy game. We found that children's digital literacy knowledge and behavioural intent both improved significantly, immediately after playing the game and one-week later. These results show that children had internalized the knowledge that they learned from the game. They also found the game usable, found the main 
characters to be relatable, and liked that the scenarios represented real situations which they may encounter in the future. 


\section{Chapter 6}

\section{Usability evaluation of the JOs with teachers}

I conducted a user study with grade 4-8 teachers in Canada, with two main research objectives:

1. Objective 1: to evaluate the usability of the JOs game with teachers

2. Objective 2: to understand the strategies that teachers use to help students deal with issues involving digital media

In this chapter, we provide our study methodology, research instruments, and address our first research objective. Chapter 7 addresses the second research objective.

\subsection{Motivation and research questions}

An abundance of educational games are currently available for K-12 subjects such as Math, Language, and Geography [55,99, 100,151,268]. Many of these games face resistance from teachers in adopting them for use in schools because they do not incorporate key pedagogic components, do not align with the curriculum requirements, or cannot be played within the constraints of a typical lesson [67, 147, 150, 180]. Thus, educational games designed for classrooms must meet additional usability constraints to be accepted and utilized by teachers. Previous research shows that some reasons that negatively influence teachers' adoption of educational games in their classroom include: lack of empirical evidence available on the effectiveness of the game, compatibility with existing technology, time constraints imposed by a class period, and compatibility with the curriculum [8, 13, 147, 150]. As part of our process, we tested the JOs with teachers to evaluate the usability of our game for classroom use.

Research questions We set the following four research questions pertaining to the first objective of our user study: 


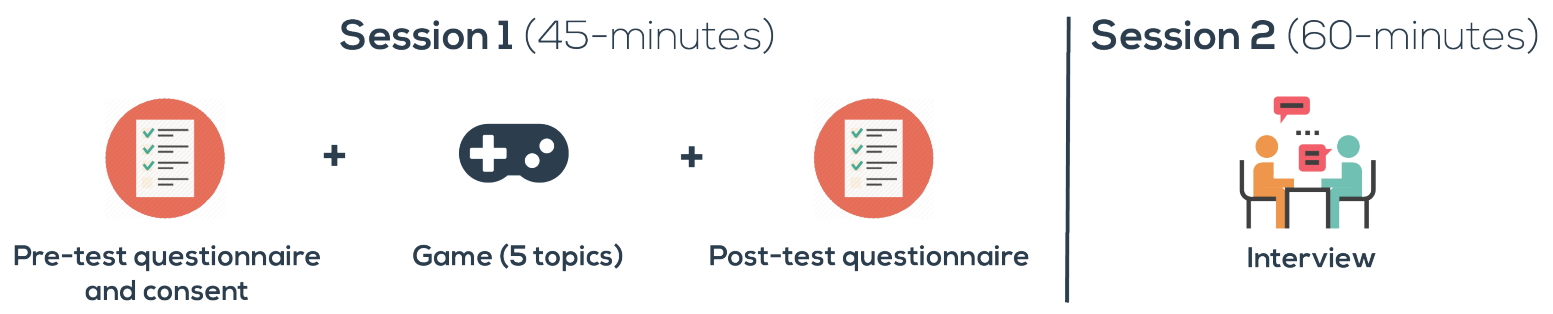

Figure 6.1: Methodology of the user study with teachers

1. OB1-RQ1: Do teachers find the A Day in the Life of the JOs game usable?

2. OB1-RQ2: What do teachers think about the A Day in the Life of the JOs game?

3. OB1-RQ3: How will teachers use the A Day in the Life of the JOs game in their classroom?

4. OB1-RQ4: Does the game improve teachers' own digital literacy knowledge?

\subsection{Methodology}

Figure 6.1 shows the methodology of our study, which was cleared by Carleton University's Research Ethics Board (REB). The study consisted of two sessions.

Session 1: The first session was completed online and took about 45-minutes. To begin, participants completed a pre-test questionnaire online (Appendix G). The first page of the questionnaire collected their consent for participating. After consent was provided, participants completed the pre-test questionnaire. Next, participants played all five days in the game on their own time and completed a post-test questionnaire (Appendix $\mathrm{H}$ ).

Session 2: The second part took 60-minutes and was completed in person or via videoconferencing, whichever was more convenient for the participant. Participants completed a semi-structured interview (Appendix (I) with me, discussing their experience of playing the game and teaching digital literacy in their school.

Participants were compensated with a $\$ 50$ Chapters eGift card or an email money transfer, depending on their preference. The questionnaires were created and distributed using the Qualtrics 1 survey tool. Upon completion of a questionnaire, I was notified and used a

\footnotetext{
${ }^{1}$ https://www.qualtrics.com/
} 
templated email in Qualtrics to send instructions to the participant on the next step of the study. Interviews were audio recorded, and the audio was transcribed using the automated transcription service Trint ${ }^{2}$, Trint uses Artificial Intelligence to automatically transcribe audio with a high degree of accuracy. After processing the interviews through Trint, the transcriptions were manually edited by another researcher to correct any inaccuracies.

\subsubsection{Recruitment}

Teachers were recruited from Facebook groups, teacher blogs, and other teacher-related websites such as the Canadian Teacher's Magazine ${ }^{3}$. Posters were also distributed at Carleton University and community centres in Ottawa. Due to the difficulty of obtaining approval from school boards, we found recruitment through these informal mechanisms more successful than directly recruiting through the schools. Teachers were recruited from across Canada, and needed to have experience in teaching digital literacy, media literacy or digital citizenship. In addition, they needed to have experience teaching grades $4-8$, which is the target audience of our game, but they could be currently teaching any grade. All had to be employed as teacher in a Canadian school.

\subsubsection{Participants}

21 teachers were recruited from eight different cities and four provinces across Canada, and taught at eighteen different schools. The majority $(\mathrm{n}=12)$ taught at schools in Ottawa. All have experience teaching grades 4-8. At the present, they are teaching grades 1-8. 48\% of participants taught in private schools and 52\% taught in public schools. The majority $(86 \%, \mathrm{n}=18)$ are female and a few $(14 \%, \mathrm{n}=3)$ are male, which is representative of this user population.

\subsubsection{Pilot testing}

Before testing with teachers, we pilot tested our questionnaires with friends and members of our research lab, and made changes based on their feedback. We then conducted the study with two teachers, who helped test the study materials and the methodology. From

\footnotetext{
${ }^{2}$ https://trint.com

${ }^{3}$ https://canadianteachermagazine.com
} 
this testing, we found that some of our interview questions were too specific, and were not providing the rich data that we required to answer our research questions. We also noticed that the interviews were skewed towards feedback about the game, so we were not collecting enough data to understand digital literacy in classrooms. Teachers were able to complete the interview in about 30 minutes, which is half the time allocated for this session. Based on these results, we updated our interview script to make the questions more open-ended, and included new questions to understand digital literacy in classrooms. The updated interview script was used with the remaining 19 participants. Although short, these two interviews did provide useful feedback so we include their data in our analysis.

\subsection{Research instruments}

Data from teachers was collected using game logs, questionnaires, and a semi-structured interview.

\subsubsection{Game}

The game was hosted on a web server in our research lab. Each teacher was assigned a unique identifier (e.g., t01), which they used to play the game and complete the questionnaires. The identifier was used to connect teacher data from the game, questionnaires, and interview. Teachers could play the game in either English or French. After loading the game, they selected the language and entered their unique identifier in the login screen, which gave them access to the game. Teachers could play the entire game in one session or save their progress after playing a scenario, and complete the rest later. They could also switch languages between sessions, and replay a day if desired.

\section{Game logs}

The game was instrumented with logs, which recorded teachers' actions in the game. Specifically, we recorded the time they took to play each scenario, the score per scenario, and the number of times a scenario was played. If a scenario was replayed, the logs provided performance data for all attempts. 


\subsubsection{Questionnaires}

Teachers completed two online questionnaires in the study, one before playing the game and the other after playing the game.

\section{Pre-test questionnaire}

This questionnaire (Appendix G) collected demographics information, details about their classroom, and teachers' use of technology and social media. Classroom details included the number of students in the teacher's class, technology use in the classroom, and types of resources used for digital literacy education. The questionnaire also included fifteen 5-point Likert scale questions to measure teachers' digital literacy knowledge. These questions were identical to the questions that we used in our user study with children to evaluate their digital literacy knowledge before and after playing the game (Section 5.5.4). An example question was When using your mobile device, how often would you use your full name online?.

\section{Post-test questionnaire}

In the post-test questionnaire (Appendix $[\mathrm{H}$ ), we evaluated the perceived usability of the game using the following 5-point Likert scale questions:

1. How easy was it to find the navigation controls (like the next button) in the game?

2. How easy was it to use the navigation controls in the game?

3. How easy was it to understand the content in the game?

4. How interesting did you find the storyline?

5. How enjoyable did you find the storyline?

6. How fun was the game?

7. How challenging was the game for you? 
We also repeated the fifteen 5-point Likert scale digital literacy knowledge questions from the pre-test questionnaire, to see whether teachers' digital literacy knowledge improved after playing the game. We slightly reworded the questions to ask teachers what they would do in the future, as opposed to what they currently do in the pre-test.

\subsubsection{Interview guide}

The post-test interview (Appendix I) was organized into the following three themes. Each theme included several questions and prompts that could be used to guide the conversation as needed to collect rich data about their experiences.

1. Types of issues encountered around children's use of media in schools

- Example question: What kind of issues are you seeing around kids' media use?

- Prompts: What types of problems are they bringing up in the classroom? How do kids bring up these problems to you or another teacher?

2. Teaching digital literacy in classrooms

- Example question: Can you describe your last experience of teaching a digital literacy topic?

- Prompts: Which grade did you teach? What kind of techniques did you use to teach the material?

3. Teachers' perception of the JOs game, and how to use it in classrooms

- Example question: How would you use the game in a classroom?

- Prompts: Can you describe what an actual lesson might look like? Which sections of the game would you incorporate in the lesson? 


\begin{tabular}{cccc}
\hline \multicolumn{1}{c}{ Day } & N & Score $(/ \mathbf{1 0})$ & Time $(\mathbf{m i n}: \mathbf{s e c})$ \\
\hline Cyberbullying & & $\boldsymbol{M}(\boldsymbol{S D})$ & $\boldsymbol{M}(\boldsymbol{S D})$ \\
\hline Online tracking & 21 & $6.9(1.45)$ & $5: 20(2: 07)$ \\
\hline Privacy & 21 & $6.8(1.65)$ & $4: 54(1: 13)$ \\
\hline Sharing photos & 21 & $7.1(1.58)$ & $5: 40(2: 00)$ \\
\hline Fact checking & 21 & $8.9(1.09)$ & $5: 02(1: 17)$ \\
\hline
\end{tabular}

Table 6.1: Teachers' mean game score and mean time per game day (each day was played once per participant).

\subsection{Results}

\subsubsection{Time and Scores}

Table 6.1 shows teachers' scores and the time they took to complete each day (comprised of 5 scenarios each) in the game. The results are similar to children's performance of playing the game. On average, teachers' took 5 minutes to complete each day, same as the time that children spent. This suggests that the speed of the text animations in the game may have prevented teachers from progressing through the scenarios at a faster pace. The speed of the text animations was predefined in the game to match children's reading speed, and could not be modified by players.

Assuming that teachers tried to advance through the game by providing correct answers, the scores suggest that teachers found the topics of online tracking and fact checking information most difficult, and the topic of sharing photos to be the easiest. Children also found these topics most difficult. Given this, the game can also be used as a learning tool for teachers, who can play it to improve their own knowledge before teaching certain topics to children. It is important to note that since the game is exploratory, teachers may have picked the wrong choice on purpose to see its consequences in the game. For example, one teacher stated that "I clicked the ones I knew were the middle of the road answers just to kind of see what happened, I was curious from the Choose Your Own Adventure approach to the game. I was like 'I want to know what happens if I press this one' ” (t20). Thus, the scores should not be used as the only indicator of learning in the game. 


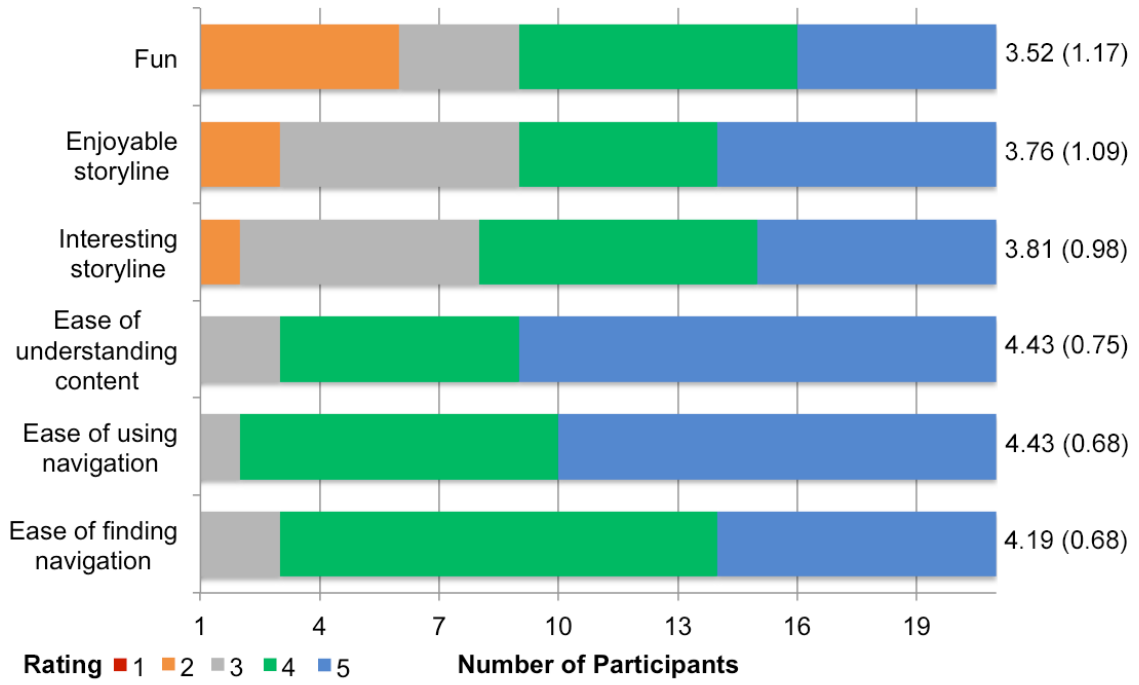

Figure 6.2: Teacher's usability evaluation of the game $(1=$ most negative, $5=$ most positive $)$

\subsubsection{Usability}

The usability of the game was measured using semi-structured interview questions and seven 5-point Likert scale questions in the post-test questionnaire (Figure 6.2). I analyzed the interview data using thematic analysis. We excluded one question ${ }^{4}$ from the analysis of the Likert scale data because teachers interpreted it differently, which made the results unreliable.

We assessed the usability of our game according to the following criteria:

1. The game must be easy for teachers to use.

2. The game must be fun to play.

3. Teachers should be able to incorporate the game into their classrooms.

\section{Ease of use}

Most teachers found the game easy to use, visually appealing, and they liked the design of the user interface. Figure 6.2 shows that teachers were able to find and use the navigation controls easily, and understood the content in the game. One teacher stated that "I found it

\footnotetext{
${ }^{4}$ The question measured the challenge aspect of the game, however we found that teachers had different interpretations of "challenge", which made the results unreliable, so we excluded this question from our analysis.
} 
really easy to play, like to navigate through. So when I first logged on, like I'm pretty tech savvy I'm not the highest, but I'm certainly not the low end of the spectrum, so I found it easy to get to, easy to look at. I never got frustrated with where I was supposed to go next or what I was supposed to do next. The directions/instructions were pretty clear" (t14).

\section{Fun}

Figure 6.2 shows that many teachers found the game fun $(M=3.52, S D=1.7)$. Several factors contributed to the enjoyment of the game, including animations, humor, storyline, graphics, and the challenge presented by the choices in the game. With regards to the fun aspect, one teacher stated "It was really fun. I really enjoyed it. Yeah I thought it was very colorful and attractive. It looked current. It was something that I think they would enjoy playing. I think the thing that immediately turns kids off is if it looks dated. So I think making it look sort of current and modern is really important. And I thought this game did a good job with that. I thought the game did a great job of balancing the information with the fun aspect" (t10).

Teachers liked that the correct or best choice was not always clear, requiring them to critically think about each option before making their choice. This made the game challenging, which contributed to it being fun to play. Teachers looked forward to seeing the consequences of their choices and were disappointed when they made the wrong choice.

For example, one teacher stated that "I actually didn't get full marks always, because I like that there was kind of that ambiguity. It's not fun when you're playing a game like that. It's like what should you do? Be really angry and freak out or be a nice person and think nice thoughts, it's like no, there was some that was like it was a little bit unclear. There was a little bit of gray area so I thought that was good" (t22).

From an educational perspective, teachers particularly liked that the game allowed students to explore the consequences of less desirable choices in a simulated and safe environment. In their teaching, they often focus only on teaching students the best choices to make online, which does not sufficiently prepare them for the digital world. Specifically, if children are unaware of the potential consequences of the wrong choices, then they are more likely to make these choices online. For example, one teacher stated "I think a lot of times in school and how I teach, I always teach the desirable outcome. But I think kids 
sometimes need to know the consequence of those actions [bad choices] too. And this is like the safe way of doing it" (t17).

Comparison with children: We observed that teachers found the game less fun $(M=$ $3.52, S D=1.7)$ compared to our user testing with children $(M=4.16, S D=0.60)$. This is understandable, since the game is designed for 11-13 year old children who are more engaged with the storyline because it is representative of experiences and situations in their real life.

\section{Authenticity}

The most common aspect of the game that teachers liked is that it was realistic, and represented situations that children may face in real life. Teachers stated that when children are unable to see themselves in the game, they are less engaged, and less likely to take the educational content seriously. In educational games, authenticity is needed throughout the entire game and within each game component. For our game, this includes the characters, visual design, storyline, and scenarios.

Characters: Children need to see themselves represented in the characters of a game. For our game, teachers appreciated the diversity of the characters. They liked that the scenarios were gender inclusive and included situations from both the girl and boy characters' perspectives. As one teacher stated, in education about digital literacy, girls are often portrayed as victims, especially in situations about online reputation and rumors. So, they liked that situations in the game were inclusive and did not use traditional gender stereotypes. "I like that [it] came from a boy and girl perspective, girls are usually seen as the only targets or more of the majority of the targets but I like that the boy could also be in a targeted role and that was really pushed to the forefront. So I thought it was very equal in that way" (t6).

Teachers also liked the sibling duo of Jo and Josie. It allows children to see the consequences of their actions on someone close to them, which can have a greater impact from a learning perspective. For example, in a cyberbullying scenario, Josie stands up for her brother by cursing the bully. However, this action inadvertently increases the bullying and makes things worse for Jo. By using a sibling duo, teachers thought that the game creates a realistic emotionally charged scenario that teaches children to think before they act. 
While the game makes a good effort at being inclusive, there is still room for improvements, as pointed out by a teacher who teaches at an inner-city school with a fairly diverse student body. She stated that "So are my kids seeing themselves in these games? No. I mean, I thought there was good ethnic diversity in the game, which I was purposely looking for. And I was looking for names. Are you using different kinds of names or are you using like, you know, certain centric names? Because, our ESL population is more than half the school. So did we see any girls in the hijab in that game? I don't think we did. So, we're not seeing it. I want to see that you are capturing my community. There is no reference to anybody on the autism spectrum" ( $\mathrm{t} 30)$.

Visual design: Teachers found the visual design of the game age appropriate for the target audience. Similar to prior research [76], they noted that games using a "babyish" design are taken less seriously by children. They are also unable to relate to designs that are too old for them. Thus, teachers noted that the design of our game is too babyish for high school students and too old for primary students, but is age-appropriate for tweens. One teacher stated that "The graphics were pretty good. Sometimes when you play those games you have graphics that are either way too young or way too old and especially with grade four and five, they're kind of in the middle. And so they don't [like] all the cutesy cartoony graphics, but then if you have realistic characters they usually look like you are adults and kids don't connect them" (t15).

Scenarios and storyline: Teachers liked the A Day in the Life storyline because they found it relatable for children, who are using technology throughout the day, both at home and at school. Specifically, they liked that the game showed scenarios unfolding at home, as digital literacy education in classrooms often focuses on using technology safely at school. As one teacher stated "I liked that there were different times of day that you could click on. It wasn't always at school. It was also at home before school because we know the kids wake up, first thing they do is go on their social media. You see them waking up at 7:30 and oh they are already on their phone. [There were] situations at school with friends, peers, classmates, in the evening, at home, and then you piece [it all together] at the end of every day. These are the choices you made today. And these are the ramifications or consequences or this is the learning that happens from your choices" (t16).

Children's online behaviours at home are determined by several factors such as their 
access to technology, the rules set by their parents, and how comfortable they are with using technology. For example, children whose parents allow them to play multi-player games online will have some experience and understanding of how to communicate with strangers on the internet. However, this may not be true for children who do not engage in activities where they interact with strangers online.

For our game, teachers liked that the scenarios also covered different ways that children are using technology at home. As one teacher stated "I thought the game did a really good job of giving scenarios that a student could relate to. Like there wasn't a scenario that I thought like there's no way a kid's gone through this or would go through this. Like I thought it was all really good examples and like a wide variety of examples too, which is what I really liked, like home and school was good" (t24).

Teachers thought that the wide range of scenarios in the game increases its authenticity, as a wide variety of children can see themselves represented in the different situations. We made the design decision to avoid situations that may potentially scare or traumatize children. From our conversations with teachers, we found that police and invited speakers often talk to children about sexting and the dangers of communicating with strangers online. These talks often left children scared, because they were presented with possibly scary information and were not provided with an opportunity to discuss what they learned.

While these topics are important, we excluded them from our role-playing game to prevent possible negative psychological consequences on children. We believe that these types of topics should be introduced to children in a different format before they experience them in a game. They also require parents and teachers to be more involved, and available to offer support and answer students' questions. Affirming our decision, none of the teachers indicated a need for them to be included in the game. Their inclusion could be considered in future iterations, possibly as an optional/advanced topic that teachers could introduce with additional supports.

A recurring comment was that teachers found scenarios representative of real situations that their students are currently encountering in their daily lives. This increased teachers' confidence in using the game in their classrooms. For example, one teacher stated "I loved that it was things that totally could happen to my students. So if I'm going to post this picture and its meaning had an issue, or a student posted a picture that the other student 
didn't want posted of them. And then you have to talk about, why they are not allowed to do that and what they should have done beforehand. You have to talk to the student. And so the examples within the game were great" (t15).

Choices: In addition to the situations, the choices in most scenarios were also realistic and representative of the choices that children have in real life. For example, one teacher stated "I thought the choices were pretty authentic and ones that I could see people, you know good people just making... Because they're swept up in the emotion of something, that photo is hilarious, I'm going to send to my best friend and I know they won't share it, smash, get to five minutes later, they share it with everyone. So I thought that the scenarios were good. And I could see it being used in a classroom” (t20).

Teachers liked that each scenario included three choices, with one of them being the gray or uncertain option. They found it representative of the real-world where the correct choice is not always clear and thought that it can be used to generate post-game discussions among students. They also thought that the choices gave students an opportunity to practice or build their critical thinking skills. As one teacher stated "I liked the different options that the game gave them too, that had to actually make them think. 'oh, I could do this or maybe I'll do that or that option sounds better.' And then it gave them the feedback based on their choice. I thought that was really valuable too" (t16).

There were a couple of scenarios where teachers did not agree with a choice, felt their choice was not included, or wanted to pick multiple options. We also observed this in our user testing with children. After reviewing these scenarios, we found that the choices are nuanced and represent real life situations where adults also often have incorrect mental models. For example, in one scenario players need to decide whether a photo shared by a friend is communicating factual information about school bus cancellations. The best choice is to use a search engine to look for secondary sources that convey the same information. However, both teachers and children believed that checking the date when the photo was shared is sufficient. This is problematic because users can share old photos on social media (which would have a current date), and this can lead to spreading misinformation - the lesson of this scenario. We consider these types of scenarios to be important in the game, as they can improve teachers' knowledge and mental models and also lead to interesting discussions in class. 


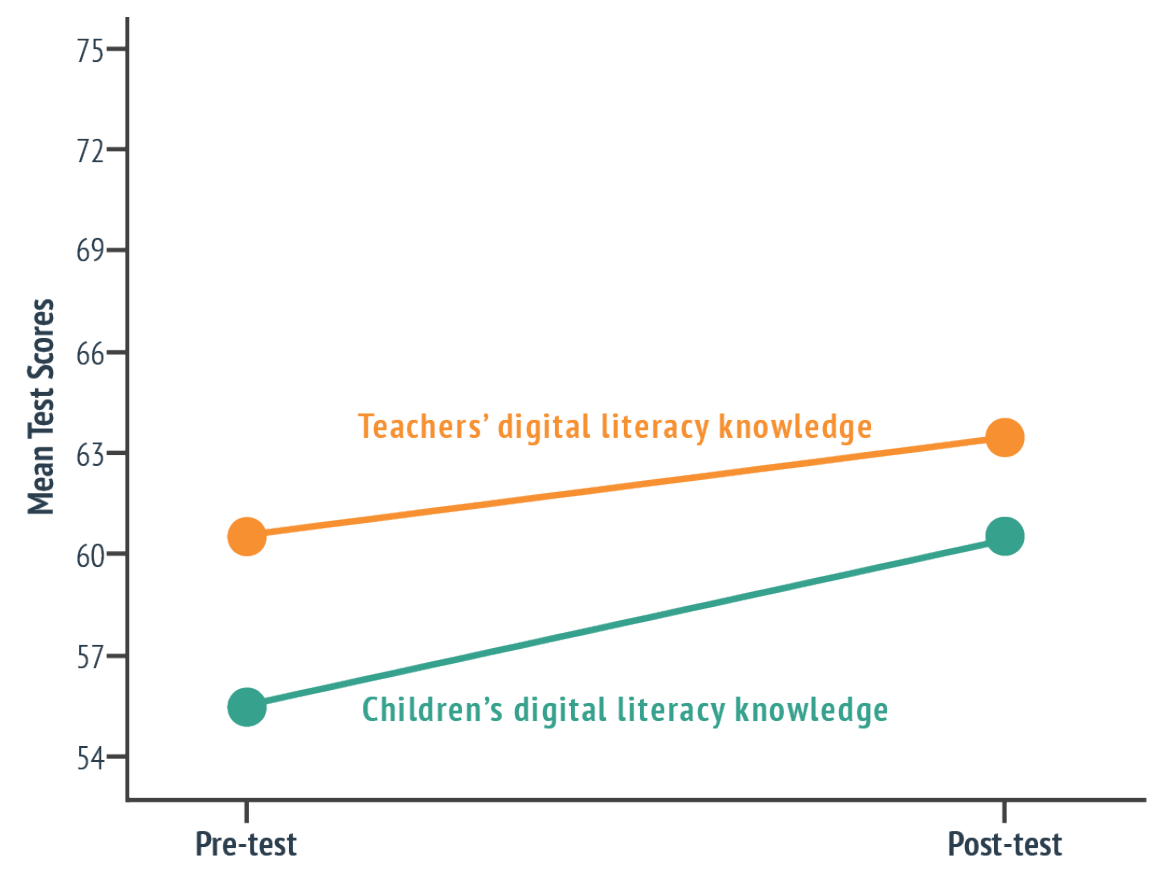

Figure 6.3: Teacher's digital literacy knowledge scores.

\subsubsection{Learning}

Teachers' digital literacy was measured using fifteen 5-point Likert scale knowledge questions that they completed at two time points: pre-test and post-test. (Figure 6.3). The scores for all fifteen questions were summed to give a total digital literacy knowledge score out of 75 ( 5 points per question). I conducted a paired t-test to determine whether teachers' digital literacy knowledge scores (Pre-test: $M=60.43, S D=5.84$ ) improved after playing the game (Post-test: $M=63, S D=4.77$ ). A paired t-test found that teachers' digital literacy knowledge scores improved significantly after playing the game $(t(20)=-2.24, p<.037)$.

We note that teachers had a fairly high initial digital literacy score and their improvements after playing the game were small. This could be because our participants were fairly experienced in teaching digital literacy, and were probably more knowledgeable about these issues than the average teacher. Thus, it is possible that the game would result in more improvements for teachers who are new to teaching digital literacy.

In their interviews, teachers stated that they learned from the game, as they did not know the answers to certain scenarios or had not thought of some situations that children may encounter online. For example, one teacher stated "I really liked in the game how those kinds of concerns were addressed with private messages. And I thought that was not 
something I would have necessarily thought about teaching kids. And I think that's really

important. Like sending a private message to someone to say 'you know what you said to so-and-so was not kind and I think you should take that comment down' or 'I think it's hurtful' or whatever. And that way you're not starting this troll-y conversation but you're addressing it. I thought that was a really positive strategy that the kids could use to deal with those things" (t10).

For some teachers, the game also improved their own privacy attitudes. "When we first started this discussion, my daughter, who's 13, said 'I don't want you to post that photo on your Facebook'. [...] In playing the game I really thought about it. I thought 'she's right. It's not okay for me to do that'. And I think about Facebook ten years ago I would have posted a picture of someone's kid. No problem. And now I wouldn't. And when kids come over for a playdate or something, [now] I wouldn't. I wouldn't do that. I liked in the game where they quickly said 'hey would this be okay?' 'Actually no it's a really silly picture of me [and I don't want] you to do that'. I felt like in the game that perspective was clearly shown, that, like, 'no it's mine'. I thought that was really well done" (t10).

Comparison with children: Teachers had a slightly higher pre-test digital literacy knowledge score $(M=60, S D=5.84)$ compared to children $(M=55, S D=4)$. This suggests that teachers were more knowledgeable about digital literacy issues before playing the game compared to children, which was expected.

\subsubsection{Usage in classrooms}

Overall, teachers had positive comments about the game, and wanted to use it in their classrooms. "So the whole time, while I was playing the game as the example I was, like, this is excellent, I wish this was already available for us to use in our classrooms because what a great tool for us to give them. I think that's great, these kinds of tools are just invaluable to us as teachers in the classroom" (t28).

Teachers thought the game addressed topics that are important and relevant to their students. For example, several teachers stated that the topic of copyright and verifying online information is particularly important. "One of your situations does involve copyright issues. And I was really happy to see that in the game by the way. So awesome about that. In class, that is a specific thing that does come up, is being able to understand that digital 
ownership is a thing, when taking ideas is not $O K$, just as taking something from the store is not OK. Sometimes there is a disconnect between those two tangible and intangible concepts" (t20).

Teachers have limited time to prepare for digital literacy lessons, and are always looking for resources that are informative, engaging, align with their curriculum, and can be easily incorporated into traditional classroom lessons. All teachers felt that the game met these criteria and expressed interest in using it in their classrooms. For example, one teacher stated "Sometimes it's hard to find the right one, that is age-appropriate, targets learning outcomes that we need to reach as teachers, and a lot of times we're just spending hours and hours looking for these resources. There's been times when I really wanted to find an engaging activity for this specific type of thing that I want to talk about, whether it be game, a video, or whatever. And it just does not exist online for what I'm envisioning. So, I might as well make a really cool fancy PowerPoint presentation on it. And [it might] still be as engaging, but I wasted like hours and hours of my time. So I think if the game becomes available to teachers I would really hope that there is a lot of advertisement where like a lot of teachers know about it. Because I'm sure teachers are looking, but we just don't know where to find it" (t17).

\section{Fit with the curriculum}

The game is designed to be used in the thirteen provinces and territories across Canada, and each has their own curriculum requirements for grade 6-8 students. We evaluated the game with a diverse group of teachers from both public and private schools in different areas to determine whether the game met their curriculum needs. Teachers found that the game addresses several core components of the Health, Language Arts, and Technology curriculum. For example, cybersecurity scenarios fit within Health and Technology, while scenarios regarding fact checking information fit within the Language Arts curriculum. One teacher stated "Well it definitely covers some of the stuff as far as the media literacy part, where the kids have to use critical thinking skills when it comes to determining how they're using media. It covers some of the expectations. Well I think the critical thinking section of media literacy is kind of the most important piece there, because that's what I thought the game did the most, it got them thinking critically about the choices that they 
were making. And that's such a key piece for [grades 7 and 8]. So that's the section I'd focus on the most” (t14).

Another stated "The last day really hit home with my curriculum. So talking about looking for those fake news, looking for emotionally loaded language, and stuff like that, all that stuff right out of the Grade 6 curriculum. So I would actually use that because anything that can help us kind of learn those terms, learn biases in media, learn fake news in general. For me that would be my number one, because I think that's less intuitive" (t22).

Since digital technology is used in every aspect of children's school work, some teachers thought that the game could be incorporated into every single subject ranging from Math to French.

\section{Target audience}

Although the game is designed for grade 6-8 students, teachers found the game appropriate for different age groups depending on the digital literacy levels of students in their school. Typically, students in rural and lower-socioeconomic areas have less access to technology at home, so they are less digitally literate than their peers in urban schools. For example, while many grade 6 students in urban schools are starting to use social media, that is not the case in rural schools, where students use social media at an older age. We also found this to be the case in religious schools, where students are more sheltered in terms of their use of digital media. Given this, teachers stated that they would use different parts of the game for different age groups, depending on children's current digital literacy skills, their use of technology, and common issues that they are observing in school.

\section{Using the game in a lesson}

When asked how they would use the game in a digital literacy lesson, teachers expressed several different strategies, reflecting their individual teaching styles. We model the three most common approaches in Figure 6.4. The most common strategies included using the game as a pre-assessment or post-assessment activity in a lesson, or using it as the lesson itself. Some also mentioned using it as a required component that children must complete before getting their technology privileges in the school. Some teachers stated that they 


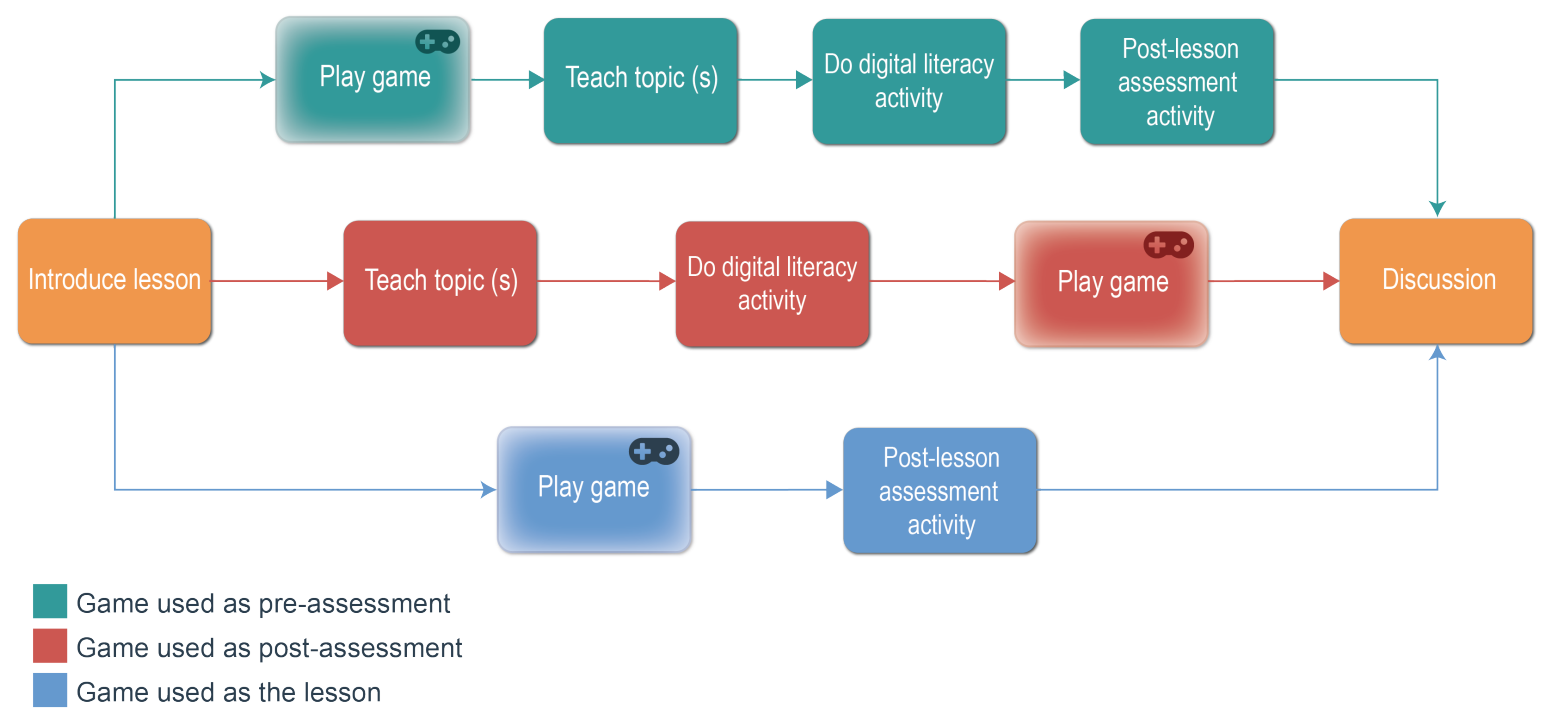

Figure 6.4: Methods of using the game in a classroom

would use it repeatedly throughout the school year to reinforce material that students have learned.

Pre-assessment: Several teachers stated that they would use the game as a pre-assessment tool to evaluate students' current digital literacy knowledge and use the results to design their actual digital literacy lessons. For example, as one teacher stated, if all students are knowledgeable about a topic (e.g., passwords), then that will be excluded from the lesson and the focus will be on other topics that are more important (e.g., copyright). Similarly, if students are not familiar with fundamental topics, then teachers will focus on those instead of teaching more advanced topics. Thus, using the game as a pre-assessment tool allows teachers to optimize their lessons and adapt them to the learning needs of their students.

Some teachers also envisioned using the game at the beginning of the year to get to know their new students and build a rapport with them. For example, one teacher stated “So I wouldn't necessarily use it as a marking or an assessment tool but as a tool for me to target who my priority is gonna be when we work on digital literacy things. Like who seems to get it, especially from a safety perspective. And I think this would be a great activity to do early in the school year because it sets you up to really get to know your students and their digital fluency, for your other digital literacy activities throughout the school year. Yeah so [I'd] start in the first week of school kind of thing. Once a week, we have a conversation about it. It's great because through those conversations you're also getting to know your 
students" (t28).

Post-assessment: Some teachers stated that they would use the game as a post-assessment activity for their digital literacy lesson. After teaching a lesson, students can play the game to practice what they learned. This helps them practice their critical thinking skills by roleplaying different situations in a safe simulated environment. Many teachers liked that the game tracked students' performance and stated that they would need to access this data in order to determine areas of strengths and weaknesses, which would then be used to inform their discussion with students. Most expressed that they would not be able to use the game without this feature. For example, one teacher stated "It would be cool again from a teacher perspective if I could get kind of a summary of areas that were weak. If you've ever done a Google forum quiz or something like that, [it] gives you 'here is the question that most kids failed at'. So that would be really helpful as a teacher for me to then look and see clearly 'when it comes to sharing pictures online, that's a really weak point' and then I can focus on that. But if I notice that all kids really did well at the 'don't put my password' or whatever section, then I don't have to go over that independently. As a teacher, that would be what would make it a good assignment that I would do, an assignment that I absolutely include is something that gives me analytics as to what's weak and what I need to address" (t22).

The teacher evaluation portal that comes packaged with our game provides these features, however, teachers were unable to access it during testing because it was out of scope of our user study. The production version of the game distributed to schools will include this component. Based on our discussions, we believe it will meet teachers' needs.

Traditionally, when creating a digital literacy lesson, teachers create their own postassessment activities. By using the game, teachers can save time in their lesson planning. Some of the post-assessment activities used by teachers include the following:

1. Student(s) role-play a scenario in front of the entire class.

2. Students write a possible scenario, provide the list of choices possible in the scenario, and explain why a particular choice is good or bad.

3. Create a comic strip (e.g., Bitstrips) to depict a possible scenario.

4. Create a poster, and present to other classes in the school. 
5. Complete a quiz by selecting the correct choice for a given situation.

We note close relationships between several of these activities and the game, and can envision ways to incorporate components of these activities and the game into new post assessment activities. Alternatively, the game could be used for pre-assessment, and these activities used for post-assessment.

Game as the lesson: Most teachers stated that they would use the game as the lesson itself (Figure 6.4). They would briefly introduce the topic, and then have students play the game to learn the material. Next, they would review students' performance in the game and have a discussion with the class on the choices they made in the game. We believe that the game on its own is insufficient as a lesson because children have different levels of digital literacy, and need to be introduced to certain concepts before encountering them in the game. For example, some children may be familiar with social media, while others might have little to no direct experience with it.

Teachers may adopt this approach because they do not have the time to create lesson plans. In fact, several wanted to see a teacher guide for the game that includes lesson plans. As one teacher stated "I think if this was to be accessible for teachers what I would really like is a lesson plan, a very general lesson plan. Almost like how to structure this day? How should I introduce it? What's the best thing to do? Is there another video that's really good that describes digital literacy and what copyright means?" (t17). The version of the game deployed in schools comes packaged with a teacher guide, which should help teachers better plan their lessons.

Playing the game: In class, the game can be played individually or in small groups. Teachers stated that playing in groups would be advantageous for ESL or students with learning disabilities who can benefit from working with their peers. For example, a student with low reading comprehension would learn better in a group, where another student can read aloud and help interpret the text in the game. "A couple of the kids I could see pairing up just based on their learning difficulties. I have a little boy that's new to Canada, so his English is pretty limited. I would probably pair him up with somebody else because the language would be difficult for him to understand. There's another girl that's reading at the grade 2 level. I might have her just paired with a friend, but most students could do it on their own" (t1). Limited access to devices in the classroom was also another reason for 
playing the game in groups.

When playing in groups, teachers stated that the optimal group size is 3-4 students, which allows everyone to participate and reduces the risk of students slacking off. However, when access to the required number of devices is possible, most teachers preferred students to play the game individually, either in class or as homework. Most teachers stated that they would include the entire game in their lessons. However, due to time constraints they would only play one day in each lesson. So, the entire game would be played over multiple lessons spanning days or weeks, depending on access to technology.

Some teachers stated that they would only teach specific days in the game that addressed topics of interest to their students. For example, one teacher stated "Definitely the ones about making the right choices based on your friends. That is really important I think. And when you're playing games and things, those ones really stuck out to me like this would be really useful. I think the ones about having phones and turning off your G.P.S. and that kind of stuff wouldn't be as applicable to my kids. Most of them don't have their own phones. I wouldn't really think about that, but it would still be an interesting thing to talk about" (t12).

When the game is played individually in the classroom, a potential risk is that some students may copy the choices of their peers, instead of playing the game themselves. To mitigate this, teachers stated that they may assign different days to students or include other digital literacy activities in addition to the game. So at any given time, some students may play the game while others complete a non-game based digital literacy activity.

Discussion: After playing the game, all teachers stated that they would have a discussion with students about what they learned in the game, the choices they made, and the advantages/disadvantages of each choice. This type of discussion allows children to reflect on their choices, understand why a particular choice was not ideal, and learn from the experiences of their peers. For example, children can compare their choices in the game with their peers and discuss why their peers made a different choice.

This would also give teachers an opportunity to provide additional scaffolding to children on topics that are unclear or require more details. Several teachers stated that an open and safe discussion environment will allow children to share their own personal experiences online with other students, which will make the lesson more relatable. For example, 
one teacher stated that "Like what are they really seeing online but that they didn't think was big enough to tell me. But then they saw this example in the game, we talked about it and what variables would make it different. Then they go 'ding ding ding ding ding: We had a situation like this and this is how it was different"' (t28).

Through discussion, teachers can also explore the game topics holistically and look at each scenario from different perspectives. For example, the game primarily explores each scenario only from the victim's perspective, and does not provide insights into why individuals may engage in negative behaviours online. Teachers noted that it is important to explore these scenarios holistically, especially for situations where children are both the victims as well as the perpetrators. For example, in cyberbullying scenarios the game educates children about what to do if they are a victim or bystander of a cyberbullying incident. However, it does not explore why a child may engage in cyberbullying behaviours. As one teacher stated, this perspective is important to help perpetrators of cyberbullying reflect on their behaviours, understand how it effects others, and makes the lesson relatable for them. "Why would Ben [perpetrator] want to do that? Why would Ben want to abuse this, why would somebody want to have people miss their class because of snow day? Because you're gonna have different kids in each class and some are going to be naturally the kids that want that and don't know a way to get out of it. And this might not reach them because they might be on the other side, [but] it doesn't need to be a lost lesson" (t6).

Teachers stated that they will review students' performance in the game to determine the topics for discussion. They expressed using traditional strategies for facilitating group discussions such as the following:

1. Fishbowl: A group of students discuss a scenario, while others observe. The students around the first group then pick up the discussion and discuss the scenario from their perspectives.

2. Think-pair-share: Students are asked to individually think about a scenario, and then discuss it in pairs.

3. Sharing circle: Students sit in a circle and each person provides their perspective on a scenario in the game. 


\subsection{Discussion}

For educational games to be usable, they need be accepted by teachers who will use them in their classrooms. Our testing of the JOs showed that teachers found the game usable, liked the scenarios, and learned from the game. They also thought the content in the game fit well with the curriculum for their school, and described various strategies on how they would use the game as part of a digital literacy lesson.

Usability: Similar to our user study with children, teachers found the game easy to use, liked the visual design and the characters. They especially liked that the game had a modern look and feel, which contributes to children taking the game seriously. They found the scenarios and the characters authentic and representative of what children may actually encounter in real life. They liked that the game allowed children to explore the consequences of negative situations in a safe and simulated environment. Some teachers expressed that they often focus on teaching children the correct behaviour, but to adequately prepare for the digital world, they also need to be made aware of the consequences of less desirable options. To this effect, they liked the exploratory nature of the game.

Teachers found that going through the less desirable options in the game will promote interesting discussion among children. For the most part, teachers found the number and type of choices provided in the game to be adequate. However, in several situations they disagreed with the choices provided or could not find the option that they wanted to choose. For some of these situations, we found that teachers had incorrect security and privacy mental models, and wanted to make a choice that is incorrect and was not part of our list.

Usage in classrooms: Teachers expressed that they typically have to search for appropriate digital literacy resources that meet their criteria, which is time consuming. Some of their criteria include resources being age appropriate, engaging, and fit within their curriculum requirements. They found that the JOs game met these criteria. All teachers agreed that the game fit within their curriculum. Although, we only tested the game with four of the thirteen Canadian provinces and territories, MediaSmarts has created curriculum connection guides showing exactly how the game fits into the curriculum of each province and territory [191]. Having these guides can increase teachers' confidence in the game, and also help them in their lesson plans.

Teachers described various strategies of how they would incorporate the game into their 
classrooms, which shows that the game is flexible enough to accommodate different types of teaching styles. The most common approaches they described included using the game as the lesson or using it as the pre-assessment or post-assessment for a custom digital literacy lesson they developed. Some expressed that access to classroom technology would determine how they would use the game in a lesson. For example, in one-to-one device schools, teachers expressed that the since each child has access to their own device, they would play the game on their own device and then discuss it with the rest of the class. However, in schools that have access to a limited number of devices, teachers stated that students would play the game in groups determined by the number of devices available. Some teachers also stated they would pair up students based on experience with digital media, so novice students can learn from their experienced peers. While there are advantages to group-based learning, we believe that for the first time, children should play the game on their own if possible. This will allow them to proceed at their own pace and take advantage of the reflection opportunities in the game.

Learning: Teachers' digital literacy improved significantly after playing the game, and they found that it also improved their security and privacy attitudes. Some teachers stated that the game presented situations which they had not thought of before, and they planned to incorporate them in their future lessons. As digital literacy skills needed by children are constantly evolving due to changes in technology, this places a burden on teachers to keep up with the latest threats and update their lesson plans accordingly. Thus, the JOs game and associated teacher guides provide teachers with a starting point of what children need to know according to the curriculum of their school. Teachers can use the game to improve their own knowledge of certain topics before teaching them to children.

Opportunities for reflection: As an experiential learning tool, most teachers expressed that the JOs game can be used to generate discussion among the students. All teachers included an explicit discussion activity at the end of their lesson, where participants will discuss what they learned from the game, the choices they made, and compare their choices with those of their classmates. As teachers explained, this type of discussion is engaging for children and may encourage them to share their own experiences on digital media, so others can learn from their experiences. Teachers described that, in their opinion, peer learning is most effective for teaching children about issues on digital media. 


\subsection{Limitations}

We note several limitations of our study. The first relates to the recruitment of our participants. While we made an effort to recruit teachers from different provinces across Canada, the majority were from Ottawa, possibly employed in schools located in areas of medium to high socioeconomic status. We also note that a disproportionate number of participants taught at private schools. Due to the difficulty in recruiting teachers who met the eligibility criteria for our study, we were unable to control for socioeconomic status and type of school. However, this can be addressed in future work. The majority of our teachers were also female, which may have impacted our results. As we recruited teachers who were experienced and interested in teaching digital literacy, it is possible that the game may be used differently by teachers who have less experience in teaching this subject. Future studies should recruit teachers from schools in different socioeconomic status communities to collect a more representative sample of the user population. Less experienced teachers in teaching digital literacy should also be recruited.

When looking at improvements in teachers' digital literacy from the playing the game, we only evaluated their digital literacy immediately after playing the game, so we are uncertain whether these improvements are sustained long-term.

\subsection{Future work}

In future work, we will recruit a more diverse group of teachers and explore whether gender, socioeconomic status, or experience of teaching digital literacy has an effect on teachers' perception of the game. We would also like to conduct an ethnographic study to explore how the game is actually used in classrooms at different schools.

\subsection{Conclusion}

We conducted a user study with Grade 4-8 teachers in Canada to evaluate the usability of the JOs game. Our results showed that teachers found the game easy to use, liked the scenarios presented in the game, and thought that the game represented authentic experiences of children on digital media. They also liked that the game fit within their curriculum, and were interested in using it in their classrooms. They described various strategies on how 
they would incorporate the game into their digital literacy lessons such as using it as the learning activity or for pre-assessment / post-assessment. 


\section{Chapter 7}

\section{Exploring issues associated with children's media use}

For the JOs game to be effective, it needs to address common issues that children regularly experience on digital media. In our user study with teachers, one of the objectives was to explore whether the types of issues that teachers' observe around children's use of digital media today are still reflected in the JOs, 4 years after its inception. We were also interested in how teachers handle these issues. In this chapter, we analyze relevant data from our user study with teachers to address this research objective. This will ideally give us an indication of the game's continued relevance and provide assurance that appropriate topics were selected, but in either case serves as a type of ground truth by which to view the game.

\subsection{Motivation and research questions}

Prior work has explored the type of risks that children face online, especially on social networking websites [140, 167, 170, 212,303]. However, most research is focused on teens or treats tweens and teens as one user group. As part of the EU Kids Online project, Livingstone et. al [170] surveyed 9-16 year old European children and found that the most common risks encountered by children were excessive use of technology and sexting; cyberbullying, on the other hand, was relatively uncommon [170]. Since tweens are at a different psychosocial development stage than teens, their technology use and risks are also different compared to teens. For example, teens may encounter more online risks and participate in more risky behaviours because they are more technology literate than younger children [281]. Thus, our research specifically explores issues faced by tweens, which is the target audience of our digital literacy game. We explore these issues from the teachers' perspectives, whereas previous research looks at them from the children's perspectives [140, 167, 170, 212, 303]. Teachers play a key role in educating children about digital literacy and are often at the forefront, witnessing incidents, the consequences of incidents, and helping the children deal with issues related to technology. We believe that 
teachers offer a unique perspective. First, as adult third-party observers, they may have a better sense of the situation as a whole and how it evolved for the different participants. They can also reflect on patterns and changes that they have witnessed over time as technology has become ingrained into children's lives.

We address the following research questions in this chapter:

1. OB1-RQ1: What issues are teachers seeing around children's use of digital media?

2. OB1-RQ2: What strategies do teachers use to help students deal with issues involving digital media?

\subsection{Methodology}

As described in Section 6.1, we conducted semi-structured interviews with 21 elementary school teachers across Canada. In this chapter, we only focus on portions of the interview relevant to our current research questions. Specifically, we analyze responses to the following interview questions, although we occasionally draw from other portions if it enriches the analysis.

1. What kind of issues are you seeing around kids' media use?

2. What types of problems are children bringing up in the classroom?

3. How do kids bring up these problems to you or another teacher?

4. How do you (or another teacher) address these problems?

(a) Do the parents get involved?

The audio recordings of the interviews were transcribed using the automated transcription service Trint, and we manually verified and corrected them as needed. We analyzed data from the final transcripts. 


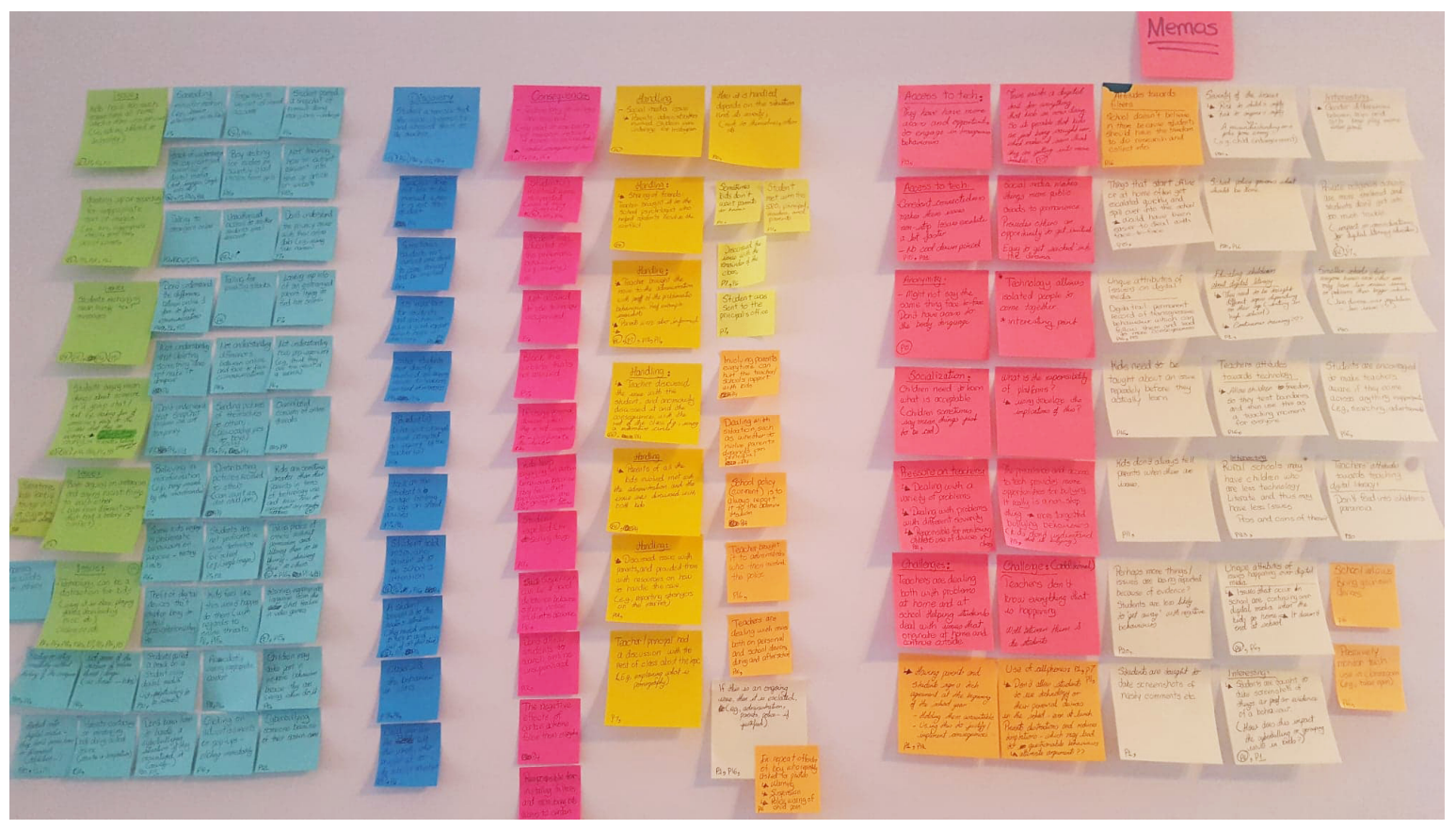

Figure 7.1: Snapshot of our codes organized on post-it notes

\subsection{Analysis}

I used Grounded theory as described by Strauss and Corbin [288] to analyze responses to our interview questions. The process of using Grounded Theory has three main stages: open coding, axial coding, and selective coding. In open coding, data is repeatedly reviewed to create unique categories (i.e., codes) that are emerging from the data. Next, these open codes are reviewed in axial coding to establish relationships between the them. In the final stage of selective coding, the codes and their relationships are used to form a larger theory emerging from the data [288].

\subsubsection{Application of Grounded theory}

I started by printing the transcripts of our 21 interviews. Next, I read through the first 10 transcripts to get a sense of our data. Out of the 10 transcripts reviewed, I selected 5 , and read them in detail, while annotating interesting details within the margins of the printed transcript. In terms of granularity, I read and coded the answer to each relevant interview question, including if the participant provided additional details at a later point in the interview. 
After annotating 5 transcripts, I noticed four categories emerging from our annotated data: digital literacy issues reported by children, teachers' discovery of these issues, teachers' / schools' handling of these issues, and potential consequences that children received by the teacher and/or the school. Next, I coded the remaining 16 transcripts using these four categories. During the coding process, I also made note of any insights or questions that came up, and coded these into the category of memos. In total, I coded 420-pages of transcriptions created from 26 hours of audio recorded interviews.

I wrote each code on a post-it note and organized the post-it notes into the four categories. Figure 7.1 shows the organization of our post-it notes into the categories of Issue, Discovery, Handling, and Consequences. It also shows the memos I identified during the coding process. I reviewed the codes on our list, read the transcripts again, and re-coded data or re-arranged codes within categories as necessary. In total, I created 72 codes. Table 7.1 provides an example of how I coded excerpts of our transcripts into the four categories. I primarily used a paper-based process to analyze our data, but used Microsoft Excel to record meaningful participant quotes as we progressed through the analysis.

I looked at all the codes and categories to identify a central theme through a sensemaking process. I noticed that the types of issues children encountered seemed to be the central theme, and all the other categories were related to this theme. Given this, I asked myself some questions to understand this theme and develop a model. Specifically, I asked "Why do these issues happen?" and "How are these issues different from children's offline behaviours?". After completing the sense-making process, I developed the Behaviours, Technology, and Literacy (BTL) model which captures the central theme of our data. The details of this model are explained in the next section.

\subsubsection{Researcher profile}

I analyzed the data myself. I have a background in HCI (Masters) and Computer Science (BCS), with expertise in usable security. I have taught undergraduate courses in HCI and Introduction to Computer Science. I am also familiar with doing qualitative analysis, including using Grounded Theory. Since I was primarily home-schooled, I do not have personal classroom experiences of being a tween and interacting with teachers. My background may have unintentionally influenced the analysis, however, I tried to remain objective and did 


\begin{tabular}{|c|c|c|c|}
\hline Category & $\begin{array}{l}\text { Number } \\
\text { of Codes }\end{array}$ & Code & Excerpt \\
\hline Issue & 35 & $\begin{array}{l}\text { Exchanging } \\
\text { mean messages }\end{array}$ & $\begin{array}{l}\text { "Lots of kids [are] commenting rude stuff. } \\
\text { [They are] sending each other nasty texts. } \\
\text { The biggest issue is online bullying and stuff." } \\
\text { (t14) }\end{array}$ \\
\hline Discovery & 11 & $\begin{array}{l}\text { Student brought } \\
\text { it to teacher }\end{array}$ & $\begin{array}{l}\text { "When it's gotten too far, the proof will come } \\
\text { into the school. Sometimes there's proof, and } \\
\text { sometimes there's not. It would be like a } \\
\text { screenshot of Snapchat so would be a conver- } \\
\text { sation. And then, when the proof has been } \\
\text { brought forward then you can act on it in a } \\
\text { disciplinary manner." (t11) }\end{array}$ \\
\hline Handling & 15 & $\begin{array}{l}\text { Informed the } \\
\text { principal }\end{array}$ & $\begin{array}{l}\text { "So the group chat was sent to me. The next } \\
\text { step is that I alert the administration right } \\
\text { away. If there is any certain thing, at any time, } \\
\text { that makes my spidey sense go a little bit nuts, } \\
\text { especially since it was documented: 'he said, } \\
\text { she said, you said, you're a b word, you are } \\
\text { not a b word'. So, then basically it goes to the } \\
\text { administration's hands, to be honest." (t6) }\end{array}$ \\
\hline Consequences & 11 & $\begin{array}{l}\text { Tech privileges } \\
\text { revoked }\end{array}$ & $\begin{array}{l}\text { "We had a child one year who was looking } \\
\text { up pretty inappropriate pictures of women on- } \\
\text { line. So we talked with his parents, and then } \\
\text { he was really limited in his usage at school. } \\
\text { He was also told that if he continued he would } \\
\text { lose the use of [his] iPad, and he would have } \\
\text { to use a desktop computer for completing as- } \\
\text { signments which he did not want to do." (t12) }\end{array}$ \\
\hline
\end{tabular}

Table 7.1: Example of how interview excerpts were coded. 


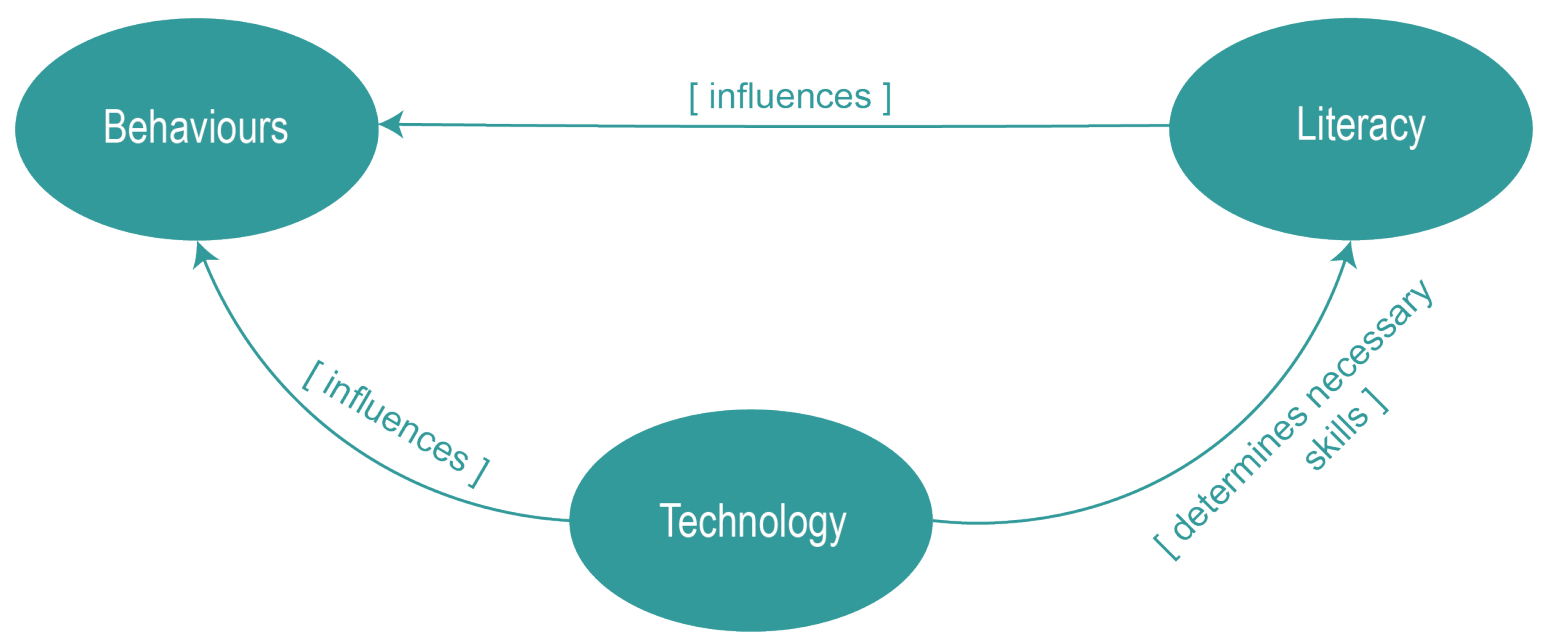

Figure 7.2: Behaviours, Technology, and Literacy (BTL) model

not do the analysis with a pre-conceived theoretical model or understanding.

\subsection{Behaviours, Technology, and Literacy (BTL) model}

During early adolescence, tweens experience major developmental changes which, coupled with their increased use of technology, introduces them to new risks and situations that they must learn how to handle. The Behaviours, Technology, and Literacy model (Figure 7.2) provides an overview of how tweens use technology, the types of issues they may encounter, and the role of teachers. The following is a brief description of each component of the BTL model:

1. Behaviours: As part of their development, tweens are learning how to socialize and build relationships with others. They are also developing an identity that is different from their family [36, 205, 264,293]. During this process they seek out new experiences, opportunities, and individuals in order to figure out who they are and find their place in the world [36, 264]. The Behaviours component of the BTL model looks at distinct issues that occur when children socialize and test their boundaries using digital media. As part of testing their boundaries, children may engage in transgressive behaviours: behaviours that are considered socially unacceptable for children of a particular age group [174].

2. Technology: This component explores how technology affects children's social and 
transgressive behaviours. Technology is the mediator, enabling, hindering, or amplifying social and transgressive behaviours.

3. Literacy: The evolution of technology has created new digital literacy skills that children need to interact safely in the digital world. This component of the BTL model explores several areas of low digital literacy among tweens and their effects on children's social and transgressive behaviours. It also looks at teachers' roles in improving children's digital literacy.

\subsection{Behaviours}

From our data, we found that tweens primarily used digital media for socializing and sometimes engaged in transgressive behaviours. In this section, we describe issues that teachers reported when children used digital media to socialize or engage in transgressive behaviours.

\subsubsection{Social behaviours}

For tweens, peer relationships are extremely important, and they value the opinions of their friends over those of their family [293]. Given the importance of peers, children are also more sensitive to their feedback and criticisms, and try to fit into their peer groups [264, 293]. Common issues reported by our teachers when tweens used digital media to socialize include: cyberbullying, failing to respect the privacy of others, and pulling pranks.

\section{Cyberbullying}

According to the Kids Helpline [152], cyberbullying is defined as "a form of behaviour that is inherently disrespectful of others". Teachers stated that one of the biggest problem they observed was children using digital media to exchange mean messages, make fun of others, fight over friends, or participate in "drama". All these behaviours fall within the definition of cyberbullying and can have serious consequences for everyone involved, especially on the psychological and physical well-being of the victims [122, 237, 289, 295]. Teachers reported that most of these incidents happened over group chats or in private messages, since most tweens are just beginning to use more public forms of social media. 
Spectrum of incidents: We found that teachers reported a spectrum of cyberbullying incidents, ranging from innocent jokes to more serious forms of harassment, such as racist comments being exchanged on social media. We had one teacher share several incidents to demonstrate the range of issues they handle.

As a first example, the teacher stated that "So, only girls involved. There was one student sending a message to two other students where they are just kind of judging them and commenting on something that they were wearing or also on one student's voice as well. Yeah, so like, 'your voice is so annoying' or like 'why would you act this way?' and just passing judgement and it was done through text." ( $\mathrm{t} 2$ ). While seemingly minor, this type of behaviour can be quite distressing to the victim who wants to fit in.

Another incident involved two girls fighting over a friend, in an argument that could have been better handled face-to-face, but they used text messaging instead: "There was a social issue that they could have handled very easily like face-to-face and that was around sharing of friends. We had a new girl join the grade 6 class last year, and she became really close with another girl, and there was just some jealousy around sharing friends and it was just like 'You can have her' and like 'you won and I won't be friends with her anymore'. So [it was] that idea around friendship and that you can have more than one best friend. Sometimes things could be handled really easily face-to-face [by] talking about them at school or approaching a teacher." (t2).

At the more severe end of the spectrum, we heard about public racist comments: "It was two boys, and it actually became a cultural thing. One boy was from Saudi Arabia and the other boy was from Somalia. I don't know enough about the Muslim faith but I know that there was tension historically between those two groups. This is what came out in the classroom, but they were going back and forth on Instagram [making racist comments], but neither family knew that their child had Instagram." (t2). Because this happened publicly over social media, other children were able to view this exchange, and brought it to a teacher's attention, who then informed the parents and the principal. We found that an incident's severity and its effects on children were factors in how teachers handled the incident. The details about this process are explained in Section 7.7.1.

Intent: As opposed to cyberbullying with teens [303], our data shows that most cyberbullying incidents with tweens were unintentional, where the children did not know their 
behaviour was considered cyberbullying. As one teacher stated "I would say that there's a lot more of the targeted bullying behaviour that kids don't even realize is a bullying behaviour at that point because they think of bullying as being beat up on the playground versus somebody targeting you consistently over time which is a lot easier to do over a phone or a computer than it is to do face-to-face.” (t15). Teachers felt that children need more education more about cyberbullying, especially about nuanced situations that may be unclear to them.

Online vs. offline bullying: Consistent with previous literature [306], teachers reported that students who are bullied offline are often bullied online as well. This causes intense emotional distress for these students, as they do not get a break from the bullying. For example, one teacher stated that "One of the boys that would have been targeted pretty well all year long in my class was the target of this cyberbullying incident. He was a lot older than others, and was the only 13 year old we had. He repeated a grade, and has like facial hair coming in and is already being teased in person. So, now when he created his Instagram account name [...] all the other kids just took that as an opportunity to just tease him even further.” (t21).

Our data shows that children engage in behaviours that are considered cyberbullying because they are trying to act cool in front of their friends, or because they may not consider how others would perceive their actions. In some ways, these behaviours resemble typical offline adolescent tween behaviours, where tweens are developing their social skills and learning about socially acceptable behaviours [264]. However, we believe that several characteristics of digital media make these behaviours more problematic. These characteristics and their effects on cyberbullying are discussed in Section 7.6 .

Targets: In most cases, peers are the targets of tweens' cyberbullying. Typically, the bully and the target know each other in real life first. We saw little evidence of tweens harassing strangers they had met solely online. In some cases, educators were the target of children's harassment. For example, a student frustrated with a teacher may post something negative about them on social media. While students have always expressed frustrations about their teachers, traditionally this took place privately in school hallways or outside of school. When these comments are made publicly online, they can have negative professional consequences for teachers as parents and employers may be able to access them. 
One teacher described the following incident: "A student last year had a grumpy day at school, and she posted something really mean about the educational system that I worked with. Another saw it on Instagram, showed it to us and then we had to chat with her, saying 'Hey we see this and [when] you post nasty stuff about us, it comes back to us. Why don't we just have a conversation instead?" ” (t31).

\section{Respecting others' privacy}

Teachers reported that children often violate other people's privacy when using their mobile phones in public. They take pictures of other children without their consent, record private conversations, and share them with their friends. For example, one teacher stated "They take photos of one another without permission. So you know like Snapchat is an app where you can sneakily just take a quick little [photo] and the next thing you know you've sent it to your 10 friends and the person is none the wiser. So they're taking pictures of each other without permission.” ( $\mathrm{t} 21)$.

In some cases, they take pictures of their peers, manipulate them using an app, and share them with their friends as a joke. These behaviours can turn into cyberbullying, when the child in the picture is not part of the joke or did not consent to their picture being taken and manipulated. One teacher described such an incident "A guy took a picture of a girl in class or during somewhere in school that she did not give him consent to have her photo taken. And then he sent it back to her through this like Snapchat, a version of Snapchat. And she was very unhappy with the situation because like it's [an issue of] consent and [this] crosses that [line]. It's almost like manipulating her in a way, like 'oh if you're not my friend then I'll share this photo with everyone,.” (t17).

In some situations, children deliberately disregard the privacy of others, but in other cases, this is unintentional. For example, when children take pictures of themselves on a field trip, they may capture other children in the background who may not want to be included in the photo. Thus, when children are permitted to use their personal devices during school related activities, it places additional responsibilities on teachers who have to monitor how these devices are used. One teacher stated that "I guess toward the end of the year it was a little more apparent when they had a bit more freedom. You know you'd be on a field trip and like sneakily see the phone and it's like, 'he he he'. And in that case 
I would be kind of worried that they're sneakily taking Snapchats or other pictures of the educators as well because they don't seem to see it as very big deal." (t21).

While children are concerned about privacy violations from others, it seems like they are not as concerned when they are the ones violating the privacy of someone else [56]. Since mobile devices allow users to easily record or photograph someone discreetly, it appears that children may be more likely to engage in these behaviours because there is less risk of them being caught. Our data shows that children violate someone's privacy because they are immersed in the moment, do not think of the consequences of their actions, or how others would feel about them. However, when they share a recording with someone else it can be used in ways that they did not expect. As one teacher stated, children need to be made aware of how permanent these recordings really are: "The fact that once they take these pictures, it's a permanent tattoo. Like it just can go anywhere. So even if they deleted [it] off their phone, whether it's a conversation, or pictures, or whatever, it can be out somewhere else, like that they've shared it with somebody or shown it to somebody. It's still out there, they can't pull that back." (t16).

\section{Pranks}

Children use technology to pull pranks on their peers. Joking or pulling pranks is a form of socialization among tweens [74], and is an acceptable social behaviour as long as no one gets hurt. Sometimes, children do not understand social cues, especially in the digital environment, and make jokes that end up hurting their peers. One teacher described an incident where a student sent a message to a friend, pretending to be someone else, which scared the recipient. "A friend thought it would be funny to pull a prank where they borrowed a third person's phone and sent a message that was scary. Like along the Slender Man, Bloody Mary sort of scariness, but because the student who received the message didn't recognize the phone number, they were freaked out and in the end it was a prank.” ( $\mathrm{t} 20)$.

These types of pranks can be upsetting, humiliating, and sometimes dangerous for the intended target. It may cause them further emotional distress if someone takes a photo or video of their reactions, and shares it online. Pranks and challenges are popular on childfriendly websites such YouTube, where content creators are constantly coming up with new pranks, but many of them are dangerous for children. For example, the Slender Man 
challenge mentioned by our participant is an internet hoax which originated in 2010 [243]. In this hoax, users are led to believe that a creepy skeletal figure called Slender Man is real, and can control children's minds to get them to do terrible things, such as kill their friends and family [243]. This hoax was popularized by the collaborative internet community, where users created and uploaded photoshopped pictures of the Slender Man appearing at real places [243]. Since many children watch videos on YouTube [38], they may be exposed to these pranks and challenges, and encouraged to take part in them. To make YouTube safer for children, in 2019, Google introduced a policy to remove dangerous prank and challenge videos, especially those targeted towards children [108].

\subsubsection{Transgressive behaviours}

As their cognitive abilities are still developing, children at this age are more likely to engage in risky behaviours, find rules limiting, and test the boundaries of acceptable behaviours [281]. Due to this, children may engage in transgressive behaviours that can have negative long-term consequences [281]. Since transgressive behaviours go against the social norms of a society, we note that what is considered transgressive depends on these social norms, and these are different for various societies. For example, tweens socializing at the mall after school is considered normal behaviour in Western society, but may be considered transgressive in a society with more conservative social norms. Social norms may also vary across different communities within a larger society (e.g., rural Canada vs. urban Canada). Children are typically aware of social norms pertinent to them. Our data shows that transgressive behaviours exist on a continuum, ranging from minor incidents of children testing boundaries as part of their identity development, to truly problematic cases of disregarding the law or endangering themselves. In this section, we focus on digital behaviours that teachers considered especially problematic such as sexting, looking up sexual content, and talking to strangers online.

\section{Sexting}

Teachers reported that the most common transgressive digital behaviour among tweens was sexting photos. This included sending inappropriate pictures of themselves to others, and requesting inappropriate pictures from others. For example, one teacher described a 
situation where a girl sent inappropriate pictures of herself to several boys "So, it was photos. She had been sending these photos to people, and it's parents of other children who brought it forward. So these kids told their parents that these photos shouldn't have been sent. Like they were provocative photos. And, who knows what she was thinking when she took them. Maybe she didn't see the photos as being provocative because she sees these on covers of magazines and things like that. So then it's bringing her parents in to let them know that their daughter's doing this. So that was dealt with [using] more of an education [approach] on why it is that you don't want these types of photos resurfacing or even being put out there." (t11).

In this situation, some boys received the photos unsolicited and informed their parents. Their parents reported the incident to the school, and the principal met with the girl and her parents. In another situation, a boy repeatedly asked multiple girls to send him nude photos, and one of the girls reported the incident to her teacher. In both these cases, children reported being uncomfortable, possibly because the sexting was unsolicited. However, children's attitudes may be different when both parties engage in sexting willingly. But it should be noted that none of these children have reached the age of consent, so even "willingly" participating is concerning.

Role of police: Schools took sexting incidents seriously and immediately informed children's parents after finding out about an incident. All of the incidents reported by teachers to the police involved unsolicited sexting between children, where a child requested or sent pictures someone else which made the recipient uncomfortable. Under the Canada Criminal Code, sexting in children under the age of 18 is considered distribution of child pornography [222]. Because of this, some schools had a zero-tolerance policy for these behaviours and immediately involved the police while others informed the police only if they deemed that it was necessary. Schools were more likely to involve police if the child engaged in the behaviour repeatedly, distributed explicit photos of someone, or their actions caused severe harm to the recipient.

Schools that immediately involved the police typically had a preexisting relationship with them, where the police regularly came and spoke to the students about sexting and other transgressive behaviours that are considered a criminal offence. A teacher at one such school explained "We have a good relationship with our community police officers 
here. They come into the schools and they do presentations, they do quite a bit of our media presentations especially with the older grades. If you contact them and say 'I'm having some issues with social media, can you come in and do a presentation?', they'll come in." (t14). This type of community engagement activities can help police build a rapport with children, and have them view police as less adversarial. Having a good rapport with children creates an environment where children feel safe asking the police for help when they face risky situations in the future.

Another teacher explained that her school only involves the police if the child engages in the behaviour repeatedly. She described an incident where a boy repeatedly sent nude photos or asked girls from different schools for nude photos. "We had a situation where a boy was sending pictures that were unclothed to other children. And he did it three times, and it was to different children all the time. So after the first time he was suspended and was warned 'you can't do this'. The second time they called the police and said 'you're going to be suspended again you can't do this'. The third time he did it, he was asking girls for lingerie shots, so he thought he found a loophole [because lingerie shots are not considered child pornography under the Criminal code]." (t16). In this situation, the child had a clear disregard for the law and potential consequences for his actions. He repeatedly engaged in the behaviour to push boundaries and figure out how far he could push without severe repercussions. These types of situations are deeply concerning and time consuming for teachers. Some teachers feel responsible for monitoring these children's use of technology at school, to at least prevent them from engaging in the problematic behaviours at school.

\section{Looking up sexual content}

In early adolescence, children begin to explore their sexuality, and may use the internet to search for sexual content. While being curious about sexual topics is a normal part of children's development, our data shows that searching for this information online may expose them to unwanted content and risks if they do not possess the appropriate digital literacy skills and psychological maturity. Several teachers expressed concerns over these behaviours, and described incidents where children looked up this type of information during class. For example, one teacher described an incident: "We had one child one year who was looking up like pretty inappropriate pictures of women online. So we talked with his 
parents and then he was really limited in his usage at school and he was in Grade 4. I think he was just doing it to be really silly and to show everyone what he could do. And then he was also told that if he continued that he would lose the use of iPad and he would have to use a desktop computer for completing assignments which he did not want to do." (t12).

When children look up sexual information online during class, they may inadvertently expose other children to this information, requiring the teacher to explain it to the rest of the class. In many cases, teachers felt unprepared to have these conversations with middle school students. One teacher explained her anxiety about having to deal with these type of situations: "So far as any students talking about anything illegal or anything along those lines, thankfully it hasn't come up but I always try to keep it in the back of my mind, it's just like, 'how am I going to deal with it if that does come up in the discussion'. It frightens me honestly, as the teacher who is teaching digital literacy. The idea of that being a potential thing that is talked about in class, and the fallout from that, does weigh in the back of my mind sometimes. You have to have a game plan. How do we talk about the fact that something horrible is happening? So I think, as you know, sometimes that just happens in teaching so you gotta be prepared." (t20).

\section{Talking to strangers}

Some children talk to strangers online despite knowing the risks of talking to strangers in the real world. Some are looking to socialize with people who have the same interest as them. For example, many children who are interested in games primarily talk to strangers on gaming websites and chatrooms. One teacher described this situation: "They think it's totally fine to talk to somebody on the Internet they don't know, without any research, when they're doing games or things. Although, that being said, they [either] also automatically assume that the persons are totally fine or trying to kidnap them, like there's no in-between. When we did talk about cybersecurity and being safe on the Internet, they assumed someone was trying to kidnap them constantly.” (t12). Some children, especially those with social anxiety, may also talk to strangers because they find it easier to communicate online than have face-to-face communication with people [273]. Another advantage of communicating with people online is that it provides children an opportunity to interact with diverse communities and learn from their experiences. However, this presents risks to children as 
they do not have the necessary digital literacy skills to navigate these environments safely.

Most of the incidents reported by teachers of children talking to strangers online were minor and mostly included children talking to strangers in online communities with shared interests. However, one teacher described an incident where a girl was talking to strangers on social media to find a parent with whom she did not have any contact: "I had a student, her parent was not at all involved in her life, had zero custody over [her]. She was looking for her parent on the Internet, searching her parent's name. She was messaging with people she didn't know, who were much older than her." (t7). This situation, like many cases of transgressive behaviours, highlighted a deeper underlying issue with the child's home life. Having access to technology enabled her to engage in risky behaviour and place herself in a vulnerable situation without full understanding of the risks.

A recent survey by Common Sense Media showed that $61 \%$ of teens preferred to communicate with their friends online, rather than meeting them face-to-face, which shows evolving social norms around children's communication practices [252]. Thus, it is possible that children do not perceive talking to strangers online the same as their parents and teachers. To children, talking to a stranger online may be the same as having a conversation with someone that they have met through shared interests (e.g., teammates, or members of a club). The main difference, however, is that these offline groups typically have some adult supervision, at least during group formation, and it is more easily apparent if the other person is of similar age. However, these checks are lacking in an online environment.

\subsection{Technology}

In this section, we explore the Technology component of the BTL model. Specifically, we look at how three properties of technology affect children's behaviours in the digital world. We also look at how technology is changing social norms, which affect children's behaviours. Finally, we look at some protection mechanisms that schools are using to protect children from digital risks.

\subsubsection{Properties of technology}

Vorderer et. al [305] define the permanently online / permanently connected phenomenon to describe how technology is used in our everyday lives. We are constantly connected 
to technology and frequently use it to move between the physical and digital worlds. In addition, most of what we do online has a permanent digital footprint. We used this idea in conjunction with our data to describe four aspects of technology that affect children's behaviours on digital media. These include public, permanent, always on and always connected, and anonymity.

\section{Public}

The internet allows children to share content with anyone in the world, and also provides them with easy access to a variety of content. While having access to diverse content and being able to share content with others allows tweens to explore their identities, it also exposes them to various risks.

Attention seeking: The need for attention is a basic emotional need for humans [163]. When tweens do not receive positive attention from their families and social groups, they may turn to the internet to fulfil this need [137,242]. The public nature of the internet and social media allows children to immediately receive attention (positive or negative) from large group of people. Our data shows that children may engage in transgressive behaviours online to seek attention from others. They may share controversial content online, talk to strangers online, or engage in cyberbullying behaviours, in an effort to gain attention.

In our user study with children (Chapter 5, several children mentioned that they had seen this type of content from their friends on social media. Teachers also expressed seeing these types of behaviours from children. One teacher described an incident where a girl shared a picture on social media that caused concerns among her friends. "Sometimes I would say it's attention seeking behaviour and sometimes it's a true cry for help. But like them posting things on social media and then what they've posted gets reported back, usually to a teacher or to a principal at school. Like so-and-so took/posted a picture of a pill bottle and said 'I took ten of these'. But then you think 'why did you do this?', but it's not really adding up in terms of true self-harm behaviour. Yes, that is like obviously a big red flag for self-harm, but when you pull back the layers it was more about the parents at home not really paying attention and it was like a test: 'If I post this on Instagram, what's going to happen?' " (t28).

When teachers come across attention seeking behaviours, they meet with the child and 
their parents to figure out the underlying reason instead of focusing on the behaviour itself. For example, teachers stated that sometimes there may be issues in children's home or personal life that cause them to act a certain way on social media. In the previous situation, the girl's social media behaviour was due to her feeling isolated because she was new to Canada and did not speak much English. In this case, technology acted as an enabler: it enabled the transgressive behaviour, and it also enabled the adults in the child's life to recognize that there was an underlying issue.

Status seeking: For tweens, status and approval of their peers is very important [36, 205]. Technology provides children more opportunities to engage in transgressive behaviours, and some children may engage in these behaviours to impress their peers. They may share videos or photos of themselves engaging in these behaviours on social media to show off to their peers. One teacher described an incident where a group of students shared a video of themselves doing drugs on Snapchat. "So we found out through a Snapchat story from another child that someone had been smoking weed in their personal life, but they're in Grade 7, so then we had photos of that. When the school is made aware of something like this, you have to act on it. Then [the school] had to communicate with the student and the family and there ended up being a drug deal [discovered through] an investigation that I was part of. So then we found out that there had been some drugs that had been sold on campus. We started investigating the kid [in this] photo who was doing drugs off campus and then they [were] expelled." (t11). Sharing these behaviours may also encourage other children to take part due to peer pressure, which is an important factor in the lives of early adolescents.

Unwanted exposure to inappropriate content: Children may be exposed to inappropriate content from the internet or from their peer groups. However, being exposed to this content can be traumatizing for children who are not sufficiently psychologically and emotionally mature to understand them. For example, one teacher described an incident where an 11-year old boy shared a pornography video with some of his friends through a group chat. "I had a little boy in my Grade 5 class this year who got himself into trouble watching online pornography and then he started sharing that with all the other little boys in the class. And it was very scary for the little boys who were not ready for that kind of information. And it happened that he was playing an online game and he stumbled upon 
it and then sort of got hooked. And you know because his parents were not watching everything he was doing they didn't know what was going on until it came up in school as an issue.” (t10). The boy may have shared the video to act cool or show off to his friends. However, some of the other boys were not prepared to view such content, and reported it to their parents, who then informed the school. The internet makes it easy for children to inadvertently be exposed to inappropriate content. While this may also occur offline, it is less frequent and typically requires more effort. Sharing that content offline is also more challenging.

Modelling: Tweens often use the internet to explore different interests as part of their identity development. They may join different social media groups or participate in online communities with members who have similar interests as them. For example, many tween boys are interested in online gaming, and participate in gaming communities or chats associated with their preferred game. Since these communities are not exclusively designed for children, the tweens socialize with older individuals from whom they may learn negative online behaviours and language, which the tweens internalize as socially acceptable. For example, one teacher stated 'There's that Roblox game that has 'Briefings', where they'll gang up on other people online. So they see the other people doing it, and they mimic those actions, which is teaching them that it's $O K$ to do that. And usually [they are learning from] older people because you never know who you're playing with online. So chances are you're playing with an 18 year old or older and they've got issues and you're mimicking their behaviour. So I do see a lot more aggression for the kids that are playing games like that." (t15).

When children use these learned aggressive behaviours with their peers, it can lead to cyberbullying situations, where the recipient is unprepared to handle these behaviours. For example, one teacher described an incident between two 11-year olds, which spanned several days and made the recipient physically ill. The teacher stated "A group chat between two Grade 6 students got to a very violent level, and the little girl was throwing up every night and it was just very very scary. And when they were caught, because it was a third party that alerted us to what was going on, the little girls bursts into tears and said 'Oh my God! I'm so happy that you found out'. And you think 'they're 11 years old'. But you read through these text conversations and it looks like you're reading a conversation between 
a bunch of adults. The language was very inappropriate and very aggressive and violent compared to how they would behave in real life." ( $\mathrm{t} 10)$. The children engaged in online behaviour that was not age-appropriate and did not have the skills to disengage. Contrary to older teens, they were relieved to have adults step in to help diffuse the situation.

\section{Permanent}

Everything that children do online leaves a digital trail, which can possibly follow them throughout their lives. Teachers stated that children did not understand the concept of a digital trail, and how their actions online can have long-term consequences.

Misconceptions of the digital trail: Many teachers expressed that Snapchat's popularity with tweens may contribute to their misconceptions of a digital trail. A key feature of Snapchat is that content shared on the app disappears after some time. However, even though the content disappears from the app, someone can take a screen capture of it and share it with individuals other than the intended audience. Teachers stated that many children do not understand this aspect of Snapchat and believe that what they share is temporary. “They think it just goes away. 'I only sent the Snap to that one person', and they don't get it. We've had parents come in with printed text [messages] between kids where it makes it look like this one kid was bullying their kid. Meanwhile [their child] deleted some of the texts back and forth so that their side isn't being shown. But then you get a hold of the other people involved and they have the whole conversation. They don't realize that just because they deleted something it's not really gone. They don't get that. They think 'I can just delete something and then it's gone forever.' "' (t14).

Effects on cyberbullying: Since children's online activities leave a digital footprint, participating in cyberbullying can have possible long-term negative consequences even for the perpetrators. Due to the public nature of the incidents, anyone can participate, which can further increase the intensity of the situation. All these characteristics create an environment where issues can escalate quickly, and children do not have time to think things through before responding. One teacher identified this as the major issue she observed with children's communication over digital media. "I think the biggest problem is that kids are so 'in the moment' [that] they don't reflect. They react immediately without reflecting. And because it goes live and because you can't take it back, they get themselves into trouble. So 
it's not, you know, looking at it, taking a beat, putting it away. They respond right away or they send it right away without thinking. It's there in the moment, it's so quick, it's right there, 'I need to check it'. I think that's the biggest issue." (t11).

Severe long lasting consequences: Sexting can lead to negative long-term consequences for children such as damage to their reputation, cyberbullying, and revenge porn [?, 251]. One teacher from a small town described a sexting incident where a middle school girl sexted a photo to her boyfriend, who then shared it with his friends. This incident followed her through high school and into the workplace, and damaged her reputation and relationships "It follows them all the way through high school and they can't get away from it. The girls that I've known that have had that happen, it's hurt them forever, like all the way through their high school and they've never gotten away from it. To me that's the most harmful thing. It's not like some of the bigger cities, where you can find a different friend group or find a different social group and remove yourself. You can't do that in [town name]. It's going to follow you forever. I've seen people completely socially isolate themselves, like they become an outcast. It hurts all their friendships and their potential future relationships and even employers here start hearing about that kind of stuff." (t14).

Discovery of incidents: While leaving a digital trail of problematic behaviours can have long-term consequences for children, it can also be helpful for teachers in discovering problematic behaviours, so they can intervene and help the children involved. Teachers encourage children to take screenshots of problematic behaviours, and report them to a teacher or parent. Many teachers reported finding out about problematic situations using this method, where a child brought it to their attention and showed them the digital trail. For example, one teacher learned about drug dealing happening on school grounds because a student brought a private Snapchat of these behaviours to her attention. Teachers also stated that having a digital trail or proof helps them handle these situations and deliver appropriate consequences to the children involved. For example, one teacher stated: "one of the things that we talked about was, if ever you're having an issue after school with somebody and it's getting nasty, screenshot it and bring it to school or print it up and show me because then I've got evidence as opposed to you just saying to me, 'Well Sarah said this about me'. OK, but where's your proof? 'Well she said it.' OK, can you show me the text? 'I deleted it.' Well, if I don't have proof, I can't approach her!' ( $\mathrm{t} 1)$. This leads to an 
interesting dynamic where children are encouraged to capture potential 'evidence' on one hand, but are also being taught to respect other people's privacy and to ask for consent. It may be challenging for children to navigate these seemingly contradictory behaviours.

\section{Always on and always connected}

This property of technology represents the state that children are constantly connected to the digital world, and can access it at anytime. Children are receiving information and stimulation from the digital world at all times. This affects children's mental health and their behaviours on digital media [246, 257, 258, 278].

Effects on cyberbullying: Cyberbullying is more persistent compared to traditional bullying, as children are unable to escape it after school. As one teacher stated "We are seeing that the issues coming up in person are not just ending there anymore. They can carry on because for middle school students, Grade 6,7,8, it's very common, especially in our schools, for the kids to all have cellphones. So it just doesn't stop at 3:45 when the school day ends. You see it continue at home through digital platforms. It could be through chat, it could be through Skype, or it could be anything but they don't just stop anymore at school and [it continues when] kids go home." (t2).

Disproportionate use of technology: Teachers reported that children are using technology at a disproportionate rate both at home and school, and this is affecting their performance at school. One teacher reported that children are communicating with each other over text message late into the night, which means they are not getting enough sleep. Because of the always connected property of technology, children are worried that they will miss something important if they step away from their digital devices.

We believe that when tweens spent a disproportionate amount of time on digital media, they are missing opportunities to spend time with their friends and family, and develop key life skills that are required at this age. Teachers stated that their lack of social skills can result in problems in the physical and digital world, when children are interacting with their peers. Most teachers stated that parents are responsible for monitoring children's device usage and, for various reasons, allow them to overuse technology at home. One teacher explained: “I think kids are hooked. They don't necessarily know when to disconnect. And we can get into parenting. We also have parents asking us how it is that they are 
supposed to stop their kids from using the devices at home because it's an issue when it comes to sleeping, when it comes to completing work. It's almost like parents use the word 'addiction'.” (t11).

\subsubsection{Protection mechanisms}

Our data shows that schools and teachers are using various mechanisms to mitigate issues occurring around children's use of digital media. In this section, we highlight two mechanisms commonly reported by teachers.

Policy around use of personal devices: Some schools have created policies disallowing students to use their personal devices during school. This reduces technologyrelated distractions and deters children from participating in drama or cyberbullying while at school. One teacher explained her school's policy “We're not a Bring Your Own Device school so that's one area that we don't really have an issue with. I know that come high school that becomes more of an issue. In our elementary school, it's not. If they have a cell phone, it needs to be in their bag. We don't see it, it doesn't come up in class. If someone uses it in class, it gets confiscated, sent to the office, [and] you go pick it up at the end of the day. I don't like to keep it in my desk in case it does go missing and then I have a parent say 'well it was stolen, you took it from my child, it was stolen from your desk'. If I give it to the principal, it's out of my hands. And then if it gets stolen off his desk, it's not my responsibility." ( $\mathrm{t} 1)$. Even with strict policies, teachers have the responsibility to monitor students' device use and enforce the rules. They also feel extra responsibility given that these devices are expensive and frequent targets for theft.

Schools that allow personal devices at school moderate their use to prevent situations that may result in cyberbullying. For example, a drama teacher had a no "cell phone" rule for her class to prevent children from taking embarrassing videos of their classmates. She explains "We have lip sync battles coming up, and for lip sync battles we actually get the kids to put their phones away and we say 'we want you guys to be here in the moment'. We don't want it to end up on social media because we're going to make fools of ourselves, and we're going to be really in the moment with you and even the teachers are doing one. And I don't want it on social media." (t11). The teacher created this rule based on her previous experience, where a student recorded an embarrassing video clip of 
another student's performance and shared it on social media. Without clear policies, the onus is placed on teachers to regulate device usage and create appropriate rules for their classrooms.

Filters: Some schools have implemented filters to prevent children from visiting certain websites or looking up certain keywords, while others find that these limit children's intellectual development. Teachers had mixed reactions of these filters. Some use it as a tool to minimize distractions in their class, and to manage student behaviours. Other teachers felt that the filters are not representative of the real-world, where children are able to freely explore the internet. One such teacher stated that "We don't have filters in the school system, because I believe the school board thinks the kids should have that freedom to do that research or to collect that information. As educators, we have to be proactive and let them know that there is no firewall or there is no protection. 'You could end up where you don't need to be or you shouldn't be'.” (t16). The debate here revolves around whether children should be kept in a digital "walled garden" to protect them or be given freedom but taught coping skills, recognizing that some mistakes will be made.

\subsection{Literacy}

The Technology component of the BTL model includes issues that teachers are seeing around children's understanding of how to use technology. It also looks at how technology literacy affects children's social and transgressive behaviours. Teachers reported that around Grade 4, children start to use more technology for school work, which introduces new issues that teachers have to mitigate.

\subsubsection{Technology literacy}

Teachers reported several areas where children's technology literacy skills were lacking, and it affected their school work. These include searching for information, detecting misinformation, understanding ownership and copyright, password practices, and understanding of online threats. 


\section{Searching for information}

Children use search engines to do research for school projects. However, teachers stated that most do not know how to use them correctly, and this can accidentally expose them to inappropriate content. For example, one teacher explained that children prefer to use an image search instead of text, which is more likely to show inappropriate content. "I noticed that when they are Google searching something, they will almost 100 percent of time do an image search for anything, which can be a little bit dicey at times. You never know what's coming up. I had a little girl doing a report on Gentoo penguins. She just started image searching, so we had a big lesson about that because I said to them 'What are you expecting to find for images? What information is that going to get you?' And they seem to think that if they find an image that they like then that website will be great." (t12).

Since children's reading skills are still developing, they may prefer using the image search because it is easier to review the results of the search compared to using the textbased search. Our teachers explain that when analyzing the results of their search, children are cognitively overloaded by the variety of options and are unsure of how to choose the best option, which is consistent with findings from previous research [63]. Children need to learn how to differentiate between reliable and unreliable sources of information. One teacher described a situation where children were unable to differentiate between advertisements and search results when they were looking up information for a bank: "We have all this information coming at us that they're like, 'click on it!'. When they first saw the pop-up, they were like 'Look what I found!' And I was like, 'Well, do you know what that is? You didn't find it'. They didn't know it was a pop-up aimed at them. They thought they searched and that's what they got as a result of the search. Kind of is, but it was aimed at them, rather than finding it." (t7).

These findings suggest that although children are digital natives, they still lack fundamental computer literacy skills, such as composing useful searches, analyzing search results, and determining the reliability of online information. In classrooms, these skills are often taught as part of another lesson that requires children to use a computer. For example, one teacher incorporated it into her Math class. As a group, the class used Google to find information about interest rates. The teacher mediated the experiential activity, helping students learn to create keywords, perform a search, and navigate the results. 


\section{Detecting misinformation}

Teachers reported that a common issue among tweens is that they fall victim to misinformation online, and share it with their peers. According to our teachers, the latest significant case of misinformation aimed at children online was the Momo challenge, which became viral in 2019 [121, 255, 261]. This was a hoax, where people were led to believe that a creepy doll named Momo randomly appears in YouTube videos and encourages children to commit suicide. Teachers reported that children were hearing about this challenge, and were scared that Momo was going to appear and cause them harm. One teacher described that "The Momo was a big topic for a long period of time and how kids were believing stories that were about Momo that was true or not true. Lots of kids took it very seriously and then a couple weeks later, we realized it was just a hoax. But some kids were genuinely scared that maybe one day while they're watching YouTube or while they were like talking to their friends, Momo would show up on their screen and would encourage them to commit suicide." (t17).

The Momo challenge became a viral sensation due to media coverage and many parents believing it to be true. In this case, the adults believed the misinformation, and propa-

gated unnecessary fear in children. The responsibility then falls on teachers to correct the misinformation, and reassure children. Some teachers said that they stay informed about dangerous viral challenges and proactively discuss them with their students. Others are more reactive, and address issues as they come up in the classroom. Several teachers designed lessons to proactively teach children about misinformation online. For example, one teacher designed a lesson using the Save The Northwest Pacific Tree Octopus hoax website [317]. In this activity, children are provided a hoax website, and are asked to assess the reliability of the website. Many children fall for the hoax and believe that the Pacific Tree Octopus is real, which leads to an informative class discussion.

\section{Ownership and copyright}

In Grades 4-6, school projects involve using information from websites, blogs, and multimedia. Teachers reported that most children do not understand how to properly reference information from websites. For example, one teacher stated "They're still not fully understanding what plagiarism is. They're not really understanding that they can't just copy and 
paste from a site and put it in their report. So that's kind of a big challenge, teaching that and finding the resources to say how we do this" (t7).

Teachers described several incidents where students plagiarized entire essays because they copied information verbatim from a website. Sometimes, this was the result of them not understanding copyright rules, and other times they did it knowingly with the hope of not being caught. Students primarily learn about copyright and plagiarism in their Language Arts classes, and through librarians in some schools. For example, one teacher explained "Every single class has library time each week and it's just not for checking out books. Our librarian is running classes on teaching students about different media literacy and digital citizenship issues. So, she is running workshops on teaching them about plagiarism, citing, or how to find reliable sources" (t2). Teachers are always looking for engaging ways to teach these concepts to children, and several noted that the JOs game would be an effective resource.

\section{Password practices}

In middle school, each student is assigned a school email account used to communicate with their teachers and classmates. The use of email introduces children to new cybersecurity risks. The common issues teachers observed included students sharing their passwords with others, using default passwords, and clicking on suspicious email links. When default passwords were used or shared, students reported that other people were accessing their account and sending emails on their behalf. Some students did this to prank their friends. The children lacked good password management practices and sometimes underestimated the consequences of not protecting their accounts, particularly against targeted attacks by acquaintances.

Students might be learning poor password management practices from their teachers, who often create a large number of student passwords for applications used in their class. In these cases, teachers use a predicable pattern to create passwords or create the same password for everyone, which allows a student easy access another student's account. For

example, one teacher stated "I did that with one of my Read Theory things and I gave them all the same password. Then they started going 'Well what if I log in as this other person', so that became an issue. Now for everything else we have our own passwords. 
But yeah I kind of did that and thought 'yeah I shouldn't be putting passwords on the whiteboard'." (t12).

Some schools are one-to-one device schools, where each student is provided with their own device (e.g., iPad or laptop) to use at school. However in most schools, students share devices with other classes. In these schools, teachers reported that students often forget to $\log$ out of their accounts, and this allows the next user to access their account. It is possible that students forget to log out because they do not have to do this step on their personal devices at home.

\section{Understanding of online threats}

A common concern among teachers was that children do not understand the full spectrum of possible online threats. Some children trust everything and everyone online, and engage in risky behaviours, while others have an exaggerated interpretation of threats, which prevents them from exploring the online world. One teacher stated that "The students, especially in the younger grades, tend to have an over-inflated concern with some threats and I think that comes from parents, adults, media. They seem to have a very focused idea of what an online predator might be and it always seems to be a 60 year old man somewhere in the woods. They have a very stereotypical person in their head who is preying upon children, so they're blindsided by a story of a younger person taking advantage of people online" ( $\mathrm{t} 20)$.

\subsubsection{Teacher roles}

Teachers play an important role in improving children's digital literacy. Our participants reported several strategies that they use to improve these skills in children and protect them from online risks.

\section{Developing workshops}

Teachers and schools employ various strategies to prevent cyberbullying incidents. Teachers stated that most cyberbullying incidents occur because children lack proper interpersonal and social skills to communicate with others. Thus, they believe that focusing on developing these skills is key to mitigating cyberbullying incidents. One teacher worked 
with the school psychologist to develop a workshop for Grade 6 students. She stated that "We are doing some workshops, which is around social skill building and how to interact with friends, so it will be helpful for that group. We have a great school psychologist who comes in 2.5 days a week. That's part of my job too, as I am the student life coordinator. So the two of us have identified this as a need for Grade 6 around social dynamics: How do you solve social conflicts? How do you treat one another? How do you act face-to-face? How do you act online? So we are gearing a workshop on those needs and we [will be running it] next week" ( $\mathrm{t} 2$ ). Another teacher also expressed that children should be taught how to be nice to others, and not say things online that they would not say face-to-face.

\section{Community learning experience}

After an incident, many teachers reported having a discussion with the entire class about the problematic behaviour and discussing prevention strategies. In these cases, teachers used the incidents as teaching moments, because they found that children learn best from the experience of their peers, as they can relate to them. For example, after a sexting incident, the school had a broader discussion with the entire class: "Last year we had a student in Grade 6 sending naked pictures of herself to some boys in the school. And obviously, one of the boys finally came to a teacher and said 'hey this is going on'. So we approached the parents, 'guys like this is an incredibly serious matter'. We brought in a school resource officer, and had a whole kind of conference as a school, not just for this one student, but as the school, on what that can look like, what kind of effect putting something online or putting something through an app, even an app like Snapchat that deletes it. How that can be something that sticks with you for the rest of your life. And so I think it was a really good opportunity even though obviously the reason for it was pretty awful." (t22)

\section{Using guest speakers}

Some teachers stated that children may have an exaggerated sense of threats because of what they hear from the media and their parents. However, this may also be happening from what they are hearing at school from their teachers or invited speakers. Some schools invite speakers such as local police officers and cybersecurity experts to talk to children about online safety. These speakers, especially police officers, seem to focus on more 
serious threats and behaviours that are considered criminal. For example, they may focus on sexting and online predators. A disadvantage of this approach is that it can scare children from going online and may cause them undue anxiety. As an educational method, it does not create a safe space where children can freely discuss their concerns and experiences, and learn from each other. One teacher described an event where the speaker left the children feeling overwhelmed "[The children] talk about it for a long time afterwards. It's usually quiet [during the lesson], like 'that's scary' or 'that's wrong' or 'that was embarrassing' or 'I hope that doesn't happen to me'. The [speakers] that have come in the last two years probably haven't been quite so direct as the previous guy was. We have two new guys who are doing it. But still, it seems to have much more of an impact than a classroom lesson that I would do.” (t14).

Teachers like the guest speakers because they feel that students need to hear this information from a third party instead of parents and teachers. "What I like about it is sometimes you know, I can talk to it until I'm blue in the face and they get sick of hearing me after about the first month. They hear me say the same stuff time after time. So hearing it from somebody else, sometimes makes a bigger impact, especially if it's somebody that they're taught to have respect for, like the police. I like that they can talk about the legal aspects, and they often give very specific local examples without naming names. But some kids are anti-police and when the police come in and talk about the legal aspects it just kind of adds to their distrust of police." (t14). These speakers may also be used in schools where the teachers do not have the knowledge or training to teach children about online safety. However, it is unclear whether they are actually effective at improving children's online safety behaviours.

\subsection{Discussion}

Tweens' digital and physical worlds have become increasingly intertwined, and they must learn to navigate between the two seamlessly. Specifically, they are using technology at home and school for work, entertainment, and socializing with friends. In this chapter, we created the Behaviours, Technology, and Literacy (BTL) model to conceptualize the issues that occur in tweens' use of technology from the perspective of middle school teachers. In this section, we offer some reflections on our BTL model. 
Teachers reported a spectrum of problematic behaviours observed among tweens, ranging from innocent jokes to behaviours causing serious harm to themselves or others. We classified these behaviours as either social or transgressive. Social includes problematic behaviours that occur when tweens use technology to socialize with their peers. These include cyberbullying, not respecting the privacy of others, and doing pranks. Transgressive includes more serious problematic behaviours that occur when tweens use technology to engage in socially unacceptable behaviours. These include sexting, looking up sexual content, and talking to strangers online.

Some of these behaviours are a natural part of tweens' psychosocial development. However, many are the result of new and evolving social norms that are created by technology. For tweens, some examples of new social norms include: understanding the rules of communicating over digital media, understanding the difference between a private and public identity, and knowing appropriate online sharing practices. Many incidents reported by teachers occurred because children had difficulty navigating these new social norms. For example, children might make fun of someone in a private group chat because they believe the conversation is private but someone else in the group chat may make the conversation public at anytime. Thus, children need to learn the new social norm of communicating on digital media: there is a digital trail, so they should not say anything online that they prefer be kept private.

Other issues, such as still developing overall social and emotional skills, are exacerbated by having constant access to technology. For example, a lack of emotional regulation skills can cause children to be reactive on digital media, because there is no cool down period between experiencing something upsetting and reacting to it. This can lead to increased interpersonal conflicts between children, as they respond in the heat of the moment, without thinking of its long-term consequences. The lack of self-regulation skills also contributes to children's overuse of digital technology. Several teachers reported that children overuse technology at home because their parents are not setting boundaries and teaching them self-regulation skills. These skills are increasingly important for children because digital technology has addictive properties [144,209,316] and can negatively impact children's physical, emotional, and mental health. Several teachers described situations where children were sleep-deprived because they were texting their friends late at night. 
Technology also introduces new digital literacy skills that children must learn to stay safe online and adeptly use technology for school. These skills include learning to use a search engine, detecting misinformation, and understanding ownership and copyright. Children use the internet for research in earlier grades at school, which means they need to learn the relevant technical skills as well. Teachers stated that ownership and copyright is particularly difficult for children to understand and they need to be taught about it several times in different grades. Poor understanding of these issues can result in children accidentally plagiarizing essays, which can have serious consequences for them, especially in higher grades. Teachers also reported that some children have incorrect mental model of online threats and attackers. Having incorrect mental models and not possessing the required digital literacy skills to safely navigate the digital world can cause anxiety in children, as they feel unprepared. For example, teachers reported that some children feel anxious about encountering cyberbullying online because they are unsure how to handle it. In summary, technology introduces new literacy skills that children must learn to prevent certain problematic behaviours and exposure to online risks.

Teachers felt that they have been given the primary responsibility for teaching these digital literacy skills to children. In addition, they also help children deal with various problematic situations and behaviours on digital media. They use several techniques for teaching digital literacy, including guest speakers, hands-on activities, and community learning opportunities. They also use digital literacy resources provided by organizations such as MediaSmarts and Common Sense Media. However, they stated that the most effective approach for teaching digital literacy is peer learning. Since peer relationships are important for tweens, teachers found that children learn the best from each other's experiences. Thus, they aim to create and facilitate learning environments that encourage sharing. Teachers also focus on building relationships and good rapport with their students, so the children feel comfortable confiding in them about a problem and seeking help. When children engage in problematic behaviours online, they may not ask for help because they fear the repercussions from adults. For example, a teacher described an incident where a girl who was cyberbullied was afraid to ask for help because she had used inappropriate language in the exchange, and was worried about getting in trouble. To maintain a positive rapport with students, teachers prefer to deal with these relatively minor incidents on their own rather 
than involving the school's principal or administration. In cases that are escalated to the administration, teachers prefer not to be involved in the actual handling of the situation.

Thus, teachers have a great amount of responsibility in helping children navigate the digital world. With tweens, these issues cover a wide spectrum, requiring teachers to have a broad understanding of how children use digital media. In general, teachers are children's support system, confidant, and a source of advice and guidance when it comes to using digital media. However, despite this level of responsibility, teachers reported that they often feel unprepared for this role. Most of the teaching they are doing is reactive rather than proactive, and they are learning on the job. This is partly due to the evolving nature of technology, requiring teachers to keep up-to-date with the latest threats that children may encounter online. We found that more experienced teachers (i.e., 10+ years of teaching) felt more confident in dealing with uncertain situations than less experienced teachers. Inexperienced teachers reported feeling anxious about having to help students with particularly problematic situations in the future. Similar results were found when it came to teaching digital literacy. Teachers reported not receiving any pre-service training to help them in their role, and more experienced teachers had more effective techniques for teaching digital literacy than inexperienced teachers. Some teachers used their own social media to stay informed about the latest online threats, and then discussed these with students. Overall, teachers reported needing tools to help teach digital literacy to their students. We believe that our JOs game can help with this by saving teachers time required to design lessons, so they can spend more time on delivering the lesson and helping students.

\subsection{Limitations}

We note that our Behaviours, Technology, and Literacy model is based on qualitative data from a small sample of 21 middle school teachers in Canada. Thus, the findings cannot be generalized to the larger population of all middle school teachers. Furthermore, since we recruited teachers experienced at teaching digital literacy, it is possible that their views may not be representative of all teachers who teach digital literacy. 


\subsection{Conclusion}

We conducted semi-structured interviews with 21 Grade 4-8 teachers in Canada to understand issues that teachers face around children's use of digital media and how they help children resolve these issues. We also looked strategies that teachers use to educate children on preventing these issues in the future. We analyzed our data using Grounded Theory, to build the Behaviours, Technology, Literacy model (BTL). The BTL model conceptualizes the issues around children's use of digital media, and the teachers' role in helping them. Specifically, our model shows that the issues children experience are influenced by technology and the changing social norms. The technology also determines the type of digital literacy skills that children need, and teachers are primarily responsible for teaching children these skills. 


\section{Chapter 8}

\section{Discussion, future work, and conclusion}

In this chapter, we review our main research goal and then provide some preliminary reflections on the process of designing, developing, and user testing the JOs game. These lessons learned may be helpful for future designers and researchers in the area of digital literacy. The chapter concludes with a summary of the contributions to this thesis.

\subsection{Addressing our research goal}

Our main research goal was to design and develop an effective and empirically validated digital literacy game for tweens, meant for use in the classroom. Our secondary goal was to explore whether procedural rhetoric is an effective strategy for digital literacy games. We first designed and developed the JOs game and reflected on its design through the lens of procedural rhetoric. We then evaluated the game with children and teachers, and looked at issues of digital literacy from the perspective of teachers.

\subsubsection{Acceptance by children}

Our user testing with children showed that children found the game fun, and liked the realistic situations portrayed in the game. Their digital literacy knowledge and behavioural intent improved significantly immediately after playing the game, and the learning was sustained one week later. Children appreciated certain aspects of the game that can be attributed to procedural rhetoric. For example, they liked the anticipation of waiting to see the consequences of their actions. They found this aspect of the game enjoyable, which made learning the digital literacy content fun. They also liked the exploratory nature of the game, and trying out different things to see different outcomes. This aspect of games is what makes them truly effective as a learning tool. It was important for our game to be accepted and enjoyable by children. When children are engaged and invested in the game, it leads to better learning outcomes because they are willing to invest the time in the 
learning activity [97]. We believe that children's engagement with the JOs, contributed to their improved digital literacy scores after playing the game.

\subsubsection{Acceptance by teachers}

Our evaluation of the JOs with teachers revealed similar results. Specifically, teachers found that the situations portrayed in the game reflected children's actual experiences with digital media. They also found the game engaging, and thought their students would enjoy playing the game. Teachers appreciated specific aspects of procedural rhetoric in the game, such as feedback and the experiential learning environment. They liked that the game offers feedback, which allows children to reflect on their choices. Many teachers considered debriefing an important part of their lessons, and planned on using the feedback provided by the game to have further discussions with their students. Recent research with teachers in the US showed that in order to be accepted, cybersecurity educational tools for classroom use should highlight teachable privacy and security moments, and incorporate privacy and security features that meet educators' needs [160]. Our teacher feedback about the JOs by teachers suggests that we have created such a tool.

We note that children and teachers have different acceptance criteria for educational games. For children, the most important factor is whether the game is fun. Regardless of the educational content, children are unmotivated to play games that are not fun. Teachers recognize this but they also value the game content, which must meet their curriculum and learning goals. They need to use the game within the constraints of a typical classroom lesson. Teachers found that the JOs adequately met their learning goals for digital literacy. Teachers often frame lessons around issues that they are observing from their students' use of digital media. Teachers reported that recent issues they find concerning include cyberbullying, respecting the privacy of others, and copyright and ownership. These topics are among those addressed by the JOs game. Our game also provides a modular design so that MediaSmarts can easily add new topics with no programming effort.

The JOs supports the digital literacy curriculum requirements of all thirteen provinces and territories in Canada. Teachers specifically appreciated this aspect of the game, and indicated that they often struggle to find relevant and engaging digital resources that also meet their curriculum needs. Many of the popular resources that they have seen are US 
based (e.g., Google Interland [109], Common Sense Media [188]) and do not align with the Canadian curriculum. Teachers described various strategies of incorporating the game in their lessons, indicating that the game can accommodate different teaching styles and meet diverse classroom needs. Overall, the teachers in our study positively perceived the JOs game and wanted to use it in their classroom. However, we acknowledge that a selection bias of participants may have skewed the results in favour of the game. Specifically, we recruited teachers who were interested in digital literacy and their participation in the study may indicate that they are in favour of using educational games. Thus, teachers who have unfavourable views of educational games may have different perceptions of the JOs. For these teachers, we hope that the alignment with the curriculum and the teacher guides (including lesson plans) developed by MediaSmarts, would make the JOs an appealing educational tool.

\subsubsection{Procedural rhetoric approach}

Aligning with procedural rhetoric, we tried to create an environment where children can explore meaningful digital literacy scenarios and gain an understanding of the consequences of their actions. Our game shows that simple game mechanics and narrative as advocated by procedural rhetoric can effectively teach children about a complex issue such as digital literacy. In most cases, security and privacy cannot be adequately defined by a set of rules; situations are nuanced and we need children to develop empathy, awareness, vigilance, and an ability to weigh the potential consequences of their actions.

The game helped children become more conscious of their decisions, even for topics that they had not yet learned, since each child answered pre/post questions relating to all topics regardless of whether they had viewed that scenario. We believe that our procedural rhetoric approach was at least in part responsible for this shift in mindfulness. The children were overall more conscious of their actions after game-play, and several families reported that the game led to conversations about online security and privacy issues. Given these positive outcomes, we believe that procedural rhetoric is an effective approach for children's educational games addressing such nuanced subjects, at least for this age group.

Our game used simple game mechanics and an engaging narrative, and was effective at improving children's digital literacy knowledge and behaviour after being played for a short 
time. The simplicity of our game allows children to focus on the persuasive message of the game instead of being distracted by complex narrative or game mechanics. This also means that the game can easily be played by children with different gaming experience, which is particularly important for educational games. In our summative user study, many children who did not regularly play games were able to play the JOs without any difficulties.

\subsection{Collaborating with MediaSmarts}

We designed, developed, and deployed the JOs game in a 4-year collaboration with MediaSmarts. In this section, we discuss the advantages of this collaboration, its impact on the design of the JOs, and recommendations for future designers.

Advantages: An advantage of interdisciplinary design teams is that each member provides a unique perspective to the project. For the JOs, the MediaSmarts team included educators who provided insights into teaching digital literacy in schools, which helped shape the game requirements. For example, they helped choose the game topics and advised on the technical requirements based on the technology available in schools. We believe that the JOs was positively received by teachers in our user testing because it adequately met their needs which were represented by the educators on our design team. Without MediaSmarts, it would have been considerably more challenging to include teachers on the design team full-time. MediaSmarts also had the experience and expertise of deploying educational games to schools, so we were able to leverage this to deploy the JOs to many schools across Canada.

Impact on game design: During the design of the JOs, we had to balance the requirements of different groups, such as MediaSmarts, teachers, and the children, along with our research agenda. As such, sometimes compromises were made to the design in order to satisfy another more important requirement. An example of this was the number of topics addressed by the game. MediaSmarts needed the game to address several different looselyrelated topics to improve their ability to license the game to a large number of schools. This limited our options in terms of the type of design we could choose for the game. We needed something that was flexible enough to accommodate all 25 topics. We selected a narrative based design because it allowed us to create a custom narrative for each topic. Another factor in choosing this design was MediaSmarts' prior experience in designing and deploying 
narrative style games. Our iterative design approach was helpful in designing the narratives for the topics. If a suitable narrative could not be designed for a particular topic, then we replaced it with another topic approved by the design team.

Recommendations: We provide several recommendations based on our experience of designing the game in collaboration with a non-academic partner.

1. Create shared goals: We believe that for this type of collaboration to be successful, all parties must specify their individual goals for the game, and then create shared goals before beginning the design activity. We had several meetings to clarify the goals for the JOs game. MediaSmarts had important practical goals such as being able to complete a production quality game within a specific timeline, crosscompatibility requirements, and being involved in the design activity. We had specific research requirements, such as using an iterative user-centered methodology, respecting established game design principles, and relying on empirical evaluations. MediaSmarts understood the value of our goals, and approved the methodology. We worked together to create the timeline for the design activities so that it respected both ours and MediaSmarts goals.

2. Choose appropriate collaborators: We were able to significantly influence the design of the JOs due to nature of our relationships with MediaSmarts. Although, MediaSmarts was the owner of the game, they treated us as an equal partner and valued our ideas and feedback. We note that this may not be case for other collaborations, where the owner of the game may make the majority of design decisions. Our recommendation for researchers and designers is to choose collaborators based on how well they fit your design approach. We believe that a positive relationship with the collaborator is key for long-term projects such as the JOs.

3. Manage technical requirements: We recommend using a process to manage changes in the technical requirements for the game. While design is an iterative activity, we recommend creating some high-level requirements for the technical design and development. For the JOs game, we found that some of the technical requirements kept changing as the project progressed, which significantly increased the development time. An example of this is cross-compatibility requirement, which changed from 
a few web browsers to a more comprehensive list of web browsers, platforms, and devices.

\subsection{Application of game design principles}

\subsubsection{Meaningful choices and scenarios}

The game choices and narrative allowed users to gain a more thorough understanding and be more mindful of the digital literacy issues, including privacy and security. We used established game design principles [27, 97, 262] to design choices such that both the "right" and "wrong" choices were meaningful for children, reflecting real-life situations where the line between right and wrong is unclear. While the game nudges children towards more desirable security and privacy-conscious behaviours by offering more positive outcomes for these choices, the "wrong" choices help children understand the main message of the game by demonstrating possible negative consequences and encouraging reflection.

We spent significant effort into devising realistic, relatable situations to engage players and have them be invested in the game outcomes. Some scenarios required the main characters to engage in negative behaviours (e.g., sharing someone's photo without permission). To make these scenarios relatable, we framed them to represent situations where the characters accidentally engaged in the behaviour without malicious intent. Our intent was to encourage children to develop empathy for the characters, and understand how children their age could engage in these behaviours. Thus, by playing the game, we encouraged children to learn how to avoid these behaviours and also develop an understanding, empathy, and tolerance for individuals (e.g., friends) who might inadvertently engage in them.

\subsubsection{Characters}

Characters in our game were part of the narrative, which persuaded children's digital literacy behaviours in the game. For the game to be effective at persuading children, it was important that they had positive associations with the game characters, otherwise they would be less inclined to learn from them. To facilitate positive associations, we chose two main characters so both boys and girls could relate, and designed them to be representative of 11-13 year old children. When using them in game scenarios, we made sure that both Jo 
and Josie were represented equally in situations where they were the victims of negative behaviour and situations where they had an opportunity to practice negative behaviour. While children had an overall positive perception of the characters, some showed a same-gender preference for either Jo or Josie. Some boys expressed that they would be friends with Jo and not Josie and the girls expressed a similar preference for Josie. We similarly tried to include diversity in ethnicity, abilities, and appearance among the secondary characters. Based on our participants' positive reactions, we believe that this diversity helped make the game more relatable.

\subsection{Designing digital literacy games}

Security and privacy are key digital literacy topics. Designing educational material for these topics presents some unique challenges. First, security advice keeps changing due to the evolution of attacks and introduction of new threats. Thus, we simply cannot educate users about the correct behaviour once, as in other domains such as health (e.g., brushing teeth), and need to constantly re-educate them. This requires users to unlearn certain behaviours and re-learn new behaviours, which is difficult for adults let alone children. Thus, in addition to teaching correct behaviours, security games need to develop critical thinking skills in children which they can use to deal with new types of attacks.

Some digital literacy topics, such as privacy are nuanced and do not always have a correct answer, so it requires users to learn and understand the consequences of different choices, some of which may not be apparent for many years. For youth, an example of this is sharing questionable pictures on social media. A potential consequence of this action is that it might affect their employability, as employers often take social media profiles into consideration during the hiring process [43, 105, 119, 158, 201, 254, 279] or admission to university [101,245, 274]. Because this consequence is so far in the future, it can be difficult to persuade youth to change their current behaviour. In real life, some security and privacy situations have multiple reasonable paths, while others provide choices where each choice has different benefits and risks. In these cases, the best approach is to educate users about all possible choices and consequences, and allow them to choose the best path given their personal preferences. Thus, the objective of digital literacy tools is not only behaviour change, but also to create informed digital citizens equipped with critical-thinking skills in 
an evolving digital world. Our game achieves this by providing an environment which allows children to explore the consequences of different choices, in situations representing children's real-life digital experiences. While the game does identify a correct choice for each scenario, its main objective is to allow children to explore different options and foster discussion about the lessons in the game. Disagreements about the correct choice in the game will create opportunities for discussion among children and teachers. Children may discuss why they believe a specific choice would be appropriate in a situation modeled by the game. These types of discussion are key in children's learning of digital literacy, as they foster critical thinking skills and create a sense of agency, which is required when children encounter these types of situations in real-life. To this effect, our game respects recent design recommendations for creating educational cybersecurity games for children [159]. For example, based on findings from co-design sessions with children, Kumar et. al recommend that privacy games should include relatable elements, go beyond instructing children through "dos and don'ts", and expose children to a range of privacy consequences, highlighting both positive and negative outcomes [159].

Security and privacy advice presented in games should reflect children's reality and not an adult's perspective on how children should behave online. For instance, with regards to social media, some security experts believe that children under 13-years old should not use social media because they are under the minimum age requirement of most social media platforms [3]. However, the reality is that many children under the minimum age are regularly using these platforms. Thus, instead of simply telling children to not use these platforms, we should advise them on how to use them safely and avoid common pitfalls associated with their use.

\subsubsection{Design recommendations}

Our work provides empirical support for the following design recommendations. We note that many of these have previously appeared in various forms in existing literature [24, 26, 72, 127]. Our contribution is therefore not in the novelty of the guidelines, but in providing further evidence and confirmation of their validity. We focus on the subset of recommendations that are particularly well suited for persuasive digital literacy games for children. 


\section{R1: Game must have a strong and engaging narrative}

Mechanics (rules) are at the heart of a procedural rhetoric game [26]. However, we argue that having a strong narrative is equally important. In fact, an effective application of procedural rhetoric must include both, and the narrative should be used to convey the message encoded in the game mechanics. In the JOs game, children liked the scenarios (narrative) and the ability to make a choice (mechanic) the most. In our user study, children played 15 scenarios and wanted to play more because they were interested in seeing what else would happen to Jo and Josie. Thus, the narrative kept the children engaged and motivated to play the game, which appeared to help their retention of the learned material [127]. Due to this, we believe that without an engaging narrative children would have been less interested in playing the game, regardless of the game mechanics, decreasing its ability to change the intended user behaviour. However, it is important to not make the narrative too complex because it will increase the cognitive load on the player and take away resources from the learning material [24,178].

\section{R2: Game must be age appropriate}

Persuasive games are composed of a narrative and game mechanics, where the narrative includes context, setting, storyline, scenario, and characters. All these elements of the narrative should be designed to be age appropriate and relatable for children. We designed the Jos game so that the characters and scenarios were relatable for our target audience of 11-13 year old children. These were validated by our user study, where one of the things children most liked in the game was that the scenarios were realistic and modeled situations they would encounter in their daily life. They had positive associations with the game's main characters (Jo/Josie) and thought they were good characters who always tried to do the right thing, even in negative situations. They also found the characters relatable for children their age.

The realistic scenarios and characters may have allowed the children to learn the educational material more effectively in the game, because they could use prior experiences and knowledge to process new information and concepts from the game [178]. It may also help them apply the learned material to situations outside of the game, as shown in the posttest interviews. Children's positive perception of the main characters may have made them 
more likely to trust the advice given by these characters. To establish a positive association, the main characters of a persuasive game should model positive behaviours relevant to the simulated environment, be age appropriate and relatable [24]. For certain domains, designers need to find a balance between realism and age appropriateness of the simulation. This is true for cybersecurity, where some children take part in risky online behaviours which may be inappropriate to model in a simulation for all children of that age group.

\section{R3: Game must provide realistic choices}

While many types of realism can be applied to a game, choice is at the heart of procedural rhetoric; therefore, it is particularly important that choices within the game are realistic. The choices provided in the game must be realistic and reflect the kinds of choices that children would make in real life. If children are unable to find a relevant choice in the game, they will pick something that does not reflect their real world behaviour, and this will negatively impact the effectiveness of the game. In one scenario of our game, some children wanted to choose an option that was not present in the list of choices, and they were disappointed that they could not make a choice reflective of their behaviour. Their desired choice was positive and equivalent in points to the choice they ended up making. However, we note that this could have negatively impacted the effectiveness of the game. Since procedural rhetoric is used to model complex systems, the game needs an adequate number of choices to children rather than providing only extremely positive and negative options. We need a realistic range of options without providing an overwhelming number of choices. In our experience, this appeared to be 3-5 choices. We suggest providing nuanced choices to reflect the types of choices available to children in real life. We chose this strategy for the Jos game, and most children were content with the number of choices provided. With respect to realism of the narrative as it relates to the choices, the main message of our game was not to disengage and stay offline. Rather, we offered options for handling tricky situations and making informed choices. 


\section{R4: Game must provide an opportunity for reflection}

The game should provide opportunities for children to reflect on the consequences of their choices. Reflection allows children to realize what they did wrong and how they can improve in the subsequent parts of the game. In the Jos game, we offered two opportunities for reflection: immediately after viewing the consequences of a choice and after completing a whole day ( 5 scenarios). To minimize disruptions, the short message at the end of a scenario only tells the player how their choice affected Jo or Josie. The complete summary provided at the end of a day shows them their choice, consequences, the correct choice, and how they can improve in the future. This kind of reflection leads to a better understanding of the educational material than simply being told that a choice was incorrect [50]. It also helps with the retention and knowledge transfer of the material learned form the game [127], as shown in the post-test interviews and questionnaires. However, too many opportunities to reflect can be disruptive and annoying for children because it takes away their attention from the primary task, which is to play the game. Thus, designers should provide a balance between offering opportunities to reflect and not disrupting the player's flow.

\subsection{Contributions}

This thesis makes the following contributions:

1. Provides a bilingual, web-based, production-quality digital literacy game for tweens. The game has been deployed in over 300 Canadian elementary schools, with plans for it to be available in more schools later this year.

2. Provides empirical evidence that the game was usable, and that playing it can improve children's digital literacy immediately after playing, with sustained effects one week later.

3. Provides evidence that procedural rhetoric is effective at teaching digital literacy to tweens. Rather than providing a prescriptive set of "dos and don'ts", the game fosters a more reflective and engaged type of learning that encourages children to reflect more deeply about what they would do if they encounter these situations in real-life. 
4. Provides evidence that the game is usable for teachers and appropriate for classroom use.

5. Provides the Behaviours, Technology, and Literacy (BTL) model to conceptualize issues that teachers identify around children's use of digital media.

6. Provides lessons learned based on our research and experience of developing and evaluating a production-quality digital literacy game.

\subsection{Future work}

In future work, we plan to evaluate the JOs with a more diverse group of children and teachers, such as those from different socio-economic statuses, and, ideally, conduct a longerterm field study observing use of the game and its impact in real classrooms. We will also analyze remaining qualitative data from our interviews with teachers to understand their current digital literacy practices in classrooms. The Behaviours, Technology, and Literacy model revealed issues that teachers face with children's use of digital media. We plan to use the situations represented by the BTL model to build new scenarios in the JOs game. Finally, we would like to further explore the educational aspects of procedural rhetoric when applied to digital literacy. Specifically, we intend to use procedural rhetoric to design a new digital literacy game for younger children, as they have different usage patterns of digital media.

\subsection{Conclusion}

With the growth of children's technology use, it has become increasingly important to improve their digital literacy skills to protect them from various online threats. This thesis explores how a game exhibiting properties of procedural rhetoric can be used to improve children's digital literacy. To this effect, we designed and developed a web-based game for tweens, which has been deployed to over 300 Canadian elementary schools. We conducted two user studies to evaluate the usability and effectiveness of the game with children and teachers. From our user study with children, we learned that the game was usable, improved children's digital literacy, and overall was positively received. Children liked the main 
characters and enjoyed playing scenarios in the game, because they reflected what they would encounter in real life. Our second user study showed that teachers found the game usable, liked that it aligned with their curriculum, and wanted to use it in their digital literacy lessons. We also developed the Behaviours, Technology, and Literacy (BTL) model to conceptualize the issues that teachers identify around children's use of digital media and how they help them resolve these issues.

Overall, we contribute a fully-functional and deployed educational game. Based on feedback from both tweens and teachers, we provide evidence of its relevance and effectiveness at addressing real-world issues of digital literacy for tweens, and at promoting larger discussions between tweens and the adults in their lives. 


\section{Bibliography}

[1] Alex Abreu, Gye Won Gho, and Daragh Byrne. Scatter!: A mobile non-parallel multiplayer exertion game. In Conference on Interaction Design and Children, IDC, pages 632-634. ACM, 2013.

[2] Academica. New project focused on improving digital literacy, curriculum kicks off in nwt. Retrieved June 25, 2019 from https://www.academica. ca/indigenous/new-project-focused-improving-digital-literacycurriculum-kicks-nwt.

[3] ADWEEK. Minimum age requirements: Twitter, facebook, instagram, snapchat, whatsapp, secret, 2014. Retrieved January 4, 2018 from http://www.adweek. com/digital/social-media-minimum-age

[4] Icek Ajzen. The theory of planned behaviour. organizational behaviour and human decision processes, 50, 179-211. De Young, 50(2):509-526, 1991.

[5] Khorshed Alam and Sophia Imran. The digital divide and social inclusion among refugee migrants: A case in regional australia. Information Technology \& People, 28(2):344-365, 2015.

[6] Science Alert. Google spent months hiding a security breach affecting the data of 52.5 million google+ users. Retrieved June 20, 2019 from https://www.sciencealert.com/google-kept-a-bug-secret-formonths-that-risked-google-users-privacy

[7] Stephen M Alessi and Stanley R Trollip. Multimedia for learning: Methods and development. Allyn \& Bacon, Inc., 2000.

[8] Yasemin Allsop and John Jessel. Teachers' experience and reflections on gamebased learning in the primary classroom: Views from england and italy. International Journal of Game-Based Learning (IJGBL), 5(1):1-17, 2015.

[9] Leonard A Annetta and Stephen Bronack. Serious educational game assessment: Practical methods and models for educational games, simulations and virtual worlds. Springer Science \& Business Media, 2011.

[10] Panagiotis Apostolellis, Michael Stewart, Chris Frisina, and Dennis Kafura. Rabit escape: A board game for computational thinking. In Conference on Interaction Design and Children, IDC, pages 349-352. ACM, 2014.

[11] Sonia M. Arteaga, Mo Kudeki, Adrienne Woodworth, and Sri Kurniawan. Mobile system to motivate teenagers' physical activity. In Conference on Interaction Design and Children, IDC, pages 1-10. ACM, 2010. 
[12] Per Backlund and Maurice Hendrix. Educational games-are they worth the effort? a literature survey of the effectiveness of serious games. In 2013 5th international conference on games and virtual worlds for serious applications (VS-GAMES), pages 1-8. IEEE, 2013.

[13] Young Kyun Baek. What hinders teachers in using computer and video games in the classroom? exploring factors inhibiting the uptake of computer and video games. CyberPsychology \& Behavior, 11(6):665-671, 2008.

[14] Haiyan Bai, Wei Pan, Astusi Hirumi, and Mansureh Kebritchi. Assessing the effectiveness of a 3-d instructional game on improving mathematics achievement and motivation of middle school students. British Journal of Educational Technology, 43(6):993-1003, 2012.

[15] David Barnard-Wills and Debi Ashenden. Playing with privacy: Games for education and communication in the politics of online privacy. Political Studies, 63(1):142-160, 2015.

[16] David J Bartholomew. Measuring intelligence: Facts and fallacies. Cambridge University Press, 2004.

[17] Malak Baslyman and Sonia Chiasson. " smells phishy?": An educational game about online phishing scams. In 2016 APWG Symposium on Electronic Crime Research (eCrime), pages 1-11. IEEE, 2016.

[18] David Bawden et al. Origins and concepts of digital literacy. Digital literacies: Concepts, policies and practices, 30:17-32, 2008.

[19] John C Beck and Mitchell Wade. Got game. Harvard Business School Press, Boston, 2004.

[20] Francesco Bellotti, Riccardo Berta, A De Gloria, and Ludovica Primavera. Enhancing the educational value of video games. Computers in Entertainment (CIE), 7(2):23, 2009.

[21] Carl Bereiter and Marlene Scardamalia. Surpassing ourselves. An inquiry into the nature and implications of expertise. Chicago: Open Court, 1993.

[22] Ilene R Berson and Michael J Berson. Children and their digital dossiers: Lessons in privacy rights in the digital age. International Journal of Social Education, 21(1):135-147, 2006.

[23] Livio Bioglio, Sara Capecchi, Federico Peiretti, Dennis Sayed, Antonella Torasso, and Ruggero Gaetano Pensa. A social network simulation game to raise awareness of privacy among school children. IEEE Transactions on Learning Technologies, 2018. 
[24] Jim Bizzocchi. The role of narrative in educational games and simulations. In Educational Gameplay and Simulation Environments: Case Studies and Lessons Learned, pages 68-83. IGI Global, 2010.

[25] Yukon Digital Literacy \& Citizenship Blog. A day in the life of the jos. Retrieved July 25, 2019 from https://yukondigitalcitizen.ca/2019/07/18/a-dayin-the-life-of-the-jos

[26] Ian Bogost. Persuasive games: The expressive power of videogames. Mit Press, 2007.

[27] Ian Bogost. The rhetoric of video games. The ecology of games: Connecting youth, games, and learning, pages 117-140, 2008.

[28] Matt Boldt. Typed: A javascript library for the typing animation, 2014. Retrieved December 24, 2019 from https://github.com/mattboldt/typed.js/.

[29] Mike Bostock. D3: A javascript library for manipulating documents based on data, 2014. Retrieved August 17, 2018 from https://d3js.org/.

[30] Caro Boston. The concept of formative assessment, practical assessment. Research \& Education, 8(9), 2002.

[31] Kara Brisson-Boivin. The digital well-being of canadian families. 2018.

[32] Ann L Brown and Joseph C Campione. Psychological theory and the design of innovative learning environments: On procedures, principles, and systems. Lawrence Erlbaum Associates, Inc, 1996.

[33] Jasmina Byrne, Daniel Kardefelt-Winther, Sonia Livingstone, and Mariya Stoilova. Global kids online: research synthesis 2015-2016. 2016.

[34] ByteDance. Tiktok website. Retrieved June 17, 2019 from https: //www . tiktok. com.

[35] Statistics Canada. Canadian internet use survey, 2013. http://www5 . statcan. gc . ca/cansim/a26?lang=eng\&id=3580154.

[36] Micki Caskey and VA Anfara. Developmental characteristics of young adolescents. Association for Middle Level Education, 2014.

[37] Craig Caulfield, Jianhong Cecilia Xia, David Veal, and S Maj. A systematic survey of games used for software engineering education. Modern Applied Science, 5(6):28-43, 2011. 
[38] Pew Research Center. Many turn to youtube for children's content, news, how-to lessons. Retrieved December 11, 2019 from https: //wwW . pewresearch.org/internet/2018/11/07/many-turn-to-youtubefor-childrens-content-news-how-to-lessons.

[39] Alexandra Cetto, Michael Netter, Günther Pernul, Christian Richthammer, Moritz Riesner, Christian Roth, and Johannes Sänger. Friend inspector: A serious game to enhance privacy awareness in social networks. arXiv preprint arXiv:1402.5878, 2014.

[40] Eleni Chatzidaki, Nektarios Kostaras, and Michalis Xenos. Assessment of an educational online virtual game environment: the case of simsafety. 2011.

[41] S Chaudron, R Di Gioia, and M Gemo. Young children (0-8) and digital technology, a qualitative study across europe. JRC Science for Policy Report, 2018.

[42] Scott Childers. Computer literacy: Necessity or buzzword? 2003.

[43] Leigh A Clark and Sherry J Roberts. Employer's use of social networking sites: A socially irresponsible practice. Journal of Business Ethics, 95(4):507-525, 2010.

[44] Paul Cobb and Erna Yackel. Constructivist, emergent, and sociocultural perspectives in the context of developmental research. Educational psychologist, 31(3-4):175190, 1996.

[45] European Commision. The digital literacy and multimodal practices of young children. Retrieved June 20, 2019 from digilitey.eu.

[46] European Commission. Educaunet, 2001. Retrieved June 20, 2019 from https: //educaunet.be.

[47] US Federal Trade Commission. Us federal trade commission digital literacy games, 2012. Retrieved September 14, 2017 from https://www.consumer.ftc.gov/ media,

[48] Thomas M Connolly, Elizabeth A Boyle, Ewan MacArthur, Thomas Hainey, and James M Boyle. A systematic literature review of empirical evidence on computer games and serious games. Computers \& education, 59(2):661-686, 2012.

[49] Thomas M Connolly, Mark Stansfield, and Thomas Hainey. An application of games-based learning within software engineering. British Journal of Educational Technology, 38(3):416-428, 2007.

[50] National Research Council et al. How people learn: Brain, mind, experience, and school: Expanded edition. National Academies Press, 2000. 
[51] David Crookall. Simulation-gaming in Education and Training: Proceedings of the International Simulation and Gaming Association's 18th International Conference, Istituto Universitario Di Architettura Di Venezia (IUAV), Italy, 15-18 September, 1987, volume 18. Pergamon, 1988.

[52] Christine Dani Cruz. Interland - be internet awesome usability testing, 2016. Retrieved July 30, 2019 from http://christinedanicruz.com/interland.

[53] Mihaly Csikszentmihalyi. Flow: The psychology of optimal performance. New York: Cambridge University Press, 1990.

[54] CyberNB. Digital literacy strategy. Retrieved June 25, 2019 from https:// cybernb.ca/en/workforce-development/k-12.

[55] Davidson and Associates. Math blaster!: an educational math game. Retrieved December 25, 2019 from http://www . mathblaster. com.

[56] Katie Davis and Carrie James. Tweens' conceptions of privacy online: implications for educators. Learning, Media and Technology, 38(1):4-25, 2013.

[57] T De La Hera. Persuasive Structures in Advergames: Conveying Advertising Messages through Digital Games. PhD thesis, Dissertation. Utrecht University, 2014.

[58] Edward L Deci and Richard Flaste. Why we do what we do: Understanding selfmotivation. Penguins Books, 1996.

[59] John V Dempsey et al. Instructional applications of computer games. 1996.

[60] Darman Fauzan Dhahir. Pola asuh penggunaan internet di kalangan anak-anak indonesia internet parenting upon indonesian children. Jurnal Pekommas, 3(2):169$178,2018$.

[61] Lars Doucet and Vinod Srinivasan. Designing entertaining educational games using procedural rhetoric: a case study. In Proceedings of the 5th ACM SIGGRAPH Symposium on Video Games, pages 5-10. ACM, 2010.

[62] Allison Druin et al. The design of children's technology. Morgan Kaufmann Publishers San Francisco, 1999.

[63] Allison Druin, Elizabeth Foss, Leshell Hatley, Evan Golub, Mona Leigh Guha, Jerry Fails, and Hilary Hutchinson. How children search the internet with keyword interfaces. In Proceedings of the 8th International conference on interaction design and children, pages 89-96. ACM, 2009.

[64] Judith A Duffield. Designing computer software for problem-solving instruction. Educational Technology Research and Development, 39(1):50-62, 1991. 
[65] Microsoft Education. Digital literacy course. Retrieved June 20, 2019 from https: //www.microsoft.com/en-gb/digitalliteracy/legacycourse.

[66] Serge Egelman, Marian Harbach, and Eyal Peer. Behavior ever follows intention?: A validation of the security behavior intentions scale (sebis). In Proceedings of the 2016 CHI conference on human factors in computing systems, pages 5257-5261. ACM, 2016.

[67] Simon Egenfeldt-Nielsen. Third generation educational use of computer games. Journal of Educational Multimedia and Hypermedia, 16(3):263-281, 2007.

[68] Engadget. Facebook will pay $\$ 5$ billion fine for cambridge analytica data breaches. Retrieved July 26, 2019 from https://www.engadget.com/2019/07/24/ facebook-will-pay-5-billion-fine-for-cambridge-analytica-datab.

[69] Facebook. Digital literacy library, 2018. Retrieved June 20, 2019 from https: //WWW.facebook.com/safety/educators

[70] Facebook. Youth portal, 2018. Retrieved June 20, 2019 from https://www. facebook.com/safety/youth.

[71] S Shirley Feldman and Glen R Elliott. At the threshold: The developing adolescent. Harvard University Press, 1990.

[72] John Ferrara. Games for persuasion: Argumentation, procedurality, and the lie of gamification. Games and Culture, 8(4):289-304, 2013.

[73] Franco Fileni. Play as acquisition of mental structures: the case of videogames. Studi di sociologia, pages 64-74, 1988.

[74] Gary Alan Fine. The dirty play of little boys. Society, 24(1):63-67, 1986.

[75] Shalom M. Fisch. Making educational computer games "educational". In Proceedings of the 2005 Conference on Interaction Design and Children, IDC '05, pages 56-61, New York, NY, USA, 2005. ACM.

[76] Carla Fisher. Designing Games for Children: Developmental, Usability, and Design Considerations for Making Games for Kids. CRC Press, 2014.

[77] Andrew J Flanagin and Miriam J Metzger. The perceived credibility of personal web page information as influenced by the sex of the source. Computers in human behavior, 19(6):683-701, 2003.

[78] Brian J Fogg. Persuasive technology: using computers to change what we think and do. Ubiquity, 2002(December):5, 2002. 
[79] Canadian Centre for Child Protection. Neep help now. Retrieved June 20, 2019 from https://needhelpnow.ca/app/en.

[80] Canadian Centre for Child Protection. Protect kids online. Retrieved July 31, 2019 from https://protectkidsonline.ca.

[81] Canadian Centre for Child Protection. Kids in the know, 2015. Retrieved June 20, 2019 from https://kidsintheknow.ca.

[82] Canadian Centre for Child Protection. Zoe and molly online, 2015. Retrieved June 20, 2019 from https://zoeandmolly.ca/app/en/.

[83] Canadian Centre for Child Protection. Zoe and molly online teacher guide, 2015. Retrieved June 20, 2019 from http://www. zoeandmolly.ca/app/en/teacher.

[84] National Initiative for Cybersecurity Careers and Studies. Certified information systems security professional (cissp). Retrieved July 25, 2019 from https://niccs.us-cert.gov/training/search/global-informationtechnology/certified-information-systems-security-professional

[85] Google for Education. Digital citizenship and safety course, 2018. Retrieved June 20, 2019 from https://teachercenter.withgoogle.com/digital_ citizenship/unit?unit $=25 \& l e s s o n=26 \% 20 \%$.

[86] Better Internet for Kids. Saferinternet4eu campaign. Retrieved June 20, 2019 from https://www.betterinternetforkids.eu/web/portal/ saferinternet4eu.

[87] National Center for Missing and Exploited Children. Netsmartzkids, 2001. Retrieved June 20, 2019 from https://www.netsmartzkids.org/.

[88] National Centre for Missing and Exploited Children. Cyberbully zombies, 2011. Retrieved June 17, 2019 from https://www.nsteens.org/Games/ CyberbullyZombies.

[89] Asaf Friedman. The role of visual design in game design. Games and Culture, 10(3):291-305, 2015.

[90] Code Your Future. Uk code your future, 2010. Retrieved June 20, 2019 from https: //codeyourfuture.io.

[91] Persuasive Games. Debt ski, 2009. Retrieved September 14, 2017 from http: //persuasivegames.com/game/debtski.

[92] Persuasive Games. Persuasive games, 2009. Retrieved September 14, 2017 from http://persuasivegames.com. 
[93] PopCap Games. Plants and zombies, 2009. Retrieved June 17, 2019 from https: //www.ea.com/studios/popcap/plants-vs-zombies.

[94] Howard Gardner. The unschooled mind: How children think and how schools should teach. Basic Books (AZ), 2011.

[95] Urs Gasser, Sandra Cortesi, Momin M Malik, and Ashley Lee. Youth and digital media: From credibility to information quality. Berkman Center Research Publication, (2012-1), 2012.

[96] James Paul Gee. What video games have to teach us about learning and literacy. Computers in Entertainment (CIE), 1(1):20-20, 2003.

[97] James Paul Gee. Learning by design: Games as learning machines. Digital Education Review, (8):15-23, 2004.

[98] James Paul Gee. Good video games and good learning: Collected essays on video games, learning and literacy (new literacies and digital epistemologies). Bern, Switzerland: Peter Lang Publishing, 2007.

[99] Canadian Geographic. Children's geography games. Retrieved December 25, 2019 from https://www. canadiangeographic.ca/content/kids-games.

[100] National Geographic. National geographic kids games. Retrieved December 25, 2019 from https://kids .nationalgeographic. com/games.

[101] Daniel R George, Michael J Green, Anita M Navarro, Kelly K Stazyk, and Melissa A Clark. Medical student views on the use of facebook profile screening by residency admissions committees. Postgraduate medical journal, 90(1063):251-253, 2014.

[102] Filippos Giannakas, Georgios Kambourakis, and Stefanos Gritzalis. Cyberaware: A mobile game-based app for cybersecurity education and awareness. In 2015 International Conference on Interactive Mobile Communication Technologies and Learning (IMCL), pages 54-58. IEEE, 2015.

[103] Ben Gibson and Tim Bell. Evaluation of games for teaching computer science. In Proceedings of the 8th Workshop in Primary and Secondary Computing Education, pages 51-60. ACM, 2013.

[104] Paul Gilster. Digital literacy. Wiley Computer Pub. New York, 1997.

[105] The Globe and Mail. Eric andrew-gee. gaffes: When candidates accidentally tell the truth. Retrieved July 25, 2019 from http://www . theglobeandmail . com/news/ politics/elections/gaffes-when-a-candidate-accidentally-tellsthe-truth/article26713595. 
[106] Thomas A. Goldman, Frank J. Lee, and Jichen Zhu. Using video games to facilitate understanding of attention deficit hyperactivity disorder: A feasibility study. In Proceedings of the First ACM SIGCHI Annual Symposium on Computer-human Interaction in Play, CHI PLAY '14, pages 115-120, New York, NY, USA, 2014. ACM.

[107] Mark Gondree and Zachary NJ Peterson. Valuing security by getting [d0x3d!]: Experiences with a network security board game. In Presented as part of the 6th Workshop on Cyber Security Experimentation and Test, 2013.

[108] Google. Announcement: Strengthening enforcement of our community guidelines. Retrieved December 11, 2019 from https://support.google.com/youtube/ thread/1063296?hl=en.

[109] Google. Interland - be internet awesome. Retrieved June 20, 2019 from https: //beinternetawesome.withgoogle.com/en_us/interland.

[110] Google and iKeepSafe. K-12 digital citizenship curriculum, 2018. Retrieved June 20, 2019 from https://beinternetawesome.withgoogle.com/en_us/ resources.

[111] United States Government. Us digital literacy. Retrieved June 20, 2019 from http: //digitalliteracy.us.

[112] US Government. U.s. census bureau. current population survey, 2010. http:// WWW . census.gov/hhes/computer/publications/2010.html.

[113] Diana Graber and Cynthia Lieberman. Cyberwise internet safety. Retrieved June 20, 2019 from https://www . cyberwise.org.

[114] Anna Gruszczynska and Richard Pountney. Developing the concept of digital literacy in the context of schools and teacher education. Enhancing Learning in the Social Sciences, 5(1):25-36, 2013.

[115] Richard Gunther, Paul A Beck, and Erik C Nisbet. Fake news did have a significant impact on the vote in the 2016 election: Original full-length version with methodological appendix. Columbus, OH: Ohio State University. https://u. osu. edu/cnep/files/2015/03/Fake-News-Piecefor-The-Conversation-withmethodological-appendix-11d0ni9. pdf, 2018.

[116] Anton Gustafsson and Magnus Bång. Evaluation of a pervasive game for domestic energy engagement among teenagers. In International Conference on Advances in Computer Entertainment Technology, ACE, pages 232-239. ACM, 2008.

[117] Tea Hadziristic. The state of digital literacy in Canada: A literature review. Brookfield Institute for Innovation Entrepreneurship, 2017. 
[118] Cassie Hague and Sarah Payton. Digital literacy across the curriculum. Curriculum Leadership, 9(10), 2011.

[119] Claudia Hart, Margo Vroman, Karin Stulz, and Emily Stulz. Employer liability for using social media in hiring decisions. 2015.

[120] RT Hays. The science of learning: A systems theory approach, 2006.

[121] John Herrman. Momo is as real as weâĂŹve made her, 2019. Retrieved December 29, 2019 from https://www .nytimes.com/2019/03/02/style/momo-maniahoax.html.

[122] Sameer Hinduja and Justin W Patchin. Bullying, cyberbullying, and suicide. Archives of suicide research, 14(3):206-221, 2010.

[123] Michael Hoechsmann and Helen DeWaard. Mapping digital literacy policy and practice in the Canadian education landscape. MediaSmarts, 2015.

[124] Randy Hollandsworth, Lena Dowdy, and Judy Donovan. Digital citizenship in k-12: It takes a village. TechTrends, 55(4):37-47, 2011.

[125] Margaret A Honey and Margaret Hilton. Learning science through computer games and simulations. National Academies Press, 2011.

[126] Juan Pablo Hourcade et al. Interaction design and children. Foundations and Trends® in Human-Computer Interaction, 1(4):277-392, 2008.

[127] Talib S Hussain and Susan L Coleman. Design and Development of Training Games. Cambridge University Press, 2014.

[128] Annalise Huynh and Nisa Malli. Levelling Up: The Quest for Digital Literacy. Brookfield Institute for Innovation Entrepreneurship, 2018.

[129] Facebook Inc. Facebook website. Retrieved June 17, 2019 from https://www. facebook.com.

[130] Facebook Inc. Instagram website. Retrieved June 17, 2019 from https://www. instagram.com.

[131] Facebook Inc. Whatsapp website. Retrieved June 17, 2019 from https://www. whatsapp.com.

[132] Google Inc. Youtube website. Retrieved June 17, 2019 from https://www. youtube.com.

[133] Snap Inc. Snapchat website. Retrieved June 17, 2019 from https://www. snapchat.com. 
[134] Twitter Inc. Twitter website. Retrieved June 17, 2019 from https://twitter .com.

[135] The Philadelphia Inquirer. Youtube under federal investigation over allegations that it violates children's privacy. Retrieved June 23, 2019 from https://www.inquirer.com/news/nation-world/youtube-federalinvestigation-childrens-privacy-20190620.html.

[136] Cynthia E Irvine, Michael F Thompson, and Ken Allen. Cyberciege: gaming for information assurance. IEEE Security \& Privacy, 3(3):61-64, 2005.

[137] Gloria E Jacobs. Adolescents and Instant Messaging: Literacy, Language, and Identity Development in the 21st Century. VDM Publishing, 2009.

[138] Joris B. Janssen, Chrissy C. van der Wal, Mark A. Neerincx, and Rosemarijn Looije. Motivating children to learn arithmetic with an adaptive robot game. In Social Robotics, pages 153-162. Springer Berlin Heidelberg, 2011.

[139] Steven Johnson. Your brain on video games. Discover, 26(7):38-43, 2005.

[140] Lisa M Jones, Kimberly J Mitchell, and David Finkelhor. Trends in youth internet victimization: Findings from three youth internet safety surveys 2000-2010. Journal of adolescent Health, 50(2):179-186, 2012.

[141] Yi-Kai Juan and Tseng-Wei Chao. Game-based learning for green building education. Sustainability, 7(5):5592-5608, 2015.

[142] Yasmin B Kafai. How computer games help children learn. Science Education, 92(2):378-381, 2008.

[143] Dimitis Kalaitzis, Eftyxios Valeontis, Vasilis Delis, and Maria Fountana. Experiences from developing online vr environments: The simsafety case study. Social Applications for Life Long Learning, page 8, 2010.

[144] Nicholas Kardaras. Glow kids: How screen addiction is hijacking our kids-and how to break the trance. St. Martin's Press, 2016.

[145] David Kaufman. Educational Gameplay and Simulation Environments: Case Studies and Lessons Learned: Case Studies and Lessons Learned. IGI Global, 2010.

[146] Fares Kayali, Günter Wallner, Simone Kriglstein, Gerhild Bauer, Daniel Martinek, Helmut Hlavacs, Peter Purgathofer, and Rebbeca Wölfle. A case study of a learning game about the internet. In International Conference on Serious Games, pages 4758. Springer, 2014.

[147] Mansureh Kebritchi. Factors affecting teachers' adoption of educational computer games: A case study. British Journal of Educational Technology, 41(2):256-270, 2010. 
[148] Mansureh Kebritchi, Atsusi Hirumi, and Haiyan Bai. The effects of modern mathematics computer games on mathematics achievement and class motivation. Computers \& education, 55(2):427-443, 2010.

[149] John M Keller. Development and use of the arcs model of instructional design. Journal of instructional development, 10(3):2, 1987.

[150] Robert Kenny and Glenda Gunter. Factors affecting adoption of video games in the classroom. Journal of Interactive Learning Research, 22(2):259, 2011.

[151] PBS Kids. Pbs kids reading games. Retrieved December 25, 2019 from https: //pbskids.org/games/reading.

[152] Kids helpline: Cyberbullying. https://kidshelpline.com.au/parents/ issues/children-who-cyberbully

[153] Kristian Kiili. Digital game-based learning: Towards an experiential gaming model. The Internet and higher education, 8(1):13-24, 2005.

[154] James D Klein and Eric Freitag. Enhancing motivation using an instructional game. Journal of Instructional Psychology, 18(2):111, 1991.

[155] Michele Knobel. Digital literacies: Concepts, policies and practices, volume 30. Peter Lang, 2008.

[156] Sebastian Koch, Joerg Schneider, and Jan Nordholz. Disturbed playing: Another kind of educational security games. In CSET, 2012.

[157] Tibor Koltay. The media and the literacies: Media literacy, information literacy, digital literacy. Media, Culture \& Society, 33(2):211-221, 2011.

[158] Nalini P Kotamraju, Somaya Ben Allouch, and Kirsten van Wingerden. Employers' use of online reputation and social network sites in job applicant screening and hiring. Living inside mobile social information, pages 247-267, 2014.

[159] Priya Kumar, Jessica Vitak, Marshini Chetty, Tamara L Clegg, Jonathan Yang, Brenna McNally, and Elizabeth Bonsignore. Co-designing online privacy-related games and stories with children. In Proceedings of the 17th ACM Conference on Interaction Design and Children, pages 67-79, 2018.

[160] Priya C Kumar, Marshini Chetty, Tamara L Clegg, and Jessica Vitak. Privacy and security considerations for digital technology use in elementary schools. In Proceedings of the 2019 CHI Conference on Human Factors in Computing Systems, pages $1-13,2019$.

[161] Kristiina Kumpulainen and Julia Gillen. Young children's digital literacy practices in the home. The Routledge Handbook of Digital Literacies in Early Childhood, page 95, 2019. 
[162] Cold Brew Labs. Pinterest. Retrieved June 17, 2019 from https://www. pinterest.com.

[163] Randy J Larsen and David M Buss. Personality psychology: domains of knowledge about human nature. Psicología de la personalidad: dominios de conocimiento sobre la naturaleza humana. Number Sirsi) i9789701050651. 2005.

[164] NWY Law, DJ Woo, J de la Torre, and KWG Wong. A global framework of reference on digital literacy skills for indicator 4.4. 2. 2018.

[165] Lai-Chung Lee and Kuang-Chung Hao. Designing and evaluating digital gamebased learning with the arcs motivation model, humor, and animation. International Journal of Technology and Human Interaction (IJTHI), 11(2):80-95, 2015.

[166] G Lemos and F Nascimbeni. Elinet position paper on digital literacy. ELINET network, 2016.

[167] Amanda Lenhart. Teens and sexting. washington, dc: Pew research center, 2009.

[168] Tsung-Yu Liu and Yu-Ling Chu. Using ubiquitous games in an english listening and speaking course: Impact on learning outcomes and motivation. Computers \& Education, 55(2):630-643, 2010.

[169] Sonia Livingstone and Jasmina Byrne. Parenting in the digital age. DIGITAL PARENTING, page 19, 2018.

[170] Sonia Livingstone, Leslie Haddon, Anke Görzig, and Kjartan Ólafsson. Risks and safety on the internet. The perspective of European children. Full findings and policy implications from the EU Kids Online survey of, pages 9-16, 2011.

[171] Minhua Ma, Andreas Oikonomou, and Lakhmi C Jain. Serious games and edutainment applications. Springer, 2011.

[172] Mary Madden, A Lenhart, S Cortesi, and U Gasser. Pew internet and american life project. Washington, DC, USA: Pew Research Center, 2010.

[173] Krystina Madej. Physical Play and Children's Digital Games. Springer, 2016.

[174] Ole Jacob Madsen. Transgression. Encyclopedia of Critical Psychology, pages 2002-2004, 2014.

[175] Thomas W Malone. Toward a theory of intrinsically motivating instruction. Cognitive science, 5(4):333-369, 1981.

[176] Thomas W Malone and Mark R Lepper. Making learning fun: A taxonomy of intrinsic motivations for learning. Aptitude, learning, and instruction, 3(1987):223253, 1987. 
[177] Mobile Marketer. Snapchat's phishing attack breached 50k accounts. Retrieved June 20, 2019 from https://www.mobilemarketer.com/news/snapchatsphishing-attack-breached-50k-accounts/517377/.

[178] Caroline Masse, Kelly Pounds, Eric Church, Robert E Waters, and Vance Souders. Story for learning and gaming. Design and Development of Training Games: Practical Guidelines from a Multidisciplinary Perspective, page 1720, 2014.

[179] Richard E Mayer. Multimedia learning and games. 2011.

[180] A McFarlane, A Sparrowhawk, and Y Heald. Report on the educational use of games. teachers evaluating educational multimedia, 2002.

[181] Common Sense Media. Common sense education. Retrieved June 20, 2019 from https://www.commonsense.org/education/.

[182] Common Sense Media. Digital citizenship. Retrieved June 20, 2019 from https: //www.commonsense.org/education/digital-citizenship

[183] Common Sense Media. Digital citizenship resources for the home. Retrieved July 31, 2019 from https://www. commonsensemedia.org/educators/ digitalcitizenshipweek/home.

[184] Common Sense Media. Digital compass. Retrieved June 20, 2019 from『.

[185] Common Sense Media. Digital compass teacher guide. Retrieved June 20, 2019 from】.

[186] Common Sense Media. Digital passport. Retrieved June 20, 2019 from https: //wwW.digitalpassport.org.

[187] Common Sense Media. Digital passport teacher guide. Retrieved June 20, 2019 from https://www.commonsense.org/education/app/digital-passportteacher-review/4087121.

[188] Common Sense Media. K-12 digital citizenship curriculum, 2010. Retrieved June 20, 2019 from https://www.commonsense.org/education/digitalcitizenship/curriculum.

[189] Common Sense Media. Just in time for back to school, common sense adds new lessons for a new world to its award-winning digital citizenship curriculum, 2019. Retrieved June 20, 2019 from https://https://www. commonsensemedia.org/ about-us/news/press-releases/just-in-time-for-back-to-schoolcommon-sense-adds-new-lessons-for-a-new.

[190] Verizon Media. Tumblr website. Retrieved June 17, 2019 from https://www. tumblr.com. 
[191] MediaSmarts. A day in the life of the jos - curricular connections. Retrieved December 25, 2019 from http://mediasmarts.ca/teacher-resources/licensedresources/day-life-jos-grades-6-8/day-life-jos-curricularconnections.

[192] MediaSmarts. A day in the life of the jos (grades 6-8). Retrieved June 20, 2019 from http://mediasmarts.ca/teacher-resources/licensed-resources/ day-life-jos-grades-6-8.

[193] MediaSmarts. Digital literacy resources for parents. Retrieved June 20, 2019 from http://mediasmarts.ca/parents.

[194] MediaSmarts. Digital literacy resources for teachers. Retrieved June 20, 2019 from http://mediasmarts.ca/teacher-resources.

[195] MediaSmarts. Jo Cool or Jo Fool Game, 2000. Retrieved January 20, 2017 from http://mediasmarts.ca/game/jo-cool-or-jo-fool-grades-6-8.

[196] MediaSmarts. Digital and media literacy outcomes by province and territory, 2012. Retrieved December 24, 2017 from http://mediasmarts.ca/teacherresources/digital-and-media-literacy-outcomes-provinceterritory.

[197] MediaSmarts. Mediasmarts educational games, 2012. Retrieved January 20, 2017 from http://mediasmarts.ca/digital-media-literacy/ educational-games.

[198] MediaSmarts. USE, UNDERSTAND \& CREATE: A Digital Literacy Framework for Canadian Schools, 2015. Retrieved January 20, 2017 from http://mediasmarts.ca/teacher-resources/use-understand-createdigital-literacy-framework-canadian-schools.

[199] Christine Mekhail. A day in the life of the jos: The design of an educational game on privacy. Master's thesis, Carleton University, Ottawa, Canada, 2016.

[200] David R Michael and Sandra L Chen. Serious games: Games that educate, train, and inform. Muska \& Lipman/Premier-Trade, 2005.

[201] Aleksandra Milovanović. Audio-vizuelne arhive: Metod, model, mediji1.

[202] MITACS. New video game helps kids fight online dangers. Retrieved July 30, 2019 from https://www.mitacs.ca/en/impact/new-video-gamehelps-kids-fight-online-dangers

[203] Thomas Monk, Johan Van Niekerk, and Rossouw von Solms. Sweetening the medicine: educating users about information security by means of game play. In Proceedings of the 2010 Annual Research Conference of the South African Institute of Computer Scientists and Information Technologists, pages 193-200. ACM, 2010. 
[204] Curtiss Murphy. Why games work and the science of learning. In Interservice, Interagency Training, Simulations, and Education Conference, pages 260-272. Citeseer, 2011.

[205] Engineering National Academies of Sciences, Medicine, et al. The promise of adolescence: Realizing opportunity for all youth. National Academies Press, 2019.

[206] CBC News. Negative amanda todd post costs man his job. Retrieved July 25, 2019 from https://www . cbc . ca/news/canada/calgary/negative-amandatodd-post-costs-man-his-job-1.1134230

[207] CTV News. Mp clement admits to inappropriate online behaviour, says alleged extortionist was 'foreign actor'. Retrieved July 25, 2019 from https://www.ctvnews.ca/politics/mp-clement-admits-toinappropriate-online-behaviour-says-alleged-extortionist-wasforeign-actor-1.4168944.

[208] The Hacker News. Twitter discloses suspected state-sponsored attack after minor data breach. Retrieved June 20, 2019 from https://thehackernews . com/2018/ 12 /twitter-data-breach.html.

[209] Brian D Ng and Peter Wiemer-Hastings. Addiction to the internet and online gaming. Cyberpsychology \& behavior, 8(2):110-113, 2005.

[210] Wan Ng. Can we teach digital natives digital literacy? Computers \& education, 59(3):1065-1078, 2012.

[211] Bukelwa Ngoqo and Stephen V Flowerday. Exploring the relationship between student mobile information security awareness and behavioural intent. Information \& Computer Security, 23(4):406-420, 2015.

[212] OECD. The protection of children online. (179), 2011.

[213] Government of Alberta. Information and communication technology curriculum - grades 1-12, 2017. Retrieved December 24, 2017 from https://education. alberta.ca/media/3114953/ictpos.pdf.

[214] Government of Australia. Cybersmart challenge. Retrieved June 20, 2019 from https://wWw.esafety.gov.au/education-resources/classroomresources/challenge.

[215] Government of Australia. Young \& esafe lesson plans. Retrieved June 20, 2019 from https://esafety.gov.au/education-resources/classroomresources/young-and-esafe.

[216] Government of British Columbia. Applied design, skills, and technologies curriculum - grades 1-12, 2017. Retrieved December 24, 2017 from https:// curriculum.gov.bc.ca/curriculum/adst/6/core. 
[217] Government of Canada. Get cyber safe. Retrieved June 20, 2019 from https: //wwW.getcybersafe.gc.ca/index-en.aspx.

[218] Government of Canada. National cyber security strategy, 2018. Retrieved June 20, 2019 from https://www.publicsafety.gc.ca/cnt/rsrcs/pblctns/ntnlcbr-scrt-strtg/index-en.aspx.

[219] Government of Canada. Digital literacy exchange program, 2019. Retrieved June 20, 2019 from http://www.ic.gc.ca/eic/site/102.nsf/eng/home

[220] Ministry of Education. The ontario curriculum - grades 1-12, 2012. Retrieved September 14, 2017 from http://www.edu.gov.on.ca/eng/teachers/ curriculum.html.

[221] United States. Department of Education. A blueprint for reform: The reauthorization of the elementary and secondary education act. US Department of Education, Office of Planning, Evaluation and Policy Development, 2010.

[222] Department of Justice. Criminal code (r.s.c., 1985, c. c-46). Retrieved December 11, 2019 from https://laws-lois.justice.gc.ca/eng/acts/c-46/section163.1.html.

[223] Government of Manitoba. Literacy with information and communication technology curriculum - grades 1-12, 2012. Retrieved December 24, 2017 from http://www. edu.gov.mb.ca/k12/tech/lict/index.html.

[224] Government of New Zealand. Newsafe: Online safety for new zealand. Retrieved June 20, 2019 from https://www.netsafe.org.nz.

[225] Government of Nova Scotia. Nova scotia's action plan for education. Retrieved June 25, 2019 from https://www.ednet.ns.ca/education-actionplan.

[226] Government of Prince Edward Island. Prince edward island senior high curriculum. Retrieved June 25, 2019 from http://www . gov . pe.ca/photos/original/edu_ cmp52109.pdf.

[227] Government of Saskatchewan. Technology in education framework, 2012. Retrieved December 24, 2017 from http://publications.gov.sk.ca/documents/11/ 85655-Technology-in-Education-Framework.pdf.

[228] Government of the United Kingdom. School online safety policy templates. Retrieved June 20, 2019 from https://swgfl.org.uk/online-safety-policytemplates-for-schools.

[229] Government of Yukon. Digital literacy and citizenship for yukon students and teachers. Retrieved June 25, 2019 from https://yukondigitalcitizen.ca. 
[230] Cuteacute Media OG. Data dealer. Retrieved June 20, 2019 from https:// datadealer.com/.

[231] Marc Olano, Alan Sherman, Linda Oliva, Ryan Cox, Deborah Firestone, Oliver Kubik, Milind Patil, John Seymour, Isaac Sohn, and Donna Thomas. Securityempire: Development and evaluation of a digital game to promote cybersecurity education. In 2014 \{USENIX\} Summit on Gaming, Games, and Gamification in Security Education (3GSE 14), 2014.

[232] Krebs on Security. Adobe breach impacted at least 38 million users. Retrieved June 20, 2019 from https://krebsonsecurity.com/2013/10/adobebreach-impacted-at-least-38-million-users/.

[233] Global Kids Online. Eu kids online. Retrieved June 20, 2019 from http: //globalkidsonline.net/eu-kids-online.

[234] Global Kids Online. Global kids online. Retrieved June 20, 2019 from http: //globalkidsonline.net.

[235] Mark Otto and Jacob Thornton. Bootstrap: An open source toolkit for developing with html, css, and js, 2011. Retrieved January 4, 2018 from https: //getbootstrap.com/.

[236] 3909 LLC Lucas P. Papers, please: a dystopian document thriller, 2013. Retrieved June 17, 2019 from http://store.steampowered.com/app/239030.

[237] Justin W Patchin and Sameer Hinduja. Bullies move beyond the schoolyard: A preliminary look at cyberbullying. Youth violence and juvenile justice, 4(2):148169, 2006.

[238] Giani Petri and Christiane Gresse von Wangenheim. How to evaluate educational games: a systematic. Journal of Universal Computer Science, 22(7):992-1021, 2016.

[239] Jean Piaget. Judgement and reasoning in the child (English Translation). Routledge, 2002.

[240] Daniel H Pink. Drive: The surprising truth about what motivates us. Penguin, 2011.

[241] María Pinto and Dora Sales. Insights into translation students' information literacy using the il-humass survey. Journal of Information Science, 36(5):618-630, 2010.

[242] Matthew Pittman and Brandon Reich. Social media and loneliness: Why an instagram picture may be worth more than a thousand twitter words. Computers in Human Behavior, 62:155-167, 2016. 
[243] The Washington Post. The complete history of 'slender man,' the meme that compelled two girls to stab a friend. Retrieved December 11, 2019 from https://www.washingtonpost.com/news/the-intersect/wp/2014/06/ 03/the-complete-terrifying-history-of-slender-man-the-internetmeme-that-compelled-two-12-year-olds-to-stab-their-friend.

[244] Marc Prensky and Mark Prensky. Digital game-based learning, volume 1. Paragon house St. Paul, MN, 2007.

[245] Kaplan Test Prep. Kaplan test prep survey finds colleges and applicants agree: Social media is fair game in the admissions process. Retrieved July 30, 2019 from https://www.kaptest.com/blog/press/2018/04/17/kaplan-test-prepsurvey-finds-colleges-applicants-agree-social-media-fair-gameadmissions-process.

[246] Raija-Leena Punamäki, Marjut Wallenius, Clase-Håkan Nygård, Lea Saarni, and Arja Rimpelä. Use of information and communication technology (ict) and perceived health in adolescence: the role of sleeping habits and waking-time tiredness. Journal of adolescence, 30(4):569-585, 2007.

[247] Kate Raynes-Goldie and Matthew Allen. Gaming privacy: a canadian case study of a children's co-created privacy literacy game. Surveillance \& Society, 12(3):414-426, 2014.

[248] Janet C Read. Validating the fun toolkit: an instrument for measuring children's opinions of technology. Cognition, Technology \& Work, 10(2):119-128, 2008.

[249] UNESCO Global Education Monitoring Report. A global framework to measure digital literacy, 2018. Retrieved June 20, 2019 from http://uis.unesco.org/ en/blog/global-framework-measure-digital-literacy.

[250] John Resig. jquery: A javascript based toolkit for web development, 2006. Retrieved December 24, 2019 from https://github.com/jquery/jquery.

[251] Bradford W Reyns, Melissa W Burek, Billy Henson, and Bonnie S Fisher. The unintended consequences of digital technology: Exploring the relationship between sexting and cybervictimization. Journal of Crime and Justice, 36(1):1-17, 2013.

[252] V Rideout and M Robb. Social media, social life: Teens reveal their experiences. San Francisco, CA: Common Sense Media, 2018.

[253] Ute Ritterfeld, Michael Cody, and Peter Vorderer. Serious games: Mechanisms and effects. Routledge, 2009.

[254] Sherry J Roberts and Terry Roach. Social networking web sites and human resource personnel: Suggestions for job searches. Business Communication Quarterly, 72(1):110-114, 2009. 
[255] Andy Robertson. Don't panic, what parents really need to know about 'momo challenge'. Retrieved December 30, 2019 from https://www.forbes.com/ sites/andyrobertson/2019/02/27/dont-panic-what-parents-reallyneed-to-know-about-momo-challenge.

[256] Margaret D Roblyer and Aaron H Doering. Integrating educational technology into teaching. 2012.

[257] Larry D Rosen, AF Lim, Julie Felt, L Mark Carrier, Nancy A Cheever, Jose M LaraRuiz, Jessica S Mendoza, and Jeffrey Rokkum. Media and technology use predicts ill-being among children, preteens and teenagers independent of the negative health impacts of exercise and eating habits. Computers in human behavior, 35:364-375, 2014.

[258] Cris Rowan. UnplugâĂ ̌̌́donâĂŹt drug: A critical look at the influence of technology on child behavior with an alternative way of responding other than evaluation and drugging. Ethical Human Psychology and Psychiatry, 12(1):60-68, 2010.

[259] Dana N Ruggiero. Spent: changing students' affective learning toward homelessness through persuasive video game play. In Proceedings of the 32nd annual ACM conference on Human factors in computing systems, pages 3423-3432. ACM, 2014.

[260] Jungwoo Ryoo, Angsana Techatassanasoontorn, Dongwon Lee, and Jeremy Lothian. Game-based infosec education using opensim. In Proceedings of the 15th Colloquium for Information systems security Education, pages 101-106, 2011.

[261] National Online Safety. What parents need to know about the momo challenge. Retrieved December 29, 2019 from https://nationalonlinesafety. com/resources/wake-up-wednesday/momo-online-safety-guide-forparents.

[262] Katie Salen and Eric Zimmerman. Rules of play: Game design fundamentals. MIT press, 2004.

[263] AV Salin. Principles of procedural hermeneutics. In The Philosophy of Computer Games Conference, 2018.

[264] Renata Arrington Sanders. Adolescent psychosocial, social, and cognitive development. Pediatrics in Review, 34(8):354-8, 2013.

[265] Jesse Schell. The Art of Game Design: A book of lenses. CRC Press, 2014.

[266] Alex Schmitz. jquery ui: A curated set of javascript based user interface interactions, effects, widgets, and themes, 2007. Retrieved December 24, 2019 from https: //jqueryui.com. 
[267] Kristin L Schneider, John Ferrara, Bri Lance, Andrew Karetas, Susan Druker, Emily Panza, Barbara Olendzki, Victoria Andersen, and Lori Pbert. Acceptability of an online health videogame to improve diet and physical activity in elementary school students: "fitter critters". Games for Health: Research, Development, and Clinical Applications, 1(4):262-268, 2012.

[268] Scholastic. Math missions grades 3-5: The amazing arcade adventure.

[269] Barry Schwartz. The paradox of choice: Why more is less. Ecco New York, 2004.

[270] Jim Seale and Nicole Schoenberger. Be internet awesome. Emerging Library \& Information Perspectives, 1:34-58, 2018.

[271] Bank Info Security. 5 million google passwords leaked: Stolen credentials surface on russian cybercrime forums. Retrieved June 20, 2019 from https://www. bankinfosecurity.com/5-million-google-passwords-leaked-a-7299.

[272] Julian Sefton-Green, Jackie Marsh, Ola Erstad, and Rosie Flewitt. Establishing a research agenda for the digital literacy practices of young children. A White Paper for COST Action IS1410, 2016.

[273] Lauren A Spies Shapiro and Gayla Margolin. Growing up wired: Social networking sites and adolescent psychosocial development. Clinical child and family psychology review, 17(1):1-18, 2014.

[274] Emily Shugerman. 10 students have harvard acceptances withdrawn over facebook memes. Retrieved July 30, 2019 from http://wwW . independent. co. uk/news/ world/americas/harvard-facebook-memes-student-acceptance-takenaway-withdrawn-university-a7775991.html.

[275] Valerie J Shute. Focus on formative feedback. Review of educational research, 78(1):153-189, 2008.

[276] Miguel Sicart. Against procedurality. Game studies, 11(3):209, 2011.

[277] Mikko Siponen, Seppo Pahnila, and Adam Mahmood. Employees' adherence to information security policies: an empirical study. In IFIP International Information Security Conference, pages 133-144. Springer, 2007.

[278] David Smahel, Michelle F Wright, and Martina Cernikova. The impact of digital media on health: childrenâĂŹs perspectives. International journal of public health, 60(2):131-137, 2015.

[279] William P Smith and Deborah L Kidder. You've been tagged!(then again, maybe not): Employers and facebook. Business Horizons, 53(5):491-499, 2010. 
[280] Mara Soekarjo and Herre van Oostendorp. Measuring effectiveness of persuasive games using an informative control condition. International journal of serious Games, 2(2):37-56, 2015.

[281] Nathalie Sonck and Jos de Haan. Safety by literacy? rethinking the role of digital skills in improving online safety. In Minding minors wandering the Web: Regulating online child safety, pages 89-104. Springer, 2014.

[282] Kurt Squire, Henry Jenkins, Walter Holland, Heather Miller, Alice O'Driscoll, Katie Philip Tan, and Katie Todd. Design principles of next-generation digital gaming for education. Educational Technology, 43(5):17-23, 2003.

[283] Valerie Steeves. Young canadians in a wired world, phase iii: Life online. 2014.

[284] Valerie Steeves. Young canadians in a wired world, phase iii: Trends and recommendations. 2014.

[285] Valerie Steeves, Trevor Milford, and Ashley Butts. Summary of research on youth online privacy. Office of the Privacy Commissioner of Canada, 2010.

[286] Tony Stephanou and Rabelani Dagada. The impact of information security awareness training on information security behaviour: The case for further research. In ISSA, pages 1-21, 2008.

[287] Peter Stordy. Taxonomy of literacies. Journal of documentation, 71(3):456-476, 2015.

[288] Anselm Strauss and Juliet Corbin. Grounded theory methodology. Handbook of qualitative research, 17:273-85, 1994.

[289] Paris S Strom and Robert D Strom. Cyberbullying by adolescents: A preliminary assessment. In The Educational Forum, volume 70, pages 21-36. Taylor \& Francis, 2006.

[290] Chung-Ho Su and Ching-Hsue Cheng. 3d game-based learning system for improving learning achievement in software engineering curriculum. Turkish Online Journal of Educational Technology-TOJET, 12(2):1-12, 2013.

[291] Radio Télévision Suisse. Datak. Retrieved June 20, 2019 from https: //seriousgamessociety.org/2017/03/13/datek-a-game-on-the-useof-personal-data.

[292] The Sun. Google chrome and firefox extensions harvested data of millions of users without them or the companies knowing. Retrieved July 26, 2019 from https://www. thesun.co.uk/tech/9563564/google-chromewarning-data-breach/ 
[293] Hershel D Thornburg. Early adolescents: Their developmental characteristics. The High School Journal, 63(6):215-222, 1980.

[294] Financial Times. Netflix, youtube, amazon and apple accused of gdpr breach. Retrieved June 20, 2019 from https://wWw. ft.com/content/4a977276-1b3e11e9-b93e-f4351a53f1c3.

[295] Robert S Tokunaga. Following you home from school: A critical review and synthesis of research on cyberbullying victimization. Computers in human behavior, 26(3):277-287, 2010.

[296] Covenant House Toronto. Covenant house and global knowledge nurture digital literacy in toronto's homeless youth, 2014. Retrieved June 20, 2019 from https://www.covenanthousetoronto.ca/homeless-youth/ Global-Knowledge-digital-literacy.

[297] Carnegie Mellon University. Carnegie cyber academy, 2007. Retrieved September 14, 2017 from http://www . carnegiecyberacademy.com.

[298] Carnegie Mellon University. Carnegie cyber academy teacher guide, 2007. Retrieved September 14, 2017 from http://www.carnegiecyberacademy.com/ documents/TeachersCompanion.pdf.

[299] Martin Valcke, Sarah Bonte, Bram De Wever, and Isabel Rots. Internet parenting styles and the impact on internet use of primary school children. Computers \& Education, 55(2):454-464, 2010.

[300] The Verge. Snapchat: Your latest reminder anyone a company hires could theoretically breach your privacy. Retrieved June 20, 2019 from https://www . theverge . com/2019/4/24/18514500/company-employeehiring-privacy-breach-personal-data-theft.

[301] The Verge. Tiktok will pay $\$ 5.7$ million over alleged children's privacy law violations. Retrieved June 20, 2019 from https://www. theverge.com/2019/2/27/ 18243312/tiktok-ftc-fine-musically-children-coppa-age-gate.

[302] The Verge. Twitter advising all 330 million users to change passwords after bug exposed them in plain text. Retrieved June 20, 2019 from https://www . theverge.com/2018/5/3/17316684/twitter-passwordbug-security-flaw-exposed-change-now.

[303] Marco Flavio Michele Vismara, Joseph Toaff, Giuliana Pulvirenti, Chiara Settanni, Emma Colao, Serena Marianna Lavano, Riccardo Cemicetti, David Cotugno, Giuseppe Perrotti, Viviana Meschesi, et al. Internet use and access, behavior, cyberbullying, and grooming: results of an investigative whole city survey of adolescents. Interactive journal of medical research, 6(2):e9, 2017. 
[304] Peter Vorderer, Tilo Hartmann, and Christoph Klimmt. Explaining the enjoyment of playing video games: the role of competition. In Proceedings of the second international conference on Entertainment computing, pages 1-9. Carnegie Mellon University, 2003.

[305] Peter Vorderer, Dorothée Hefner, Leonard Reinecke, and Christoph Klimmt. Permanently online, permanently connected: Living and communicating in a POPC world. Routledge, 2017.

[306] Denis Wegge, Heidi Vandebosch, and Steven Eggermont. Who bullies whom online: A social network analysis of cyberbullying in a school context, 2014.

[307] Zikai Alex Wen, Zhiqiu Lin, Rowena Chen, and Erik Andersen. What. hack: Engaging anti-phishing training through a role-playing phishing simulation game. In Proceedings of the 2019 CHI Conference on Human Factors in Computing Systems, page 108. ACM, 2019.

[308] Nicola Whitton and Peter Whitton. The impact of visual design quality on gamebased learning. Playful Teaching, Learning Games, pages 1-19, 2011.

[309] Brian M Winn. The design, play, and experience framework. In Handbook of research on effective electronic gaming in education, pages 1010-1024. IGI Global, 2009.

[310] Jocelyn M Wishart, CE Oades, and Marylouise Morris. Using online role play to teach internet safety awareness. Computers \& Education, 48(3):460-473, 2007.

[311] World of WarCraft. https://worldofwarcraft.com.

[312] Ryan C Wright. Beyond procedurality: Situating the witness in the proceduralism debate. 2019.

[313] Ting-Ting Wu. Improving the effectiveness of english vocabulary review by integrating arcs with mobile game-based learning. Journal of Computer Assisted Learning, 34(3):315-323, 2018.

[314] Jason C Yip, Kiley Sobel, Xin Gao, Allison Marie Hishikawa, Alexis Lim, Laura Meng, Romaine Flor Ofiana, Justin Park, and Alexis Hiniker. Laughing is scary, but farting is cute: A conceptual model of children's perspectives of creepy technologies. In Proceedings of the 2019 CHI Conference on Human Factors in Computing Systems, pages 1-15, 2019.

[315] Seounmi Youn. Parental influence and teens' attitude toward online privacy protection. Journal of Consumer Affairs, 42(3):362-388, 2008.

[316] Kimberly S Young. Internet addiction: The emergence of a new clinical disorder. Cyberpsychology \& behavior, 1(3):237-244, 1998. 
[317] Lyle Zapato. Save the pacific northwest tree octopus. Retrieved December 11, 2019 from https://zapatopi.net/treeoctopus.

[318] ZDNet. Twitter bug shared location data for some ios users. Retrieved June 20, 2019 from https://www.zdnet.com/article/twitter-bug-sharedlocation-data-for-some-ios-users.

[319] Leah Zhang-Kennedy, Yomna Abdelaziz, and Sonia Chiasson. Cyberheroes: The design and evaluation of an interactive ebook to educate children about online privacy. International Journal of Child-Computer Interaction, 13:10-18, 2017.

[320] Leah Zhang-Kennedy and Sonia Chiasson. Teaching with an interactive e-book to improve children's online privacy knowledge. In Proceedings of the The 15th International Conference on Interaction Design and Childr en, pages 506-511, 2016.

[321] Leah Zhang-Kennedy, Sonia Chiasson, and Robert Biddle. The role of instructional design in persuasion: A comics approach for improving cybersecurity. International Journal of Human-Computer Interaction, 32(3):215-257, 2016.

[322] Jun Zhao, Ge Wang, Carys Dally, Petr Slovak, Julian Edbrooke-Childs, Max Van Kleek, and Nigel Shadbolt. I make up a silly name' understanding children's perception of privacy risks online. In Proceedings of the 2019 CHI Conference on Human Factors in Computing Systems, pages 1-13, 2019. 
Appendix A

Pre-test questionnaire for the children study 


\section{Pre-test Questionnaire}

\section{Demographic Information}

Participant id (assigned):

Age:

Grade:

Gender:
O Male
O Female

\section{Social Media Usage Information}

Do you use any of the following social media platforms:

\begin{tabular}{l}
$\square$ Instagram \\
$\square$ Snapchat \\
\hline$\square$ Vine \\
$\square$ Twitter \\
$\square$ YouTube \\
$\square$ Facebook
\end{tabular}

For each social media platform, how frequently do you use it:

O Once a day

O Several times a day

O Once a week

O Once a month

Which of the following activities do you do on your social media platforms:

$\square$ Post content (e.g., photos, videos, etc.) View content Interact with content (e.g., post comments, share posts etc.)

How long do you spend on your mobile device(s) daily?

O 20 min or less

O $40 \mathrm{~min}$ or less

O 1 hour

O 2 hours

O 3 hours or more 
How long are you online daily?

O 20 min or less

O $40 \mathrm{~min}$ or less

O 1 hour

O 2 hours

O 3 hours or more

Do your parents have access to your social media accounts:
O Yes
O No

In the past, have you ever learned how to protect your private information online or how to behave on social media websites?
O Yes
O No

If yes, where did you learn this information from:

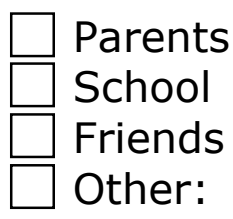

Please list the electronic device(s) that you use at home, with the primary device first.

1.

2.

3.

4.

8. 


\section{Knowledge or awareness of the topics addressed by the game}

When using your mobile device, how often do you do the following?

\begin{tabular}{|l|l|l|l|l|l|l|}
\hline $\begin{array}{l}\text { Respond to someone who posted } \\
\text { mean comments on your photo? }\end{array}$ & & & & & & \\
\hline $\begin{array}{l}\text { Comment on a thread where } \\
\text { people are arguing with your } \\
\text { best friend? }\end{array}$ & & & & & & \\
\hline $\begin{array}{l}\text { Privately send a silly photo of } \\
\text { someone to your friends, without } \\
\text { their permission? }\end{array}$ & & & & & & \\
\hline $\begin{array}{l}\text { Turn off your device's location } \\
\text { tracking so that apps cannot } \\
\text { track you? }\end{array}$ & & & & & & \\
\hline Use your full name online? & & & & & & \\
\hline $\begin{array}{l}\text { Click on email links that ask you } \\
\text { to change your password? }\end{array}$ & & & & & & \\
\hline $\begin{array}{l}\text { Adjust privacy settings on your } \\
\text { posts (e.g., photos, videos, } \\
\text { etc.)? }\end{array}$ & & & & & & \\
\hline $\begin{array}{l}\text { Privately send an embarrassing } \\
\text { photo of yourself to a friend? }\end{array}$ & & & & & & \\
\hline $\begin{array}{l}\text { Log out of your accounts on a } \\
\text { public computer? }\end{array}$ & & & & & & \\
\hline $\begin{array}{l}\text { Post a photo of someone without } \\
\text { their permission? }\end{array}$ & & & & & & \\
\hline $\begin{array}{l}\text { Show a silly picture of someone } \\
\text { on your phone to your friends? }\end{array}$ & & & & & & \\
\hline $\begin{array}{l}\text { Before using a photo from the } \\
\text { internet, check who owns that } \\
\text { photo? }\end{array}$ & & & & & & \\
\hline $\begin{array}{l}\text { Fact-check information before } \\
\text { sharing it on social media? }\end{array}$ & & & & & & \\
\hline $\begin{array}{l}\text { Check whether the information } \\
\text { you read online is true? }\end{array}$ & & & & & & \\
\hline Trust people's opinion online? & & & & & & \\
\hline
\end{tabular}




\section{Appendix B}

Post-test questionnaire for the children study 


\section{Post-test Questionnaire}

Participant id (assigned):

\section{Game Feedback}

How easy was it to find the navigation controls (like the "next" button) in the game:

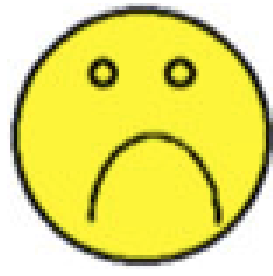

Very Difficult

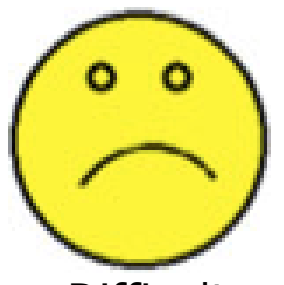

Difficult

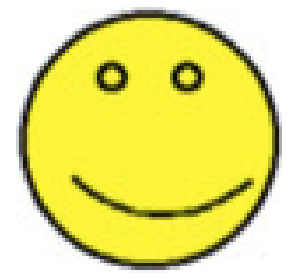

Neither

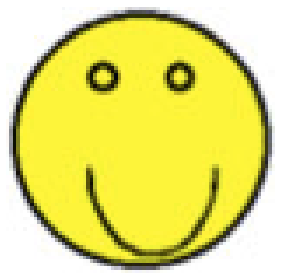

Easy

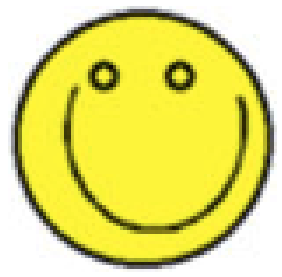

Very Easy

How easy was it to use the navigation controls in the game:

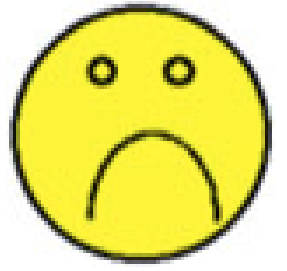

Very Difficult

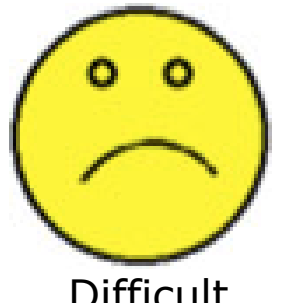

Difficult

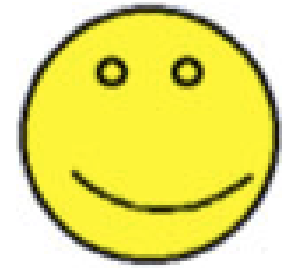

Neither
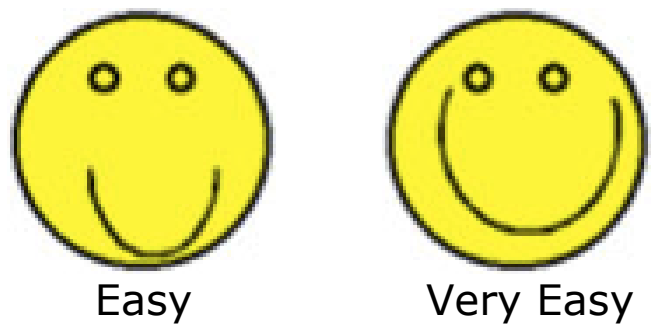

How easy was it to understand the content in the game:

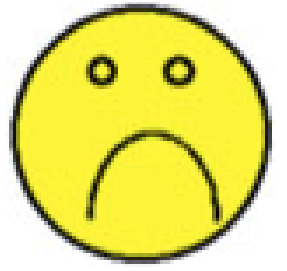

Very Difficult

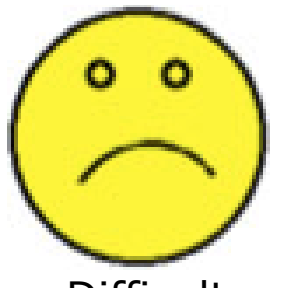

Difficult

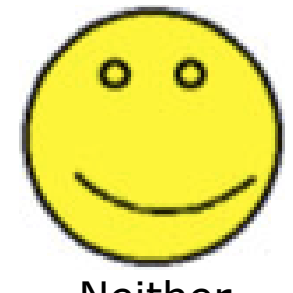

Neither
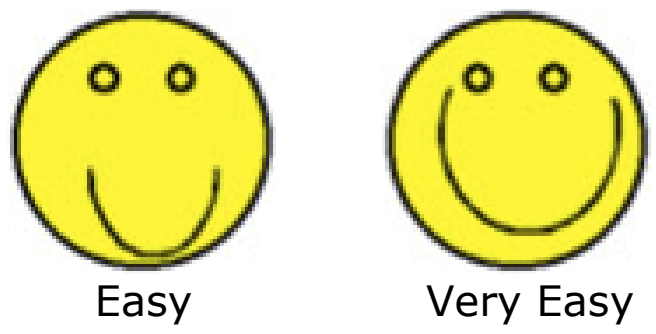
How interesting did you find the storyline?:
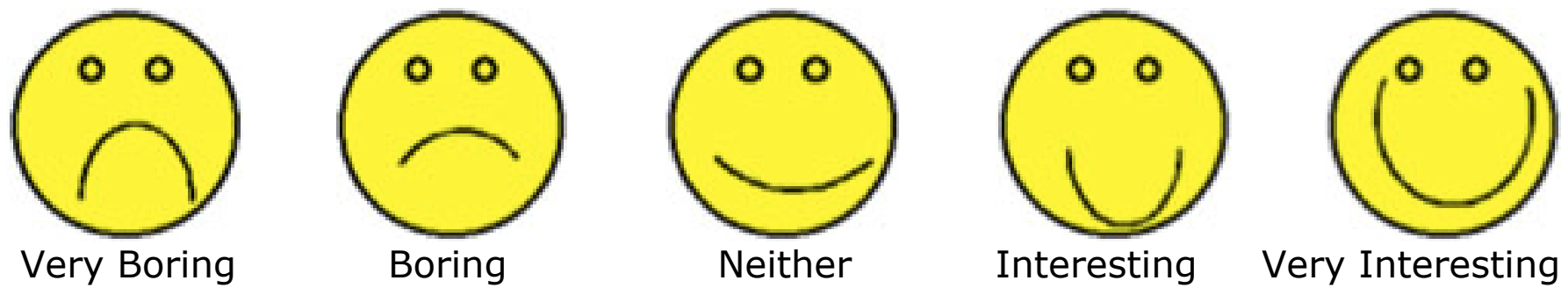

How enjoyable did you find the storyline?:

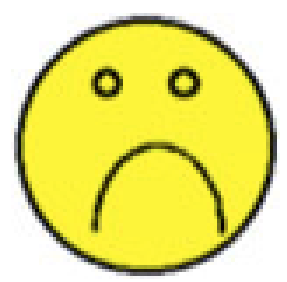

Very Unenjoyable

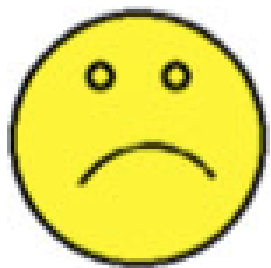

Unenjoyable

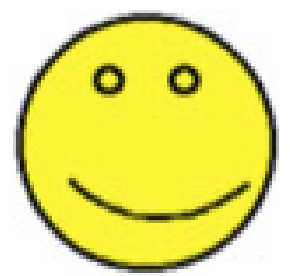

Neither

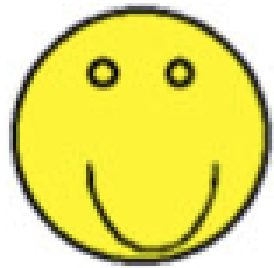

Enjoyable

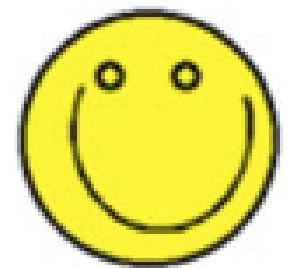

Very Enjoyable

How fun was the game?
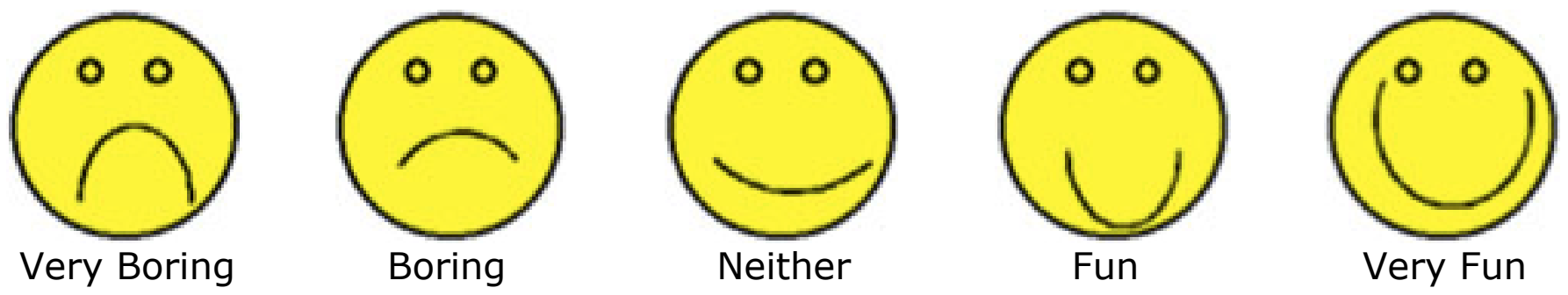

How challenging was the game for you?

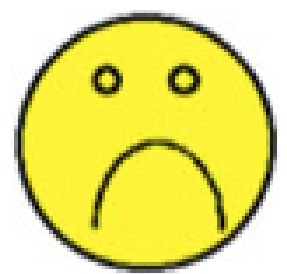

Very Challenging

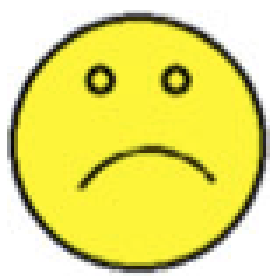

Challenging

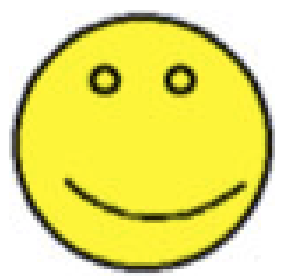

Neither
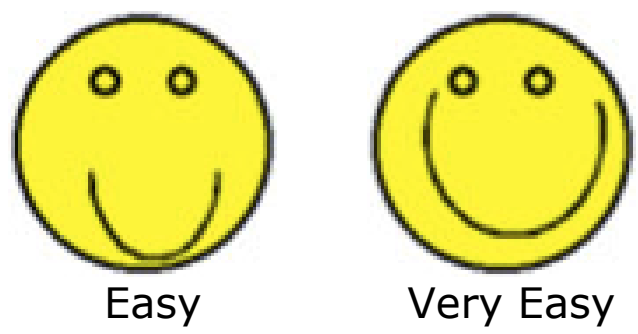


\section{Knowledge or awareness of the topics addressed by the game}

When using your mobile device, how likely would you do the following in the future?

\begin{tabular}{|c|c|c|c|c|c|c|}
\hline \multirow{2}{*}{$\begin{array}{l}\text { Respond to someone who posted } \\
\text { mean comments on your photo? }\end{array}$} & Always & Often & Sometimes & Rarely & Never & N/A \\
\hline & & & & & & \\
\hline $\begin{array}{l}\text { Comment on a thread where } \\
\text { people are arguing with your } \\
\text { best friend? }\end{array}$ & & & & & & \\
\hline $\begin{array}{l}\text { Privately send a silly photo of } \\
\text { someone to your friends, without } \\
\text { their permission? }\end{array}$ & & & & & & \\
\hline $\begin{array}{l}\text { Turn off your device's location } \\
\text { tracking so that apps cannot } \\
\text { track you? }\end{array}$ & & & & & & \\
\hline Use your full name online? & & & & & & \\
\hline $\begin{array}{l}\text { Click on email links that ask you } \\
\text { to change your password? }\end{array}$ & & & & & & \\
\hline $\begin{array}{l}\text { Adjust privacy settings on your } \\
\text { posts (e.g., photos, videos, } \\
\text { etc.)? }\end{array}$ & & & & & & \\
\hline $\begin{array}{l}\text { Privately send an embarrassing } \\
\text { photo of yourself to a friend? }\end{array}$ & & & & & & \\
\hline $\begin{array}{l}\text { Log out of your accounts on a } \\
\text { public computer? }\end{array}$ & & & & & & \\
\hline $\begin{array}{l}\text { Post a photo of someone without } \\
\text { their permission? }\end{array}$ & & & & & & \\
\hline $\begin{array}{l}\text { Show a silly picture of someone } \\
\text { on your phone to your friends? }\end{array}$ & & & & & & \\
\hline $\begin{array}{l}\text { Before using a photo from the } \\
\text { internet, check who owns that } \\
\text { photo? }\end{array}$ & & & & & & \\
\hline $\begin{array}{l}\text { Fact-check information before } \\
\text { sharing it on social media? }\end{array}$ & & & & & & \\
\hline $\begin{array}{l}\text { Check whether the information } \\
\text { you read online is true? }\end{array}$ & & & & & & \\
\hline Trust people's opinion online? & & & & & & \\
\hline
\end{tabular}




\section{Appendix C}

One-week questionnaire for the children study 


\section{One-week Questionnaire}

Participant id (assigned):

When using your mobile device, how likely would you do the following in the future?

\begin{tabular}{|c|c|c|c|c|c|c|}
\hline & Always & Often & Sometimes & Rarely & Never & N/A \\
\hline \multicolumn{7}{|l|}{$\begin{array}{l}\text { Respond to someone who posted } \\
\text { mean comments on your photo? }\end{array}$} \\
\hline \multicolumn{7}{|l|}{$\begin{array}{l}\text { Comment on a thread where } \\
\text { people are arguing with your } \\
\text { best friend? }\end{array}$} \\
\hline \multicolumn{7}{|l|}{$\begin{array}{l}\text { Privately send a silly photo of } \\
\text { someone to your friends, without } \\
\text { their permission? }\end{array}$} \\
\hline \multicolumn{7}{|l|}{$\begin{array}{l}\text { Turn off your device's location } \\
\text { tracking so that apps cannot } \\
\text { track you? }\end{array}$} \\
\hline \multicolumn{7}{|l|}{ Use your full name online? } \\
\hline \multicolumn{7}{|l|}{$\begin{array}{l}\text { Click on email links that ask you } \\
\text { to change your password? }\end{array}$} \\
\hline \multicolumn{7}{|l|}{$\begin{array}{l}\text { Adjust privacy settings on your } \\
\text { posts (e.g., photos, videos, } \\
\text { etc.)? }\end{array}$} \\
\hline \multicolumn{7}{|l|}{$\begin{array}{l}\text { Privately send an embarrassing } \\
\text { photo of yourself to a friend? }\end{array}$} \\
\hline \multicolumn{7}{|l|}{$\begin{array}{l}\text { Log out of your accounts on a } \\
\text { public computer? }\end{array}$} \\
\hline \multicolumn{7}{|l|}{$\begin{array}{l}\text { Post a photo of someone without } \\
\text { their permission? }\end{array}$} \\
\hline \multicolumn{7}{|l|}{$\begin{array}{l}\text { Show a silly picture of someone } \\
\text { on your phone to your friends? }\end{array}$} \\
\hline \multicolumn{7}{|l|}{$\begin{array}{l}\text { Before using a photo from the } \\
\text { internet, check who owns that } \\
\text { photo? }\end{array}$} \\
\hline \multicolumn{7}{|l|}{$\begin{array}{l}\text { Fact-check information before } \\
\text { sharing it on social media? }\end{array}$} \\
\hline \multicolumn{7}{|l|}{$\begin{array}{l}\text { Check whether the information } \\
\text { you read online is true? }\end{array}$} \\
\hline Trust people's opinion online? & & & & & & \\
\hline
\end{tabular}




\section{Appendix D}

Pre-test interview for the children study 
1. Your friend Dave texted you that Brian is failing his math class. Brian is a good friend of yours and you want to help him out. You realize that your friend Nancy is really good at Math and you want to ask her if she can tutor Brian in math.

a. What would you do in this situation?

b. How might this affect your privacy?

c. How might this affect other's privacy?

2. All your friends are playing a popular online game so you decide to sign-up for the game as well. When you sign-up the game asks you to provide your full name (first and last name) and your home address, so that other players can contact you.

a. What would you do in this situation?

b. How might this affect your privacy?

c. How might this affect other's privacy?

3. On the weekend, you had a sleepover at your best friend's house where you wore your favourite unicorn PJ's. After the sleepover, your friend posted a picture of you in your PJ's with the caption "Had a great sleepover with my best friend yesterday!". You think the photo is a bit embarrassing and are afraid that your friends may see it and think that your PJ's are silly.

a. What would you do in this situation?

b. How might this affect your privacy?

c. How might this affect other's privacy?

4. One of your friend's is really into soccer and she is always posting soccer related photos on her social media page. Recently, instead of her usual photos, she is posting a lot of sad photos either of her or other people. You are a bit worried about your friend after seeing her behaviour online.

a. What would you do in this situation?

b. How might this affect your privacy?

c. How might this affect other's privacy?

5. A friend of yours has just shared the following post on your social media page: "Beware: Your photos are no longer private! ---- Hey everyone, our social media platform just updated their privacy policy, and they now own any content, including photos, that we post! This means that our private photos can be used in advertisement and sold to other companies $*$. Please share this message to 
spread the news!----". After reading this message, you really want to share it on your social media page, so that your friends and family are aware of this change.

a. What would you do in this situation?

b. How might this affect your online reputation?

c. How might this affect other people? 
Appendix E

Post-test interview for the children study 


\section{Post-test Interview}

1. Jessica overhead Matt breaking up with Susan in the park. After hearing this, she texted you "OMG, Matt just broke up with Susan, he is sooo single now!". You know that your good friend Emily likes Matt, and you really want to tell her that Matt is single now.

a. What would you do in this situation?

b. How might this affect your privacy?

c. How might this affect other's privacy?

2. You are on your favourite online store and they have a new type of candy bar in store. You can sign-up to get a free sample of the new candy bar. To sign-up, all you need to do is provide your first name, last name, and home address and they will ship the sample to your house. A limited quantity of the samples is available and only the first 100 users who signup will receive one.

a. What would you do in this situation?

b. How might this affect your privacy?

c. How might this affect other's privacy?

3. Say, you went to the skatepark with some friends and fell off your skateboard while doing your signature trick. The following day, one of your friends posted a photo of you falling on his social media page with the caption "Epic fail at the skate park yesterday! Glad no one got hurt :)". You think the photo is embarrassing.

a. What would you do in this situation?

b. How might this affect your privacy?

c. How might this affect other's privacy?

4. Recently, one of your classmates moved to a new school because of his parents' work. Shortly after moving, you notice on your classmate's social media page that he is listening to a lot of sad songs. Since your friend usually doesn't listen to these types of songs, you're a bit worried about him.

a. What would you do in this situation?

b. How might this affect your privacy?

c. How might this affect other's privacy?

5. Your best friend loves to get deals on stuff and she often shares interesting deals with you. She just shared the following post on her social media page: "Get a 
free iPad!!! ---- Enter into a draw to win an iPad 2. To enter the contest, all you have to do is share this post with your friends! Hurry, this contest closes in 5 days after which the winners will be chosen! ----". You really want to take advantage of the deal that your friend has shared.

a. What would you do in this situation?

b. How might this affect your online reputation?

c. How might this affect other people?

6. What did you think of the characters of Jo \& Josie:

7. If Jo \& Josie were real people, would you like to be friends with them?
$\mathrm{O}$ Yes
O No
$\odot$ Don't know

8. How likeable were the characters of Jo \& Josie:

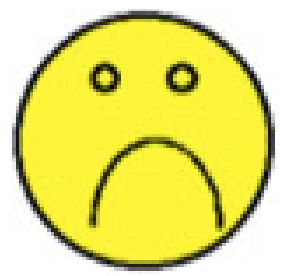

Very Dislikeable

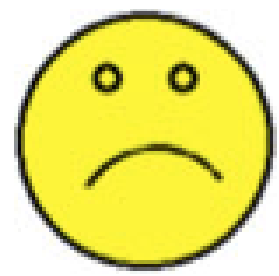

Dislikeable

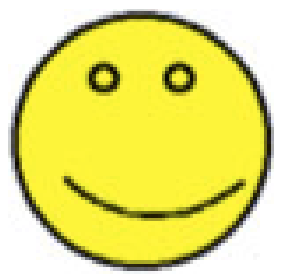

Neither

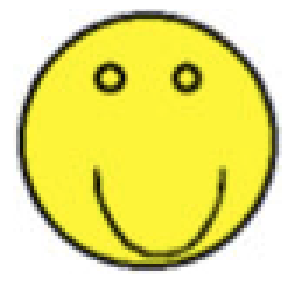

Likeable

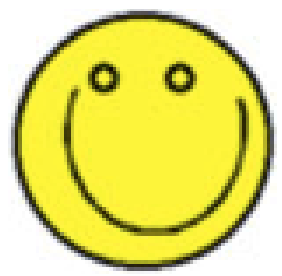

Very Likeable

9. What was your favourite part in the game?

10. What was your least favourite part in the game?

11. What did you find most difficult in the game:
$\square$ Navigation
$\square$ Text
$\square$ Other:

12. What do you think can be improved in the game: 
Appendix F

One-week interview for the children study 


\section{Carleton \\ U N I V E R S I T Y}

Canada's Capital University

\section{One-week Interview}

1. A friend told you that they saw Joey go into the principal's office at lunch today. Joey is a mean kid at school, so you're a little happy that he got called into the principal's office. In the past, Joey has been mean to your friend Julia, so you really want to text her and tell her that Joey got in trouble at school today.

a. What would you do in this situation?

b. How might this affect your privacy?

c. How might this affect other's privacy?

2. You visit a fansite for your favourite musician and see that they have released a preview of their new song exclusively for the website. In order to listen to the new song you need to create an account on the website. You really want to listen to the song, so you decide to create an account on the website and it asks you to provide your full name (first and last) and home address.
a. What would you do in this situation?
b. How might this affect your privacy?
c. How might this affect other's privacy?

3. At your last soccer game you accidently scored a goal in the opponents' net. One of your teammates took a photo of you making this shot and posted it to the team's social media page with the caption "Great game guys, but let's make sure THIS doesn't happen again!". You're totally embarrassed by this photo and don't want people to tease you about the shot online.

a. What would you do in this situation?

b. How might this affect your privacy?

c. How might this affect other's privacy?

4. One of your friend's loves posting and sharing interesting quotes on her social media page. Usually, she posts motivational and uplifting quotes but recently she has been sharing a lot sad quotes. Based on this behaviour, you're a bit worried about your friend.

a. What would you do in this situation?

b. How might this affect your privacy?

c. How might this affect other's privacy? 
5. You are an animal lover and often raise awareness of animal cruelty on your social media page. One of your friends has just shared the following post on your social media page: "Animals dying in African zoos!! --- Because of the recent drought in Africa, zoo staff are unable to take care of their animals. Please share this message with your friends to raise awareness of this dire situation. If this message is shared enough, humanitarian organizations may be able come in and save these animals! ---". You really want to share this message with your friends so that they know what is happening to these poor animals.

a. What would you do in this situation?

b. How might this affect your online reputation?

c. How might this affect other people? 


\section{Appendix G}

Pre-test questionnaire for the teacher study 


\section{Pre-test Questionnaire}

Participant id (assigned):

Age:

Gender:
O Male
O Female
O Other

As a teacher, which language do you teach in?

Which School District do you teach in?

How many years have you been a teacher?

How many years have you taught at your current school?

Which subjects have you have taught?

Which grades have you taught?

Which grade do you currently teach?

\section{Classroom information}

How many students do you typically have in your classroom?

How many hours during the week do students use digital technology as part of classroom activities?

What types of digital technology can children access (e.g., iPad, computer, smartboard, chromebook etc.)?

Describe how digital technology is used in your classroom?

What type of educational resources (if any) are currently used in your school to educate students about digital literacy or cybersecurity issues:

What do you like or dislike about these resources: 
Have you ever used any electronic resources from MediaSmarts?
O Yes
O No

If yes, please describe these resources:

Have you used educational games in your classroom:

O Yes O No

If yes, please describe the experience:

Have you ever helped a student deal with a digital literacy or cybersecurity issue (e.g., cyberbullying, accidently sharing personal information):

O Yes O No

If yes, please describe the incident (without identifying the student):

\section{Use of Technology and Social Media}

Please list the electronic device(s) that you use at home, with the primary device first.

1.

2.

3.

4.

How comfortable are you with technology?

$$
\text { Very Uncomfortable }
$$$$
1
$$

How knowledgeable are you of cybersecurity issues?

Very Unknowledgeable

$$
1
$$

5.

6.

7.

8

Very Comfortable 4 5

Very Knowledgeable 3 
How knowledgeable are you of digital literacy issues?

\begin{tabular}{|ccccc|}
\hline $\begin{array}{c}\text { Very Unknowledgeable } \\
1\end{array}$ & 3 & \multicolumn{2}{c|}{ Very Knowledgeable } \\
\hline
\end{tabular}

How long do you spend on your mobile device(s) daily?

O $20 \mathrm{~min}$ or less

O $40 \mathrm{~min}$ or less

O 1 hour

O 2 hours

O 3 hours or more

How long are you online daily in total, on all your devices?

O 20 min or less

O $40 \mathrm{~min}$ or less

O 1 hour

O 2 hours

O 3 hours or more

For which of the following activities do you use your primary electronic device?
$\square$ Email
Web browsing
$\square$ Social media
$\square$ Watching TV/movies
$\square$ Preparing for class
$\square$ Other:

Have you ever worked in a computer, computer security, or information technology related field?
O Yes
O No

If yes, please describe this job:

In the past, have you ever learned how to protect your private information online and on social media websites?
O Yes
O No

If yes, from where did you learn this information: 
How frequently do you use each of the following social media platforms:

\begin{tabular}{|l|l|l|l|l|l|l|}
\hline $\begin{array}{l}\text { Social } \\
\text { media } \\
\text { platform }\end{array}$ & \multicolumn{5}{|c|}{ Frequency } \\
\hline Instagram & $\begin{array}{l}\text { Several } \\
\text { times per } \\
\text { day }\end{array}$ & Daily & Weekly & Monthly & $\begin{array}{l}\text { Less than } \\
\text { once a } \\
\text { month }\end{array}$ & Do not use \\
\hline Snapchat & & & & & & \\
\hline Vine & & & & & & \\
\hline Twitter & & & & & & \\
\hline YouTube & & & & & & \\
\hline Facebook & & & & & & \\
\hline Google+ & & & & & & \\
\hline Pinterest & & & & & & \\
\hline
\end{tabular}

Which of the following activities do you do on your social media platforms:

\begin{tabular}{|l|l|l|l|l|}
\hline $\begin{array}{l}\text { Social } \\
\text { media } \\
\text { platform }\end{array}$ & \multicolumn{4}{|c|}{ Activity } \\
\hline Instagram & $\begin{array}{l}\text { Post content (e.g., } \\
\text { photos, videos, etc.) }\end{array}$ & $\begin{array}{l}\text { View } \\
\text { content }\end{array}$ & $\begin{array}{l}\text { Interact with content (e.g., } \\
\text { comment on other people's } \\
\text { posts, share other people's } \\
\text { posts etc.) }\end{array}$ & $\begin{array}{l}\text { Do not } \\
\text { use }\end{array}$ \\
\hline Snapchat & & & & \\
\hline Vine & & & & \\
\hline Twitter & & & & \\
\hline YouTube & & & & \\
\hline Facebook & & & & \\
\hline Google+ & & & & \\
\hline Pinterest & & & & \\
\hline
\end{tabular}

Do you use any social media platforms that are not listed above? If yes, please list them, their frequency of use, and activities performed on them: 
When using your mobile device, how often do you do the following?

\begin{tabular}{|l|l|l|l|l|l|l|}
\hline & Always & Often & Sometimes & Rarely & Never & N/A \\
\hline $\begin{array}{l}\text { Respond to someone who } \\
\text { posted mean comments on } \\
\text { your photo? }\end{array}$ & & & & & & \\
\hline $\begin{array}{l}\text { Comment on a thread where } \\
\text { people are arguing with your } \\
\text { best friend? }\end{array}$ & & & & & & \\
\hline $\begin{array}{l}\text { Privately send a silly photo of } \\
\text { someone to your friends, } \\
\text { without their permission? }\end{array}$ & & & & & & \\
\hline $\begin{array}{l}\text { Turn off your device's } \\
\text { location tracking so that apps } \\
\text { cannot track you? }\end{array}$ & & & & & & \\
\hline Use your full name online? & & & & & & \\
\hline $\begin{array}{l}\text { Click on email links that ask } \\
\text { you to change your } \\
\text { password? }\end{array}$ & & & & & & \\
\hline $\begin{array}{l}\text { Adjust privacy settings on } \\
\text { your posts (e.g., photos, } \\
\text { videos, etc.)? }\end{array}$ & & & & & & \\
\hline $\begin{array}{l}\text { Privately send an } \\
\text { embarrassing photo of } \\
\text { yourself to a friend? }\end{array}$ & & & & & & \\
\hline $\begin{array}{l}\text { Log out of your accounts on } \\
\text { a public computer? }\end{array}$ & & & & & & \\
\hline $\begin{array}{l}\text { Post a photo of someone } \\
\text { without their permission? }\end{array}$ & & & & & & \\
\hline $\begin{array}{l}\text { Show a silly picture of } \\
\text { someone on your phone to } \\
\text { your friends? }\end{array}$ & & & & & & \\
\hline $\begin{array}{l}\text { Before using a photo from } \\
\text { the internet, check who owns } \\
\text { that photo? }\end{array}$ & & & & & & \\
\hline $\begin{array}{l}\text { Fact-check information } \\
\text { before sharing it on social } \\
\text { media? }\end{array}$ & & & & & & \\
\hline $\begin{array}{l}\text { Check whether the } \\
\text { information you read online } \\
\text { is true? }\end{array}$ & & & & & & \\
\hline Trust people's opinion online? & & & & & & \\
\hline
\end{tabular}




\section{Appendix H}

Post-test questionnaire for the teacher study 
Post-test Questionnaire

Participant id (assigned):

How easy was it to find the navigation controls (like the "next" button) in the game?

Very Difficult

1 2 3

Very Easy 5

How easy was it to use the navigation controls in the game?

Very Difficult

1

2

3

Very Easy

4

5

How easy was it to understand the content in the game?

Very Difficult

1

2

3

4

Very Easy 5

How interesting did you find the storyline?

Very Boring

1

2

3

Very Interesting 4 5

How enjoyable did you find the storyline?

Very Unenjoyable 1
2

3
Very Enjoyable 4 5

How fun was the game?

\begin{tabular}{|c|c|c|c|c|}
\hline $\begin{array}{c}\text { Very Boring } \\
1\end{array}$ & 2 & 3 & 4 & $\begin{array}{l}\text { Very Fun } \\
5\end{array}$ \\
\hline \multicolumn{5}{|c|}{ How challenging was the game for you? } \\
\hline $\begin{array}{c}\text { Very Challenging } \\
1\end{array}$ & 2 & 3 & 4 & $\begin{array}{l}\text { Very Easy } \\
5\end{array}$ \\
\hline
\end{tabular}


When using your mobile device, how likely would you do the following in the future?

The following set of questions are repeated from the demographics questionnaire, to allow us to compare participant responses before and after playing the game.

\begin{tabular}{|l|l|l|l|l|l|l|}
\hline & Always & Often & Sometimes & Rarely & Never & N/A \\
\hline $\begin{array}{l}\text { Respond to someone who } \\
\text { posted mean comments on } \\
\text { your photo? }\end{array}$ & & & & & & \\
\hline $\begin{array}{l}\text { Comment on a thread where } \\
\text { people are arguing with your } \\
\text { best friend? }\end{array}$ & & & & & & \\
\hline $\begin{array}{l}\text { Privately send a silly photo of } \\
\text { someone to your friends, } \\
\text { without their permission? }\end{array}$ & & & & & & \\
\hline $\begin{array}{l}\text { Turn off your device's } \\
\text { location tracking so that apps } \\
\text { cannot track you? }\end{array}$ & & & & & & \\
\hline Use your full name online? & & & & & & \\
\hline $\begin{array}{l}\text { Click on email links that ask } \\
\text { you to change your } \\
\text { password? }\end{array}$ & & & & & & \\
\hline $\begin{array}{l}\text { Adjust privacy settings on } \\
\text { your posts (e.g., photos, } \\
\text { videos, etc.)? }\end{array}$ & & & & & & \\
\hline $\begin{array}{l}\text { Privately send an } \\
\text { embarrassing photo of } \\
\text { yourself to a friend? }\end{array}$ & & & & & & \\
\hline $\begin{array}{l}\text { Log out of your accounts on } \\
\text { a public computer? }\end{array}$ & & & & & & \\
\hline $\begin{array}{l}\text { Post a photo of someone } \\
\text { without their permission? }\end{array}$ & & & & & & \\
\hline $\begin{array}{l}\text { Show a silly picture of } \\
\text { someone on your phone to } \\
\text { your friends? }\end{array}$ & & & & & & \\
\hline $\begin{array}{l}\text { Before using a photo from } \\
\text { the internet, check who owns } \\
\text { that photo? }\end{array}$ & & & & & & \\
\hline $\begin{array}{l}\text { Fact-check information } \\
\text { before sharing it on social } \\
\text { media? }\end{array}$ & & & & & & \\
\hline $\begin{array}{l}\text { Check whether the } \\
\text { information you read online } \\
\text { is true? }\end{array}$ & & & & & & \\
\hline Trust people's opinion online? & & & & & & \\
\hline
\end{tabular}




\section{Appendix I}

Post-test interview for the teacher study 


\section{Game Interview}

This will be a semi-structured interview around 4 main themes. We may ask some/all of these questions, and may deviate slightly depending on participant replies.

\section{Theme \# 1: Digital literacy}

1. What kind of issues are you seeing around kids' media use?

a. What types of problems are they bringing up in the classroom?

b. How do kids bring up these problems to you or another teacher?

c. How do you (or another teacher) address these problems?

i. Do the parents get involved?

\section{Theme \# 2: Teaching digital literacy}

1. Can you describe your last experience of teaching a digital literacy topic?

a. Which grade did you teach?

b. What kind of techniques did you use to teach the material?

c. How did the kids react to the material?

i. Were they enthusiastic or uninterested?

d. Can you describe the process of creating the lesson plan(s)?

i. What made the lesson plan work or not work?

ii. Did you find that the lesson had an effect on the students?

e. What kind of changes did you see in children's behaviour or attitudes?

2. How else is digital literacy addressed in your school?

3. In your opinion, what are the most and least effective ways of teaching about digital literacy?

4. What do you see as the teacher/school's role in teaching kids about digital literacy and what do you see as the parents' role?

\section{Theme \# 3: Using the JOs game in a classroom}

1. Can you describe your experience of playing the game?

a. What did you like about the game?

b. What do you think can be improved?

2. What did you think about the game content?

a. How closely does it reflect situations that children may face real-life?

3 . For which age range is the game content appropriate?

4. How would you use the game in a classroom?

a. Can you describe what an actual lesson might look like? 
b. Which sections of the game would you incorporate in the lesson?

c. How would the game fit into the curriculum for your grade?

5. What do you think about the use of educational games in schools?

6 . Do you have any advice for the design of future games in this domain?

7. How do you currently evaluate students' performance on educational resources (e.g., games, other electronic resources)?

8. What would you need a system like this to provide?

9. Do you have any other feedback that you would like to share?

\section{Theme \# 4: Use of technology in the classroom}

1. Do you think students are equipped to make their own decisions about what information they should disclose online? What skills, if any, do you think students need in order to deal with privacy issues?

2. How do you think technology is making a difference in the quality of students' school work? (any specific examples?)

3. When you assign class or homework that involves using the Internet, what kinds of things do you ask students to do and what specific instructions do you give to students in this regard? (Probe to see if these assignments challenge students to use technology more creatively.) Do you assign class or homework that involves using social networking sites, cell phones/texting or the creation of online content (text and/or videos) in any way? What specific instructions do you give to students regarding [specific technology named]?

4. Did you receive any pre-service training about how to use technology as a learning tool? Was the training sufficient? What was good about it? What needed improvement?

5. Does your school board offer professional development courses or other forms of PD on technology issues? Do these courses give you what you need to effectively incorporate technology into the classroom as a learning tool? If not, what kinds of training do you need?

6. Do you have any computers in your classroom? Has this made teaching easier or harder? More effective? More interesting? Why? Can you give me an example?

7. Do your students bring their own devices (cell phones, iPods, laptops, etc.) into the classroom?

a. If yes, in what ways, if any, has the presence of these devices changed the classroom? Do they make it easier or harder to teach? How does it impact your teaching? How does it impact the classroom environment? Why? Can you think of specific examples?

b. If no, is there a school policy banning, or otherwise providing direction on the use of such devices? Do you think this policy is a good idea? Why or why not?

8. Do they use these devices to test the boundaries of what they can get away with, with their peers? (Probe to see if the presence of devices magnifies 
adolescent behaviours such as intense communications with friends, experimenting with identities/relationships, bullying, cheating, etc.)

9. Do you use any of these devices to communicate with students, either during the school day or outside of school? Do you use them to enhance student learning say, for collaborative learning? Do students use them to test the boundaries of what they can get away with, with you as the teacher? (Probe to see if the presence of devices causes any privacy issues between the teacher and students.) 